Florida International University FIU Digital Commons

4-23-2010

\title{
The Interactive Effects of Predators, Resources, and Disturbance on Freshwater Snail Populations from the Everglades
}

Clifton B. Ruehl

Florida International University, cruehl@gmail.com

DOI: $10.25148 /$ etd.FI10080412

Follow this and additional works at: https:// digitalcommons.fiu.edu/etd

Part of the Biology Commons, Other Ecology and Evolutionary Biology Commons, Population Biology Commons, and the Terrestrial and Aquatic Ecology Commons

\section{Recommended Citation}

Ruehl, Clifton B., "The Interactive Effects of Predators, Resources, and Disturbance on Freshwater Snail Populations from the Everglades" (2010). FIU Electronic Theses and Dissertations. 266.

https:// digitalcommons.fiu.edu/etd/266 


\title{
FLORIDA INTERNATIONAL UNIVERSITY
}

Miami, Florida

\section{THE INTERACTIVE EFFECTS OF PREDATORS, RESOURCES, AND \\ DISTURBANCE ON FRESHWATER SNAIL POPULATIONS FROM THE \\ EVERGLADES}

\author{
A dissertation submitted in partial fulfillment of the \\ requirements for the degree of \\ DOCTOR OF PHILOSOPHY \\ in \\ BIOLOGY \\ by \\ Clifton Benjamin Ruehl
}

2010 
To: Dean Kenneth Furton

College of Arts and Sciences

This dissertation, written by Clifton Benjamin Ruehl, and entitled The Interactive Effects of Predators, Resources, and Disturbance on Freshwater Snail Populations from the Everglades, having been approved in respect to style and intellectual content, is referred to you for judgment.

We have read this dissertation and recommend that it be approved.

Zhenmin Chen

Timothy M. Collins

Evelyn E. Gaiser

Mary E. Power

Joel C. Trexler, Major Professor

Date of Defense: April 23, 2010

The dissertation of Clifton Benjamin Ruehl is approved.

Dean Kenneth Furton

College of Arts and Sciences

Interim Dean Kevin O'Shea

University Graduate School

Florida International University, 2010 


\section{DEDICATION}

I dedicate this dissertation to my wife Christy. She was patient, understanding,

consistent, supportive, critical, and loving through it all. Thank you for the freedom to pursue my goals. I look forward to many more joyful years together. 


\section{ACKNOWLEDGMENTS}

Many people have contributed their time, effort, thoughts, sweat, and blood to help me succeed in graduate school. I am grateful to my parents for their unconditional support of my choice to become a life-long student. They instilled in me values and ethics as a youth that have kept me grounded and driven as an adult. My brothers and their families have provided me encouragement and support along the journey.

Joel Trexler gave me the opportunity and innumerable resources to explore, learn, and study the Florida Everglades. The ecosystem-wide cage experiments gave me knowledge and insight about the Everglades that resulted in thoughtful experimental designs and execution of those experiments. Thank you for challenging me to be a critical thinker, a better scientist, and for being a good mentor.

Bill Loftus has been a wealth of knowledge and experience about the Everglades and life in general that started on my first trip across the Glades in an airboat and continued through research trips in Belize and Mexico. Thank you for giving me a peaceful retreat in the Redlands to stay and the many opportunities and resources for my work at the Beard Center.

The department has provided numerous resources and opportunities that have enriched my graduate education. The faculty has challenged me and offered insights and equipment that has enabled me to improve the quality of my research. I am grateful to the many graduate students, technicians, and friends in both the Aquatic Ecology lab and the department at large that have offered help, ideas, and social opportunities.

I thank my committee for their feedback and support. Evelyn Gaiser and her lab opened the doors to the world of algae. Tim Collins introduced me to the literature on 
pulmonate snail life history and taxonomy. Zhenmin Chen taught me critical skills in multivariate statistics. Mary Power has long been a source of inspiration and her critical thoughts on my proposal and manuscripts have improved my work.

I am grateful for financial support from the Everglades Foundation, the Judith Evans Parker Travel Fellowship, the Graduate Student Association at FIU, the Doctoral Evidence Acquisition fellowship from the University Graduate School at FIU, the Dissertation Year Fellowship from the University Graduate School at FIU, and NSF Grant No. DBI-0620409 to the Florida Coastal Everglades Long-Term Ecological Research program. 


\author{
ABSTRACT OF THE DISSERTATION \\ THE INTERACTIVE EFFECTS OF PREDATORS, RESOURCES, AND \\ DISTURBANCE ON FRESHWATER SNAIL POPULATIONS FROM THE \\ EVERGLADES \\ by
}

Clifton Benjamin Ruehl

Florida International University, 2010

Miami, Florida

Professor Joel C. Trexler, Major Professor

The origins of population dynamics depend on interplay between abiotic and biotic factors; the relative importance of each changing across space and time. Predation is a central feature of ecological communities that removes individuals (consumption) and alters prey traits (non-consumptive). Resource quality mitigates non-consumptive predator effects by stimulating growth and reproduction. Disturbance resets predatorprey interactions by removing both. I integrate experiments, time-series analysis, and performance trials to examine the relative importance of these on the population dynamics of a snail species by studying a variety of their traits. A review of ninety-three published articles revealed that snail abundance was much less in the Everglades and similar ecosystems compared to all other freshwater ecosystems considered. Separating consumptive from non-consumptive (cues) predator effects at different phosphorous levels with an experiment determined that phosphorous stimulated, but predator cues inhibited snail growth (34\% vs. 23\%), activity (38\% vs. 53\%), and reproductive effort (99\% vs. 90\%) compared to controls. Cues induced taller shells and smaller openings 
and moved to refugia where they reduced periphyton by $8 \%$. Consumptive predator effects were minor in comparison. In a reciprocal transplant cage experiment along a predator cue and phosphorous gradient created by a canal, snails grew $10 \%$ faster and produced $37 \%$ more eggs far from the canal (fewer cues) when fed phosphorous-enriched periphyton from near the canal. Time-series analysis at four sites and predator performance trials reveal that phosphorous-enriched regions support larger snail populations, seasonal drying removes snails at all sites, crayfish negatively affect populations in enriched regions, and molluscivorous fish consume snails in the wet season. Combining these studies reveals interplay between resources, predators, and seasonality that limit snail populations in the Everglades and lead to their low abundance compared to other freshwater ecosystems. Resource quality is emerging as the critical factor because improving resources profoundly improved growth and reproduction; seasonal drying and predation become important at times and places. This work contributes to the general understanding in ecology of the relative importance of different factors that structure populations and provides evidence that bolsters monitoring efforts to assess the Comprehensive Everglades Restoration Plan that show phosphorous enrichment is a major driver of ecosystem change. 


\section{TABLE OF CONTENTS}

CHAPTER

PAGE

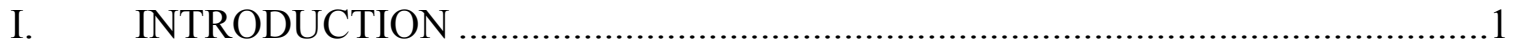

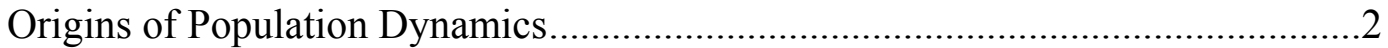

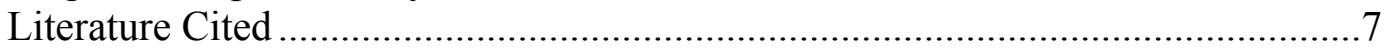

II. INFERRING ENERGY PATHWAYS FROM COMPARISONS OF SNAIL DENSITY AND STANDING CROP AMONG FRESHWATER

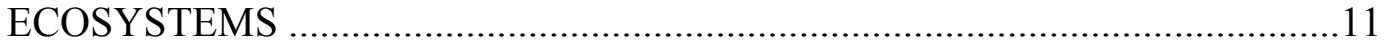

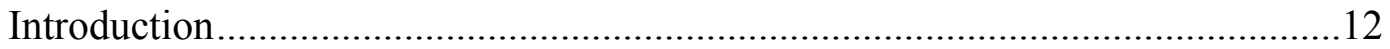

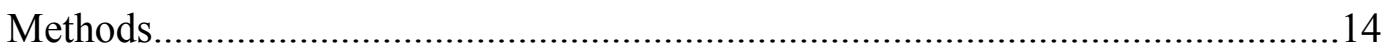

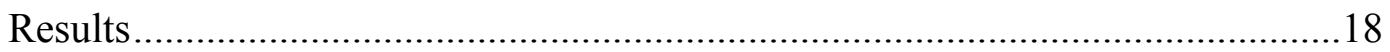

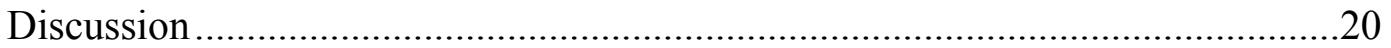

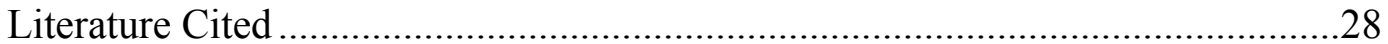

III. SEPARATING CONSUMPTIVE AND NON-CONSUMPTIVE EFFECTS

IN THE PRESENCE OF NUTRIENT ENRICHMENT …….............................42

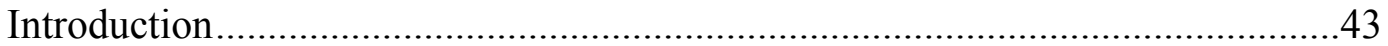

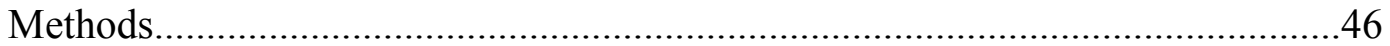

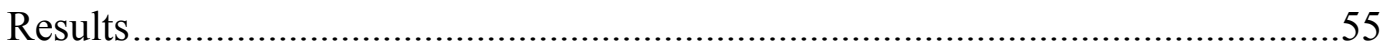

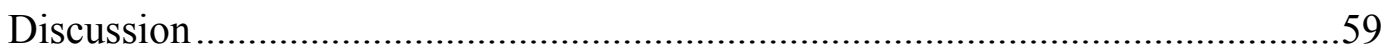

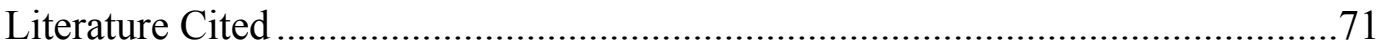

IV. TRADE-OFFS BETWEEN RESOURCE AND PREDATOR EFFECTS ON A PRIMARY CONSUMER ALONG A GRADIENT CREATED BY

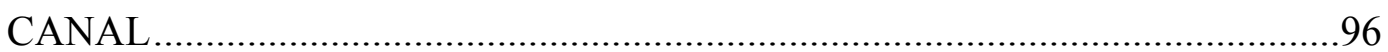

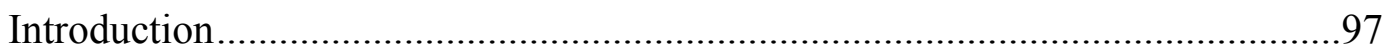

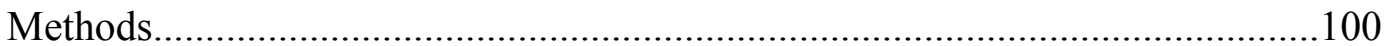

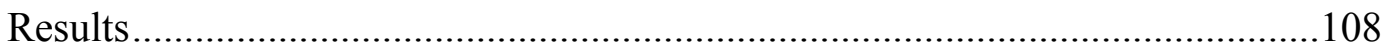

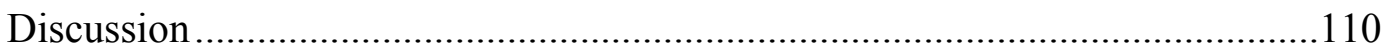

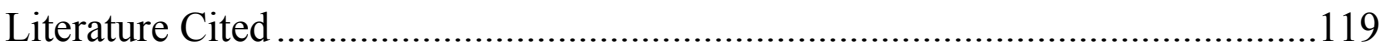

V. BIOTIC AND ABIOTIC DRIVERS OF SNAIL POPULATION DYNAMICS IN A SEASONALLY FLOODED WETLAND ...........................138

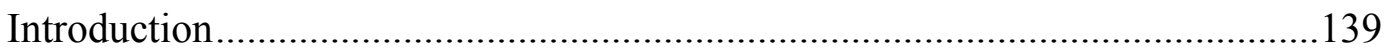

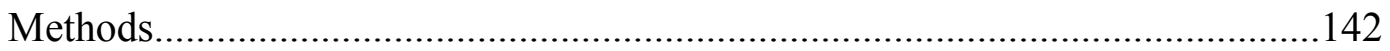

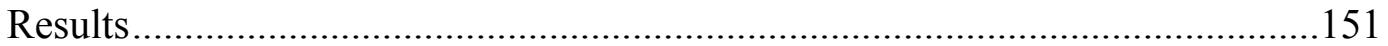

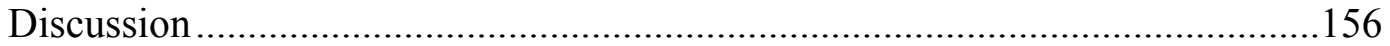

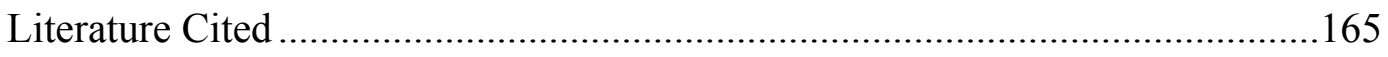




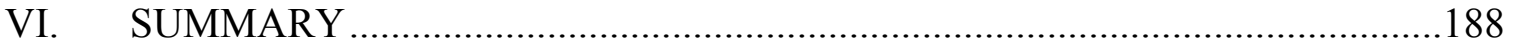

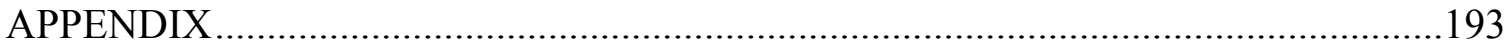

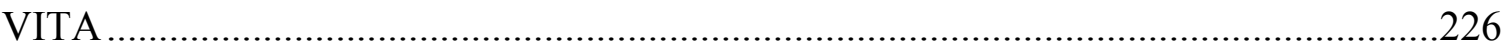




\section{LIST OF TABLES}

TABLE

PAGE

\section{CHAPTER II}

2.1 Different sampling devices used among the 92 studies, 2 unpublished datasets, and my data. Several studies used multiple devices for sampling different habitats within ecosystems

\section{CHAPTER III}

3.1 Repeated measures ANOVA of individual snail biomass (g/individual) during the $41 \mathrm{~d}$ experiment. Denominator degrees of freedom estimated by the Satterthwaite method. Block was treated as a random effect

3.2 MANCOVA of shell shape for lateral and aperture aspects. I used PCA to reduce the number of dependent variables to 5 for lateral and 4 for aperture shape, which explained greater than $95 \%$ of shape variation for each aspect. Multivariate effect size was estimated with Wilk's partial variance explained $\left(\eta_{\mathrm{p}}^{2}\right)$

3.3 Direct, indirect, and total effects from path analysis for the effects of predator cue, consumption, and phosphorous addition on $\mathrm{C}: \mathrm{P}$ ratios, chlorophyll $a$ concentrations from periphyton associated with plastic strips, and benthic periphyton mat as well as a variety of snail traits. Note the similarities in total (net) effects for C:P ratios, and non-consumptive effects (predator cue) as well as the dearth of effects for snails experiencing lower densities

\section{CHAPTER IV}

4.1 Abiotic and biotic measurements (mean $\pm \mathrm{SE}$ ) for the two sites near and the two sites far from the canal taken in late June, before the experiment, and mid August, after the experiment. The marsh filled, periphyton grew, and the number of fish and invertebrates generally increased during the experiment as the wet season progressed. Snail predator density is the sum of Mayan cichlids, peninsula newts, belostomatids, leeches, crayfish, Anisoptera, and creeping water bugs. Snail mortality was assessed with tethered snails. All other parameters were quantified with $1-\mathrm{m}^{2}$ throw traps..... 128

4.2 Repeated measures analysis of variance of snail growth on local periphyton alone and with local and transplanted periphyton. 


\section{CHAPTER V}

5.1 Model selection results from different competing models that predicted the change in snail density at site 03 in WCA with exogenous and endogenous independent variables. Akaike Information Criterion (AIC) values are the -2 log likelihood for ecah model, $\triangle$ AIC is the difference from the base model, and $\omega$ i is the Akaike weight for each model that gives the relative likelihood. Lower AIC values indicate a better model and the best model in each set is in bold.

5.2 Model selection results from different competing models that predicted the change in snail density at site 11 in WCA with exogenous and endogenous independent variables. Akaike Information Criterion (AIC) values are the $-2 \log$ likelihood for ecah model, $\triangle$ AIC is the difference from the base model, and $\omega$ i is the Akaike weight for each model that gives the relative likelihood. Lower AIC values indicate a better model and the best model in each set is in bold.

5.3 Model selection results from different competing models that predicted the change in snail density at site CP in TSL with exogenous and endogenous independent variables Akaike Information Criterion (AIC) values are the $2 \log$ likelihood for ecah model, $\Delta$ AIC is the difference from the base model, and $\omega \mathrm{i}$ is the Akaike weight for each model that gives the relative likelihood. Lower AIC values indicate a better model and the best model in each set is in bold.....

5.4 Model selection results from different competing models that predicted the change in snail density at site TS in TSL with exogenous and endogenous independent variables Akaike Information Criterion (AIC) values are the $2 \log$ likelihood for ecah model, $\triangle$ AIC is the difference from the base model, and $\omega \mathrm{i}$ is the Akaike weight for each model that gives the relative likelihood. Lower AIC values indicate a better model and the best model in each set is in bold

5.5 Summary statistics for the final models from the selection procedure for each site. The per-capita rate of change in snail density served as the dependent variable in each model. 
5.6 Logistic model selection results from long-term data on large fish occurrence in two regions (TSL and WCA). Seasonality was modeled as period and was treated as a continuous variable, while year was modeled as a fixed effect. Akaike Information Criterion (AIC) values are the $-2 \log$ likelihood for ecah model, $\triangle$ AIC is the difference from the base model, and $\omega \mathrm{i}$ is the Akaike weight for each model that gives the relative likelihood. Lower AIC values indicate a better model and the best model in each set is in bold.

5.7 Logistic regression model-selection results from tethering experiments conducted in 2007 at four sites in two regions testing for effects that predict mortality and mode of predation (entry, 0 vs. crushing, 1 ). Sites were modeled as fixed effects and nested within regions. Periods represented seasonal variation and was modeled as a continuous variable. Akaike Information Criterion (AIC) values are the $-2 \log$ likelihood for ecah model, $\Delta$ AIC is the difference from the base model, and $\omega$ i is the Akaike weight for each model that gives the relative likelihood. Lower AIC values indicate a better model and the best model in each set is in bold 


\section{LIST OF FIGURES}

FIGURE

PAGE

\section{CHAPTER I}

1.1 Conceptual diagram of abiotic and biotic drivers affecting changes in snail population dynamics $\left(r_{t}\right)$ in the Everglades that were measured in my dissertation. Snail populations at time $t$ and $t+1$ are shown with juveniles and adults to represent the continuous variation in size. Abiotic and biotic drivers are represented with ovals; diamonds constitute the variables measured. Disturbance affects the survival (S) of emergent stems, periphyton, snails, crayfish and fish; it also affects the presence of fish in the marsh. Habitat complexity was measured as periphyton volume (V) and stem density (D) which affect changes in snail population growth. Molluscivorous fish and crayfish negatively affect snail growth $(\mathrm{G})$, morphology $(\mathrm{M})$, and reproduction $(\mathrm{R})$ through non-consumptive effects that alter population growth. Their consumptive effects were quantified with handling time $(\mathrm{H})$, consumption rate $(\mathrm{Q})$, and encounter rate $(\mathrm{E})$ from tethering studies. Periphyton, in addition to habitat complexity, is a resource for snails and the quality alters individual growth and reproduction

\section{CHAPTER II}

2.1 Cumulative number of studies reporting snail density (gray), standing crop (white), or both (black) from 1959 through 2008. The 6 studies that I estimated standing crop from reported density and snail size were counted in the density tally. The current study is included, but unpublished datasets used for ecosystem comparisons are not included

2.2 Regression and 95\% CI results (top) and rank-density (mean $\pm 1 \mathrm{SE}$ ) with standing crop (mean $\pm 1 \mathrm{SE}$ ) (bottom) from 15 ecosystems. Data were from 12 published studies, 2 unpublished datasets, and our data that reported both measures; I estimated standing crop from density and individual size data for 6 published studies. The regression is through all of the points, but I distinguish studies that reported a single species (open circles) to illustrate that reporting multiple species (closed circles) did not inflate ecosystem estimates of density or standing crop. The number of ecosystems in each category is shown in, or above, each bar 
2.3. Rank-size of individual snails (mean $\pm 1 \mathrm{SE}$ ) among ecosystems calculated by dividing average standing crop by average density for each ecosystem and then calculating a mean and SE for each category. Note the large size of individuals in karstic wetlands and the small size in streams with introduced snails

2.4. Rank-density (mean $\pm 1 \mathrm{SE}$ ), for 28 ecosystems from 85 published, 2 unpublished datasets, and my data. Numbers inside, or above, the bars represent the number of ecosystems in each category used to generate the estimate. Note that karstic wetlands and the Venezuelan llanos revealed the lowest values

2.5. Rank-biomass (mean $\pm 1 \mathrm{SE}$ ) for 17 ecosystems from 19 published studies, 2 unpublished datasets, and my data. I estimated standing crop from density and individual snail size data for 6 studies. Numbers in, or above, the bars represent the number of ecosystems used to generate estimates for each category. Note that karstic wetlands yielded the lowest values

\section{CHAPTER III}

3.1 Landmarks (black) and semi-landmarks (white) used in geometric morphometric analysis. Location where shell thickness was measured

3.2 Individual snail biomass (mean \pm S.E.) through time. Phosphorous additions (filled) led to larger individuals than ambient (open) conditions. Snails experiencing cues from a caged crayfish (circle) were smaller than those with no cue (triangle). There was no difference between density manipulation treatments (upper vs. lower panel). Lines are drawn to aid the eye

3.3 Planorbella production (mean $\pm \mathrm{SE}, \mathrm{g} /$ tank/day) during the $41 \mathrm{~d}$ experiment. I found no difference between removal treatments after accounting for the removed snails, but cue (black bars) slowed and nutrients stimulated production primarily because production was high in treatments with nutrient additions but without cue when snail density was constant

3.4 Proportion of snails observed by visual census (mean \pm SE) that experienced crayfish cue, density reductions, and phosphorous additions compared to tanks without these manipulations. Note that proportionally fewer snails were observed when cue was present, when densities were lower, and at ambient phosphorous levels 
3.5 The first 3 principal components (mean) of lateral shape variation from a PCA on covariances of superimposed landmarks and semilandmarks. Treatment combinations are above symbols; the first letter refers to predator cue ( $\mathrm{c}=$ cue, $\mathrm{n}=$ no cue), the second letter indicates snail density $(\mathrm{s}=$ non-removal, $\mathrm{r}=$ removal), and the last letter refers to phosphorous $(\mathrm{p}$ $=$ added, $1=$ ambient $)$. Note, that in cue treatments without phosphorous additions snails did not develop anti-predator morphologies and snails developed distinct morphologies at low densities without predator cue. These two responses led to the cue-by-phosphorous and cue-by-density interactions in the MANCOVA

3.6 Thin-plate spline transformation grids depicting lateral and aperture aspects of shell shape variation among snails grown in the presence of crayfish cue. Lateral shape variation for the cue-by-density and cue-by-phosphorous interactions were qualitatively similar to shape variation for the predator main effect. Deformation grids were generated using the derived effect scores from the MANCOVA on principal components. Note the tall and narrow aperture in predator cue treatments

3.7 Allocation of resources into shell thickness (mean $\pm \mathrm{SE}$ ), measured at the top edge of the aperture. Snails without crayfish cue that received phosphorous additions and that experienced lower density (R) developed thin shells

3.8 Per capita F1 standing stock (mean $\pm \mathrm{SE}, \mathrm{g} / \mathrm{ind}$./tank) scaled to the density (no./tank) of adult snails at the end of experiment. There was no difference in F1 standing stock for removal treatments after accounting for removed specimens. Phosphorus additions in the absence of crayfish cue exhibited the largest $\mathrm{F} 1$ standing stock (Tukey, $\mathrm{P}<0.05$ )

3.9 Periphyton mat characteristics during the experiment. Phosphorous additions lowered C:P ratios indicating that resource quality improved, but quantity decreased as both periphyton chlorophyll $a$ concentration and dry weight declined. C:P ratios in ambient tanks were lower by the end of the experiment 
3.10 Chlorophyll $a$ concentration (lmean $\pm \mathrm{SE}$ ) in benthic periphyton mat and in periphyton on plastic strips located on the tank floor. Snail grazers were absent (black bars), removed during the experiment to simulate predation (gray bars), or were kept at similar densities (white bars) and either did or did not experience crayfish cue. Different letters indicate significant differences using Tukey HSD ( $\mathrm{P}<0.05)$. Note, the similarities between the two graphs except for the tanks with crayfish cues and snails that had much lower chlorophyll $a$ concentrations on plastic strips. Tanks with crayfish and snails generally had higher chlorophyll $a$ concentrations compared to tanks without snails

3.11 Path model showing non-consumptive (crayfish cue) and consumptive (snail density) effects of crayfish in the midst of phosphorous enrichment on a variety of traits of the snail, Planorbella duryi. I represented periphyton resources with three variables to examine the potential for indirect effects of crayfish cue on localized periphyton (chl $a$ strips) and test for elemental constraint on growth and reproduction $(\mathrm{C}: \mathrm{P}$ ratio and Periphyton chl $a$ ). Solid lines represent positive relationships between traits, while dashed lines are negative. Thick lines are significant relationships $(\mathrm{P} \leq 0.05)$, medium lines are marginal $(0.1>\mathrm{P}<0.05)$ and thin lines are non significant paths $(\mathrm{P}>0.1)$. Lateral $\mathrm{PC}$ and aperture $\mathrm{PC}$ are the first principal components describing shell lateral shape and aperture shape that explained greater than $70 \%$ and $60 \%$ of shape variation respectively. Shell thickness is the residuals from a regression of tissue mass and shell length to control for the effects of body size

\section{CHAPTER IV}

4.1 Snail predator density (least square mean \pm SE) at sites near (black) and far (grey) from the canal, top. The probability that tethered snails would be consumed by a predator, bottom....

4.2 Periphyton characteristics from containers with (gray) and without (black) snails added. Periphyton ash-free dry mass, and chlorophyll $a$ values used in analysis were scaled up from sub-samples. The least-square means with standard errors are plotted

4.3 Canonical axes from the MANOVA of soft algae counts for the site-bytransplant interaction. The first axis separates sites located near (filled) compared to far (open) from the canal. Axis two largely separates blocks. Grazing did not affect algal composition. Pins are labeled to indicate periphyton held at the home site where it was collected $(\mathrm{H})$ or away site (A) distant from where it was collected 
4.4 Relative abundance (mean $\pm \mathrm{SE}$ ) of soft algae groups identified by MANOVA to be different between near and far sites from a canal

4.5 Relative abundance of periphyton and snail lipids identified as biomarkers from the second block (one near and one far site from the canal). Local periphyton (home) was placed into bags at the site; transplanted (away) was placed in bags at the opposite site. Half of the bags had snails. Note the accumulation of 18:109 in snail tissue. It has been identified as a green algae biomarker and suggests snails assimilate green algae compared to other types

4.6 The first two principal components (mean $\pm \mathrm{SE}$ ) from an analysis on the relative abundance of lipids in periphyton that was reciprocally transplanted in experimental bags between a site near and a site far from a canal. Half of the bags received snails (open), while no snails were added to the others (filled)

4.7 Snail growth rate (mean $\pm \mathrm{SE}$ ) near and far from a canal fed periphtyon that originated near or far from the canal and reciprocally transplanted. Lines connect local periphyton (home, filled) to transplanted periphyton (away, open)

4.8 Number of egg masses on a standard substrate between sites near and far from a canal. The y-axis is the log difference between egg masses in bags with experimental snails and bags without experimental snails. More egg masses were laid far from the canal

\section{CHAPTER V}

5.1 Conceptual diagram of abiotic and biotic drivers affecting snail populations in the Everglades that were measured in this study. Snail populations at time $t$ and $t+1$ are shown with juveniles and adults to represent the continuous variation in size used in the model. Disturbance affects the survival (S) of emergent stems, periphyton, snails, crayfish and fish; it also affects the presence (P) of fish in the marsh. Habitat complexity affects the change in juvenile and adult snail density by variation in the density of stems (D) and the volume (V) of periphyton. Fish and crayfish affect the change in snail density. Predator effects on the change in snail density were measured by quantifying handling time $(\mathrm{H})$, consumption rate $(\mathrm{Q})$, and encounter rate $(\mathrm{E})$. Encounter rate was measured with tethering studies in the field

5.2 Snail shell remains found at the end of tethers. Intact empty shells were left by entry based predators like a crayfish (top), while a crushing predator, like a fish, left shell fragments (bottom).... 
5.3 Snail density, closed circle and invertebrate density, square, compared to water depth, open circle, for a twelve year period at four sites in the Everglades. Site 03 and 11 are in WCA, while CP and TS are in TSL. Site 3 was deeper and did not dry as often as site 11, while the two sites in TSL had very similar hydrology. Note the log scale on the left y-axis for density and the right $y$-axis for water depth is a linear scale.

5.4 Seasonal variation (mean $\pm \mathrm{SE}, 12 \mathrm{y}$ ) in a variety of biotic variables. Plots show crayfish density, A, snail density, B, and individual snail size, $\mathrm{C}$ at two sites in WCA $(03,11)$ and TSL $(C P, T S)$

5.5 Seasonal variation (mean $\pm \mathrm{SE}, 12 \mathrm{y}$ ) in abiotic variables. Plots show stem density, A, periphyton volume, B, and water depth, $\mathrm{C}$ at two sites in WCA $(03,11)$ and TSL $(\mathrm{CP}, \mathrm{TS})$

5.6 Partial regression plots for the log change in snail density $\left(\mathrm{no} / \mathrm{m}^{2}\right)$ and depth $(\mathrm{cm})$, lag log-snail density $\left(\mathrm{no} / \mathrm{m}^{2}\right), \log$ stem density $\left(\mathrm{no} / \mathrm{m}^{2}\right)$, or lag log-crayfish density $\left(\mathrm{no} / \mathrm{m}^{2}\right)$ at two sites in WCA and two sites in TSL. Not all independent variables retained in the final model exhibited strong correlations $(>|0.2|)$ with the change in snail density and are not shown. Site and region labels are on right. Plots show residuals for the dependent and independent variables after each was regressed separately on the other independent variables. Note that the $\mathrm{x}$ - and $\mathrm{y}$-axis scales change

5.7 Probability and 95\% confidence bands of catching a molluscivorous fish with increasing depth in WCA and TSL between 1996 and 2007. Results are from a model selection procedure where water depth was the best model in WCA and water depth and year was the most parsimonious model in TSL

5.8 Variation in the probability of snail mortality estimated from tethering, A, and the probability that a mortality resulted from a crushing predator, B. Each plot displays the predicted relationship and 95\% confidence band with the independent variable that was the best predictor chosen from a set of models using AIC. The probability of mortality was greatest in July and October during the wet season and the probability that the consumed snails were eaten by a crushing predator increased with water depth

5.9 Snail biomass (g) consumed in 24-hours by different sized Mayan cichlids, top, and two species of crayfish, bottom. Note the positive relationship between fish and consumption of snail biomass as indicated by the regression line (solid) and 95\% CI lines (dashed); there was no size relationship with crayfish consumption 
5.10 Time to consumption of different sized snails by different sized Mayan cichlids. Exponential curves and 95\% confidence intervals demonstrate snail size refugia. Standard length, model fit, and the equation for each line is in the upper left, or right of each panel. Note the y-axis is different for each row. Long handling times are not necessarily associated with larger fish. 


\section{CHAPTER I}

INTRODUCTION 


\section{ORIGINS OF POPULATION DYNAMICS}

Most populations exhibit some form of regulation that causes population size to fluctuate within bounds (Turchin 2003). The study of population dynamics has garnered the formal attention of ecologists for at least eight decades and been the source of much debate (Elton 1924, Nicholson 1933, Andrewartha and Birch 1954, Strong 1986, Wolda 1989, Berryman 1991, Turchin 1995). Despite the attention, the challenge to understand the relative role of different abiotic and biotic processes that regulate population dynamics remains a critical area of research. For example, the periodic cycles of snowshoe hare and lynx populations have been studied since the pioneering work of Charles Elton in the 1920's but the proximate causes of the phenomenon are still debated (Lindstrom et al. 2001) and additional mechanisms including the threat of predation continue to emerge (Boonstra et al. 1998, Peckarsky et al. 2008). The importance of understanding the mix of abiotic and biotic factors responsible for population dynamics is important because it reveals how nature works, which empowers workers to manage, restore, and protect ecosystems more effectively.

Populations are composed of individuals, and population fluctuations emerge from the births, deaths, and growth rates, of those individuals. Examining how members of populations respond to different abiotic and biotic factors provides the basis for studying population dynamics. Disturbance is perhaps the most important abiotic factor affecting the survival of individuals, which alters population and community structure (Sousa 1984). Disturbance, defined here as any process that removes biomass (Grime 1977), includes seasonal fluctuations in temperature or water depth that indiscriminately 
removes individuals from populations. Productivity or resource quality is another abiotic factor that profoundly influences population and community dynamics (Power 1992, Sterner and Elser 2002). Improving resource quality by adding nutrients that are in short supply stimulates individual growth rates, reproductive rates, and ultimately results in improving the population growth rate which can alter community structure. Among biotic interactions, predation is widely considered to be an important factor affecting population dynamics and community structure (Sih et al. 1985). Predators remove individuals from populations by consuming them, but they also alter prey behavior, growth rates, and reproductive rates by their presence and release of chemical cues. Interactions between disturbance, resource quality, and predators can alter the magnitude of predator effects on prey (Norrdahl et al. 2002, Richards and Coley 2007). Therefore, these factors must be studied in concert to understand population dynamics (Fig 1).

The Florida Everglades is a compelling location to examine the relative importance of disturbance, resource limitation, and predator risk on population dynamics. The ecosystem is a large $\left(\sim 11,000-\mathrm{mi}^{2}\right)$ sub-tropical karstic wetland that extends from just south of Lake Okeechobee in the north to Florida Bay in the south. Historic flow patterns were altered during the mid $20^{\text {th }}$ century by construction of extensive canal systems that drained large tracts of wetland and serves as deep water refugia for large predators. Concurrent with land reclamation, increased agricultural activity in the Everglades watershed led to phosphorous enrichment in an otherwise extremely oligotrophic ecosystem (Browder et al. 1994, Noe et al. 2001, McCormick et al. 2002, Steinman et al. 2002, Gaiser et al. 2004). A defining characteristic of the Everglades are the high levels of primary production but low standing crops of aquatic organisms (Turner et al. 1999, 
Gaiser et al. 2006). Phosphorous enrichment threatens this distinguishing characteristic. At intermediate levels of enrichment periphyton standing crop declines, but quality (C:P ratio) increases along with the abundance of many aquatic taxa; high levels of enrichment lead to depletion of dissolved oxygen, a total loss of periphyton mat structure, and a loss of animal biomass. The response of invertebrates to phosphorous enrichment remains unclear. Several studies have found invertebrates, like snails, to increase (Rader and Richardson 1994), while others find the reverse or no response (Turner et al. 1999, McCormick et al. 2004). Additionally, some research suggests that invertebrate response to nutrient enrichment might be related to hydroperiod (Liston 2006). Moreover, no research has explicitly considered the role of snails as grazers in the Everglades although in many ecosystem they are integral components of aquatic communities (Dillon 2000). Thus, for my dissertation, I examine the interactive roles of nutrients, predators, and disturbance in shaping snail population dynamics in the Everglades. I use the Seminole Ramshorn snail (Planorbella duryi) in these studies because it is the most abundant snail in the ecosystem. I divided my examination of these factors into four parts, each characterized by a question:

1. How does snail standing crop $\left(\mathrm{g} / \mathrm{m}^{2}\right)$ and density $\left(\right.$ no. $\left./ \mathrm{m}^{2}\right)$ in sub-tropical karstic wetlands compare to other freshwater ecosystems around the world?

2. How do phosphorous enrichment and the consumptive and non-consumptive predator effects trade-off to affect a variety of traits in the Seminole Ramshorn snail? 
3. How does a naturally occurring gradient of predators and phosphorous enrichment created by canals affect snail diet, growth, and reproduction?

4. What is the relative importance of disturbance, phosphorous enrichment, crayfish, and molluscivorous fishes in determining snail population dynamics in a twelve year time series?

I address the first question in Chapter II with a literature review of studies reporting snail standing crop $\left(\mathrm{g} / \mathrm{m}^{2}\right)$ and density $\left(\right.$ no. $\left./ \mathrm{m}^{2}\right)$ or both in rivers, streams, ponds, lakes, and wetlands. Data on snail standing crop and density in karstic wetlands were obtained from a long-term study of aquatic communities in the Everglades and collection trips to the Sian Kaan Biopreserve on the Yucatan Peninsula of Mexico and Crab-Catcher lagoon in central Belize. This study provides the foundation for the rest of my dissertation as it places snail population size in karstic wetlands in the context of other ecosystems.

Chapter III considers the second question with a factorial mesocosm experiment that crossed the consumptive (removal) and non-consumptive (conspecific cue) effects of crayfish (Procambarus fallax) predators with phosphorous enrichment. I quantified the effects of these factors on snail behavior, morphology, growth, and reproduction and used path analysis to examine the relative importance of predators and nutrients on snail standing crop in the next generation.

The third question was contemplated in Chapter IV with a reciprocal transplant experiment along a gradient of phosphorous enrichment and predators that both decline with distance from the canal. The abiotic and biotic factors at sites near and far from the canal were determined before and after the experiment with $1-\mathrm{m}^{2}$ throw traps and 
tethering studies. I separated the effects of predator cues from phosphorous enrichment on snails by reciprocally transplanting periphyton between sites near (more predator cues) and far (fewer predator cues) from the canal and stocking snails from a common source into bags that contained either local or transplanted periphyton.

Chapter V addressed the final question by examining the differential effects of disturbance, crayfish, and molluscivorous fish density, and phosphorous enrichment with a time-series analysis of snail density and body size among four sites in two regions that varied in productivity from phosphorous enrichment. Ancillary data on predators were collected to determine snail size refugia and estimate their consumption rates. Field estimates of mortality were determined by tethering snails at the four sites five times during one year to capture seasonal and spatial variation in snail mortality.

As a body of work, my dissertation examines the proximate causes of snail population dynamics with a variety of comparative, correlative, and experimental approaches. 


\section{LITERATURE CITED}

Andrewartha, H. G., and L. C. Birch. 1954. The distribution and abundance of animals. University of Chicago Press, Chicago.

Berryman, A. A. 1991. Stablization or regulation: What it all mean! Oecologia 86:140143.

Boonstra, R., D. Hik, G. R. Singleton, and A. Tinnikov. 1998. The impact of predatorinduced stress on the snowshoe hare cycle. Ecological Monographs 68:371-394.

Browder, J. A., P. J. Gleason, and D. R. Swift. 1994. Periphyton in the Everglades: Spatial variation, environmental correlates, and ecological implications. Pages 379-418 in S. M. Davis and J. C. Ogden, editors. Everglades: The ecosystem and its restoration. St. Lucie Press, Del Ray Beach, Florida.

Dillon, R. T. 2000. The ecology of freshwater molluscs. Cambridge University Press, Cambridge.

Elton, C. S. 1924. Periodic fluctuations in the number of animals: Their causes and effects. British Journal of Experimental Biology 2:119-163.

Gaiser, E. E., J. H. Richards, J. C. Trexler, R. D. Jones, and D. L. Childers. 2006. Periphyton responses to eutrophication in the Florida Everglades: Cross-system patterns of structural and compositional change. Limnology and Oceanography 51:617-630.

Gaiser, E. E., L. J. Scinto, J. H. Richards, K. Jayachandran, D. L. Childers, J. C. Trexler, and R. D. Jones. 2004. Phosphorus in periphyton mats provides the best metric for detecting low-level P enrichment in an oligotrophic wetland. Water Research 38:507-516.

Grime, J. P. 1977. Evidence for the existence of three primary strategies in plants and its relevance to ecological and evolutionary theory. American Naturalist 111:11691194.

Lindstrom, J., E. Ranta, H. Kokko, P. Lundber, and V. Kaitala. 2001. From artic lemmings to adaptive dynamics: Charles Elton's legacy in population ecology. Biological Reviews 76:129 - 158.

Liston, S. E. 2006. Interactions between nutrient availability and hydroperiod shape macroinvertebrate communities in Florida Everglades marshes. Hydrobiologia 569:343-357. 
McCormick, P. V., S. Newman, S. Miao, D. E. Gawlik, and D. Marley. 2002. Effects of anthropogenic phosphorus inputs on the Everglades. Pages 83-126 in J. W. Porter and K. G. Porter, editors. The Everglades, Florida Bay, and coral reefs of the Florida Keys: An ecosystem sourcebook. CRC Press, Boca Raton.

McCormick, P. V., R. B. E. Shuford, and P. S. Rawlik. 2004. Changes in macroinvertebrate community structure and function along a phosphorus gradient in the Florida Everglades. Hydrobiologia 529:113-132.

Nicholson, A. J. 1933. The balance of animal populations. Journal of Animal Ecology 2:132-178.

Noe, G. B., D. L. Childers, and R. D. Jones. 2001. Phosphorus biogeochemistry and the impact of phosphorus enrichment: Why is the Everglades so unique? Ecosystems 4:603-624.

Norrdahl, K., T. Klemola, E. Korpimaki, and M. Koivula. 2002. Strong seasonality may attenuate trophic cascades: Vertebrate predator exclusion in boreal grassland. Oikos 99:419-430.

Peckarsky, B. L., B. L. Kerans, B. W. Taylor, and A. R. McIntosh. 2008. Predator effects on prey population dynamics in open systems. Oecologia 156:431-440.

Power, M. E. 1992. Top-down and bottom-up forces in food webs: Do plants have primacy. Ecology 73:733-746.

Rader, R. B., and C. J. Richardson. 1994. Response of macroinvertebrates and small fish to nutrient enrichment in the northern Everglades. Wetlands 14:134-146.

Richards, L. A., and P. D. Coley. 2007. Seasonal and habitat differences affect the impact of food and predation on herbivores: A comparison between gaps and understory of a tropical forest. Oikos 116:31-40.

Sih, A., P. Crowley, M. Mcpeek, J. W. Petranka, and K. Strohmeier. 1985. Predation, competition, and prey communities - A review of field experiments. Annual Review of Ecology and Systematics 16:269-311.

Sousa, W. P. 1984. The role of disturbance in natural communities. Annual Review of Ecology and Systematics 15:353-391.

Steinman, A. D., K. E. Havens, H. J. Carrick, and R. VanZee. 2002. The past, present, and future hydrology and ecology of lake Okeechobee and its watersheds. Pages 19-38 in J. W. Porter and K. G. Porter, editors. The Everglades, Florida Bay, and coral reefs of the Florida Keys: An ecosystem sourcebook. CRC Press, Boca Raton. 
Sterner, R. W., and J. J. Elser. 2002. Ecological stoichiometry: The biology of elements from molecules to the biosphere. Princeton University Press, Princeton, New Jersey.

Strong, D. R. 1986. Density-vague population change. Trends in Ecology \& Evolution 1:39-42.

Turchin, P. 1995. Population regulation: Old arguments and a new synthesis. Pages 19 40 in N. a. P. Cappuccino, P. W., editor. Population dynamics: New approaches and synthesis. Academic Press, San Diego.

Turchin, P. 2003. Complex population dynamics: A theoretical/empirical synthesis. Princeton University Press, Princeton, NJ.

Turner, A. M., J. C. Trexler, C. F. Jordan, S. J. Slack, P. Geddes, J. H. Chick, and W. F. Loftus. 1999. Targeting ecosystem features for conservation: Standing crops in the Florida Everglades. Conservation Biology 13:898-911.

Wolda, H. 1989. The equilibrium concept and density dependence tests. What does it all mean? Oecologia 81:430-432. 


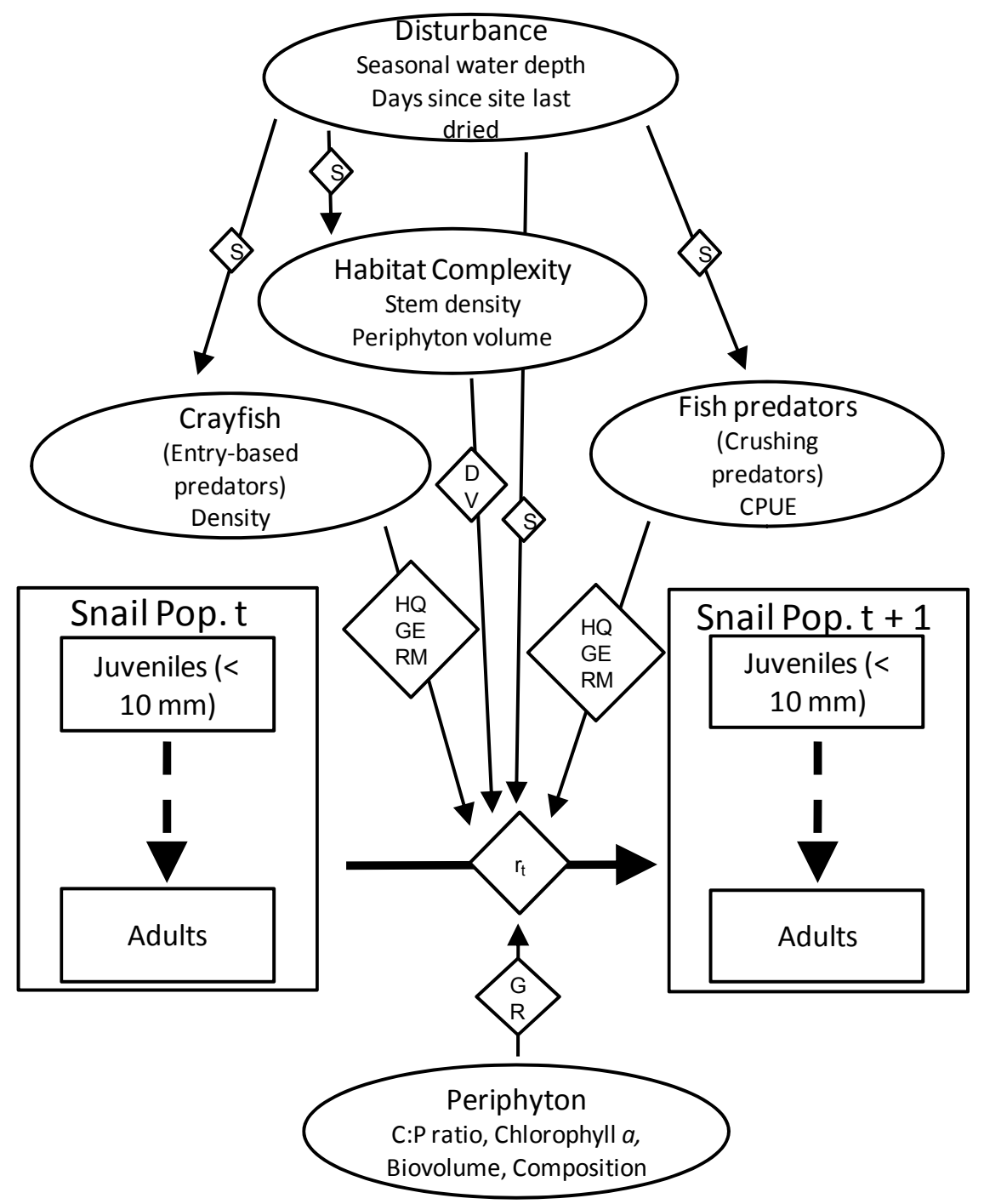

Fig 1.1. Conceptual diagram of abiotic and biotic drivers affecting changes in snail population dynamics $\left(r_{t}\right)$ in the Everglades that were measured in my dissertation. Snail populations at time $t$ and $t+1$ are shown with juveniles and adults to represent the continuous variation in size. Abiotic and biotic drivers are represented with ovals; diamonds constitute the variables measured. Disturbance affects the survival (S) of emergent stems, periphyton, snails, crayfish and fish; it also affects the presence of fish in the marsh. Habitat complexity was measured as periphyton volume (V) and stem density (D) which affect changes in snail population growth. Molluscivorous fish and crayfish negatively affect snail growth $(\mathrm{G})$, morphology $(\mathrm{M})$, and reproduction $(\mathrm{R})$ through nonconsumptive effects that alter population growth. Their consumptive effects were quantified with handling time $(\mathrm{H})$, consumption rate $(\mathrm{Q})$, and encounter rate $(\mathrm{E})$ from tethering studies. Periphyton, in addition to habitat complexity, is a resource for snails and the quality alters individual growth and reproduction. 
CHAPTER II

INFERRING ENERGY PATHWAYS FROM COMPARISONS OF SNAIL DENSITY AND STANDING CROP AMONG FRESHWATER ECOSYSTEMS 


\section{INTRODUCTION}

Water chemistry and water residence time are important abiotic factors affecting snail species distribution and abundance in freshwaters. Snail shells are primarily constructed of calcium carbonate (White et al. 2007b) and a rich literature connects water chemistry to snail species distributions (e.g., Boycott 1936, Williams 1970, McKillop and Harrison 1972, Nduku and Harrison 1976, Dussart 1979, McKillop 1985, Eleutheriadis and Lazaridou-Dimitriadou 1995). Lodge et al. (1987) developed a model of the relative importance that abiotic and biotic factors that combine to determine snail species distributions. They concluded the relationship between water chemistry and snail distributions was complex, but that most species require $5 \mathrm{mg} / \mathrm{l}$ of water-born calcium, which excludes them from most soft-water ecosystems. Water residence or permanence is the other broad filter determining the distribution of aquatic snails (Costil et al. 2001, Gerard et al. 2008). However, some species thrive in ephemeral ecosystem by possessing traits like aestivation that enable them to survive drought conditions (Boss 1974, Heeg 1977).

Within these broad abiotic constraints, snails are important primary consumers that also are prey for higher trophic level consumers. Snails can dramatically reduce periphyton standing crop (Brönmark 1989, Hill 1992, Rosemond 1994, Feminella and Hawkins 1995), alter producer assemblages (Power et al. 1988, McCormick and Stevenson 1989), and promote nutrient regeneration through positive feedbacks (McCormick and Stevenson 1991, Hillebrand et al. 2002). As prey for a number of taxa, they channel energy to higher trophic levels (Eckblad 1976, Brown and Devries 1985, Brönmark and Malmqvist 1986, Kesler and Munns 1989, Alexander and Covich 1991, 
Reed and Janzen 1999). Because snails are both important primary consumers and fall prey to numerous predators, altering the predator-prey interaction has community and ecosystem wide consequences. Brönmark and Weisner (1996) surveyed 44 ponds and found abundant snails but little periphyton in fishless ponds, while ponds with molluscivorous fishes were depauperate of snails but periphyton was abundant. Experimental studies confirm the strong linkage between molluscivores, snails, and periphyton by demonstrating reduced snail growth and activity when molluscivores were present, which cascades to positively affect overall periphyton growth (Underwood and Thomas 1990, Brönmark et al. 1992, Lodge et al. 1994, Bernot and Turner 2001, Lewis 2001). Therefore, snails are representative of other primary consumers that predators eat and provide a good metric for understanding energy flow in many aquatic ecosystems.

The wide distribution of freshwater snails and their role in energy transfer makes them good candidates for ecosystem comparisons. Synthesizing data from multiple ecosystems is a powerful tool for generating hypotheses about the ecological processes governing community structure and ecosystem function. Several studies have compared the relative importance of top-down and bottom-up processes among ecosystems (e.g., Shurin et al. 2002, Gruner et al. 2008), but few have used the copious natural history data available for many taxa in comparison studies. Such an evaluation could reveal general trends about the relative importance of biotic and abiotic processes affecting community structure and demonstrate shifts in the ecological role of taxa among ecosystems.

In this study, I review the literature on snail density $\left(\mathrm{no} . / \mathrm{m}^{2}\right)$ and standing $\mathrm{crop}\left(\mathrm{g} / \mathrm{m}^{2}\right)$ across a diversity of freshwater ecosystems. This review was motivated by three questions: 1. Can natural history data collected from a diversity of freshwater ecosystems 
for different purposes be used to make board comparisons among ecosystems; 2. If so, are the patterns that emerge interruptible in the context of community and ecosystem ecology theory; 3. What do these findings mean for making conclusions about the major pathways of energy flow within aquatic ecosystems?

\section{METHODS}

\section{Literature Review}

I used Web of Science to find studies that reported freshwater snail density and standing crop to generate my database. I also mined the literature-cited sections of studies identified in the online search. Two unpublished datasets bolstered my database with data from under-represented ecosystems. Studies had to report data on an areal basis $\left(\right.$ area $\left.^{-1}\right)$ and provide information on sampling scheme to be included in the review. I used data reported in tables, from the text, and I estimated data reported in figures.

\section{Karstic Tropical and Sub-tropical Wetlands}

I estimated snail density and standing crop at a site in the Florida Everglades to supplement published studies from this ecosystem and I sampled karstic wetlands in Belize and Mexico to increase the number of karstic wetlands in the review. I used a 10$y$ dataset (Trexler unpublished data) to estimate snail density and standing crop for the Everglades site. This site was selected from 20 sites located throughout the middle and southern regions of the Everglades (see Ruetz et al. 2005) because it had the highest snail density over the $10 \mathrm{y}$, thus providing a liberal estimate of both measures. The site consisted of 3 plots, where the contents of five $1-\mathrm{m}^{2}$ throw traps $(1.5-\mathrm{mm}$ mesh) were 
collected 5 times a year (February, April, July, October, December) for 750 samples total. Throw-traps were cleared with a bar seine (1.5-mm mesh) and 2 dip nets (1- and 2-mm mesh, Jordan et al. 1997 for methods).

I traveled to Belize (New River Lagoon, Orangewalk; $17^{\circ} 45^{\prime} \mathrm{N}, 88^{\circ} 38^{\prime} \mathrm{W}$ ) in May and November 2007, and Mexico (Sian Káan Biosphere Preserve; $19^{\circ} 48^{\prime}$ N, $87^{\circ} 41^{\prime} \mathrm{W}$ ) in December 2006 and March 2008 with a team of researchers. We sampled at 6 sites in Belize, 3 sites on both dates, 1 site in May only, and 2 additional sites in November. We sampled 7 sites in Mexico, 3 sites on both visits, 1 site in March only, and 3 additional sites in December. Not all sites were sampled every visit because, either some sites were too deep $(>100 \mathrm{~cm})$ in the rainy season (November, December) or they were dry in the dry season (May, March). Sites in Mexico had 1 plot because we were limited to areas accessible by car. We had access to airboats in Belize that allowed us to increase our sampling effort and establish 2 plots per site. In both countries, plots were sampled with seven $1-\mathrm{m}^{2}$ throw traps using the same protocol and gear as in the Everglades. We collected 147 samples in Belize and 70 samples in Mexico.

\section{A Common Currency}

I chose total snail wet-tissue mass and total snail count scaled to $1 \mathrm{~m}^{2}$ as a common metric for standing crop and density comparisons. Mass reported in other units (e.g., ashfree dry mass) was converted to wet mass by assuming an $85 \%$ loss for dried, and a $90 \%$ loss for ashed samples. Loss estimates were determined from pulmonate and caenogastropod snails found in the Everglades (CBR unpublished data). Wet tissue mass was estimated for the site in the Everglades by measuring the shell length for all snails 
collected during the $10 \mathrm{y}$ period and using species-specific length-to-weight regressions (CBR unpublished data). In Belize and Mexico, I removed the soft tissue from the shell with forceps, patted it dry, and weighed it.

Studies from the literature review and my own collections generated density and standing crop at multiple spatial and temporal scales within and between ecosystems. I adopted a standardized aggregation method for estimates. When data were reported within ecosystems (e.g., multiple plots or sites and/or multiple events), I averaged across space (plots then sites) and then time (years then months). I aggregated data on multiple species separately within ecosystems and then summed the values for each species to calculate the total snail standing crop or density. I treated each ecosystem (e.g., multiple streams) within a study separately.

Hunter (1975), Eversole (1978), and Costil and Daguzan (1995) provided snail size and density that allowed me to estimate individual wet mass with species or generic level (for similarly shaped species, e.g., planospiral) size-to-weight regressions. Rosemond et al. (1994), Hill et al. (1995), and Hill (1992) reported density for Elimia clavaeformis in streams located at Oak Ridge National Laboratories, Tennessee and A. D. Rosemond provided an average snail size to estimate individual wet mass from published regressions. I multiplied individual wet mass by density to calculate standing crop for these studies. Newbold et al. (1983), Huryn et al. (1995), Stewart and Garcia (2002), and Hall et al. (2006) reported ash-free dry mass (afdm) with the shell, while Hershey (1990) reported wet mass that included the shell. Shell afdm is around $12 \%$ of total for the species Pomacea paludosa and Haitia cubensis, but around 30\% for Planorbella duryi from the Everglades; there was similar variability for the proportion of wet shell mass to 
total mass for these species. Variability in the organic matter of the shell among species prevented us from removing shell mass from these estimates; however, I include the studies because their standing crop estimates were similar to other ecosystems in the same category. Kushlan (1975) reported wet mass of the shell and tissue for P. paludosa in the Everglades and provided individual size data, so I removed shell mass with species-specific regressions (CBR unpublished data).

\section{Ecosystem Comparisons}

I used Pearson correlations to determine how latitude and the sampling area affected density and standing crop estimates. I used a t-test to determine differences between studies that reported species level data and those that reported data at higher taxonomic classifications.

With the sub-set of studies that reported density and standing crop, I explored the feasibility of using density as a surrogate for standing crop with regression; density served as a predictor of standing crop. I used this same dataset to estimate body size for an ecosystem by taking the quotient of standing crop and density estimates for each ecosystem. For all analyses, I log transformed density, standing crop, and sampling area estimates to meet assumptions of normality and used SAS 9.2 (SAS Institute Inc., Cary NC, USA) to calculate Pearson correlations, regressions, and t-tests.

Individual ecosystems served as the unit of observation and I took the mean of ecosystems with similar characteristics (e.g., ponds) for comparative purposes.

Ecosystems were categorized based on information in the studies, or I contacted authors and searched other literature on a particular ecosystem when it was missing; otherwise, I 
used the most specific category reported in the study. I grouped streams into small $\left(1^{\text {st }}\right.$ and $2^{\text {nd }}$ order $)$, medium ( $3^{\text {rd }}$ and $4^{\text {th }}$ order $)$, large $\left(5^{\text {th }}\right.$ order and above $)$, and a general “stream" category when order could not be determined. Lakes and ponds were distinguished based on descriptions in the study. I identified 7 wetland ecosystems: swamps, temperate, fluvial, floodplain, tropical-cultivated, tropical, and karstic. Ecosystems with introduced snails and those altered by human activities were categorized based on descriptions in the study.

\section{RESULTS}

Seventy-three studies reported only density, 7 reported only standing crop, and 13 reported both for 93 studies including my data (Fig. 1). I did not include the 2 unpublished datasets in the tally and I grouped the 6 studies that I estimated standing crop, from density and snail size, with the density tally. Ecosystems in the review ranged from the northern temperate zone to the tropics and included the Americas, Africa, Spain, Russia, Europe, New Zealand, and Thailand (Appendix). However, I found no relationship between density and latitude or standing crop and latitude (Pearson correlation: $p>0.05$ ). Researchers used 24 different sampling devices of various sizes to collect snails (Table 1). I found a negative correlation between density and the area sampled (Pearson correlation: $r_{173}=-0.34, p<0.0001$ ) as well as standing crop and sampling area (Pearson correlation: $\left.r_{57}=-0.47, p<0.0002\right)$. There was also a negative correlation between latitude and sampling area for density (Pearson correlation: $r_{173}=-$ $0.29, p<0.0001)$ and standing crop (Pearson correlation: $\left.r_{57}=-0.53, p<0.0001\right)$. Taxonomic resolution ranged from Order down to Species. Despite this wide range, I 
found no difference in ecosystem estimates of density or standing crop among studies that reported data on a single species and those reporting higher levels of classification $(p$ $>0.05$, in both cases).

I identified 230 different ecosystems that I grouped into 28 general ecosystem categories. Streams, ponds, and lakes were the most well-represented ecosystem categories. Density data were available for all ecosystem categories, standing crop for $57 \%$, and both estimates were available for $50 \%$ of the categories (Appendix). On the basis of the regression with studies that reported both measures, density explained $55 \%$ of the variation in standing crop among ecosystem categories (Fig. 2). A fluvial wetland, a canal, a rice field, and swamps had lower standing crop than expected and ditches had higher standing crop than expected on the basis of their densities. My calculation of individual size revealed that lentic ecosystems tended to have larger individual snails than lotic ones (Fig. 3). Karstic tropical and sub-tropical wetlands had the largest snails of all ecosystems considered, owing to the presence of caenogastropod snails in the family Ampullariidae.

Snail density and standing crop ranged over 7 and 3 orders of magnitude, respectively. Density was highest in snail-invaded streams, tropical cultivated wetlands, a fluvial wetland, and lakes, while karstic wetlands and wetlands associated with the Venezuelan llanos had the lowest estimates, 8-times lower than the nearest category (Fig. 4). Standing crop was highest in a ditch, snail-invaded streams, streams of all sizes, and rivers. Similar to density results, karstic wetlands in Belize, Mexico, and Florida had the lowest standing crop estimates, which were 3-times less than the nearest category (Fig. $5)$. 


\section{DISCUSSION}

I found large differences in snail density and standing crop estimates among the 28 ecosystem categories identified in the 93 studies, 2 unpublished datasets, and my data. Researchers used a plethora of sampling devices that were reflective of their creativity and the challenges associated with quantitatively sampling different ecosystems.

Quadrats and cores of various sizes were most commonly used, but many devices were used only once. A greater concern for ecosystem comparisons was the areal coverage of sampling devices. I found negative correlations between sampling area and the estimated snail density or standing crop. Decreasing density or standing crop with increasing sampling area could result from missing small snails with larger sampling units, or researchers choosing larger sampling units when snails were sparse. I assumed researchers selected devices, sampling spatial scales, and collection schedules that minimized sampling bias in an ecosystem. Combining data from many sources likely compensated bias associated with any particular effort. Standardizing sampling methods would benefit future comparative efforts among ecosystems and all studies should include justification of the spatial and temporal scale of sampling. Despite these limitations, clear patterns emerged from the compiled data.

The majority of studies I found reported snail density, although the incidence of reporting standing crop has increased steadily during the last decade. Compared to density, standing crop is a superior measure of the ecological importance a taxon has on an ecosystem or community for at least two reasons. Standing crop is more closely related to an organism's metabolism than density (Saint-Germain et al. 2007) and it 
represents the functional significance of a taxon because it accounts for rare but large animals (Cohen et al. 2003). Thus, standing crop reveals the mechanisms that underlie population and community level processes that ultimately affect ecosystem function because it includes information on the biomass of individuals (Osenberg et al. 1994). Given the ecological significance of standing crop, I wanted to evaluate the efficacy of using density to predict standing crop. Density and standing crop increased at similar rates for many ecosystems and the positive relationship between the two measures was compelling considering the array of ecosystems, sampling methods, and the number of studies considered. However, density failed to capture forty-five percent of the variation in standing crop for a given ecosystem demonstrating that it is not an effective surrogate for standing crop. Body size variation among ecosystems likely explains the poor fit.

Density and standing crop are two measures that are closely linked through body size (e.g., length, biomass), a fundamental measure of an organism that reveals general information on life history characteristics (Peters 1983, Brown et al. 2004). Recent studies have advocated the importance of reporting both body size and density (White et al. 2007a) or body size and standing crop (Cohen et al. 2003). I calculated a coarse estimate of body size for ecosystems (g/ind.) and found that karstic tropical and subtropical wetlands had the largest snails, while snail-invaded streams had the smallest snails. Pomacea paludosa and Pomacea flagellata are snails in the family Ampullariidae that accounted for the large snail size in karstic wetlands, while the introduced New Zealand mud snail (Potamopyrgus antipodarum) was responsible for the small body size in snail-invaded streams. Disparity in body size appears to be coupled to density and standing crop for a given ecosystem because total snail density and standing crop was 
lowest in karstic wetlands (large species) and highest in snail-invaded streams (small species). This explanation confounds body size and phylogeny, particularly for Ampullariids because I found little data for this family in other aquatic ecosystems although they are found in many streams and rivers. However, the relationship between body size and density (or standing crop) among ecosystems is compelling and warrants future consideration.

Snails in lentic (e.g., ponds) ecosystems were larger than in lotic (e.g., streams), but lotic ecosystems tended to have higher standing crops of snails. A combination of predator effects and hydrodynamic constraints on body size could explain this pattern. Generally, larger snails (within and among species) are more resistant to predation (Osenberg and Mittelbach 1989, Chase 1999) and molluscivorous fishes, which consume more snails compared to other snail predators (Lodge et al. 1987), are more numerous in ponds and lakes compared to streams. Large snails are also more easily dislodged or excluded from high-flow environments because of hydrodynamic constraints on large shells, bio-energetic costs, and resource availability (Moore 1964, Denny et al. 1985, Dussart 1987, Lam and Calow 1989, Johnson and Brown 1997, Blanco and Scatena 2007). I propose that much of the available energy produced in lentic ecosystems travels to upper trophic levels through consumption of small snails and large snails enjoy higher survival which results in fewer but larger snails. Conversely, snail predation tends to be less important in lotic ecosystems where snails likely accumulate producer-derived energy resulting in high snail standing crops that are composed of small snails that are less susceptible of dislodgement from high-flow events. Studies should report density, standing crop, and body size to aid the explanation of observed patterns in nature. Each 
provides information about the influence of a taxon on ecological processes and they aid synthesizing data in community and ecosystem ecology.

High snail density and standing crop were associated with ecosystems altered by humans. I separated anthropogenic effects into studies that reported data on introduced snails and those with classifications that indicated human modification (e.g., ditch), which may have led to misclassification of some ecosystems. Despite this complication, snail-invaded streams had the highest snail density and among the highest standing crop of all ecosystems and some human modified ecosystems had high snail standing crop and density. The snail-invaded streams category was dominated by research on the New Zealand mud snail, a small species that Hall et al. (2006) concluded altered food web function. The extremely high secondary production led to an accumulation of carbon in mud snails that would otherwise be available to native invertebrates. However, high density and standing stock for an introduced snail are not necessary for them to affect ecosystem function. Golden apple snail (Pomacea canaliculata) introductions to Thai wetlands have caused ecosystem function and state change at low snail densities but large individual size; phytoplankton blooms replace aquatic vascular plants in wetlands with the snail (Carlsson et al. 2004).

Snail density and standing crop patterns for human-modified ecosystems were mixed; some ecosystems had large values, while others were typical of undisturbed ecosystems. Recent research has demonstrated that runoff from agricultural fields containing agrochemicals can cascade through snails and negatively affect other aquatic taxa. Rohr et al. (2008) found that runoff of atrazine and phosphate increased snail density by stimulating periphyton growth, which led to higher infection rates of tadpoles by 
trematodes because snails are the parasite's intermediate host. These results suggest that snails can respond positively to degradation and they can reach high densities and standing crops when introduced, suggesting they may be good indicators of anthropogenic degradation for some ecosystems.

The dearth of snails in karstic tropical and sub-tropical wetlands was the most striking result from the review. Ecosystems associated with the Venezuelan llanos were the only estimates that were near those of karstic ecosystems. This region of the llanos shares similar flora and fauna with karstic wetlands, including the presence of Ampullariids (Troth 1979, Donnay and Beissinger 1993), but I kept it separate because it lacked karstic bedrock. Surface-water calcium concentration in the Florida Everglades are sufficient for snail shell growth as it is well above $5 \mathrm{mg} / \mathrm{l}$ (Loftus and Kushlan 1987, Price 2001, McCormick and Harvey In review) suggested by Lodge et al. (1987) as a lower limit required by most snails. Belizean and Mexican karstic wetlands likely have similar water chemistry (Wicks et al. 1995, Schmitter-Soto et al. 2002, Singurindy and Berkowitz 2004), but specific data on these ecosystems have not been collected.

Low snail density and standing crop could signify substantial energy contributions to upper trophic levels via predation, but few studies have considered the importance of predators in structuring wetland communities (but see Batzer et al. 2000, Dorn et al. 2006, Chick et al. 2008). In lieu of specific experimental evidence, food-web theory predicts that numerous snail predators should occupy upper trophic levels if snails were a major energy source (Hairston et al. 1960, Brönmark et al. 1992). Tracking avian predators is difficult, but snail kites (Rostrhamus sociabilis) and limpkins (Aramus guarauna) likely consume many apple snails in Caribbean karstic wetlands (Snyder and 
Snyder 1969, Reed and Janzen 1999, Bennetts et al. 2006); however, seasonal changes in water depth limit their influence by altering habitat complexity (Bennetts et al. 2006). Evidence from the aquatic food web suggests biotic (top down) control of snails may be less important when compared to other freshwater ecosystems because standing crops of decapods, fishes, and other invertebrates are low (Turner et al. 1999) and the influence of large fish predators is diminished to times and places by seasonal drying (Chick et al. 2004, Dorn et al. 2006, Chick et al. 2008). Therefore, snails should be more numerous in karstic wetland ecosystems although abiotic factors could limit their success.

Disturbance and nutrients could each limit the role of snails in transferring energy to upper trophic levels. Disturbance, in the form of seasonal drying, is a prominent abiotic driver in wetlands, but many snails are resistant to desiccation (Boss 1974, Heeg 1977, Costil et al. 2001, Darby et al. 2003, Gerard et al. 2008) and other wetlands in the review (e.g., fluvial, swamps) ranked intermediate or high for both density and standing crop. Therefore, disturbance alone does not account for the extremely low snail density and standing crop reported in karstic ecosystems.

Tropical and sub-tropical karstic wetlands have high periphyton production values (Rejmankova and Komarkova 2000, Ewe et al. 2006) and maintain large periphyton standing crops (Vymazal 1995, Goldsborough and Robinson 1996) that cover the marsh floor and aquatic vegetation in thick mats. Periphyton mats are composed of green algae, coccoid and filamentous blue green algae, diatoms, and fungi that are held together by a calcareous matrix of mucopolysaccharides secreted by cyanobacteria (Browder et al. 1994, Rejmankova et al. 2004, Gaiser et al. 2005). These extensive periphyton mats seemingly provide ample resources for snail species from the Families Planorbidae, 
Physidae, and Ampullariidae that occur in these ecosystems and that are primarily herbivorous (Clampitt 1970, Sharfstein and Steinman 2001, Williams and Trexler 2006). Despite the large quantities of periphyton as a potential resource, it contains little phosphorous (Gaiser et al. 2005, King and Richardson 2007) and is mechanically defended from some grazers (Geddes and Trexler 2003, Chick et al. 2008) indicating that it may have low nutritional value for snails.

Large amounts of periphyton, combined with few snails and molluscivores, signify that only small amounts of producer energy reaches upper trophic levels through snails in karstic wetlands. Other herbivores could be a major route of energy to upper trophic levels, but most small fishes and other invertebrates are omnivores in these ecosystems (Loftus 2000, Dorn et al. 2006, Chick et al. 2008). Further, many of these taxa exhibit low standing crop and density compared to other ecosystems and mirror the snail result (Turner et al. 1999). Further, karstic wetlands do not support large numbers of predatory fishes (Chick et al. 2004). These indirect observations for other taxa suggest that the findings for snails are representative of other primary consumers and support the conclusion that most energy generated by primary producers is not propagated to upper trophic levels. Thus, I propose that microbial loops replace snails and other similarly sized herbivores as primary routes of energy in karstic tropical and sub-tropical wetlands (Azam et al. 1983, Hairston and Hairston 1993, Hall and Meyer 1998). Primary production shunted into microbial loops is recycled within the loop and only indirectly transferred to upper trophic levels through small detritivores that are consumed by animals occupying higher trophic levels. For example, mat-dwelling bacteria might recycle nutrients from the pool of decomposing algae, fungi, and cyanobacteria with the 
bacterial-captured energy from the periphyton mat fueling amphipods and chironomids, which are numerous in Everglades periphyton mat (Liston and Trexler 2005). These detritivores are linked to upper trophic levels through their role as prey for fish (Loftus 2000). A recent stable-isotope study suggests detrital energy pathways are important to food-web structure in the Everglades (Williams and Trexler 2006). Research on energy flow dynamics and ecosystem function in wetlands, particularly karstic wetlands, would profit from examining the role of microbial loops.

\section{Acknowledgments}

I thank Luis Zambrano, UNAM, for access to Sian Ka'an Biosphere Reserve and Lamani Outpost lodge personnel for access to Belizean wetlands. Bill Loftus, Josette LaHee, and Evelyn Gaiser helped with fieldwork in Belize and Mexico. Andy Turner and Don Uzarski provided un-published data that greatly improved the work. I thank all authors that provided insight into their collection schemes, sampling methods, and ecosystem descriptions, particularly Alexander Huryn for information on stream order in Alabama. Christer Brönmark provided unpublished length weight regressions. An early version of this manuscript was greatly improved by comments from Joseph Parkos III and Chuck Goss, Tim Collins, Evelyn Gaiser, and Mary Power provided comments on a penultimate draft. A Judith Evans Parker Travel Fellowship and an Everglades Foundation Fellowship provided funding to CBR. 


\section{LITERATURE CITED}

Alexander, J. E., and A. P. Covich. 1991. Predation risk and avoidance behavior in two freshwater snails. Biological Bulletin 180:387-393.

Azam, F., T. Fenchel, J. G. Field, J. S. Gray, L. A. Meyerreil, and F. Thingstad. 1983. The ecological role of water-column microbes in the sea. Marine EcologyProgress Series 10:257-263.

Batzer, D. P., C. R. Pusateri, and R. Vetter. 2000. Impacts of predation on marsh invertebrates: Direct and indirect effects. Wetlands 20:307-312.

Bennetts, R. E., P. C. Darby, and L. B. Karunaratne. 2006. Foraging patch selection by Snail Kites in response to vegetation structure and prey abundance and availability. Waterbirds 29:88-94.

Bernot, R. J., and A. M. Turner. 2001. Predator identity and trait-mediated indirect effects in a littoral food web. Oecologia 129:139-146.

Blanco, J. F., and F. N. Scatena. 2007. The spatial arrangement of Neritina virginea (Gastropoda : Neritidae) during upstream migration in a split-channel reach. River Research and Applications 23:235-245.

Boss, K. J. 1974. Oblomovism in the Mollusca. Transactions of the American Microscopical Society 93:460 - 481.

Boycott, A. E. 1936. The habitats of freshwater Mollusca in Britian. The Journal of Animal Ecology 5:116 - 186.

Brönmark, C. 1989. Interactions between epiphytes, macrophytes and freshwater snails: A review. Journal of Molluscan Studies 55:299-311.

Brönmark, C., S. P. Klosiewski, and R. A. Stein. 1992. Indirect effects of predation in a freshwater, benthic food chain. Ecology 73:1662-1674.

Brönmark, C., and B. Malmqvist. 1986. Interactions between the leech Glossiphonia complanata and Its gastropod prey. Oecologia 69:268-276.

Brönmark, C., and S. E. B. Weisner. 1996. Decoupling of cascading trophic interactions in a freshwater, benthic food chain. Oecologia 108:534-541.

Browder, J. A., P. J. Gleason, and D. R. Swift. 1994. Periphyton in the Everglades: Spatial variation, environmental correlates, and ecological implications. Pages 379-418 in S. M. Davis and J. C. Ogden, editors. Everglades: The ecosystem and its restoration. St. Lucie Press, Del Ray Beach, Florida. 
Brown, J. H., J. F. Gillooly, A. P. Allen, V. M. Savage, and G. B. West. 2004. Toward a metabolic theory of ecology. Ecology 85:1771-1789.

Brown, K. M., and D. R. Devries. 1985. Predation and the distribution and abundance of a pulmonate pond snail. Oecologia 66:93-99.

Carlsson, N. O. L., C. Brönmark, and L. A. Hansson. 2004. Invading herbivory: The golden apple snail alters ecosystem functioning in Asian wetlands. Ecology 85: $1575-1580$.

Chase, J. M. 1999. To grow or to reproduce? The role of life-history plasticity in food web dynamics. American Naturalist 154:571-586.

Chick, J. H., P. Geddes, and J. C. Trexler. 2008. Periphyton mat structure mediates trophic interactions in a subtropical marsh. Wetlands 28:378-389.

Chick, J. H., C. R. Ruetz, and J. C. Trexler. 2004. Spatial scale and abundance patterns of large fish communities in freshwater marshes of the Florida Everglades. Wetlands 24:652-664.

Clampitt, P. T. 1970. Comparative ecology of the snails Physa gyrina and Physa integra. Malacologia 10:113-151.

Cohen, J. E., T. Jonsson, and S. R. Carpenter. 2003. Ecological community description using the food web, species abundance, and body size. Proceedings of the National Academy of Sciences of the United States of America 100:1781-1786.

Costil, K., and J. Daguzan. 1995. Comparative life cycle and growth of two freshwater gastropod species, Planorbarius corneus (L.) and Planorbis planorbis (L.). Malacologia 37:53 - 68.

Costil, K., G. B. J. Dussart, and J. Daguzan. 2001. Biodiversity of aquatic gastropods in the Mont St-Michel basin (France) in relation to salinity and drying of habitats. Biodiversity and Conservation 10:1-18.

Darby, P. C., P. L. Valentine-Darby, and H. F. Percival. 2003. Dry season survival in a Florida apple snail (Pomacea paludosa,Say) population. Malacologia 45:179-184.

Denny, M. W., T. L. Daniel, and M. A. R. Koehl. 1985. Mechanical limits to size in wave-swept organisms. Ecological Monographs 55:69-102.

Donnay, T. J., and S. R. Beissinger. 1993. Apple snail (Pomacea doliodes) and freshwater crab (Dilocarcinus dentatus) population fluctuations in the llanos of Venezuela. Biotropica 25:206-214. 
Dorn, N. J., J. C. Trexler, and E. E. Gaiser. 2006. Exploring the role of large predators in marsh food webs: Evidence for a behaviorally-mediated trophic cascade. Hydrobiologia 569:375-386.

Dussart, G. B. J. 1979. Life cycles and distribution of the aquatic gastropod molluscs Bithynia tentaculata (L.), Gyraulus albus (Muller), Planorbis planorbis (L.) and Lymnaea peregra (Muller) in relation to water chemistry. Hydrobiologia 67:223239.

Dussart, G. B. J. 1987. Effects of water flow on the detachment of some aquatic pulmonate gastropods. American Malacological Bulletin 5:66-72.

Eckblad, J. W. 1976. Biomass and energy transfer by a specialized predator of aquatic snails. Freshwater Biology 6:19-21.

Eleutheriadis, N., and Lazaridou-Dimitriadou. 1995. Density and growth of freshwater prosobranch snails (Bithynia graeca and Viviparus contectus) in relation to water chemistry in Serres, northern Greece. Journal of Molluscan Studies 61:347-352.

Eversole, A. G. 1978. Life cycles, growth and population bioenergetics in the snail Helisoma trivolvis (Say). Journal of Molluscan Studies 44:209 - 222.

Ewe, S. M. L., E. E. Gaiser, D. L. Childers, D. Iwaniec, V. H. Rivera-Monroy, and R. R. Twilley. 2006. Spatial and temporal patterns of aboveground net primary productivity (ANPP) along two freshwater-estuarine transects in the Florida Coastal Everglades. Hydrobiologia 569:459-474.

Feminella, J. W., and C. P. Hawkins. 1995. Interactions between stream herbivores and periphyton: A quantitative analysis of past experiments. Journal of the North American Benthological Society 14:465-509.

Gaiser, E. E., J. H. Richards, J. C. Trexler, R. D. Jones, and D. L. Childers. 2005. Periphyton responses to eutrophication in the Florida Everglades: Cross-system patterns of structural and compositional change. Limnology and Oceanography 50:342-355.

Geddes, P., and J. C. Trexler. 2003. Uncoupling of omnivore-mediated positive and negative effects on periphyton mats. Oecologia 136:585-595.

Gerard, C., A. Carpentier, and J. M. Paillisson. 2008. Long-term dynamics and community structure of freshwater gastropods exposed to parasitism and other environmental stressors. Freshwater Biology 53:470-484. 
Goldsborough, L. G., and G. G. C. Robinson. 1996. Pattern in wetlands. Pages 78 - 117 in R. J. Stevenson, M. L. Bothwell, and R. L. Lowe, editors. Algal ecology: Freshwater benthic ecosystems. Academic Press, New York.

Gruner, D. S., J. E. Smith, E. W. Seabloom, S. A. Sandin, J. T. Ngai, H. Hillebrand, W. S. Harpole, J. J. Elser, E. E. Cleland, M. E. S. Bracken, E. T. Borer, and B. M. Bolker. 2008. A cross-system synthesis of consumer and nutrient resource control on producer biomass. Ecology Letters 11:740-755.

Hairston, N. G., and N. G. Hairston. 1993. Cause-effect relationships in energy-flow, trophic structure, and interspecific interactions. American Naturalist 142:379-411.

Hairston, N. G., F. E. Smith, and L. B. Slobodkin. 1960. Community structure, population control, and competition. American Naturalist 94:421-425.

Hall, R. O., M. F. Dybdahl, and M. C. VanderLoop. 2006. Extremely high secondary production of introduced snails in rivers. Ecological Applications 16:1121-1131.

Hall, R. O., and J. L. Meyer. 1998. The trophic significance of bacteria in a detritus-based stream food web. Ecology 79:1995-2012.

Heeg, J. 1977. Oxygen consumption and the use of metabolic reserves during starvation and aestivation in Bulinus (Physopisis) africanus (Pulmonata: Planorbidae). Malacologia 16:549 - 560.

Hershey, A. E. 1990. Snail populations in arctic lakes: Competition mediated by predation. Oecologia 82:26 - 32.

Hill, W. R. 1992. Food limitation and interspecific competition in snail-dominated streams. Canadian Journal of Fisheries and Aquatic Sciences 49:1257-1267.

Hill, W. R., M. G. Ryon, and E. M. Schilling. 1995. Light limitation in a stream ecosystem: Responses by primary producers and consumers. Ecology 76:12971309.

Hillebrand, H., M. Kahlert, A. L. Haglund, U. G. Berninger, S. Nagel, and S. Wickham. 2002. Control of microbenthic communities by grazing and nutrient supply. Ecology 83:2205-2219.

Hunter, R. D. 1975. Growth, fecundity, and bioenergetics in three populations of Lymnaea palustris in Upstate New York. Ecology 56:50 - 63.

Huryn, A. D., A. C. Benke, and G. M. Ward. 1995. Direct and indirect effects of geology on the distribution and production of the freshwater snail Elimia. Journal of the North American Benthological Society 14:519 - 534. 
Johnson, P. D., and K. M. Brown. 1997. The role of current and light in explaining the habitat distribution of the lotic snail Elimia semicarinata (Say). Journal of the North American Benthological Society 16:545-561.

Jordan, F., S. Coyne, and J. C. Trexler. 1997. Sampling fishes in vegetated habitats: Effects of habitat structure on sampling characteristics of the $1-\mathrm{m}^{2}$ throw trap. Transactions of the American Fisheries Society 126:1012-1020.

Kesler, D. K., and W. R. Munns. 1989. Predation by Belostoma flumineum (Hemiptera): an important cause of mortality in freshwater snails. Journal of the North American Benthological Society 8:342-350.

King, R. S., and C. J. Richardson. 2007. Subsidy-stress response of macroinvertebrate community biomass to a phosphorus gradient in an oligotrophic wetland ecosystem. Journal of the North American Benthological Society 26:491-508.

Kushlan, J. 1975. Population changes of apple snail, Pomacea paludosa, in the southern Everglades. Nautilus 89:21-23.

Lam, P. K. S., and P. Calow. 1989. Intraspecific life-history variation in Lymnaea peregra (Gastropoda: Pulmonata). I. Field study. Journal of Animal Ecology 58:571-588.

Lewis, D. B. 2001. Trade-offs between growth and survival: Responses of freshwater snails to predacious crayfish. Ecology 82:758-765.

Liston, S. E., and J. C. Trexler. 2005. Spatiotemporal patterns in community structure of macroinvertebrates inhabiting calcareous periphyton mats. Journal of the North American Benthological Society 24:832-844.

Lodge, D. M., K. M. Brown, S. P. Klosiewski, R. A. Stein, A. P. Covich, B. K. Leathers, and C. Brönmark. 1987. Distribution of freshwater snails: Spatial scale and the relative importance of physicochemical and biotic factors. American Malacological Bulletin 5:73-84.

Lodge, D. M., M. W. Kershner, J. E. Aloi, and A. P. Covich. 1994. Effects of an omnivorous crayfish (Orconectes rusticus) on a freshwater littoral food web. Ecology 75:1265-1281.

Loftus, W. F. 2000. Accumulation and fate of mercury in an Everglades aquatic food web. Dissertation. Florida International University, Miami.

Loftus, W. F., and J. A. Kushlan. 1987. Freshwater fishes of southern Florida. Bulletin of the Florida State Museum 31:147-344. 
McCormick, P. V., and J. W. Harvey. In review. Influence of changing water sources and mineral chemistry on the Everglades ecosystem. Hydrobiologia.

McCormick, P. V., and R. J. Stevenson. 1989. Effects of snail grazing on benthic algal community structure in different nutrient environments. Journal of the North American Benthological Society 8:162-172.

McCormick, P. V., and R. J. Stevenson. 1991. Grazer control of nutrient availability in the periphyton. Oecologia 86:287-291.

McKillop, W. B. 1985. Distribution of aquatic gastropods across the Ordoician dolomite Precambrian granite contact in southeastern Manitoba, Canada. Canadian Journal of Zoology 63:278-288.

McKillop, W. B., and A. D. Harrison. 1972. Distribution of aquatic gastropods across an interface between the Canadian Shield and limestone formations. Canadian Journal of Zoology 50:1433-1445.

Moore, I. J. 1964. Effects of water currents on freshwater snails Stagnicola palustris and Physa propinqua. Ecology 45:558 - 564.

Nduku, W. K., and A. D. Harrison. 1976. Calcium as a limiting factor in the biology of Biomphalaria pfeifferi (Krauss), (Gastropda: Planorbidae). Hydrobiologia 49:143 - 170.

Newbold, J. D., J. W. Elwood, R. V. O'Neill, and A. L. Sheldon. 1983. Phosphorus dynamics in a woodland stream ecosystem: A study of nutrient spiraling. Ecology 64:1249-1265.

Osenberg, C. W., and G. C. Mittelbach. 1989. Effects of body size on the predator-prey interaction between pumpkinseed sunfish and gastropods. Ecological Monographs 59:405-432.

Osenberg, C. W., R. J. Schmitt, S. J. Holbrook, K. E. Abusaba, and A. R. Flegal. 1994. Detection of environmental impacts - Natural variability, effect size, and power analysis. Ecological Applications 4:16-30.

Peters, R. H. 1983. Ecological implications of body size. Cambridge University Press, Cambridge, U. K.

Power, M. E., A. J. Stewart, and W. J. Matthews. 1988. Grazer control of algae in an Ozark mountain stream - Effects of short-term exclusion. Ecology 69:1894-1898. 
Price, R. M. 2001. Geochemical determinations of groundwater flow in Everglades National Park. Ph. D. dissertation. University of Miami, Coral Gables, FL.

Reed, W. L., and F. J. Janzen. 1999. Natural selection by avian predators on size and colour of a freshwater snail (Pomacea flagellata). Biological Journal of the Linnean Society 67:331-342.

Rejmankova, E., J. Komarek, and J. Komarkova. 2004. Cyanobacteria - A neglected component of biodiversity: Patterns of species diversity in inland marshes of northern Belize (Central America). Diversity and Distributions 10:189-199.

Rejmankova, E., and J. Komarkova. 2000. A function of cyanobacterial mats in phosphorus-limited tropical wetlands. Hydrobiologia 431:135-153.

Rohr, J. R., A. M. Schotthoefer, T. R. Raffel, H. J. Carrick, N. Halstead, J. T. Hoverman, C. M. Johnson, L. B. Johnson, C. Lieske, M. D. Piwoni, P. K. Schoff, and V. R. Beasley. 2008. Agrochemicals increase trematode infections in a declining amphibian species. Nature 455:1235-U1250.

Rosemond, A. D. 1994. Multiple factors limit seasonal variation in periphyton in a forest stream. Journal of the North American Benthological Society 13:333-344.

Ruetz, C. R., III, J. C. Trexler, F. Jordan, W. F. Loftus, and S. A. Perry. 2005. Population dynamics of wetland fishes: Spatiotemporal patterns shaped by hydrological disturbance? Journal of Animal Ecology 74:322-332.

Saint-Germain, M., C. M. Buddle, M. Larrivee, A. Mercado, T. Motchula, E. Reichert, T. E. Sackett, Z. Sylvain, and A. Webb. 2007. Should biomass be considered more frequently as a currency in terrestrial arthropod community analyses? Journal of Applied Ecology 44:330-339.

Schmitter-Soto, J. J., F. A. Comín, E. Escobar-Briones, J. Herrera-Silveira, J. Alcocer, E. Suárez-Morales, M. Elías-Gutierrez, V. Díaz-Arce, L. E. Marín, and B. Steinich. 2002. Hydrogeochemical and biological characteristics of cenotes in the Yucatan Peninsula (SE Mexico). Hydrobiologia 467:215-228.

Sharfstein, B., and A. D. Steinman. 2001. Growth and survival of the Florida apple snail (Pomacea paludosa) fed three naturally occurring macrophyte assemblages. Journal of the North American Benthological Society 20:84-95.

Shurin, J. B., E. T. Borer, E. W. Seabloom, K. Anderson, C. A. Blanchette, B. Broitman, S. D. Cooper, and B. S. Halpern. 2002. A cross-ecosystem comparison of the strength of trophic cascades. Ecology Letters 5:785-791. 
Singurindy, O., and B. Berkowitz. 2004. Carbonate dissolution and precipitation in coastal environments: Laboratory analysis and theoretical considertation. Water Resources Research 40:W04401.

Snyder, N. F. R., and H. A. Snyder. 1969. A comparative study of mollusk predation by limpkins, Everglade kites, and boat-tailed grackles. LIving Bird 8:177 - 223.

Stewart, T. W., and J. E. Garcia. 2002. Environmental factors causing local variation in density and biomass of the snail Leptoxis carinata, in Fishpond Creek, Virginia. American Midland Naturalist 148:172-180.

Troth, R. G. 1979. Vegetational types on a ranch in the central llanos of Venezuela. in J. F. Eisenberg, editor. Vertebrate ecology in the northern neotropics. Smithsonian Institution Press, Washington, D. C.

Turner, A. M., J. C. Trexler, C. F. Jordan, S. J. Slack, P. Geddes, J. H. Chick, and W. F. Loftus. 1999. Targeting ecosystem features for conservation: Standing crops in the Florida Everglades. Conservation Biology 13:898-911.

Underwood, G. J. C., and J. D. Thomas. 1990. Grazing interactions between pulmonate snails and epiphytic algae and bacteria. Freshwater Biology 23:505-522.

Vymazal, J. 1995. Algae and element cycling in wetlands. CRC Press, Boca, Raton, FL.

White, E. P., S. K. M. Ernest, A. J. Kerkhoff, and B. J. Enquist. 2007a. Relationships between body size and abundance in ecology. Trends in Ecology \& Evolution 22:323-330.

White, M. M., M. Chejlava, B. Fried, and J. Sherma. 2007b. The concentration of calcium carbonate in shells of freshwater snails. American Malacological Bulletin 22:139-142.

Wicks, C. M., J. S. Herman, A. F. Randazzo, and J. L. Jee. 1995. Water-rock interactions in a modern coastal mixing zone. Geological Society of America Bulletin 107:1023-1032.

Williams, A. J., and J. C. Trexler. 2006. A preliminary analysis of the correlation of foodweb characteristics with hydrology and nutrient gradients in the southern Everglades. Hydrobiologia 569:493-504.

Williams, N. V. 1970. Studies on aquatic pulmonate snails in Central Africa I. Field distribution in relation to water chemistry. Malacologia 10:153-164. 
Table 2.1. Different sampling devices used among the 92 studies, 2 unpublished datasets, and my data. Several studies used multiple devices for sampling different habitats within ecosystems.

\begin{tabular}{lccl}
\hline \multicolumn{1}{c}{ Sampling } & & No. of & \\
\multicolumn{1}{c}{ device } & Area $\left(\mathrm{m}^{2}\right)$ & studies & \multicolumn{1}{c}{ Typical ecosystems } \\
\hline Basket trap & 0.032 & 1 & Floodplain wetland \\
Box & $0.05-0.1$ & 5 & Canals, lakes, ponds, streams \\
Bucket & 0.05 & 1 & Gravel pit, lakes, wetlands \\
Core & $0.004-0.25$ & 14 & Ditch, streams, wetlands \\
Dredge & 0.6 & 1 & Reservoir, streams \\
Drop & 0.25 & 1 & Lake \\
Ekman & $0.02-0.23$ & 9 & Lakes, ponds, streams \\
Gerking & - & 1 & Fluvial wetland \\
Grab & 0.06 & 2 & River, stream \\
Hess & - & 3 & Streams \\
Hester Dendy & 0.9 & 1 & Karstic wetland \\
Hula hoop & 0.48 & 1 & Lake \\
Mark/recapture & - & 1 & Stream \\
Peterson & - & 1 & Canal, swamps \\
Pull trap & 4.5 & 1 & Karstic wetland \\
Quadrat & $0.0015-1$ & 25 & Lakes, ponds, rivers, streams \\
Seine & 2.5 & 1 & Venezuelan llanos \\
Sieve & - & 1 & Streams \\
Stove pipe & $0.008-0.02$ & 3 & Pond, streams \\
Surber sampler & $0.02-0.5$ & 9 & Ponds, rivers, streams \\
Surface area & - & 6 & Streams \\
Sweep net & $0.25-1.5$ & 12 & Ponds, streams, wetlands \\
Throw trap & 1 & 7 & Ponds, streams, wetlands \\
Unknown & - & 4 & \\
\hline & & & \\
\hline
\end{tabular}




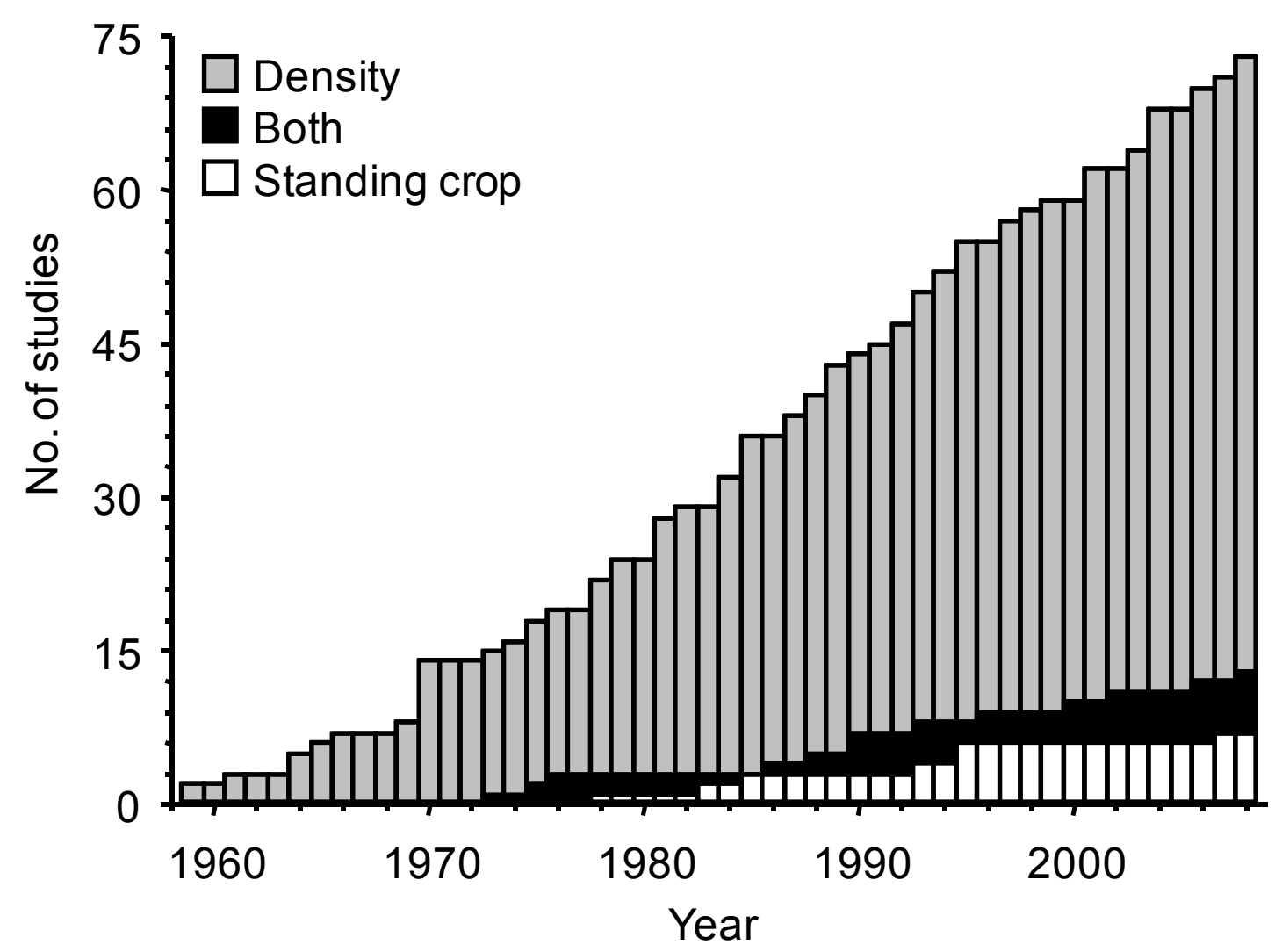

Fig. 2.1. Cumulative number of studies reporting snail density (gray), standing crop (white), or both (black) from 1959 through 2008. The 6 studies that I estimated standing crop from reported density and snail size were counted in the density tally. The current study is included, but unpublished datasets used for ecosystem comparisons are not included. 

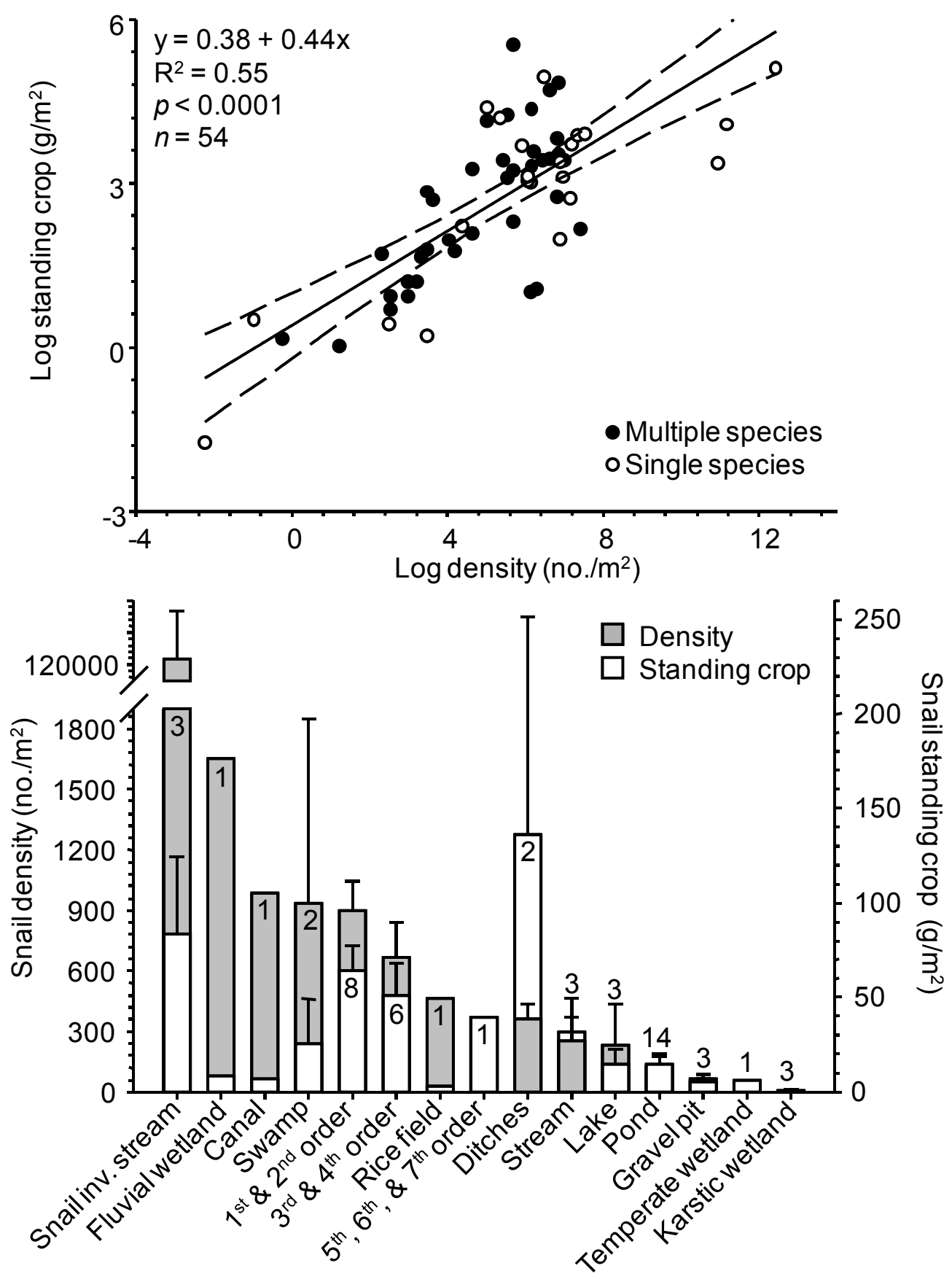

Fig. 2.2. Regression and 95\% CI results (top) and rank-density (mean \pm 1 SE) with standing crop (mean $\pm 1 \mathrm{SE}$ ) (bottom) from 15 ecosystems. Data were from 12 published studies, 2 unpublished datasets, and our data that reported both measures; I estimated standing crop from density and individual size data for 6 published studies. The regression is through all of the points, but I distinguish studies that reported a single species (open circles) to illustrate that reporting multiple species (closed circles) did not inflate ecosystem estimates of density or standing crop. The number of ecosystems in each category is shown in, or above, each bar. 


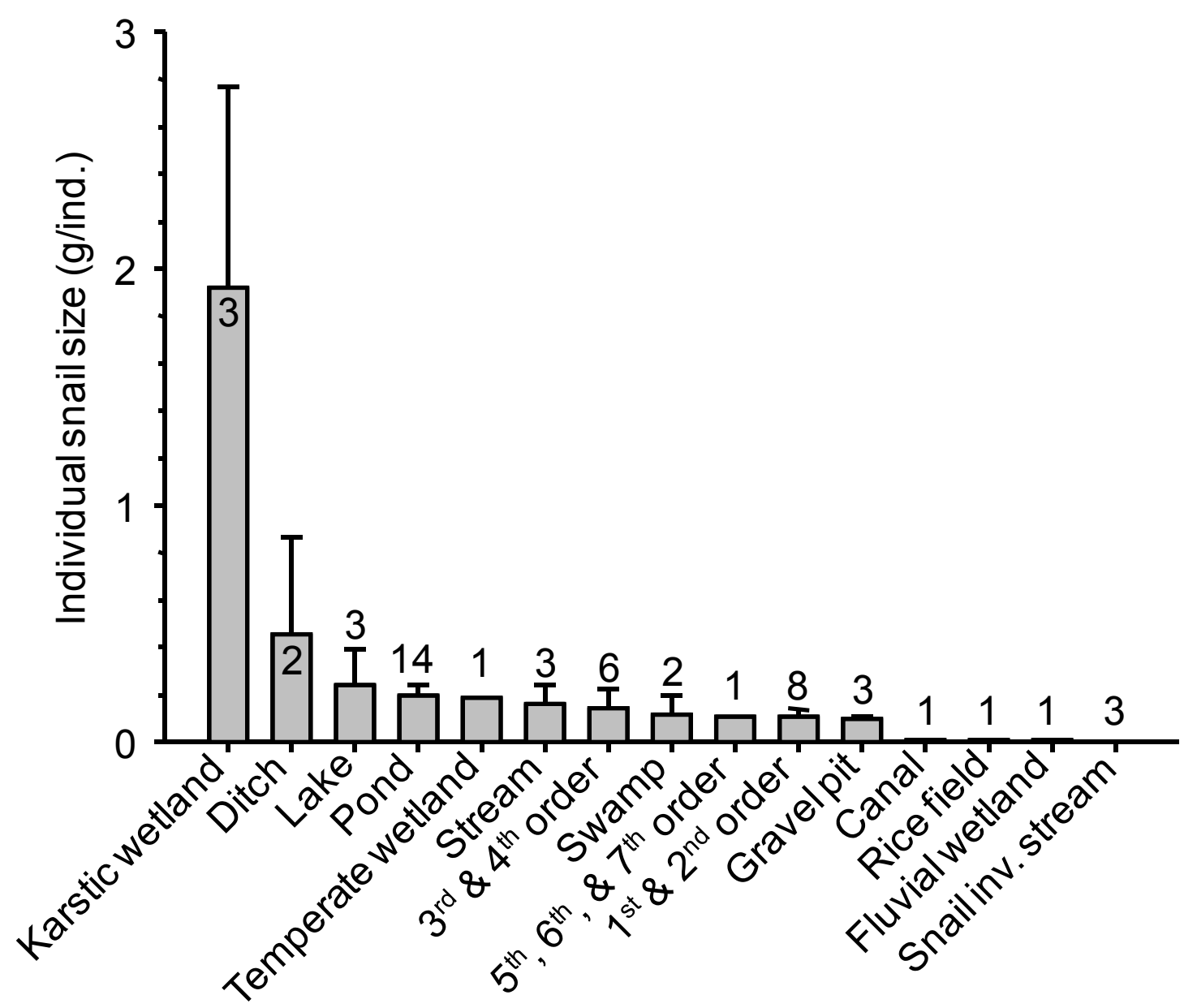

Fig. 2.3. Rank-size of individual snails (mean $\pm 1 \mathrm{SE}$ ) among ecosystems calculated by dividing average standing crop by average density for each ecosystem and then calculating a mean and SE for each category. Note the large size of individuals in karstic wetlands and the small size in streams with introduced snails. 


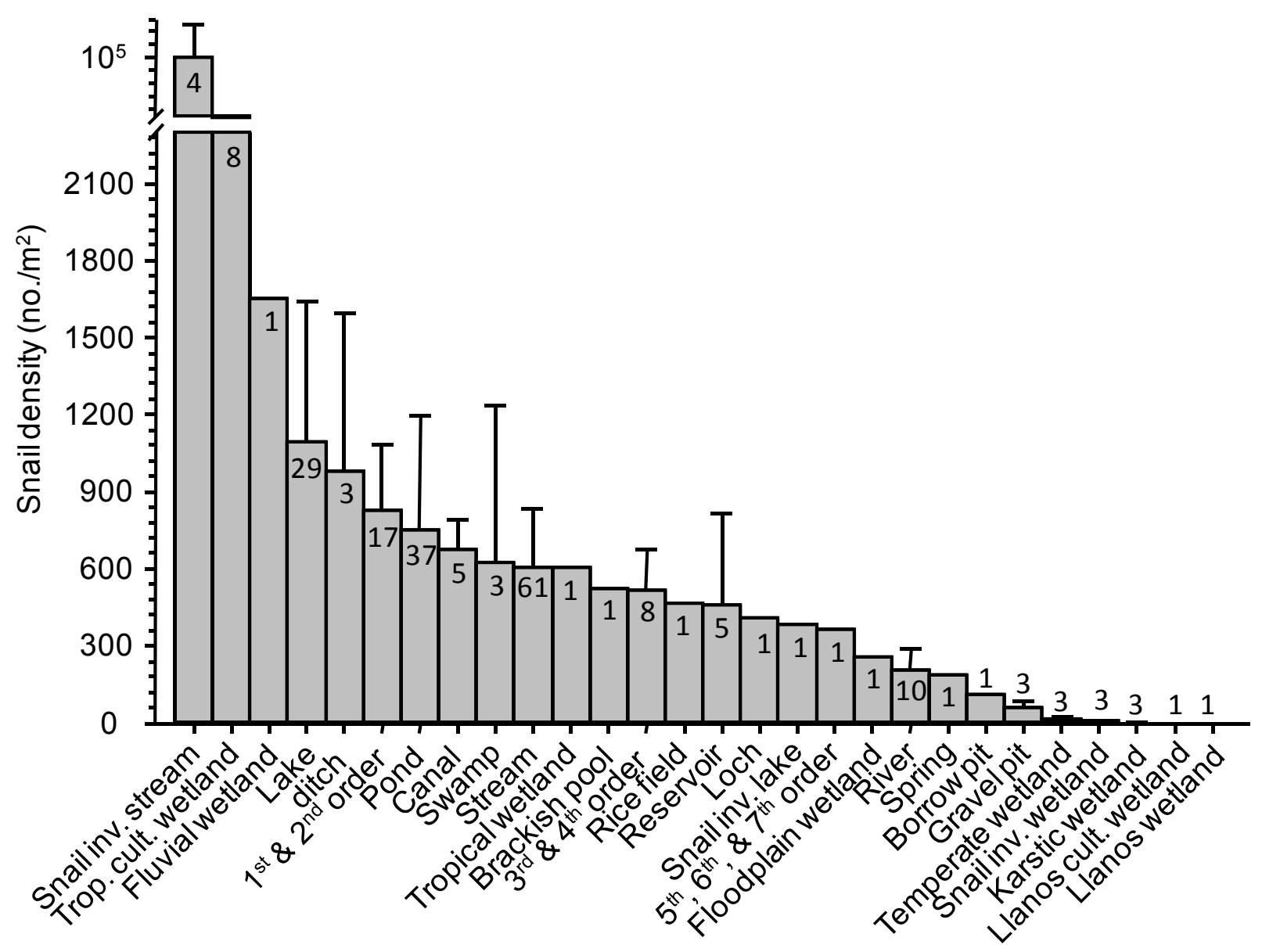

Fig. 2.4. Rank-density (mean $\pm 1 \mathrm{SE}$ ), for 28 ecosystems from 85 published, 2 unpublished datasets, and my data. Numbers inside, or above, the bars represent the number of ecosystems in each category used to generate the estimate. Note that karstic wetlands and the Venezuelan llanos revealed the lowest values. 


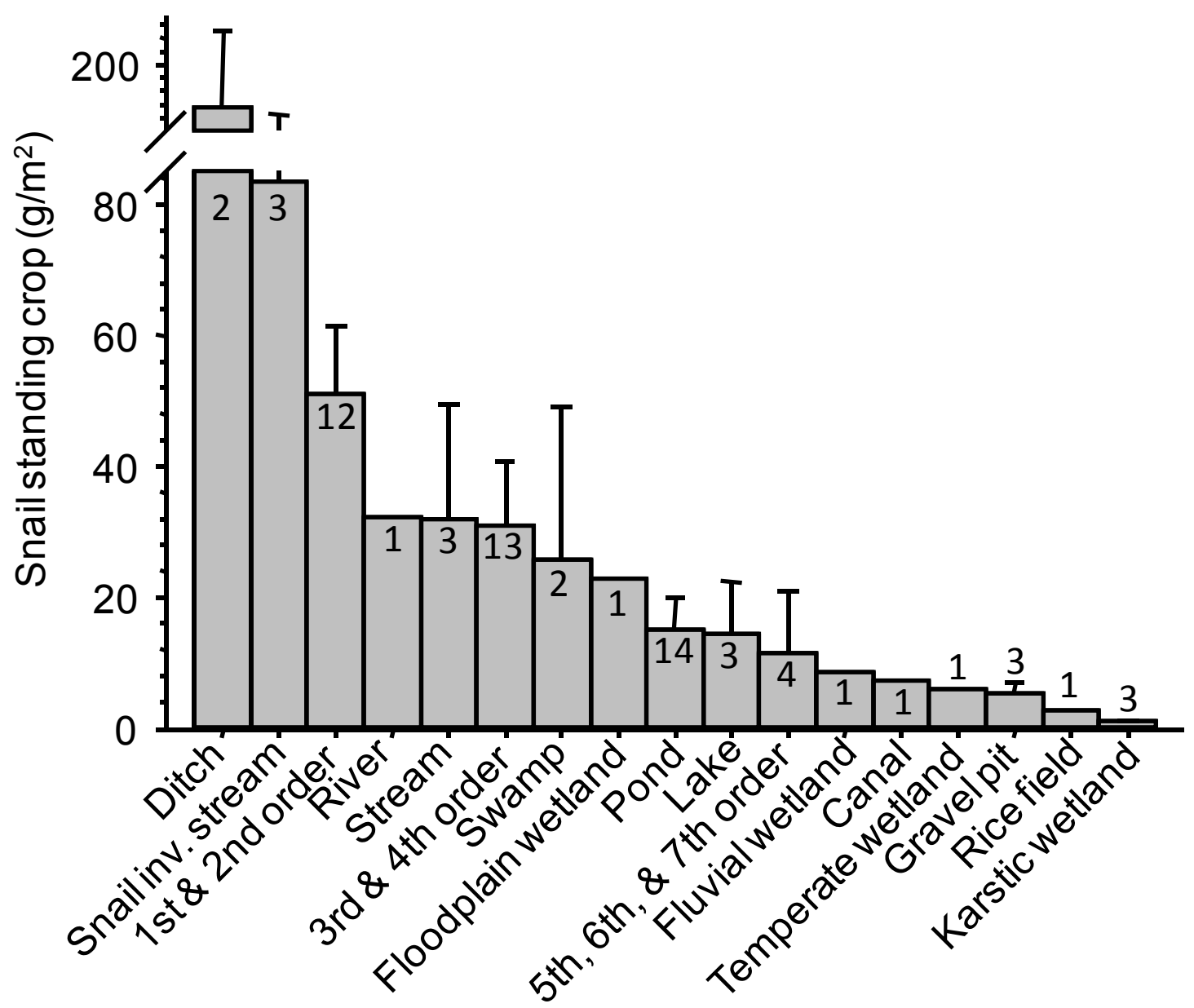

Fig 2.5. Rank-biomass (mean $\pm 1 \mathrm{SE}$ ) for 17 ecosystems from 19 published studies, 2 unpublished datasets, and my data. I estimated standing crop from density and individual snail size data for 6 studies. Numbers in, or above, the bars represent the number of ecosystems used to generate estimates for each category. Note that karstic wetlands yielded the lowest values 
CHAPTER III

SEPARATING CONSUMPTIVE AND NON-CONSUMPTIVE EFFECTS IN THE PRESENCE OF NUTRIENT ENRICHMENT 


\section{INTRODUCTION}

Measuring the relative influence of predators and resources that shape the distribution and abundance of species remains a fundamental goal in ecology (Hairston et al. 1960, Oksanen et al. 1981, Power 1992, Polis 1999, Wojdak 2005). Predators affect prey through consumption, but also by affecting prey traits. Predation decreases the density of prey that can indirectly have positive effects on resources used by prey species and can directly have positive effects on the growth of remaining individuals through reduced competition (Petranka and Sih 1986, Van Buskirk and Smith 1991, Peacor and Werner 2000). Non-consumptive effects alter prey behavior, growth rates, morphology, and life history traits (Crowl and Covich 1990, Spitze 1991, Abrams and Rowe 1996, Lima 1998, Sih et al. 1998, DeWitt et al. 1999). Both consumptive and non-consumptive effects can indirectly affect prey resources through trophic cascades because prey do not consume as many resources or shift their habitat use to refuges, which alters the spatial distribution of resources (Sih et al. 1985, Turner and Mittelbach 1990, Wootton 1994a, Turner 1997, Turner et al. 1999a, Werner and Peacor 2003). Consumptive and non-consumptive effects often depend on the productivity or quality of resources of the system (Chase 1999b, Turner 2004, Werner and Peacor 2006). High quality resources could shift interactions in favor of the prey because they could forage less to acquire the same amount of energy. Separating consumptive from non-consumptive effects in the midst of resource variation is important for understanding predator-prey dynamics in different contexts (Abrams 2008, Peckarsky et al. 2008). For example, strong non-consumptive effects by a single predator (e.g., reduced activity), could equal the consumptive effects of multiple predators eating multiple prey and result in the same positive indirect effect 
on prey resources. A growing body of literature suggests that non-consumptive effects are at least as important as consumptive effects regardless of resource quality (Lima 1998, Sih et al. 1998, Preisser et al. 2005, Peckarsky et al. 2008, Preisser et al. 2009) but relatively few studies have experimentally separated them (Abrams 2008).

Quantifying the multi-faceted plastic response of prey to biotic and abiotic processes is critical to understanding the extent of these effects on individuals (Ghalambor et al. 2003, West-Eberhard 2003) and how they scale up to affect population dynamics and community composition (DeWitt and Langerhans 2003, Turner 2004). However, many studies that examine non-consumptive effects on prey and the resulting indirect effects on resources used by prey only consider behavioral responses (but see Chase 1999b). Numerous studies find that prey respond to predator cues by altering morphology (Brönmark and Miner 1992, DeWitt et al. 2000, Relyea 2002, Dayton et al. 2005) and produce defensive structures including thicker and ornamented snail shells (Appleton and Palmer 1988, Hoverman et al. 2005) and defensive spines in daphnia (Black 1980). In response to predator cues, prey may alter growth and reproduction (Crowl and Covich 1990, Spitze 1991, Chase 1999b), two traits whose expression are potentially limited by resource quality and can affect the strength of trophic cascades (Chase 1999b, Turner 2004). Therefore, understanding the net predator effect on prey and their resources requires studying suites of traits in multiple environmental contexts (DeWitt and Langerhans 2003, Pigliucci et al. 2003).

Variation in resource quality is a distinguishing factor among many ecosystems. Experimental nutrient additions increase the amount, and change the composition of periphyton in streams (Pringle 1990), lakes (Fairchild et al. 1985), and coastal systems 
(Hillebrand and Sommer 1997, Hillebrand and Kahlert 2001), but curiously nutrient additions yield less periphyton in the Everglades despite improving periphyton quality as a potential food source (McCormick et al. 2001, Gaiser et al. 2005). Periphyton is also altered by grazing, which often occurs by prey that are evading predators or responding to their cues. Primary consumers, especially snails, are efficient periphyton grazers (Steinman et al. 1987, Rosemond 1994, Feminella and Hawkins 1995) that can also have positive effects on their resources through excretion of waste and the consumption of dead algal cells, a response commonly called nutrient regeneration (McCormick and Stevenson 1991, Rosemond et al. 1993, Hillebrand and Kahlert 2001). Few studies examine interactions between nutrients, periphyton, and grazers while simultaneously studying the multi-trait responses of prey/grazers to the consumptive and nonconsumptive effect of predators. Such an examination is likely to yield important insight into the relative influence of resources and predators in affecting prey/grazer population dynamics and their consequences on community structure.

In this study, I use a food-web fragment that includes periphyton, snails, and crayfish to examine how variation in resource quality mediates the consumptive and nonconsumptive predator effects on a variety of prey traits. This simple food-chain is conducive to studies of this sort because an extensive literature exists describing the strong relationship between snails and resources (Underwood and Thomas 1990, Hill 1992, Rosemond et al. 1993, Hillebrand et al. 2002) and their response to predators (Crowl and Schnell 1990, Covich et al. 1994, Lodge et al. 1994, Turner 2004, Hoverman et al. 2005). Further, in many freshwater ecosystems these components represent a considerable pathway of energy within the larger food web (Lodge et al. 1987, Lowe and 
Hunter 1988, Morales and Ward 2000, Munoz et al. 2000, Kawata et al. 2001). I used snails, crayfish, and periphyton from the Florida Everglades, a large oligotrophic wetland in the sub-tropics of the United States. Slough Crayfish (Procambarus fallax) occur throughout the ecosystem and consume Planorbella duryi, the most abundant snail in the ecosystem, and both animals eat periphyton, although it represents a much larger portion of the snail's diet compared to use by crayfsih. Several studies in the Everglades have found crayfish and snail density to increase (Rader and Richardson 1994), while others find the reverse or no response with the addition of phosphorous (Turner et al. 1999b, McCormick et al. 2004). Periphyton in the Everglades is a species-rich matrix of filamentous and coccoid alga and diatoms that expands with moderate phosphorous enrichment but disintegrates with high enrichment (McCormick et al. 2001, Gaiser et al. 2006).

Specifically, I tested the following hypotheses: 1 . Non-consumptive effects are stronger than consumptive effects; 2 . Snails are less active and seek refuge, develop tall narrow shells with narrow apertures, and thicker shells in the presence of crayfish; 3. Nutrient additions lead to stronger responses than predator effects and cause faster growth and earlier reproduction; 4. Snails facilitate periphyton growth in ambient tanks through nutrient regeneration.

\section{METHODS}

Experimental design-I used a $2 \times 2 \times 3$ fully factorial experiment with 2 predator densities (present or absent), 2 phosphorous levels (ambient or added), and 3 snail densities (present, present with removal, or absent). All 12 treatments were randomly 
assigned within 3 blocks with the stipulation that the same combination of treatments did not occur twice along the edge of the facility.

I conducted the experiment at the Daniel Beard Research Center, Everglades National Park (N 2523'17", W 8040'58") in $2.2 \times 1 \times 1 \mathrm{~m}(\mathrm{~L} \times \mathrm{W} \times \mathrm{H})$ concrete mesocosms that were filled to a depth of $30 \mathrm{~cm}(6601)$ with well water on 30 May 2007. Tanks were covered with $50 \%$ shade cloth to prevent colonization of invertebrate predators; stand pipes maintained water depth and were covered with fiberglass window screen to prevent animals from escaping. Prior to filling, I haphazardly attached $12(30 \times 3 \mathrm{~cm}, \mathrm{~L} \times \mathrm{W})$ black plastic strips to the bottom ( 5 strips) and sides ( 7 strips) of each tank with silicon, which provided $2,160 \mathrm{~cm}^{2}$ of common surface per tank to measure periphyton colonization, snail grazing, and use of cover by snails. The following day, I added 900 $\mathrm{ml}$ of benthic periphyton mat to each tank that was collected from a nearby marsh (Taylor Slough: N $\left.25^{\circ} 17^{\prime} 67^{\prime \prime}, \mathrm{W} 80^{\circ} 27^{\prime} 70^{\prime \prime}\right)$, mixed to ensure similar algal communities among tanks, and sorted to remove small fish and large invertebrates; aliquots were measured using a 2000-mL graduated cylinder and a sample was kept for a baseline measure of resources. Prior to the initiation of treatments, non-experimental snails, small fishes, and other invertebrates missed during sorting were noted and removed; after treatments began, these organisms were tracked. All snails found in no-snail treatments were noted and removed during the experiment.

Phosphorous additions were made over 14 days (9 June - 22 June) to allow assimilation by periphyton. I added $0.061 \mathrm{~g} \mathrm{P} / \mathrm{m}^{2} /$ day $\left(0.00197 \mathrm{~mol} \mathrm{P} / \mathrm{m}^{2} /\right.$ day $)$ in the form of $\mathrm{NaH}_{2} \mathrm{PO}_{4}$ daily for a total delivery of $0.85 \mathrm{~g} \mathrm{P} / \mathrm{m}^{2}$. This value was determined based on prior enrichment experiments in the Everglades (McCormick et al. 2001, Liston 
2004, Gaiser et al. 2005). I dissolved $10.52 \mathrm{~g} \mathrm{NaH}_{2} \mathrm{PO}_{4}$ in $2 \mathrm{~L}$ of well water and sprinkled $100 \mathrm{~mL}$ of the solution into addition tanks with a $120-\mathrm{mL}$ sample cup that had small holes in the lid. The cup and lid were rinsed with $100 \mathrm{~mL}$ of well water 3 times and each rinse was added to tanks. Ambient tanks received $400 \mathrm{~mL}$ of well water as a control.

On 23 June 2007, day 0 of the experiment, I added 25 snails $/ \operatorname{tank}\left(11.3 / \mathrm{m}^{2}\right)$ from stock populations maintained on site and at Florida International University that originated from collections throughout the ecosystem; both populations receive additional individuals seasonally, but as a precaution against the potential for genetic differences between populations, the origin was tracked during the experiment and snails from each population were distributed among tanks. I found no variation in any traits measured between populations. A size range was chosen that provided $1.71 \pm 0.004 \mathrm{~g} / \operatorname{tank}(0.77 \pm$ $0.002 \mathrm{~g} / \mathrm{m}^{2}$, total $\pm \mathrm{SE}$ ) of snail wet tissue. Snails ranged from $5.49-13.32 \mathrm{~mm}$ shell length ( $0.1-0.19 \mathrm{~g}$ wet tissue) with a median size of 8.75 ( $0.06 \mathrm{~g}$ wet tissue). I chose the density, biomass, and size range of snails to mimic natural populations in the Everglades that range in density from $0-60$ individual $/ \mathrm{m}^{2}\left(0-13 \mathrm{~g} / \mathrm{m}^{2}\right)$, but with a mean close to 3 individuals $/ \mathrm{m}^{2}\left(0.56 \mathrm{~g} / \mathrm{m}^{2}\right)$; populations are multi-voltine and therefore a few large adults are usually mixed with numerous smaller snails (Trexler unpublished data).

To measure non-consumptive effects, each tank received a predator cage (150-cm long, 74-cm diameter) made from plastic chicken wire covered with fiberglass window screen prior to filling tanks; cable ties were used to close the ends. One crayfish was added to cages in predator treatments $(25.3 \pm 0.75$, mean \pm SE carapace length $)$ on 23 June and fed two crushed snails every other day to ensure crayfish survival and provide 
conspecific cue to snails. Snyder (1967) reports that $P$. duryi respond to conspecific cue but I provided both because other studies demonstrate that snails respond to particular predators (DeWitt et al. 2000). Eight crayfish died during the experiment; each was replaced within $24 \mathrm{~h}$ with a similar sized animal. Crayfish mortality was not consistent among treatments $(\mathrm{P}>0.05$ in all cases).

Consumptive effects were simulated by instituting a $6 \%$ daily mortality rate in removal treatments based on estimates of daily mortality ranging from $1-85 \%$ from tethering experiments in the Everglades (CBR unpublished data). My goal was to reduce snail density by $88 \%$ by the end of the experiment in removal treatments. I chose an exponential removal schedule where $6,4,5,3,2$ and 2 snails were removed on 4, 7, 12, 20, 26 and 35 days of the experiment. Removing most of the snails during the first half of the experiment provides a strong test of the direct and indirect consumptive effects in food webs, avoids confinement effects of prey resulting from a free roaming predator, and simulates a density-dependent mortality rate (Werner and Peacor 2006). Snails were removed by dividing the tank into bottom and side sections; each section was then divided into a numbered grid. I used a random number table to pick the section and grid number to search for snails. If the grid number lacked snails the procedure was repeated until the goal number of snails was removed. Other tanks were disturbed in a similar manner on days when snails were removed. I ended the experiment on 3 August 2007, 41 days later, which provided adequate time for snail growth $(0.11 \mathrm{~mm} / \mathrm{d})$ and reproduction. At the end of the experiment crayfish were removed from cages and I collected all snails (experimental and non-experimental) and their offspring (F1 
generation) and placed them on ice; they were kept frozen in the laboratory until processing.

I measured snail growth and behavior during the experiment. On day 20, I collected and measured the shell length of 8 snails to the nearest $0.01 \mathrm{~mm}$ from each tank using the procedure for removal treatments. Shell-free wet tissue mass was estimated using locally derived length-to-weight regressions. All snails were returned to tanks except for the 3 from each removal tank. Snail activity was measured twice at the beginning (days 5 and 6), twice during the middle (days 16 and 18), and twice at the end (days 38 and 40)always in the morning and usually one day after feeding crayfish. The average count for the 2 censuses at the beginning, middle, and end served as the dependent variables in analyses. Snail activity was assessed by counting the number of visible snails on the bottom, vertical surfaces, and at the surface of the water in each tank. To account for variation in snail density among tanks, I divided the number observed by the number of snails collected at the conclusion of the experiment. For removal treatments, I divided the number of observed by the estimated number of snails on the day activity was assessed.

Periphyton characteristics were tracked during the experiment by subjectively collecting a $30-\mathrm{mL}$ sample of benthic periphyton with a $120-\mathrm{mL}$ sample cup and three 2 $\times 2 \mathrm{~cm}$ squares of black plastic from the sides and 3 from the tank bottom with scissors and forceps. These samples were placed on ice and frozen in the lab until processing. At the conclusion of the experiment, total periphyton volume in tanks was quantified with a 2000-mL graduated cylinder and tank periphyton volume halfway through the experiment 
was interpolated by estimating the rate of change in periphyton volume between the beginning and end of the experiment.

In the laboratory, periphyton samples were thawed and weighed; mat-dwelling invertebrates and non-periphyton material were removed, dried, and weighed; the remaining periphyton was homogenized with a hand-held blender and diluted to a known volume. Measured sub-samples were removed to estimate dry-weight, ash-free dry mass, chlorophyll $a$, total C:N:P, and soft-algae composition. Two sub-samples were dried (70 ${ }^{\circ} \mathrm{C}$ ) and weighed. The first was ashed for two hours at $500{ }^{\circ} \mathrm{C}$ and re-weighed to determine the mineral content; ash-free dry mass was calculated as the difference between the dry and mineral mass. The other sub-sample was analyzed for total C:N:P. Total carbon and nitrogen were determined with duplicate samples using an elemental analyzer (Fisons Instruments NA1500NCS); total phosphorous was measured on duplicate samples using the dry-oxidation, acid hydrolysis method (Solorzano and Sharp 1980). The sub-sample for chlorophyll $a$ was diluted 100 fold and a $1 \mathrm{ml}$ aliquot was filtered onto a $2.5 \mathrm{~cm}$ glass-fiber filter that was frozen; chlorophyll a was extracted using $90 \%$ acetone and read flurometrically within 24 hours.

I quantified snail biomass (mean g/tank), F1 standing crop (total F1 g/tank), and production (total $\mathrm{g} / \mathrm{tank} / \mathrm{day}$ ), by removing the soft tissue from the shell and weighing them separately; shell length was measured to the nearest $0.01 \mathrm{~mm}$ with digital calipers. Individual biomass was highly correlated with estimates from length-to-weight regressions; thus, I use the estimates from regressions for consistency with samples from day 20. When there were more than $20 \mathrm{~F} 1$ snails, I measured and weighed a representative subset of 20 and estimated biomass with locally derived length-to-weight 
regressions with an average shell length for the entire sample. Physid snails that entered tanks with periphyton were also measured and weighed using the same procedure to assess their importance on tank dynamics. Snail tissue was preserved in $10 \%$ formalin after weighing and shells were frozen.

I measured shell thickness at the apex of the aperture to $0.01 \mathrm{~mm}$ using digital calipers (Fig 1, sensu Hoverman et al. 2005).

Morphometrics - I used geometric morphometrics to characterize shell shape (Rohlf and Marcus 1993, Adams et al. 2004). Lateral and aperture views were captured with a 6 megapixel digital Nikon D40 using a micro-Nikkor $55 \mathrm{~mm}$ f 3.5 lens mounted on a copy stand. I used tpsDIG (Rohlf 2006) to digitize 4 landmarks and 16 semilandmarks on the lateral shell and 2 landmarks and 12 semi-landmarks around the edge of the aperture (Fig 1). Semilandmarks were used to reduce the information (i.e., bending energies) associated with characterizing shape along curves deficient in homologous landmarks (Bookstein 1991, Ruehl and DeWitt 2005). Landmark constellations were adjusted for position, orientation, and scale by generalized Procrustes analysis using tpsRelw (Rohlf 2005). I took tank means of superimposed coordinates and distilled shape variation into orthogonal variables with a principal components analysis (PCA) on the covariance matrix. I reduced the number of shape variables for subsequent analyses by using principal components $(\mathrm{PC})$ that explained greater than $95 \%$ of shape variation (lateral $=$ 5 , dorsal $=4$ ).

Analysis-I excluded one tank (no cue, no snail removal, phosphorous added) from analyses because all snails died for an unknown reason. The general form of the model I used in all analyses tested for effects of predators, phosphorous addition, snail density, 
and the associated interactions. I used repeated measures analysis of variance (RANOVA) to test for differences in individual snail biomass (mean $\mathrm{g} / \mathrm{tank}$ ), snail activity, periphyton dry weight, and periphyton chlorophyll $a$ concentration on artificial substrates and in periphyton mat. Analysis of variance (ANOVA) tested for differences in Planorbella duryi survivorship, Planorbella duryi production (total g/tank/day), F1 standing stock (total $\mathrm{g} / \mathrm{tank}$ ), and shell thickness. Physid production was not used as a covariate because it had no measurable effect on any dependent variable.

I used the Satterthwaite correction to estimate denominator degrees of freedom in analyses with individual biomass, snail production, snail activity, and shell thickness because of unequal variances among treatments.

Shell shape variation was analyzed with MANCOVA; centroid size, a multivariate measure of size, served as a covariate to control for multivariate allometry. I tested for heterogeneity of slopes for centroid size and removed all non-significant interaction terms. I used Wilks' partial-eta squared $\left(\eta_{\mathrm{p}}{ }^{2}\right)$ to estimate effect size of different variables in the model (Langerhans and DeWitt 2004, Hendry et al. 2006, Butler et al. 2007, Aguirre et al. 2008, Sharpe et al. 2008) and for an overall perspective of the morphological change between predator treatments comparable among studies, I calculated Procrustes distance (a geodesic distance in radians) between the average superimposed coordinates for each treatment (Bookstein 1996). To visualize and interpret shell shape change, I derived an effect score for each specimen; a PCA of the effect $\mathrm{H}$ matrix produced an eigenvector, which was multiplied by the mean shape variables for each tank to produce an effect score for each tank. This method is superior to using canonical variates of the effect as it multiplies the inverse of the error matrix by 
the $\mathrm{H}$ matrix $\left(\mathrm{E}^{-1} \mathrm{H}\right)$ which often distorts the multivariate space when compared to the original shape space (Klingenberg and Monteiro 2005, Tobler et al. 2008, Langerhans 2009).

To quantify the relative strength of direct, indirect, and net effects stemming from crayfish cue, simulated consumption, and phosphorous addition on traits, I conducted path analysis (Wright 1934, Wootton 1994b, Johnson 2002, Langerhans 2009). Crayfish cue and snail-density were modeled as exogenous variables because they were planned treatments. Although phosphorous was a planned treatment too, it was modeled as three separate endogenous variables; periphyton chlorophyll $a$ on black plastic strips examined the indirect effects of crayfish cue on periphyton near a snail refuge; periphyton $\mathrm{C}: \mathrm{P}$ ratio tested for elemental constraints (sensu Sterner and Elser 2002) on snail traits; periphyton chlorophyll $a$ was used for comparison and to assess the validity of chlorophyll $a$ as an indicator of resource quality. Path coefficients for the C:P ratio variable were multiplied by - 1 so that low $C: P$ ratios, which suggest high quality resources, would be represented by positive coefficients. Shape variation was modeled with the first PC for lateral shape that described $70 \%$ of variation and the first PC for aperture shape that explained $60 \%$ of variation for simplicity, path models with all PCs yielded similar results. I used the residuals from a regression of shell thickness, tissue weight, shell weight, and shell length to remove covariation for the shell thickness trait. Crayfish cue, snail density, chlorophyll $a$ on plastic strips, periphyton chlorophyll $a$, and $\mathrm{C}: \mathrm{P}$ ratio affected all traits, but I made assumptions about the directionality of paths among traits. Shape variation, shell thickness, and activity were allowed to affect both growth rate (g/tank/day) and F1 standing crop (g/tank); growth rate was allowed to affect F1 standing crop, but not the 
other way around (i.e., no reciprocal paths). Modification indices suggested that the estimates of error for morphological variables were correlated with each other and with activity; they also suggested that error estimates between periphyton chlorophyll $a$ and chlorophyll a on strips were correlated; allowing them to covary significantly improved model fit. Path coefficients were estimated with maximum likelihood and I based significance of coefficients on a two tailed test ( $\alpha$ 0.05) assuming a standard normal distribution.

\section{RESULTS}

Snail survivorship during the 41 day experiment averaged $0.80 \pm 0.0311$, (mean \pm $\mathrm{SE}, \mathrm{n})$ in non-removal treatments and $0.95 \pm 0.00912$, (mean $\pm \mathrm{SE}, \mathrm{n})$ in removal treatment, when the removed snails were treated as survivors, resulting in higher survivorship for the removal compared to the non-removal treatment $\left(\mathrm{F}_{1,15}=23.20 ; \mathrm{P}=\right.$ 0.0002). If the removed snails were considered non-survivors, then survivorship averaged $0.07 \pm 0.0112$, (mean $\pm \mathrm{SE}, \mathrm{n})$, which was lower than the expected 0.12 survivorship in the removal treatment. However, survivorship appeared higher at lower snail densities.

Planorbella duryi biomass peaked around the middle of the experiment, but despite the drop toward the end, individuals grew on average $1.1 \mathrm{mg} / \mathrm{d}$ over the 41 days (Fig 2). Individuals were $25 \%$ larger in tanks with phosphorous additions compared to ambient conditions, while snails that experienced crayfish cue were $22 \%$ smaller than those without cue (Table 1). Removing over half of the snails during the experiment did not affect the biomass of the remaining snails. 
Variation in total Planorbella duryi production (experimental + F1 standing stock, $\mathrm{g} / \operatorname{tank} /$ day) among treatments, after the removed snails were added back in (sensu Werner and Peacor 2006), was similar to results for biomass but the magnitude of difference among treatments was larger (Fig 3). Phosphorous addition increased production by $50 \%\left(\mathrm{~F}_{1,13.2}=21.09 ; \mathrm{P}=0.0005\right)$; crayfish cue decreased it by $36 \%\left(\mathrm{~F}_{1,13.2}\right.$ $=10.54 ; \mathrm{P}=0.006)$. Snail removal did not affect snail production $\left(\mathrm{F}_{1,13.2}=1.75 ; \mathrm{P}=\right.$ $0.208)$.

Planorbella duryi were $62 \%$ less active in tanks with crayfish cue $\left(\mathrm{F}_{1,41.2}=34.2 ; \mathrm{P}<\right.$ $0.001), 24 \%$ more active with phosphorous addition $\left(\mathrm{F}_{1,41.2}=5.2 ; \mathrm{P}=0.03\right)$, and $31 \%$ less active in removal tanks, after correcting for Planorbella duryi removal $\left(\mathrm{F}_{1,41.2}=8.8\right.$; $\mathrm{P}=0.005)$. Crayfish cue had the largest effect on activity; snails were rarely observed on periphyton when the predator cue was present (Fig 4); I found them under and near the black plastic strips when removing snails during and at the end of the experiment.

Crayfish cue induced lateral and aperture shape variation after controlling for multivariate allometry and allometric differences among treatments (i.e., heterogeneity of slopes) (Table 2). Specifically for lateral shape, the magnitude of variation induced by crayfish cue depended on snail density (cue-by-density interaction) and phosphorous addition (cue-by-phosphorous interaction). There was modest variation in lateral shape between snails experiencing crayfish cue and those without the cue (Procrustes distance 0.007). The magnitude of variation in lateral shape was greatest between cue and no-cue treatments when snails were removed during the experiment, which led to the cue-bydensity interaction (Fig 5). However, when densities were not altered, snails developed intermediate morphologies without phosphorous additions and developed morphologies 
consistent with those induced by crayfish cues when phosphorous was added, regardless of whether crayfish cue was present. This response resulted in the cue-by-phosphorous interaction (Fig 5). I found no interaction between predator cue and other treatment combinations for aperture morphology (Table 2). Crayfish cue induced greater aperture shape variation compared to lateral shape (Procrustes distance 0.018). Thin-plate spline transformation grids generated from effect scores of the crayfish-cue effect revealed that snails experiencing crayfish cue developed tall shells with narrow apertures (Fig 6).

Planorbella duryi that experienced crayfish cue developed $10 \%$ thicker shells than snails without cue $\left(\mathrm{F}_{1,14}=11.55 ; \mathrm{P}=0.004\right)$. Snails remaining in tanks after snail removal, with phosphorous additions, but without crayfish cue had 37\% thinner shells than other treatments (cue-by-density-by-phosphorous: $F_{1,14}=15.46 ; \mathrm{P}=0.002$ ) and this difference contributed to the differences between crayfish cue treatments (Fig 7).

Resource allocation toward reproduction resulted in $76 \%$ greater Planorbella duryi F1 standing crop (g/tank) without crayfish cue but with phosphorous additions compared to other treatment combinations (crayfish cue-by-phosphorous: $\mathrm{F}_{1,13.3}=4.8 ; \mathrm{P}=0.047$, Fig 8). Separately, there was $88 \%$ greater F1 standing crop with phosphorous additions $\left(\mathrm{F}_{1,13.3}=17.9 ; \mathrm{P}=0.001\right)$ and $56 \%$ less $\mathrm{F} 1$ standing crop with crayfish cues, although the crayfish cue effect was only marginally significant $\left(\mathrm{F}_{1,13.3}=3.4 ; \mathrm{P}=0.086\right)$.

Phosphorous additions lowered the C: P ratio of periphyton by $185 \%$ compared to ambient tanks $\left(\mathrm{F}_{1,69}=1028.40 ; \mathrm{P}<0.001\right)$. Periphyton from ambient tanks exhibited a $58 \%$ decline in C:P ratio by the end of the experiment (phosphorous-by-day: $\mathrm{F}_{2,69}=$ 35.02; P $<0.001 ;$ Fig 9). Concurrent with changes in C:P ratio, chlorophyll $a$ concentrations(ug/g dry mass) decreased with phosphorous addition during the 
experiment (phosphorous-by-day: $\mathrm{F}_{2,69}=14.39 ; \mathrm{P}<0.001$; Fig 9); chlorophyll $a$ density on black plastic strips $\left(\mathrm{ug} / \mathrm{mm}^{2}\right)$ revealed the same trend (phosphorous-by-day: $F_{2,67}=$ 7.95; $\mathrm{P}<0.001)$. The periphyton mat gradually disintegrated in tanks with phosphorous additions leading to lower periphyton dry mass compared to ambient tanks by the end of the experiment (phosphorous-by-day: $\mathrm{F}_{2,69}=32.55 ; \mathrm{P}<0.001$; Fig 9). Chlorophyll $a$ concentrations were also affected by crayfish and snail density, but these effects were not consistent between periphyton from strips and benthic periphyton mats. Periphyton chlorophyll $a$ concentrations were $22 \%$ lower in tanks without snails or crayfish compared to tanks with snails alone, with only crayfish, and those with both (crayfish-bysnail density: $\mathrm{F}_{2,66.3}=12.72 ; \mathrm{P}<0.001 ;$ Fig 10$)$. Chlorophyll $a$ from periphyton on strips in tanks without snails or crayfish was $27 \%$ lower compared to tanks with snails, with crayfish, and those with both; the difference was not greater because concentrations in tanks with both were $52 \%$ lower than tanks with only snails (crayfish-by-snail density: $F_{2}$, ${ }_{66.3}=11.49 ; \mathrm{P}<0.001 ;$ Fig 10$)$. The pattern of chlorophyll $a$ on strips among treatments was consistent between strips located on the tank bottom or side (location: $F_{1,69.3}=1.46$; $\mathrm{P}=0.231)$. Low chlorophyll $a$ concentrations without snails and crayfish suggest that their addition facilitated chlorophyll $a$ in periphyton. However, low chlorophyll $a$ concentrations in periphyton on strips when snails were present with crayfish cues combined with the finding that snails experiencing crayfish cues clustered under strips indicates that snails were responsible for reducing chlorophyll $a$ on these strips.

Path analysis revealed interplay between the effects of predators and phosphorous on a variety of snail traits. Planorbella duryi experiencing crayfish cue, a non-consumptive effect, indirectly decreased F1 standing crop by reducing activity and slowing growth 
rate; conversely, crayfish cue had a direct positive effect on F1 standing crop, although this was not significant, the effect decreased the magnitude of the net effect (Fig 11, Table 3). Lower C:P ratios increased F1 standing crop directly and indirectly through increasing activity (Table 3). Crayfish cue was negatively associated with chlorophyll $a$ on strips but did not affect periphyton chlorophyll $a$ or $\mathrm{C}: \mathrm{P}$ ratios, further evidence that crayfish cue had indirect negative effects on periphyton attached to strips by shifting snail habitat use. Periphyton chlorophyll $a$ was negatively associated with F1 standing crop, likely because it decreased as the periphyton mat disintegrated with phosphorous additions. Consumptive effects, modeled as snail density (removal or non-removal) only affected shell thickness; lower snail densities resulted in snails with thinner shells. Among traits, snails with thicker shells contributed to higher F1 standing crop. Both higher levels of activity and faster growth rates had strong stimulatory effects on the snail F1 standing stock (Fig 11).

\section{DISCUSSION}

The main conclusion from this study was that the severity of non-consumptive effects by crayfish, in many cases, depended on phosphorous additions. Ecological stoichiometric theory is based on elemental constraint; the addition of the limiting nutritional element lowers the $\mathrm{C}$ : nutrient ratio and improves resource quality (Sterner and Elser 2002). Phosphorous is commonly the limiting element for periphyton growth in freshwater ecosystems (Schindler 1977, Hansson 1992), including the Everglades (Davis 1994, Noe et al. 2001). I added phosphorous to test stoichiometric theory and results support the hypothesis; adding phosphorous increased activity, improved growth 
and F1 standing crop, which mitigated the effects of crayfish cues on these traits as well as shell morphology. Phosphorous additions also caused periphyton mats to disintegrate and resulted in lower chlorophyll $a$ concentrations. Path analysis confirmed results from individual analyses and revealed that the net effects of phosphorous additions and crayfish cues were similar in magnitude.

Behavior, Morphology, \& Shell Thickness

Most animals modify their behavior in response to predators by seeking refuge and decreasing activity (Sih 1987, Lima and Dill 1990). Research on behavioral responses of freshwater snails to predators reveals their response is usually predator dependent; crayfish cues often lead to snails crawling out of the water (Alexander and Covich 1991, DeWitt et al. 1999, Bernot and Turner 2001, Hoverman et al. 2005). However, a previous study on Planorbella duryi from the Everglades found that snails exhibited a strong burrowing response to crushed conspecifics that was not altered by predator identity (Snyder 1967). I presented conspecific cue to Planorbella duryi by feeding crayfish, pre-crushed snails, near the tank bottom. Snails were rarely observed on tank walls or out of the water; instead, they were found attached to the bottom, under and around black plastic strips, and under benthic periphyton mats. Snails with no crayfish cue were found throughout tanks. Planorbella duryi may exhibit a different behavioral response than other snail species because the Florida Everglades has extensive floating and submerged periphyton mats where snails and their invertebrate predators like crayfish and belostomatids co-occur throughout the water column. The vertical nature and complexity of periphyton mats might alter selection on behavioral responses to 
predator cues in the Everglades compared to other ecosystems despite shared predators. Future studies should expand on the work by Covich et al. (1994) and consider variation in habitat complexity on the predator cue response by prey.

Phosphorous addition and removing snails altered activity as well. Snails were more active when phosphorous was added, presumably because their other energy needs were met and they could forage more vigorously than snails in tanks with ambient phosphorous levels. Snails in removal tanks were less active, or spent more time in refuge, compared to tanks without snail removal that had relatively higher snail densities. Scramble competition for resources is one explanation for higher activity in tanks that did not experience density reductions, but there was little evidence for competition among snails in other traits like growth. Both of these responses are consistent with Turner's (2004) results, who used a snail species from the same family, Helisoma trivolvis. Future research should directly address these responses to understand the proximate causes of resources and conspecific density on refuge use.

Adaptive morphological plasticity exhibited by animals in response to predator cues is well established (Black 1980, Sultan 1987, Brönmark and Miner 1992, Dudley and Schmitt 1996, Van Buskirk and Relyea 1998, Relyea 2002, Benard and Fordyce 2003, Agrawal and Van Zandt 2004, Dudley 2004, Hoverman et al. 2005, Kraft et al. 2005). Freshwater and marine snails respond to their predators by developing defensive shell shapes and structures (Appleton and Palmer 1988, DeWitt et al. 2000, Trussell 2000, Hoverman et al. 2005). Physid snails have a spiraled shell and exhibit elongate shells with narrow apertures in the presence of crayfish cues (DeWitt et al. 1999). Helisoma trivolvis develop narrow and tall shells with no variation in aperture shape (Hoverman et 
al. 2005). However, few studies have considered the influence of resources and prey density on the extent of predator induced shape variation. Planorbella duryi in this study, developed tall and narrow shells with tall and narrow apertures in response to crayfish cue, a finding similar to Hoverman et al. (2005), except they found no variation in aperture shape. Tall shells and narrow apertures are likely an adaptive response to avoid predation as other species respond to entry based predators by producing similar morphologies (DeWitt et al. 1999, Hoverman et al. 2005). Additionally, I found that lateral shell shape, but not aperture morphology, depended on conspecific density and the addition of phosphorous. Haphazardly removing snails during the experiment induced extreme differences in lateral shape compared to snails kept at similar densities. Removing snails in the absence of crayfish cue simulated non-predator related mortality and induced much shorter shells, while those with crayfish cue from removal tanks developed tall shells similar to those without density reductions. Additionally, phosphorous additions altered the extent of shape variation induced by crayfish cue. Without phosphorous additions, snails developed intermediate shaped shells, but with additions they developed relatively tall shells regardless of whether crayfish cues were present. These results suggest that development of anti-predator shapes depend on the environmental context (i.e., multiple domains DeWitt and Langerhans 2003) and likely shift depending on conspecific density and system productivity.

In addition to shell morphology, I measured shell thickness, a trait important for the survival of crayfish attacks because they chip away shells starting at the aperture, in addition to reaching into the shell to get at soft tissue (Snyder 1967, Brown 1998). Like Hoverman et al. (2005), I found that snails developed thicker shells when they 
experienced crayfish cues. However in this study, shell thickness depended on snail density and phosphorous addition. The three-way interaction was driven by thin-shelled snails from removal tanks with phosphorous additions but without crayfish cue. It is unclear why these snails had thin shells, but it likely involves a trade-off between shell thickness and meeting other demands on metabolism.

\section{Snail Survivorship, Growth, \& Reproduction}

Density-dependent survival typically emerges as a consequence of variable growth rates from different resource levels or qualities, competitive interactions among conspecifics and the direct and indirect effects of predators (Petranka and Sih 1986, Van Buskirk and Smith 1991, Peacor and Werner 2001). High conspecific density is expected to lower survival because of intraspecific competition for limited resources. Predators directly reduce survival through consumption that also reduces competition for resources, which improves growth rates for remaining individuals. Threats of predation reduce individual growth because prey are less active; at high prey density, when predators are present reduced activity might result in higher growth because more resources are available compared to growth at high densities without predator threats (Peacor and Werner 2000, Werner and Peacor 2006). Therefore, consumptive and non-consumptive predator effects could operate synergistically to alter survival and growth of individuals by reducing competition and preventing the depletion of resources. In this study, lower snail densities did not affect growth rate, F1 standing crop, or overall production. However, survivorship appeared to be higher for remaining individuals in tanks with simulated predation. A release from competition for snails at low density would be a 
plausible explanation if individuals had responded to lower densities by increasing growth rate or production. Otherwise, mortality from disease, parasites, or senesces could explain the difference in survivorship between density treatments. I did not quantify infection from disease or parasite load for snails in this experiment, but prior research indicates natural populations of these snails in the Everglades carry high parasite loads (Sharp 2008). Future studies should explore the effects of density and incidence of disease and parasitic infection on snail survivorship.

Life history theory predicts that organisms will delay maturity to improve life-time fitness in response to a stress like size-selective predation (Cole 1954, Stearns 1977, Stearns and Koella 1986). Resource quality often covaries with predation risk and can alter life history traits; high quality resources in the midst of predators are predicted to speed growth and delay maturation, allowing organisms to reach a size refuge from predators faster than those experiencing lower quality resources (Chase 1999a, b, Day et al. 2002, Turner 2004). I did not measure time-to-first reproduction but final size is a good estimator of size-at-first reproduction (Chase 1999b). Crayfish cue and phosphorous additions had additive effects on snail growth; snails grew faster with phosphorous additions and slower with crayfish cue. Additionally, phosphorous additions led to higher F1 standing stock and crayfish cue resulted in lower F1 standing stock, but unlike growth, phosphorous additions without cue had the highest F1 standing stock compared to all other treatments. Therefore, snails experiencing lower C:P ratios without crayfish cue decreased their time-to-reproduction by growing faster, while crayfish cue increased time-to-reproduction by slowing growth regardless of C:P ratio. These findings are similar to other experimental studies (Eisenberg 1966, Hoverman et al. 
2005 ) and patterns observed in the field (Eversole 1978, Brown and Devries 1985). Specifically, Hoverman et al. (2005) found that crayfish cue caused snails to delay reproduction and produce fewer but larger egg masses regardless of resource availability, which they claim has the potential to influence population sizes over long periods. The results from this study add credence to their assertion that predator cues might negatively affect population growth with data suggesting that crayfish cue reduces F1 standing crop and that resource addition does not alter the negative effects of cue on F1 standing stock. However, these results do not support Chase (1999b) or Turner (2004) who both found faster snail growth and earlier time-to-reproduction in the presence of Belostoma cue with high resource quality. Inconsistencies among these studies should be considered further as the influence of predator cues on prey population dynamics appears to be context dependent.

Periphyton, Nutrient Regeneration \& Indirect effects

Periphyton in the Florida Everglades forms thick mats along the benthos and around emergent vegetation in shallow marshes; deeper marshes have extensive floating mats that are associated with bladderworts. Moderate phosphorous additions lead to enhanced periphyton growth, but excessive or chronic enrichment causes the mats to fall apart. Research on this phenomenon spans spatial and temporal scales. Short-term, high-dose phosphorus addition experiments (McCormick et al. 2001, Liston et al. 2008) mimic long-term, low-dose experiments (Gaiser et al. 2005), and both produce similar results to phosphorus additions from agricultural run-off (Gaiser et al. 2006, Gaiser 2009). My study builds on the work of others about the peculiar response of Everglades' periphyton 
to phosphorous enrichment by embedding phosphorous additions within an experiment that also examines the consumptive and non-consumptive effects of predators on grazers and periphyton. Like other studies, phosphorous additions caused the periphyton mat to fall apart by the conclusion of the experiment resulting in lower periphyton volume, mass, and chlorophyll $a$ concentrations. The change in mat structure probably left the remaining algae more accessible to grazers like snails (Geddes and Trexler 2003). Snails grew faster and produced more offspring with phosphorous additions indicating that phosphorous enrichment cascades up the Everglades food web causing changes in periphyton structure and quality that alters the life history of periphyton consumers.

Freshwater snails can dramatically reduce periphyton standing crop (Brönmark 1989, Hill 1992, Rosemond 1994, Feminella and Hawkins 1995), alter producer assemblages (Power et al. 1988, McCormick and Stevenson 1989), and promote nutrient regeneration through positive feedbacks (McCormick and Stevenson 1991, Hillebrand et al. 2002). Research on other grazers in the Everglades suggests grazers promote nutrient regeneration that positively affects periphyton quality (Geddes and Trexler 2003). Lower C:P ratios in tanks with snails, crayfish, or both would indicate that these animals increased resource availability for primary producers. By the end of the experiment, there was lower C:P ratios in tanks without phosphorous additions compared to earlier points in the experiment; however, decreases were not associated with tanks containing snails or crayfish but occurred across all tanks. These results may represent grazing activity by mat-dwelling invertebrates (e.g., chironomids) in addition to the snails, although I found few macroinvertebrates in periphyton samples. Focusing on chlorophyll $a$ concentrations in periphyton between tanks without snails or crayfish and those with 
crayfish, snails, or both provides more compelling evidence for nutrient regeneration. Chlorophyll $a$ concentrations in periphyton were higher when snails, crayfish, or both were present compared to their absence, suggesting that they facilitated higher chlorophyll $a$ concentrations in periphyton. Snails directly interacted with periphyton as they roamed throughout the tank. Crayfish were confined to cages on the tank bottom; they could only consume periphyton that passed into the cage, but their excrement likely stimulated production of periphyton chlorophyll $a$ concentrations. Direct effects of nutrient regeneration by snail grazing and indirect effects by crayfish are compelling explanations for these results that agree with other research on grazers in the Everglades and elsewhere (McCormick and Stevenson 1991, Hillebrand et al. 2002, Geddes and Trexler 2003) but further study is needed to establish a direct link between chlorophyll $a$ and periphyton quality.

Chlorophyll $a$ concentrations in periphyton collected from black plastic strips in tanks with snails or crayfish revealed trends that were similar to benthic periphyton mats. However, in tanks with both crayfish and snails, chlorophyll $a$ concentrations from periphyton on strips were much lower suggesting an emergent effect of crayfish cue on periphyton associated with strips. Snails experiencing cue were found under and around black plastic strips during the experiment. Combining these results reveals that crayfish cue indirectly affected periphyton on strips by causing snails to cluster under and around the strips where they removed periphyton and reduced chlorophyll $a$ concentrations by consuming periphyton. Turner (1997) found similar indirect effects of predator cue on periphyton resources under refuges for Physella and point to the importance of measuring periphyton resources in a variety of locations to capture the total effect of predator cues. 
Relative-importance of Resource quality, Non-consumptive \& Consumptive effects

Path analysis is a powerful tool for distilling large amounts of information into the salient components using multivariate multiple regression. It has been advocated for the examination of direct and indirect effects in communities (Wootton 1994b) and as a way to examine the individual and net effects of biotic and abiotic factors on multiple traits (Mitchell 1992, Johnson 2002). I used path analysis as a confirmatory investigation to quantify the relative importance of resources, consumptive effects, and non-consumptive effects on growth and reproduction that were mediated through direct and indirect effects on other traits like behavior and morphology. Snail density manipulations had few effects on snail traits except, snails at low density had relatively thin shells suggesting they allocated fewer resources into shell growth. Additionally, predator cue and resource quality did not strongly influence shell morphology or shell thickness likely because the magnitude of difference for these traits was relatively small, but become important over evolutionary time, while traits like growth and reproduction exhibit larger responses because they operate on ecological timescales.

Non-consumptive effects and resource quality had strong opposing effects on growth and reproduction. High quality resources (lower C:P ratios) had a strong positive net effect on F1 standing crop that was transmitted through the positive effects that phosphorous additions had on activity and to a lesser degree growth rate. Predator cue had strong negative effects on growth, activity, and chlorophyll $a$ concentrations associated with plastic strips. The negative effects on chlorophyll $a$ associated with strips and the negative effects on activity are inter-related and illustrate the negative indirect 
effect of crayfish cue on periphyton associated with strips by altering snail habitat use. Crayfish cue also negatively affected growth rate which was likely associated with activity because less active snails consume fewer resources and result in slower growth rates. However, activity did not directly influence growth rate, instead both activity and growth rate had strong direct effects on F1 standing stock.

Predator cue had a net negative effect on F1 standing stock that was composed of strong negative indirect effects stemming from activity and growth, and a relatively weak positive direct effect on F1 standing stock. Decomposing the predator cue net effect into separate components with path analysis revealed that snails experiencing cue started reproducing at a smaller size than those without cue, but the effect was masked by the strong negative indirect effects of cue on F1 standing stock by way of activity and growth rate. The results from the path analysis could help explain the discrepancies between the experimental results of this study and Hoverman et al. (2005), which found that snails did not reproduce earlier and those of Chase (1999b) and Turner (Turner 2004) that found that snails did reproduce earlier in the presence of higher resources.

\section{Conclusions}

Combining the direct and indirect effects of predators and resources on the various snail traits revealed that the net effects of each were similar in magnitude. Snails were limited by resources at ambient nutrient levels found in the Everglades and nonconsumptive predator effects reduced growth and reproduction. Interestingly, direct consumptive effects had negligible effects on growth but appeared to improve survival of remaining individuals. This study also revealed the potential for nutrient regeneration by 
snails and crayfish to improve periphyton growth and that non-consumptive predator effects can alter the spatial distribution of periphyton by shifting grazer habitat use into areas they perceive as refuges. Taken together, the life-history effects of improved resource quality and non-consumptive predator effects, and their interactions, are likely to have profound consequences on population dynamics of aquatic snails from the Everglades, and in natural systems generally. However, quantifying the relative importance of each in natural systems is complicated because the stimulatory effects of improved resources can largely be canceled by non-consumptive effects of predators leading to a cryptic series of interactions that regulate populations.

\section{Acknowledgments}

I thank Bill Loftus and the staff at the Beard Center for facilitating this research. Aaron Parker, Adam Obaza, Liz Harrison, Clay Williams, and Jeff Kline provided logistical support. Joel Trexler and Evelyn Gaiser provided insight into experimental design and analysis. Financial support was provided by the Everglades Foundation and the National Science Foundation grant to the Florida Coastal Everglades Long-Term Ecological Research program under Grant No. DBI-0620409 and Grant No. DEB9910514. 


\section{LITERATURE CITED}

Abrams, P. A. 2008. Measuring the impact of dynamic antipredator traits on predatorprey-resource interactions. Ecology 89:1640-1649.

Abrams, P. A., and L. Rowe. 1996. The effects of predation on the age and size of maturity of prey. Evolution 50:1052-1061.

Adams, D. C., F. J. Rohlf, and D. E. Slice. 2004. Geometric morphometrics: Ten years of progress following the 'revolution'. Italian Journal of Zoology 71:5-16.

Agrawal, A. A., and P. A. Van Zandt. 2004. Ecological play in the coevolutionary theatre: genetic and environmental determinants of attack by a specialist weevil on milkweed. Journal of Ecology 91:1049-1059.

Aguirre, W. E., K. E. Ellis, M. Kusenda, and M. A. Bell. 2008. Phenotypic variation and sexual dimorphism in anadromous threespine stickleback: Implications for postglacial adaptive radiation. Biological Journal of the Linnean Society 95:465478 .

Alexander, J. E., and A. P. Covich. 1991. Predator avoidance by the freshwater snail Physella virgata in response to the crayfish Procambarus simulans. Oecologia 87:435-442.

Appleton, R. D., and A. R. Palmer. 1988. Water-Borne stimuli released by predatory crabs and damaged prey induce more predator-resistant shells in a marine gastropod. Proceedings of the National Academy of Sciences of the United States of America 85:4387-4391.

Benard, M. F., and J. A. Fordyce. 2003. Are induced defenses costly? Consequences of predator-induced defenses in western toads, Bufo boreas. Ecology 84:68-78.

Bernot, R. J., and A. M. Turner. 2001. Predator identity and trait-mediated indirect effects in a littoral food web. Oecologia 129:139-146.

Black, R. W. 1980. The nature and causes of cyclomorphosis in a species of the Bosmina longirostris complex. Ecology 61:1122-1132.

Bookstein, F. L. 1991. Morphometric tools for landmark data. Cambridge University Press, Cambridge.

Bookstein, F. L. 1996. Combining the tools of geometric morphometrics. Pages 131-151 in M. C. L. F. Marcus, A. Loy, G. J. P. Naylor and D. E. Slice, editor. Advances in morphometrics. Plenum Press, New York. 
Brönmark, C. 1989. Interactions between epiphytes, macrophytes and freshwater snails: A review. Journal of Molluscan Studies 55:299-311.

Brönmark, C., and J. G. Miner. 1992. Predator-induced phenotypical change in body morphology in crucian carp. Science 258:1348-1350.

Brown, K. M. 1998. The role of shell strength in selective foraging by crayfish for gastropod prey. Freshwater Biology 40:255-260.

Brown, K. M., and D. R. Devries. 1985. Predation and the distribution and abundance of a pulmonate pond snail. Oecologia 66:93-99.

Butler, M. A., S. A. Sawyer, and J. B. Losos. 2007. Sexual dimorphism and adaptive radiation in Anolis lizards. Nature 447:202-205.

Chase, J. M. 1999a. Food web effects of prey size refugia: Variable interactions and alternative stable equilibria. American Naturalist 154:559-570.

Chase, J. M. 1999b. To grow or to reproduce? The role of life-history plasticity in food web dynamics. American Naturalist 154:571-586.

Cole, L. C. 1954. The population consequences of life history phenomena. Quarterly Review of Biology 29:103-137.

Covich, A. P., T. A. Crowl, J. E. Alexander, and C. C. Vaughn. 1994. Predator avoidance responses in freshwater decapod-gastropod interactions mediated by chemical stimuli. Journal of the North American Benthological Society 13:283-290.

Crowl, T. A., and A. P. Covich. 1990. Predator-induced life-history shifts in a freshwater snail. Science 247:949-951.

Crowl, T. A., and G. D. Schnell. 1990. Factors determining population density and size distribution of a freshwater snail in streams: Effects of spatial scale. Oikos 59:359-367.

Davis, S. M. 1994. Phosphorus inputs and vegetation sensitivity in the Everglades. Pages 357-378 in S. M. Davis and J. C. Ogden, editors. Everglades: The ecosystem and its restoration. St. Lucie Press, Del Ray Beach, Florida.

Day, T., P. A. Abrams, and J. M. Chase. 2002. The role of size-specific predation in the evolution and diversification of prey life histories. Evolution 56:877-887.

Dayton, G. H., D. Saenz, K. A. Baum, R. B. Langerhans, and T. J. DeWitt. 2005. Body shape, burst speed and escape behavior of larval anurans. Oikos 111:582-591. 
DeWitt, T. J., and R. B. Langerhans. 2003. Multiple prey traits, multiple predators: Keys to understanding complex community dynamics. Journal of Sea Research 49:143155 .

DeWitt, T. J., B. W. Robinson, and D. S. Wilson. 2000. Functional diversity among predators of a freshwater snail imposes an adaptive trade-off for shell morphology. Evolutionary Ecology Research 2:129-148.

DeWitt, T. J., A. Sih, and J. A. Hucko. 1999. Trait compensation and cospecialization in a freshwater snail: Size, shape and antipredator behaviour. Animal Behaviour 58:397-407.

Dudley, S. 2004. Plasticity and the functional ecology of plants. Pages 151-172 in T. J. DeWitt and S. M. Scheiner, editors. Phenotypic plasticity functional and conceptual approaches. Oxford University Press, New York.

Dudley, S. A., and J. Schmitt. 1996. Testing the adaptive plasticity hypothesis: Densitydependent selection on manipulated stem length in Impatiens capensis. American Naturalist 147:445-465.

Eisenberg, R. M. 1966. The regulation of density in a natural population of the pond snail, Lymnaea elodes. Ecology 47:889-906.

Eversole, A. G. 1978. Life cycles, growth and population bioenergetics in the snail Helisoma trivolvis (Say). Journal of Molluscan Studies 44:209 - 222.

Fairchild, G. W., R. L. Lowe, and W. B. Richardson. 1985. Algal periphyton growth on nutrient-diffusing substrates - An in situ bioassay. Ecology 66:465-472.

Feminella, J. W., and C. P. Hawkins. 1995. Interactions between stream herbivores and periphyton: A quantitative analysis of past experiments. Journal of the North American Benthological Society 14:465-509.

Gaiser, E. E. 2009. Periphyton as an indicator of restoration in the Florida Everglades. Ecological Indicators 9:S37-S45.

Gaiser, E. E., J. H. Richards, J. C. Trexler, R. D. Jones, and D. L. Childers. 2006. Periphyton responses to eutrophication in the Florida Everglades: Cross-system patterns of structural and compositional change. Limnology and Oceanography 51:617-630.

Gaiser, E. E., J. C. Trexler, J. H. Richards, D. L. Childers, D. Lee, A. L. Edwards, L. J. Scinto, K. Jayachandran, G. B. Noe, and R. D. Jones. 2005. Cascading ecological effects of low-level phosphorus enrichment in the Florida Everglades. Journal of Environmental Quality 34:717-723. 
Geddes, P., and J. C. Trexler. 2003. Uncoupling of omnivore-mediated positive and negative effects on periphyton mats. Oecologia 136:585-595.

Ghalambor, C. K., J. A. Walker, and D. N. Reznick. 2003. Multi-trait selection, adaptation, and constraints on the evolution of burst swimming performance. Integrative and Comparative Biology 43:431-438.

Hairston, N. G., F. E. Smith, and L. B. Slobodkin. 1960. Community structure, population control, and competition. American Naturalist 94:421-425.

Hansson, L. A. 1992. Factors regulating periphytic algal biomass. Limnology and Oceanography 33:121-128.

Hendry, A. P., M. L. Kelly, M. T. Kinnison, and D. N. Reznick. 2006. Parallel evolution of the sexes? Effects of predation and habitat features on the size and shape of wild guppies. Journal of Evolutionary Biology 19:741-754.

Hill, W. R. 1992. Food limitation and interspecific competition in snail-dominated streams. Canadian Journal of Fisheries and Aquatic Sciences 49:1257-1267.

Hillebrand, H., and M. Kahlert. 2001. Effect of grazing and nutrient supply on periphyton biomass and nutrient stoichiometry in habitats of different productivity. Limnology and Oceanography 46:1881-1898.

Hillebrand, H., M. Kahlert, A. L. Haglund, U. G. Berninger, S. Nagel, and S. Wickham. 2002. Control of microbenthic communities by grazing and nutrient supply. Ecology 83:2205-2219.

Hillebrand, H., and U. Sommer. 1997. Response of epilithic microphytobenthos of the Western Baltic Sea to in situ experiments with nutrient enrichment. Marine Ecology Progress Series 160:35-46.

Hoverman, J. T., J. R. Auld, and R. A. Relyea. 2005. Putting prey back together again, integrating predator-induced behavior, morphology, and life history. Oecologia 144:481-491.

Johnson, J. B. 2002. Divergent life histories among populations of the fish Brachyrhaphis rhabdophora: Detecting putative agents of selection by candidate model analysis. Oikos 96:82-91.

Kawata, M., M. Hayashi, and T. Hara. 2001. Interactions between neighboring algae and snail grazing in structuring microdistribution patterns of periphyton. Oikos 92:404-416. 
Klingenberg, C. P., and L. R. Monteiro. 2005. Distances and directions in multidimensional shape spaces: Implications for morphometric applications. Systematic Biology 54:678-688.

Kraft, P. G., R. S. Wilson, and C. E. Franklin. 2005. Predator-mediated phenotypic plasticity in tadpoles of the striped marsh frog, Limnodynastes peronii. Austral Ecology 30:558-563.

Langerhans, R. B. 2009. Trade-off between steady and unsteady swimming underlies predator-driven divergence in Gambusia affinis. Journal of Evolutionary Biology 22:1057-1075.

Langerhans, R. B., and T. J. DeWitt. 2004. Shared and unique features of evolutionary diversification. American Naturalist 164:335-349.

Lima, S. L. 1998. Nonlethal effects in the ecology of predator-prey interactions - What are the ecological effects of anti-predator decision-making? Bioscience 48:25-34.

Lima, S. L., and L. M. Dill. 1990. Behavioral decisions made under the risk of predation: A review and prospectus. Canadian Journal of Zoology 68:619-640.

Liston, S. E. 2004. Defining the role of floating periphyton mats in shaping food-web dynamics in the Florida Everglades. Ph. D. Florida International University, Miami, FL.

Liston, S. E., S. Newman, and J. C. Trexler. 2008. Macroinvertebrate community response to eutrophication in an oligotrophic wetland: An in situ mesocosm experiment. Wetlands 28:686-694.

Lodge, D. M., K. M. Brown, S. P. Klosiewski, R. A. Stein, A. P. Covich, B. K. Leathers, and C. Brönmark. 1987. Distribution of freshwater snails: Spatial scale and the relative importance of physicochemical and biotic factors. American Malacological Bulletin 5:73 - 84.

Lodge, D. M., M. W. Kershner, J. E. Aloi, and A. P. Covich. 1994. Effects of an omnivorous crayfish (Orconectes rusticus) on a freshwater littoral food web. Ecology 75:1265-1281.

Lowe, R. L., and R. D. Hunter. 1988. Effects of grazing by Physa integra on periphyton community structure. Journal of the North American Benthological Society 7:2936 .

McCormick, P. V., M. B. O'Dell, R. B. E. Shuford, J. G. Backus, and W. C. Kennedy. 2001. Periphyton responses to experimental phosphorus enrichment in a subtropical wetland. Aquatic Botany 71:119-139. 
McCormick, P. V., R. B. E. Shuford, and P. S. Rawlik. 2004. Changes in macroinvertebrate community structure and function along a phosphorus gradient in the Florida Everglades. Hydrobiologia 529:113-132.

McCormick, P. V., and R. J. Stevenson. 1989. Effects of snail grazing on benthic algal community structure in different nutrient environments. Journal of the North American Benthological Society 8:162-172.

McCormick, P. V., and R. J. Stevenson. 1991. Grazer control of nutrient availability in the periphyton. Oecologia 86:287-291.

Mitchell, R. J. 1992. Testing evolutionary and ecological hypotheses using path analysis and structural equation modeling. Functional Ecology 6:123-129.

Morales, J. B. T., and A. K. Ward. 2000. Snail grazers affect the fate of labile dissolved organic C in streams. Journal of the North American Benthological Society 19:659-669.

Munoz, I., M. Real, H. Guasch, E. Navarro, and S. Sabater. 2000. Resource limitation by freshwater snail (Stagnicola vulnerata) grazing pressure: An experimental study. Archiv Fur Hydrobiologie 148:517-532.

Noe, G. B., D. L. Childers, and R. D. Jones. 2001. Phosphorus biogeochemistry and the impact of phosphorus enrichment: Why is the Everglades so unique? Ecosystems 4:603-624.

Oksanen, L., S. D. Fretwell, J. Arruda, and P. Niemela. 1981. Exploitation ecosystems in gradients of primary productivity. American Naturalist 118:240-261.

Peacor, S. D., and E. E. Werner. 2000. Predator effects on an assemblage of consumers through induced changes in consumer foraging behavior. Ecology 81:1998-2010.

Peacor, S. D., and E. E. Werner. 2001. The contribution of trait-mediated indirect effects to the net effects of a predator. Proceedings of the National Academy of Sciences of the United States of America 98:3904-3908.

Peckarsky, B. L., P. A. Abrams, D. I. Bolnick, L. M. Dill, J. H. Grabowski, B. Luttbeg, J. L. Orrock, S. D. Peacor, E. L. Preisser, O. J. Schmitz, and G. C. Trussell. 2008. Revisiting the classics: Considering nonconsumptive effects in textbook examples of predator-prey interactions. Ecology 89:2416-2425.

Petranka, J. W., and A. Sih. 1986. Environmental instability, competition, and densitydependent growth and survivorship of a stream-dwelling salamander. Ecology 67:729-736. 
Pigliucci, M., H. Pollard, and M. B. Cruzan. 2003. Comparative studies of evolutionary responses to light environments in Arabidopsis. American Naturalist 161:68-82.

Polis, G. A. 1999. Why are parts of the world green? Multiple factors control productivity and the distribution of biomass. Oikos 86:3-15.

Power, M. E. 1992. Top-down and bottom-up forces in food webs: Do plants have primacy. Ecology 73:733-746.

Power, M. E., A. J. Stewart, and W. J. Matthews. 1988. Grazer control of algae in an Ozark mountain stream - Effects of short-term exclusion. Ecology 69:1894-1898.

Preisser, E. L., D. I. Bolnick, and M. F. Benard. 2005. Scared to death? The effects of intimidation and consumption in predator-prey interactions. Ecology 86:501-509.

Preisser, E. L., D. I. Bolnick, and J. H. Grabowski. 2009. Resource dynamics influence the strength of non-consumptive predator effects on prey. Ecology Letters 12:315323.

Pringle, C. M. 1990. Nutrient spatial heterogeneity - Effects on community structure, physiognomy, and diversity of stream algae. Ecology 71:905-920.

Rader, R. B., and C. J. Richardson. 1994. Response of macroinvertebrates and small fish to nutrient enrichment in the northern Everglades. Wetlands 14:134-146.

Relyea, R. A. 2002. Competitor-induced plasticity in tadpoles: Consequences, cues, and connections to predator-induced plasticity. Ecological Monographs 72:523-540.

Rohlf, F. J. 2005. tpsRelw. Version 1.42. Department of Ecology and Evolution, State University of New York, Stony Brook, New York.

Rohlf, F. J. 2006. tpsDig. 2.05. Department of Ecology and Evolution, State University of New York, Stony Brook, New York.

Rohlf, F. J., and L. F. Marcus. 1993. A revolution in morphometrics. Trends in Ecology and Evolution 8:129-132.

Rosemond, A. D. 1994. Multiple factors limit seasonal variation in periphyton in a forest stream. Journal of the North American Benthological Society 13:333-344.

Rosemond, A. D., P. J. Mulholland, and J. W. Elwood. 1993. Top-down and bottom-up control of stream periphyton - Effects of nutrients and herbivores. Ecology 74:1264-1280. 
Ruehl, C. B., and T. J. DeWitt. 2005. Trophic plasticity and fine-grained resource variation in populations of western mosquitofish, Gambusia affinis. Evolutionary Ecology Research 7:801-819.

Schindler, D. W. 1977. Evolution of phosphorus limitation in lakes. Science 195:260262.

Sharp, P. R. 2008. Identification, distribution, and probability of infection in sympatric gastropods by digenean parasites at Pa-Hay-Okee, Everglades National Park using molecules and morphology. dissertation. Florida International University, Miami.

Sharpe, D. M. T., K. Rasanen, D. Berner, and A. P. Hendry. 2008. Genetic and environmental contributions to the morphology of lake and stream stickleback: implications for gene flow and reproductive isolation. Evolutionary Ecology Research 10:849-866.

Sih, A. 1987. Predators and prey lifestyles: An evolutionary and ecological overview. in Predation: Direct and indirect impacts on aquatic communities. University Press of New England, Hanover, NH.

Sih, A., P. Crowley, M. Mcpeek, J. W. Petranka, and K. Strohmeier. 1985. Predation, competition, and prey communities - A review of field experiments. Annual Review of Ecology and Systematics 16:269-311.

Sih, A., G. Englund, and D. Wooster. 1998. Emergent impacts of multiple predators on prey. Trends in Ecology \& Evolution 13:350-355.

Snyder, N. F. R. 1967. An alarm reaction of aquatic gastropods to intraspecific extract. Memoir 403 of the Cornell University Agricultural Experiment Station.

Solorzano, L., and J. H. Sharp. 1980. Determination of total dissolved phosphorus and particulate phosphorus in natural-waters. Limnology and Oceanography 25:754757.

Spitze, K. 1991. Chaoborus predation and life history evolution in Daphnia pulex: Temporal pattern of population diversity, fitness, and mean life history. Evolution 45:82-92.

Stearns, S. C. 1977. The evolution of life-history traits: A critique of the theory and a review of the data. Annual Review of Ecology and Systematics 8:145-171.

Stearns, S. C., and J. C. Koella. 1986. The evolution of phenotypic plasticity in lifehistory traits - Predictions of reaction norms for age and size at maturity. Evolution 40:893-913. 
Steinman, A. D., C. D. McIntire, and R. R. Lowry. 1987. Effects of herbivore type and density on chemical composition of algal assemblages in laboratory streams. Journal of the North American Benthological Society 6:189-197.

Sterner, R. W., and J. J. Elser. 2002. Ecological stoichiometry: The biology of elements from molecules to the biosphere. Princeton University Press, Princeton, New Jersey.

Sultan, S. E. 1987. Evolutionary implications of phenotypic plasticity in plants. Evolutionary Biology 21:127-178.

Tobler, M., T. J. DeWitt, I. Schlupp, F. J. García de León, R. Herrmann, P. G. D. Feulner, R. Tiedemann, and M. Plath. 2008. Toxic hydrogen sulfide and dark caves: Phenotypic and genetic divergence across two abiotic environmental gradients in Poecilia mexicana. Evolution 62:2643-2659.

Trussell, G. C. 2000. Phenotypic clines, plasticity and morphological trade-offs in an intertidal snail. Evolution 54:151-166.

Turner, A. M. 1997. Contrasting short-term and long-term effects of predation risk on consumer habitat use and resources. Behavioral Ecology 8:120-125.

Turner, A. M. 2004. Non-lethal effects of predators on prey growth rates depend on prey density and nutrient additions. Oikos 104:561-569.

Turner, A. M., S. A. Fetterolf, and R. J. Bernot. 1999a. Predator identity and consumer behavior: Differential effects of fish and crayfish on the habitat use of a freshwater snail. Oecologia 118:242-247.

Turner, A. M., and G. C. Mittelbach. 1990. Predator avoidance and community structure: Interactions among piscivores, planktivores, and plankton. Ecology 71:22412254.

Turner, A. M., J. C. Trexler, C. F. Jordan, S. J. Slack, P. Geddes, J. H. Chick, and W. F. Loftus. 1999b. Targeting ecosystem features for conservation: Standing crops in the Florida Everglades. Conservation Biology 13:898-911.

Underwood, G. J. C., and J. D. Thomas. 1990. Grazing interactions between pulmonate snails and epiphytic algae and bacteria. Freshwater Biology 23:505-522.

Van Buskirk, J., and R. A. Relyea. 1998. Selection for phenotypic plasticity in Rana sylvatica tadpoles. Biological Journal of the Linnean Society 65:301-328.

Van Buskirk, J., and D. C. Smith. 1991. Density-dependent population regulation in a salamander. Ecology 72:1747-1756. 
Werner, E. E., and S. D. Peacor. 2003. A review of trait-mediated indirect interactions in ecological communities. Ecology 84:1083-1100.

Werner, E. E., and S. D. Peacor. 2006. Lethal and nonlethal predator effects on an herbivore guild mediated by system productivity. Ecology 87:347-361.

West-Eberhard, M. J. 2003. Developmental plasticity and evolution. Oxford University Press, New York.

Wojdak, J. M. 2005. Relative strength of top-down, bottom-up and consumer species richness effects on pond ecosystems. Ecological Monographs 75:489-504.

Wootton, J. T. 1994a. The nature and consequences of indirect effects in ecological communities. Annual Review of Ecology and Systematics 25:443-466.

Wootton, J. T. 1994b. Predicting direct and indirect effects: An integrated approach using experiments and path analysis. Ecology 75:151-165.

Wright, S. 1934. The method of path coefficients. Annals of Mathematical Statistics 5:161-215. 
Table 3.1. Repeated measures ANOVA of individual snail biomass (g/individual) during the $41 \mathrm{~d}$ experiment. Denominator degrees of freedom estimated by the Satterthwaite method. Block was treated as a random effect.

\begin{tabular}{llrr}
\hline Within subjects & DF $=2,43.1$ & \multicolumn{1}{c}{ F } \\
\hline & Day & 18.2 & $<0.001$ \\
& Day $\times$ cue & 2.1 & 0.139 \\
Day $\times$ density & 0.2 & 0.792 \\
Day $\times$ nutrient & 2.6 & 0.090 \\
Day $\times$ cue $\times$ density & 0.2 & 0.819 \\
Day $\times$ cue $\times$ nutrient & 0.2 & 0.808 \\
Day $\times$ Snail $\times$ nutrient & 0.8 & 0.467 \\
Day $\times$ cue $\times$ density $\times$ & 0 & 0.961 \\
nutrient & & \\
\hline Detween subjects $=1,43.3$ & & \\
\hline Cue & 0.1 & 0.007 \\
Density & 0.82 & 0.372 \\
Nutrient & 10.7 & 0.002 \\
Cue $\times$ density & 0.19 & 0.667 \\
Cue $\times$ nutrient & 0.59 & 0.446 \\
density $\times$ nutrient & 0.72 & 0.400 \\
Cue $\times$ density $\times$ nutrient & 0.1 & 0.752 \\
\hline
\end{tabular}


Table 3.2. MANCOVA of shell shape for lateral and aperture aspects. I used PCA to reduce the number of dependent variables to 5 for lateral and 4 for aperture shape, which explained greater than $95 \%$ of shape variation for each aspect. Multivariate effect size was estimated with Wilk's partial variance explained $\left(\eta_{\mathrm{p}}{ }^{2}\right)$.

\begin{tabular}{llccccc}
\hline Perspective & Effect & Wilk's $\lambda$ & $\mathrm{F}$ & $\mathrm{P}$ & $\eta_{\mathrm{p}}{ }^{2}$ & Rank \\
\hline lateral & Cue & 0.31 & 4.51 & 0.021 & 0.693 & 3 \\
$(\mathrm{df}=5,10)$ & Density & 0.87 & 0.29 & 0.910 & 0.125 & 7 \\
& Phosphorous & 0.44 & 2.58 & 0.095 & 0.563 & 5 \\
& Cue $\times$ density & 0.26 & 5.74 & 0.009 & 0.742 & 1 \\
& Cue $\times$ phosphorous & 0.27 & 5.32 & 0.012 & 0.727 & 2 \\
& Density $\times$ phosphorous & 0.39 & 3.18 & 0.056 & 0.614 & 4 \\
& Cue $\times$ density $\times$ phosphorous & 0.45 & 2.47 & 0.105 & 0.553 & 6 \\
\hline Aperture & Cue & 0.29 & 6.24 & 0.009 & 0.714 & 1 \\
$(\mathrm{df}=4,10)$ & Density & 0.86 & 0.41 & 0.799 & 0.140 & 7 \\
& Phosphorous & 0.61 & 1.63 & 0.242 & 0.395 & 6 \\
& Cue $\times$ density & 0.46 & 2.93 & 0.076 & 0.540 & 4 \\
& Cue $\times$ phosphorous & 0.43 & 3.26 & 0.059 & 0.566 & 2 \\
& Density $\times$ phosphorous & 0.48 & 2.74 & 0.089 & 0.523 & 5 \\
& Cue $\times$ density $\times$ phosphorous & 0.45 & 3.09 & 0.067 & 0.553 & 3 \\
\hline
\end{tabular}


Table 3.3. Direct, indirect, and total effects from path analysis for the effects of predator cue, consumption, and phosphorous addition on $\mathrm{C}: \mathrm{P}$ ratios, chlorophyll $a$ concentrations from periphyton associated with plastic strips, and benthic periphyton mat as well as a variety of snail traits. Note the similarities in total (net) effects for C: P ratios, and non-consumptive effects (predator cue) as well as the dearth of effects for snails experiencing lower densities.

\begin{tabular}{|c|c|c|c|c|c|c|c|c|c|c|c|}
\hline Effects & Variables & $\begin{array}{c}\text { Snail } \\
\text { density }\end{array}$ & $\begin{array}{c}\text { Crayfish } \\
\text { cue }\end{array}$ & $\mathrm{C}: \mathrm{P}$ & $\begin{array}{l}\text { Peri. } \\
\text { Chl } a\end{array}$ & $\begin{array}{l}\text { Chl } a \\
\text { strips } \\
\end{array}$ & $\begin{array}{c}\text { Shell } \\
\text { thick- } \\
\text { ness }\end{array}$ & $\begin{array}{c}\text { Lateral } \\
\text { PC }\end{array}$ & $\begin{array}{c}\text { Aperture } \\
\text { PC }\end{array}$ & Activity & $\begin{array}{c}\text { Growth } \\
\text { rate }\end{array}$ \\
\hline \multirow[t]{9}{*}{ Direct } & $\mathrm{C}: \mathrm{P}$ & 0 & -0.08 & 0 & 0 & 0 & 0 & 0 & 0 & 0 & 0 \\
\hline & Peri. chl $a$ & 0 & -0.20 & 0 & 0 & 0 & 0 & 0 & 0 & 0 & 0 \\
\hline & Chl $a$ strips & 0 & -0.54 & 0 & 0 & 0 & 0 & 0 & 0 & 0 & 0 \\
\hline & Shell thickness & 0.33 & 0.18 & 0 & -0.12 & -0.04 & 0 & 0 & 0 & 0 & 0 \\
\hline & Lateral PC & -0.13 & -0.43 & -0.26 & 0.30 & -0.54 & 0 & 0 & 0 & 0 & 0 \\
\hline & Aperture PC & -0.13 & -0.15 & -0.31 & 0.20 & -0.60 & 0 & 0 & 0 & 0 & 0 \\
\hline & Activity & -0.05 & -0.40 & 0.33 & 0.11 & 0.10 & 0 & 0 & 0 & 0 & 0 \\
\hline & Growth Rate & 0.04 & -0.38 & 0.15 & 0.09 & -0.08 & 0 & -0.29 & -0.57 & -0.05 & 0 \\
\hline & F1 standing crop & 0.15 & 0.32 & 0.29 & -0.40 & 0.35 & 0.34 & 0.45 & 0.14 & 0.51 & 0.62 \\
\hline \multirow[t]{9}{*}{ Indirect } & $\mathrm{C}: \mathrm{P}$ & 0 & 0 & 0 & 0 & 0 & 0 & 0 & 0 & 0 & 0 \\
\hline & Peri. chl $a$ & 0 & 0 & 0 & 0 & 0 & 0 & 0 & 0 & 0 & 0 \\
\hline & Chl $a$ strips & 0 & 0 & 0 & 0 & 0 & 0 & 0 & 0 & 0 & 0 \\
\hline & Shell thickness & 0 & 0.05 & 0 & 0 & 0 & 0 & 0 & 0 & 0 & 0 \\
\hline & Lateral PC & 0 & 0.21 & 0 & 0 & 0 & 0 & 0 & 0 & 0 & 0 \\
\hline & Aperture PC & 0 & 0.26 & 0 & 0 & 0 & 0 & 0 & 0 & 0 & 0 \\
\hline & Activity & 0 & -0.05 & 0 & 0 & 0 & 0 & 0 & 0 & 0 & 0 \\
\hline & Growth Rate & 0.12 & 0.06 & -0.24 & -0.20 & 0.50 & 0 & 0 & 0 & 0 & 0 \\
\hline & F1 standing crop & 0.11 & -0.52 & -0.25 & 0.10 & -0.03 & 0.00 & -0.18 & -0.36 & -0.03 & 0 \\
\hline
\end{tabular}


Table 3.3 continued

\begin{tabular}{|c|c|c|c|c|c|c|c|c|c|c|c|}
\hline Effects & Variables & $\begin{array}{c}\text { Snail } \\
\text { density }\end{array}$ & $\begin{array}{c}\text { Crayfish } \\
\text { cue }\end{array}$ & $\mathrm{C}: \mathrm{P}$ & $\begin{array}{l}\text { Peri. } \\
\text { Chl } a\end{array}$ & $\begin{array}{l}\text { Chl } a \\
\text { strips } \\
\end{array}$ & $\begin{array}{c}\text { Shell } \\
\text { thick- } \\
\text { ness }\end{array}$ & $\begin{array}{c}\text { Lateral } \\
\text { PC }\end{array}$ & $\begin{array}{c}\text { Aperture } \\
\text { PC }\end{array}$ & Activity & $\begin{array}{c}\text { Growth } \\
\text { rate }\end{array}$ \\
\hline \multirow[t]{9}{*}{ Total } & $\mathrm{C}: \mathrm{P}$ & 0 & -0.08 & 0 & 0 & 0 & 0 & 0 & 0 & 0 & 0 \\
\hline & Peri. chl $a$ & 0 & -0.20 & 0 & 0 & 0 & 0 & 0 & 0 & 0 & 0 \\
\hline & Chl $a$ strips & 0 & -0.54 & 0 & 0 & 0 & 0 & 0 & 0 & 0 & 0 \\
\hline & Shell thick-ness & 0.33 & 0.23 & 0 & -0.12 & -0.04 & 0 & 0 & 0 & 0 & 0 \\
\hline & Lateral PC & -0.13 & -0.22 & -0.26 & 0.30 & -0.54 & 0 & 0 & 0 & 0 & 0 \\
\hline & Aperture PC & -0.13 & 0.11 & -0.31 & 0.20 & -0.60 & 0 & 0 & 0 & 0 & 0 \\
\hline & Activity & -0.05 & -0.45 & 0.33 & 0.11 & 0.10 & 0 & 0 & 0 & 0 & 0 \\
\hline & Growth Rate & 0.16 & -0.32 & 0.39 & -0.12 & 0.42 & 0 & -0.29 & -0.57 & -0.05 & 0 \\
\hline & F1 standing crop & 0.26 & -0.20 & 0.54 & -0.30 & 0.32 & 0.35 & 0.27 & -0.22 & 0.48 & 0.62 \\
\hline
\end{tabular}



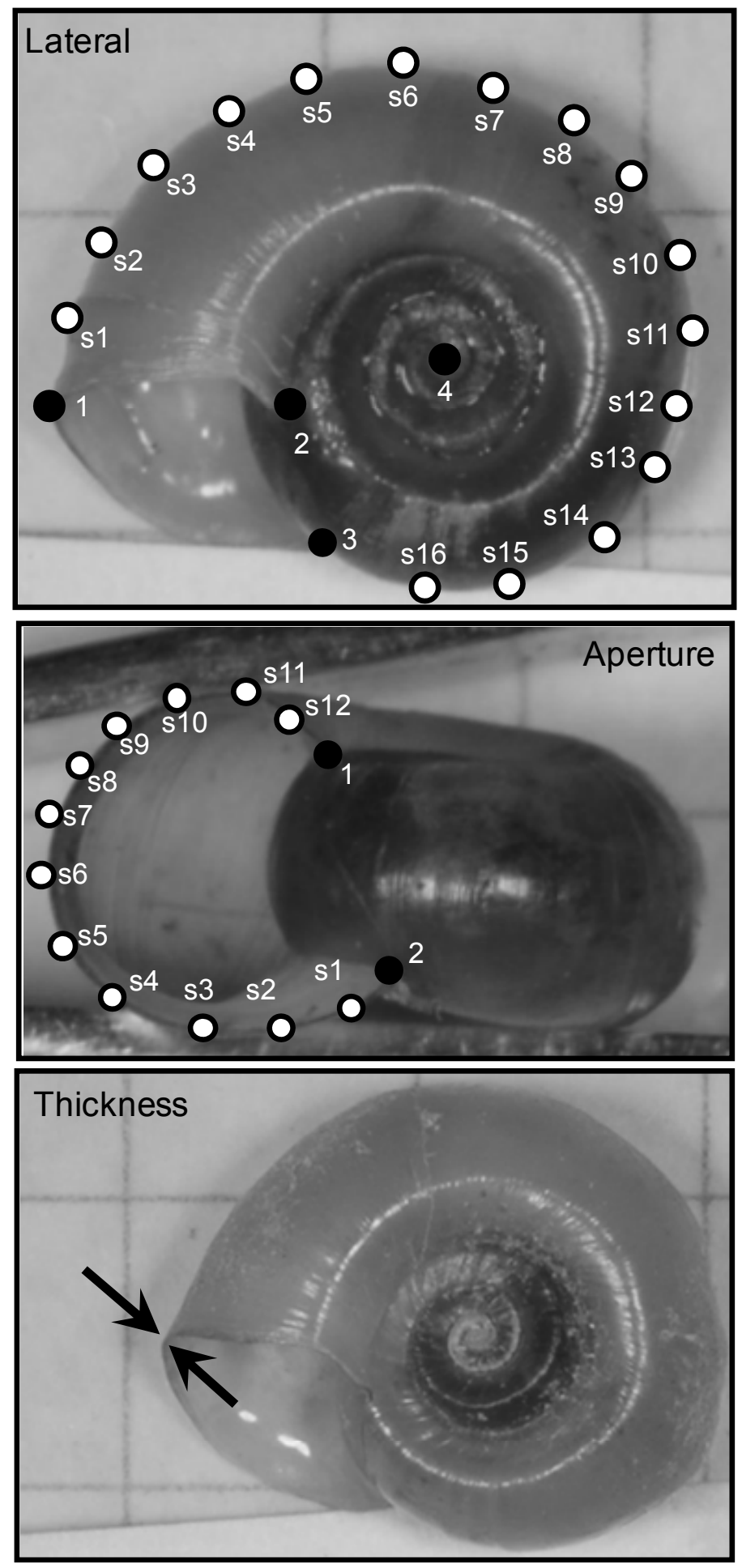

Fig 3.1. Landmarks (black) and semi-landmarks (white) used in geometric morphometric analysis. Location where shell thickness was measured. 


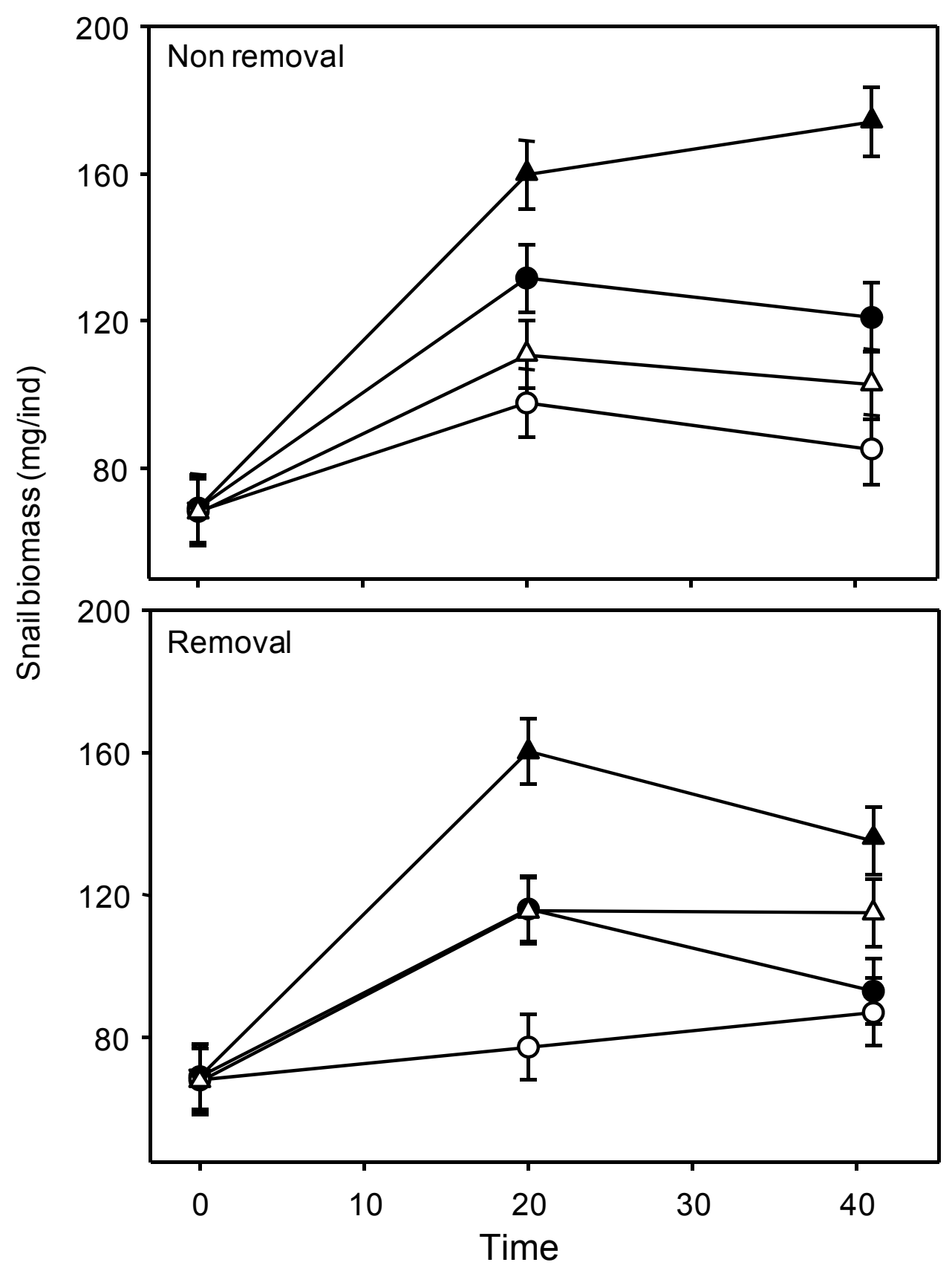

(d)

Fig 3.2. Individual snail biomass (mean \pm S.E.) through time. Phosphorous additions (filled) led to larger individuals than ambient (open) conditions. Snails experiencing cues from a caged crayfish (circle) were smaller than those with no cue (triangle). There was no difference between density manipulation treatments (upper vs. lower panel). Lines are drawn to aid the eye. 


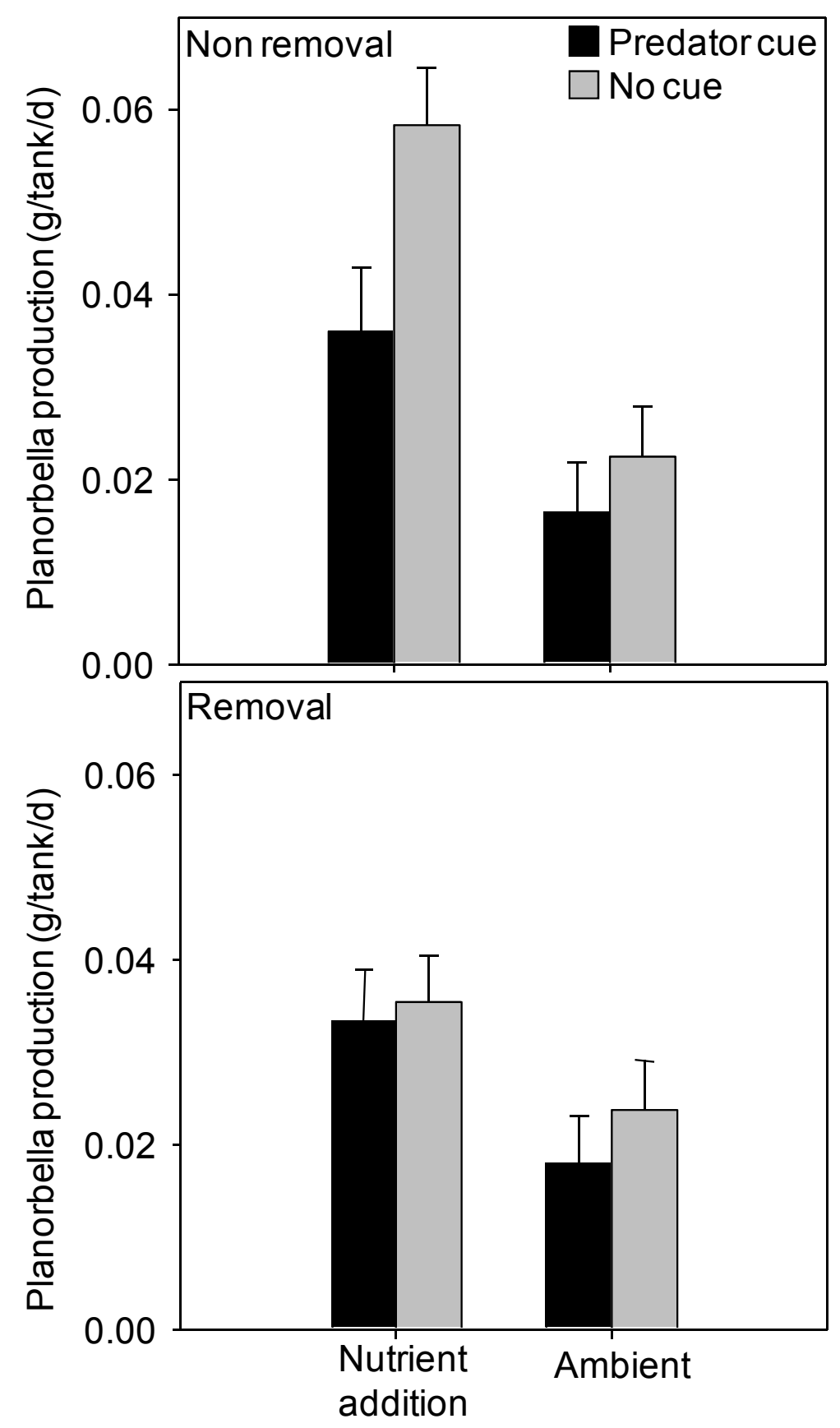

Fig 3.3. Planorbella production (mean $\pm \mathrm{SE}, \mathrm{g} / \mathrm{tank} /$ day) during the $41 \mathrm{~d}$ experiment. I found no difference between removal treatments after accounting for the removed snails, but cue (black bars) slowed and nutrients stimulated production primarily because production was high in treatments with nutrient additions but without cue when snail density was constant. 

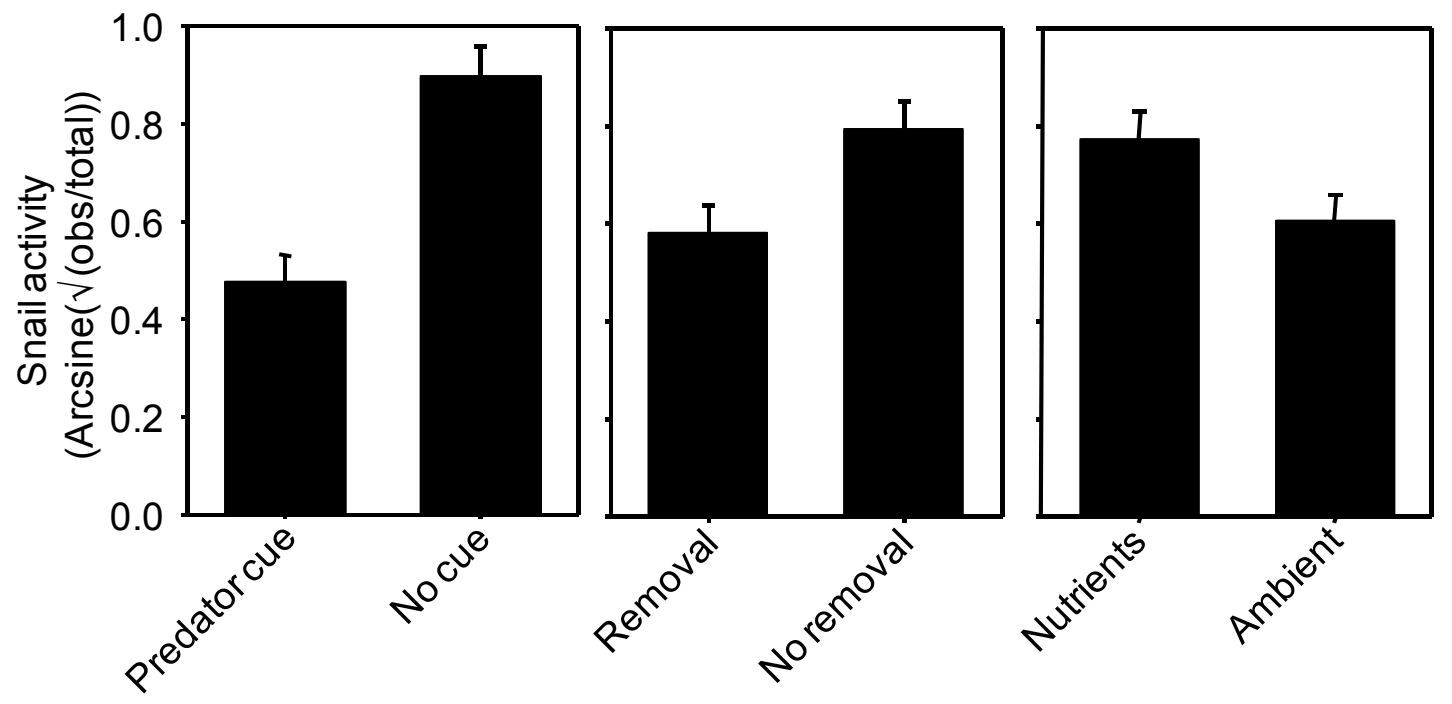

Fig 3.4. Proportion of snails observed by visual census (mean \pm SE) that experienced crayfish cue, density reductions, and phosphorous additions compared to tanks without these manipulations. Note that proportionally fewer snails were observed when cue was present, when densities were lower, and at ambient phosphorous levels. 


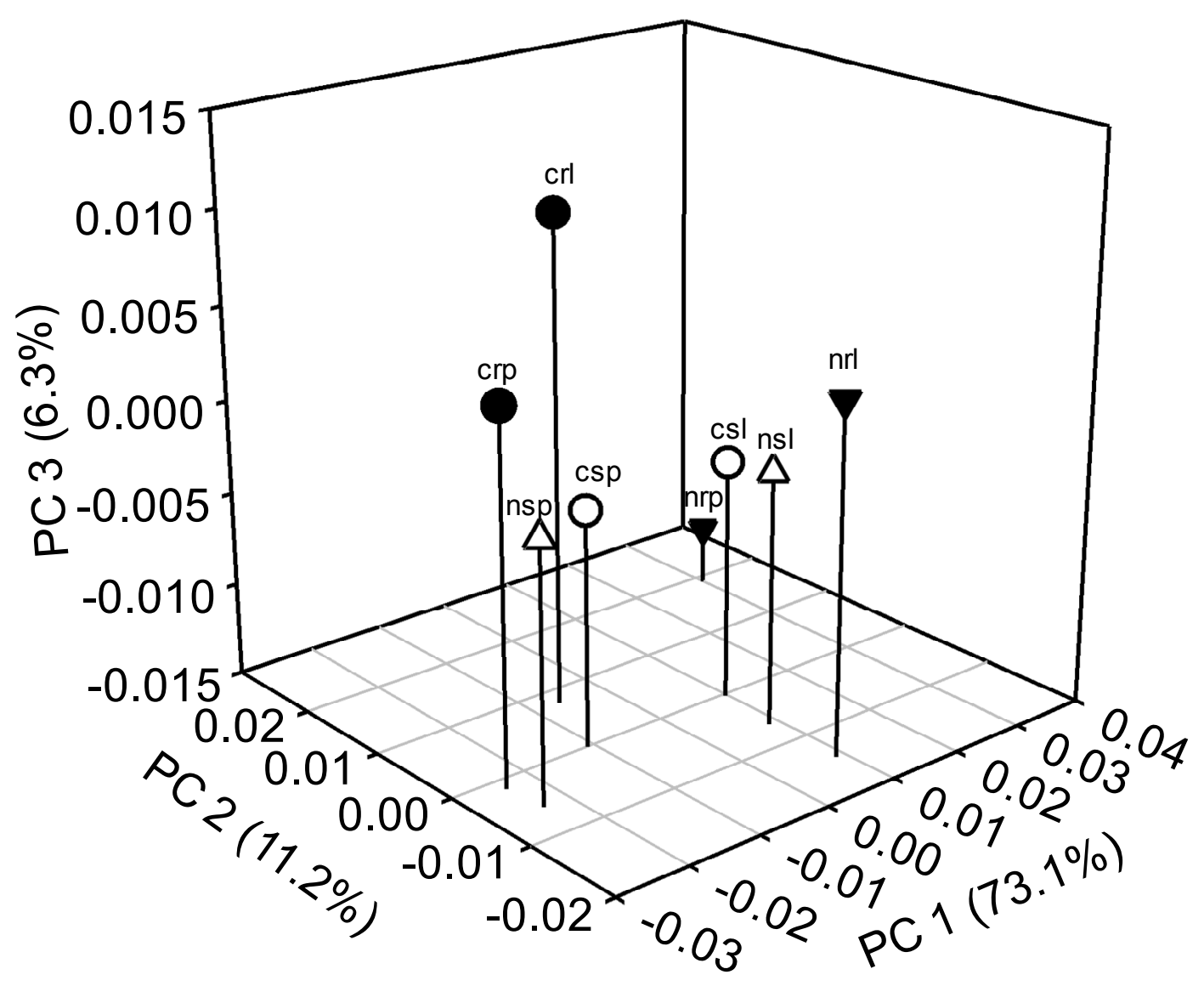

Fig 3.5. The first 3 principal components (mean) of lateral shape variation from a PCA on covariances of superimposed landmarks and semilandmarks. Treatment combinations are above symbols; the first letter refers to predator cue ( $\mathrm{c}=\mathrm{cue}, \mathrm{n}=$ no cue), the second letter indicates snail density ( $\mathrm{s}=$ non-removal, $\mathrm{r}=$ removal), and the last letter refers to phosphorous $(\mathrm{p}=$ added, $1=$ ambient $)$. Note, that in cue treatments without phosphorous additions snails did not develop anti-predator morphologies and snails developed distinct morphologies at low densities without predator cue. These two responses led to the cueby-phosphorous and cue-by-density interactions in the MANCOVA. 


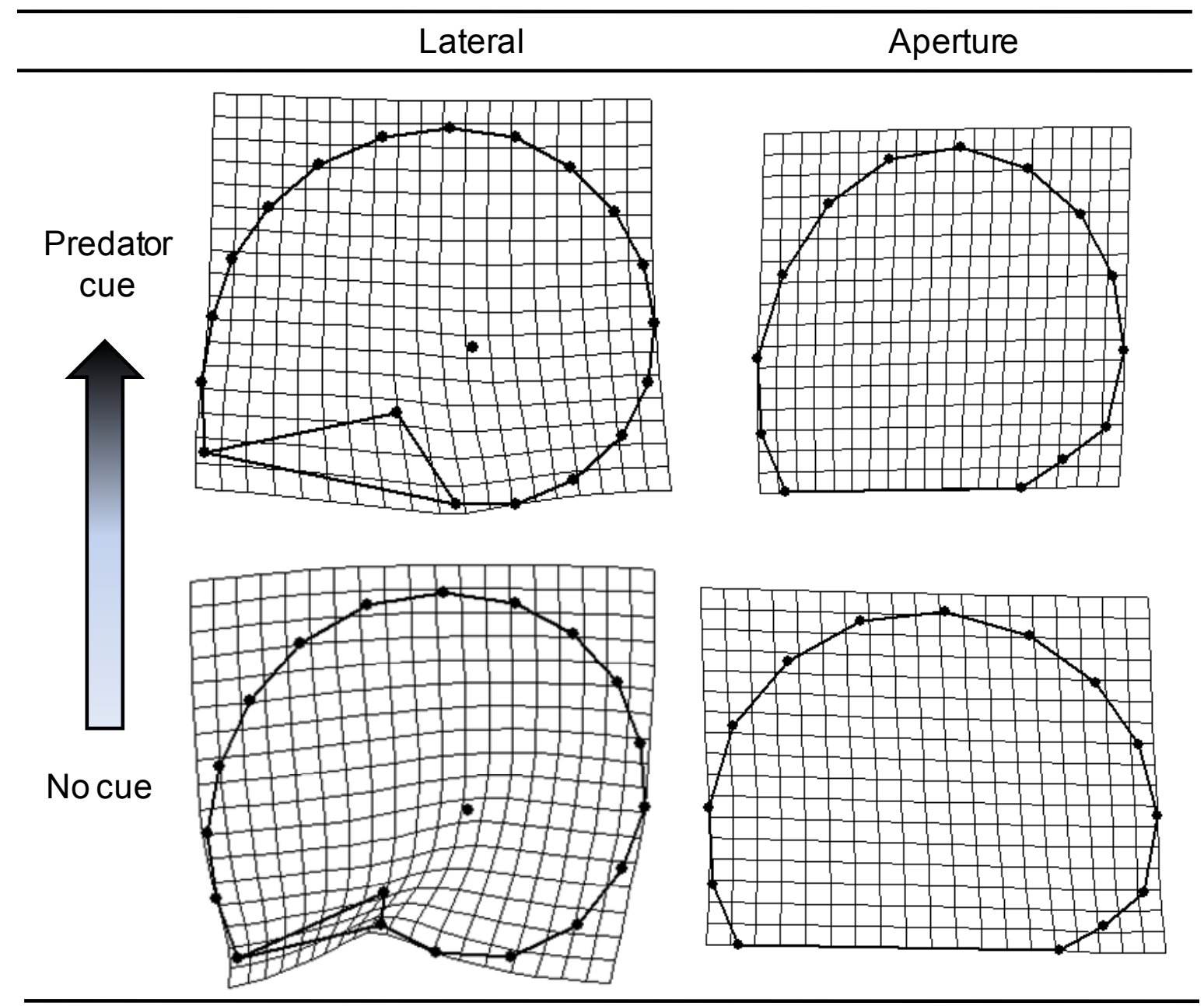

Fig 3.6. Thin-plate spline transformation grids depicting lateral and aperture aspects of shell shape variation among snails grown in the presence of crayfish cue. Lateral shape variation for the cue-by-density and cue-by-phosphorous interactions were qualitatively similar to shape variation for the predator main effect. Deformation grids were generated using the derived effect scores from the MANCOVA on principal components. Note the tall and narrow aperture in predator cue treatments. 


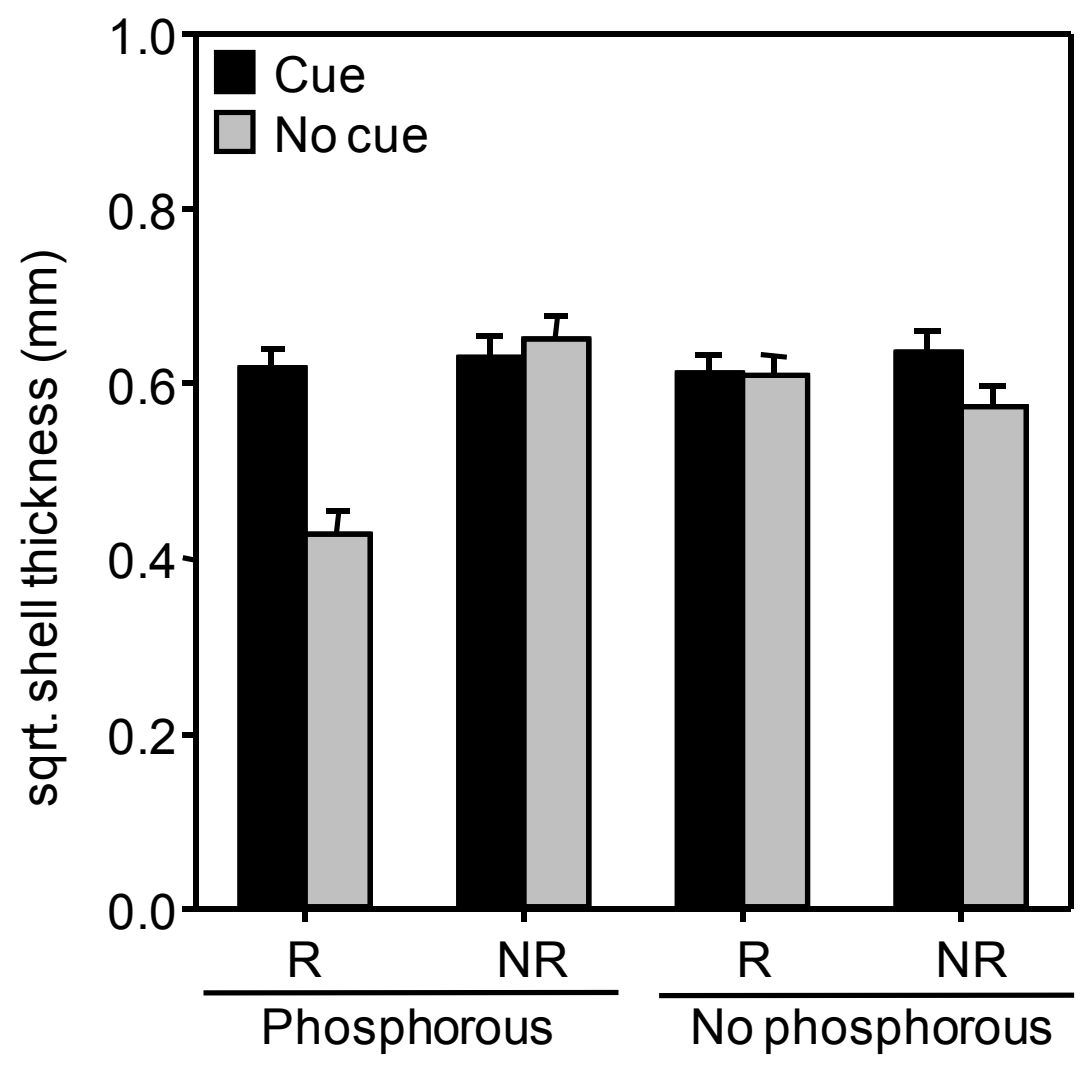

Fig 3.7. Allocation of resources into shell thickness (mean $\pm \mathrm{SE}$ ), measured at the top edge of the aperture. Snails without crayfish cue that received phosphorous additions and that experienced lower density $(\mathrm{R})$ developed thin shells. 


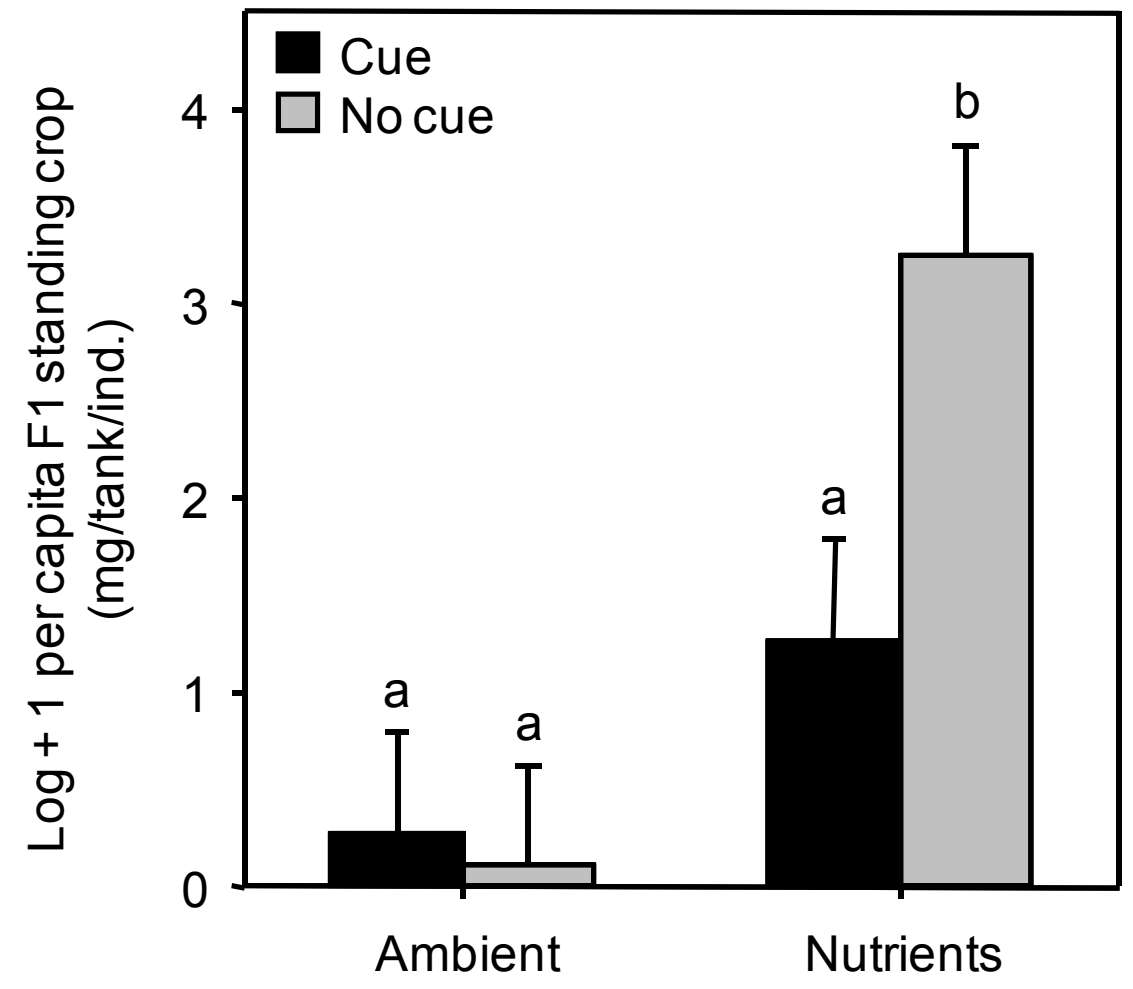

Fig 3.8. Per capita F1 standing stock (mean $\pm \mathrm{SE}, \mathrm{g} / \mathrm{ind}$./tank) scaled to the density (no./tank) of adult snails at the end of experiment. There was no difference in F1 standing stock for removal treatments after accounting for removed specimens. Phosphorus additions in the absence of crayfish cue exhibited the largest F1 standing stock (Tukey, $\mathrm{P}<0.05$ ). 

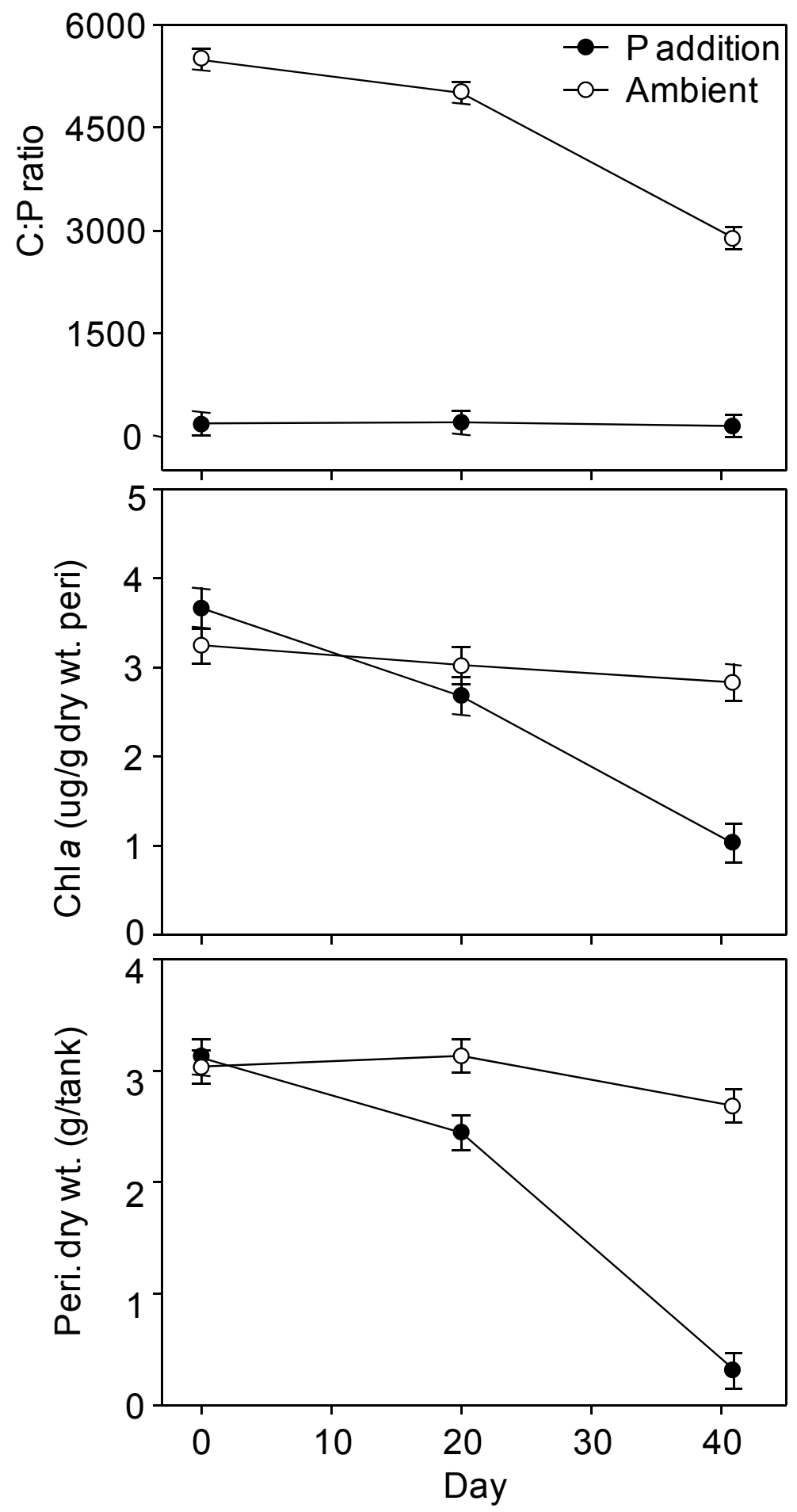

Fig 3.9. Periphyton mat characteristics during the experiment. Phosphorous additions lowered $\mathrm{C}: \mathrm{P}$ ratios indicating that resource quality improved, but quantity decreased as both periphyton chlorophyll $a$ concentration and dry weight declined. C:P ratios in ambient tanks were lower by the end of the experiment. 


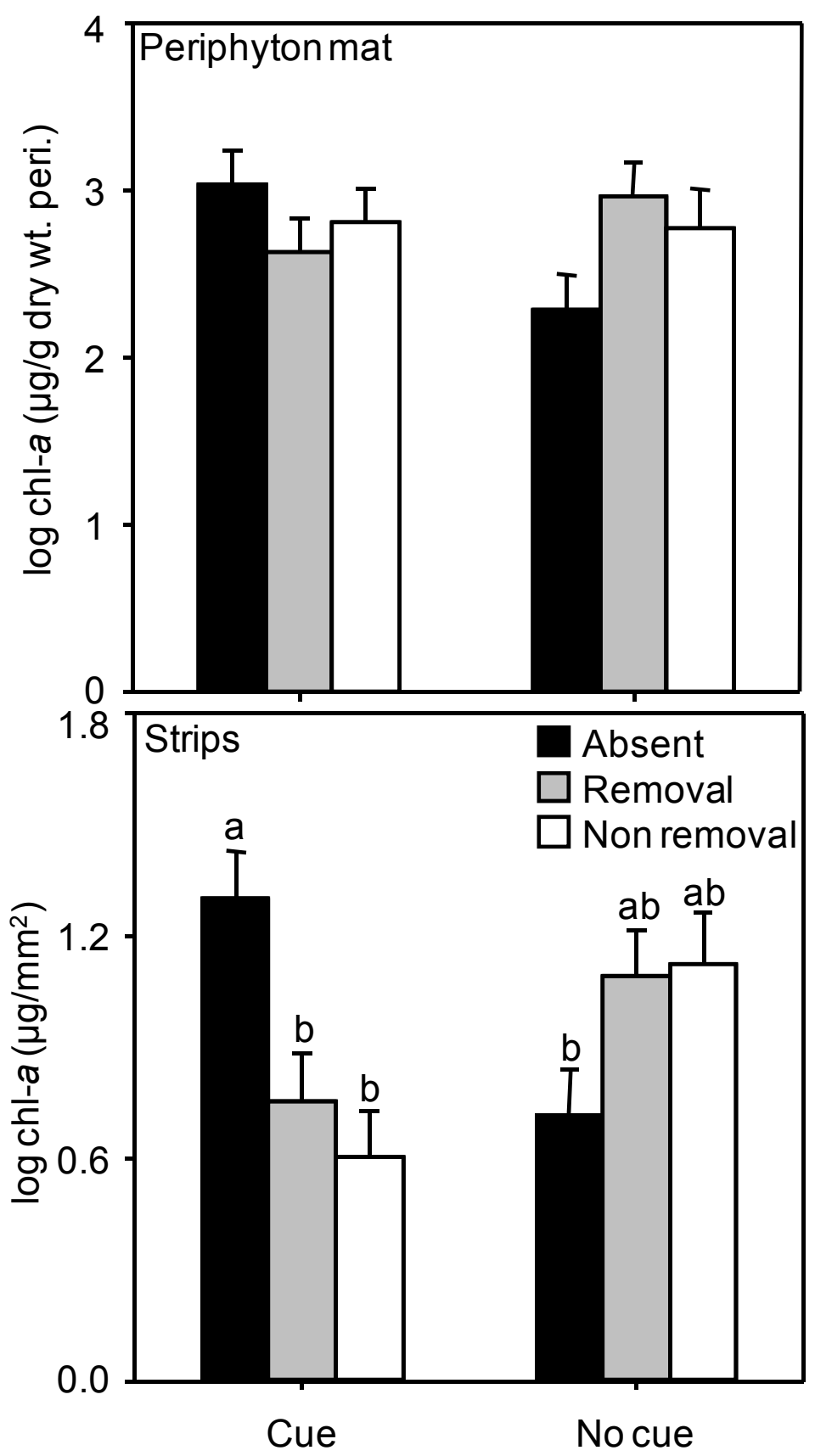

Fig 3.10. Chlorophyll $a$ concentration (1smean \pm SE) in benthic periphyton mat and chlorophyll $a$ density (lsmean \pm SE) on plastic strips located on the tank floor. Snail grazers were absent (black bars), removed to simulate predation (gray bars), or were not removed (white bars) and either did or did not experience crayfish cue. Different letters indicate significant differences using Tukey HSD $(\mathrm{P}<0.05)$. Note, the similarities between the two graphs except for the tanks with crayfish cues and snails that had much lower chlorophyll $a$ concentrations on plastic strips. Tanks with crayfish and snails generally had higher chlorophyll $a$ concentrations compared to tanks without snails. 


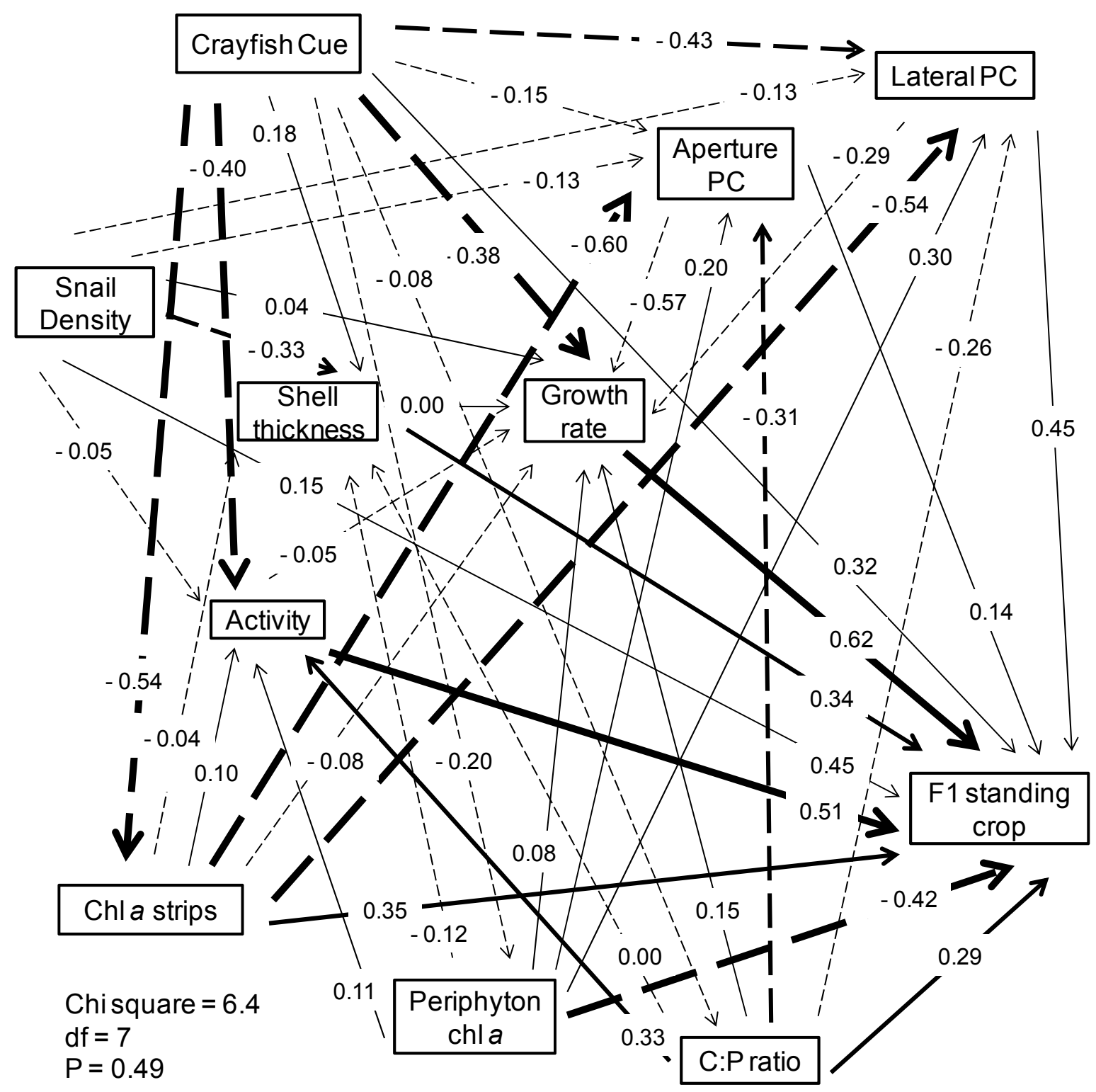

Fig 3.11. Path model showing non-consumptive (crayfish cue) and consumptive (snail density) effects of crayfish in the midst of phosphorous enrichment on a variety of traits of the snail, Planorbella duryi. I represented periphyton resources with three variables to examine the potential for indirect effects of crayfish cue on localized periphyton (chl $a$ strips) and test for elemental constraint on growth and reproduction (C:P ratio and Periphyton chl $a$ ). Solid lines represent positive relationships between traits, while dashed lines are negative. Thick lines are significant relationships $(\mathrm{P} \leq 0.05)$, medium lines are marginal $(0.1>\mathrm{P}<0.05)$ and thin lines are non significant paths $(\mathrm{P}>0.1)$. Lateral PC and aperture PC are the first principal components describing shell lateral shape and aperture shape that explained greater than $70 \%$ and $60 \%$ of shape variation respectively. Shell thickness is the residuals from a regression of tissue mass and shell length to control for the effects of body size. 


\section{CHAPTER IV}

TRADE-OFFS BETWEEN RESOURCE AND PREDATOR EFFECTS ON A PRIMARY CONSUMER ALONG A GRADIENT CREATED BY A CANAL 


\section{INTRODUCTION}

The relative effects of predators and resources that affect growth, reproduction, and survival of individuals influences population dynamics and the distribution and abundance of species. Quantifying the contribution of each is a fundamental goal of ecology. Many studies have considered the combination of predators and resources affecting food web structure (Hairston et al. 1960, Power 1992, Osenberg and Mittelbach 1996, Carpenter et al. 2001, Silliman and Zieman 2001). Resource gradients can have profound effects on individual growth rates and life history traits that change population growth rates (Tilman 1988, Pringle 1990, Power 1992, Rosemond et al. 1993, Turner 2004). Both lethal and non-lethal predator effects alter prey population dynamics. Predators remove individuals from the population and alter behavior, morphology, individual growth rate, and life history traits through chemical and visual cues (Vermeij and Currey 1980, Stearns and Koella 1986, Lima 1998, DeWitt et al. 1999, Turner et al. 2000, Peckarsky et al. 2002, Schmitz 2003, Werner and Peacor 2003, Turner 2004, Werner and Peacor 2006). Recent research has revealed that non-consumptive effects are at least as important as consumptive ones in many systems (Abrams et al. 1996, Werner and Peacor 2003, Preisser et al. 2005, Abrams 2008, Peckarsky et al. 2008b). In natural systems, separating the effects of resources and predators is difficult because they are often confounded and require manipulative experiments to identify their separate effects. One or both of these factors are altered in human-modified habitats and provide an unplanned experiment when compared to un-altered habitats in the same ecosystem.

Many freshwater aquatic ecosystems are altered for flood control by dredging canals or ditch constructing. Canals, in addition to their intended purpose, often transport water 
from agricultural and urban runoff laden with fertilizers, pesticides, herbicides, and other pollutants that enrich and alter relatively pristine aquatic ecosystems. In the Florida Everglades, canal inflows are the main sources of phosphorous that enriches an otherwise extremely oligotrophic ecosystem (Davis 1994, Noe et al. 2001, McCormick et al. 2002, Gaiser et al. 2006). Near canals, periphyton has higher levels of phosphorous that cause members of the aquatic food web to respond differently. The abundance of most small fishes increase with phosphorous enrichment, while invertebrates display a variable response; some studies find increases, while others find no change (Rader and Richardson 1994, Turner et al. 1999, McCormick et al. 2004, Rehage and Trexler 2006). Large predatory fish, including molluscivorous fishes, are often more numerous near canals than in the surrounding unaltered marshes (Rehage and Trexler 2006). Therefore, canals appear to simultaneously increase the relative importance of both resources and predators, factors that could negate each other and result in no net change in population growth compared to those in un-altered marshes far from canals.

Grazer diets may change in response to variation in resource quality, and individuals may consume less, high quality food to meet the same nutritional requirements. Snail grazers are efficient periphyton consumers (Steinman et al. 1987, Rosemond et al. 1993, Feminella and Hawkins 1995) that can also have positive effects on their food resources through excretion of waste and the consumption of dead algal cells, a response commonly called nutrient regeneration (McCormick and Stevenson 1991, Rosemond et al. 1993, Hillebrand and Kahlert 2001). There is some evidence for food preference in pulmonate snails (Clampitt 1970), but many studies find planorbid snails are generalist opportunistic grazers (Calow 1970, Calow and Calow 1975, Brown 1982). Gut content analysis is 
difficult in pulmonate snails because items either degrade rapidly (bacteria) or are resistant to digestion and would be over-represented (diatoms), but assimilatory approaches like stable isotopes and fatty acid profiles offer a promising alternative because the assimilated fraction of material can generally be traced back to the resource. Stable isotopes are limited to separating basal resources that have very different carbon signatures (detritus versus algae). Fatty acid analysis has gained the attention of ecologists because of the potential for separating among basal taxa (Napolitano 1999). Further, the composition of phospholipid fatty acids represent relatively long-term diet assimilation because they are structural lipids (Taipale et al. 2009). This technique offers great promise for categorizing snail diets. Recent studies have used this technique in estuaries and freshwater streams (Alfaro 2008, Lau et al. 2008a) to determine snail diets with success, but few studies have used this technique to examine diets of consumers in freshwater wetlands.

Resource quality is also related to diet. Resource quality regulates individual and population growth at the base of the food web. Ecological stoichiometry compares the elemental ratios of carbon, nitrogen, and phosphorous to determine resource quality. Typically, primary producers have high, but variable, carbon-to-nitrogen and carbon-tophosphorous ratios, while consumers maintain low and stable ratios. Such elemental imbalances between resources and consumers are thought to constrain both consumer somatic growth and population growth (Sterner and Elser 2002). Stoichiometric theory has proven robust in the limnetic region of lakes (e.g., Elser et al. 2000). Several studies have tested this theory in littoral food webs (Frost et al. 2002, Frost et al. 2005) and oligotrophic systems provide particularly good tests because nutrient additions likely 
cause strong responses (e.g., Elser et al. 2005). Numerous studies have demonstrated that phosphorous is limiting in the oligotrophic Everglades (Noe et al. 2001, McCormick et al. 2002, Gaiser et al. 2004). Therefore, it would be a good ecosystem to test this hypothesis.

Pulmonate snails lend themselves to separating the effects of nutrient enrichment from water born predator cues in because they move relatively short distances $(50-100$ cm/day) (Pimentel and White Jr. 1959, Corr et al. 1984, Michel et al. 2007). They cannot rapidly disperse from risky habitats, but instead they alter a variety of other traits in response to water-born chemical cues from predators (Crowl and Covich 1990, Chase 1999, DeWitt et al. 1999, Turner et al. 2000, Hoverman et al. 2005). In this study, I test for trade-offs between non-consumptive predator effects and phosphorous enrichment on growth and reproduction in Planorbella duryi (Seminole Ramshorn) with a reciprocal transplant experiment using a gradient of phosphorous enrichment and predators created by a canal. I made the following predictions: 1) Periphyton lipid profiles and periphyton composition would vary among sites; snail lipid profiles would reveal they primarily assimilated green algae; 2) Phosphorous enrichment near canals alters elemental constraints leading to higher quality resources that increase snail growth rate and reproduction, 3) but the more numerous predator cues near canals dampen growth and egg production near canals masking the effects of enrichment.

\section{METHODS}

To experimentally separate the effects of enrichment from predators, I established four sites arranged in two spatial blocks separated by $6 \mathrm{~km}$; each block consisted of one 
site near $(<0.05 \mathrm{~km})$ and one site far $(3 \mathrm{~km})$ from the canal $($ Block $1:$ Near $=$ $25^{\circ} 45^{\prime} 55.70^{\prime \prime} \mathrm{N}, 80^{\circ} 45^{\prime} 35.50^{\prime \prime} \mathrm{W}$; Far $=25^{\circ} 47^{\prime} 44.50^{\prime \prime} \mathrm{N}, 80^{\circ} 45^{\prime} 44.10^{\prime \prime} \mathrm{W}$; Block 2: Near $=$ $\left.25^{\circ} 45^{\prime} 45.20^{\prime \prime N}, 80^{\circ} 41^{\prime} 42.50^{\prime \prime} \mathrm{W} ; \mathrm{Far}=25^{\circ} 47^{\prime} 39.80^{\prime \prime} \mathrm{N}, 80^{\circ} 42^{\prime} 3.10^{\prime \prime} \mathrm{W}\right)$. Sites distant from the canal far exceed the influence of the canal (Gaiser et al. 2006, Rehage and Trexler 2006). I measured a variety of abiotic and biotic parameters at each site during the experiment to document site characteristics, track seasonal changes in the marsh, and confirm prior research on the effects of canals. Periphyton was collected at each site by haphazardly grabbing 3 samples of periphyton from the surrounding marsh before, during, and after the experiment. I sampled the aquatic community at each site before (17-24 June) and after (21-25 August) the experiment by enumerating the contents of seven $1-\mathrm{m}^{2}$ throw traps $(1.6 \mathrm{~mm}$ mesh) following standard procedures (Jordan et al. 1997). Briefly, after the trap was thrown, all emergent plants were identified and counted; periphyton volume (floating mat and epiphytic sweaters) was quantified with a 2 1 graduated cylinder with drain holes; fish and invertebrates were removed with a bar seine (1.6 mm mesh) until 3 consecutive passes were empty; a D-ring net (1.2 $\mathrm{mm}$ mesh) was swept through the water column and a second net (4.8 $\mathrm{mm}$ mesh) was scraped across the bottom until 5 passes of each net were empty. Organisms were anesthetized with MS-222 and preserved in 10\% formalin.

The effect of seasonality and phosphorous enrichment near canals represents a diverse set of biotic and abiotic interactions across space and time that combine to produce the net effect of predators on snail populations. I estimated predator density by summing the known snail predators collected in throw-traps, which included small predatory fish, juveniles of large predatory fish, and large macroinvertebrates at each 
site-Mayan cichlid (Cichlasoma urophthalmus), peninsula newts (Notophthalmus viridescens piaropicola), belostomatids (2 species), leeches (1 species), crayfish (Procambarus fallax), Anisoptera ( 7 species), and creeping water bug (Pelocoris femoratus) - that likely do not have additive effects on snails because they also eat each other (i.e., omnivory), but do represent evidence for predator cues.

I estimated the likelihood of snail predation before (16-20 June) and after (15-17 August) the experiment at the four sites with tethering techniques (Aronson and Heck 1995, Aronson et al. 2001, Silliman and Bertness 2002). At each site, twenty live snails (9-14 $\mathrm{mm}$, shell length) were glued with cyanoacrylic adhesive (super glue) to a 1-m length of 6-1b monofilament that was tied to a $12.7-\mathrm{mm}$ diameter poly-vinyl chloride (PVC) stake secured to the marsh floor. Tethers were arranged in two blocks of ten and separated by $3 \mathrm{~m}$ within blocks to prevent tangling. Tethered snails were observed moving freely through the water column and feeding on available periphyton. Four snails were tethered inside cages at each site during both rounds of tethering; I found that none of these snails died or detached from their tethers.

\section{Experimental Design}

I designed a factorial $2 \times 2$ reciprocal transplant experiment consisting of two snail densities (present or absent) and two periphyton origins (near or far from the canal), replicated 3 times at the 4 sites to isolate predator from enrichment effects along the canal gradient. At each site, I attached 12 mesh bags $(25 \mathrm{~cm}$ diameter, $30 \mathrm{~cm}$ long) with cable ties to PVC pipes (2.5-cm diameter) that were secured in the marsh floor. Periphyton was collected at each site, sorted to remove large invertebrates (e.g., snails, crayfish, 
dipteran larvae, naiads), and $200 \mathrm{ml}$ were added to six of the bags. In the other six bags, I placed $200 \mathrm{ml}$ of periphyton from the opposite site within a block. Therefore within a block, periphyton originating near and far from the canal was placed in bags at sites near and far from the canal. I set up the experiment on 5 July 2008. Fifteen snails (range: $37.15 \pm 0.74-107.08 \pm 0.83 \mathrm{mg}$, median: $62.91 \pm 1.15 \mathrm{mg}($ mean $\pm \mathrm{SE}$ wet tissue $/ \mathrm{bag}))$ marked with colored bee tags (The Bee Works, Ontario Canada, www.beeworks.com) to each of 3 bags with local periphyton and 3 bags with transplanted periphyton at each site. Every bag received a standard substrate (plastic plate) to quantify snail egg deposition as a measure of reproductive effort among treatments. Halfway through the $39 \mathrm{~d}$ experiment (d 19, 23 July 2008), I measured the shell length of 8 snails in each bag and collected $30 \mathrm{ml}$ of periphyton that was stored on ice in the field and frozen until processing. Snails were returned to bags and I added an additional $200 \mathrm{ml}$ of periphyton to each bag. Periphyton was added at two points during the experiment, instead of all at once, to prevent periphyton from adapting to the local nutrient environment. At the conclusion of the experiment (12 August 2008), I collected snails, stored them on ice in the field, and froze them until processing. I measured periphyton volume in each bag using a 21 graduated cylinder with drain holes and retained a 30-ml subsample for processing. I counted the number of egg masses on the standard substrate in all experimental bags.

\section{Sample processing}

In the lab, experimental snails were thawed and their shell length was measured and converted to mass with locally derived length-weight regressions for growth analysis. I 
removed soft tissue from the shell and dissected away the gut tract of five snails and pooled the tissue for analysis in each replicate of the second block (near and far site). Periphyton samples were thawed and weighed; mat-dwelling invertebrates and nonperiphyton plant material were removed, dried and weighed. The periphyton that remained was homogenized and diluted to a known volume with distilled water. Measured sub-samples were removed to estimate dry-weight, ash-free dry mass, chlorophyll $a$, total C:N:P, soft-algae composition, and lipid profiles. Two sub-samples were dried $\left(70^{\circ} \mathrm{C}\right)$ and weighed; one was ashed for two hours at $500{ }^{\circ} \mathrm{C}$ and re-weighed to determine the mineral content. Organic content (ash-free dry mass) was calculated as the difference between the dry and mineral mass. The other sub-sample was analyzed for $\mathrm{C}: \mathrm{N}: \mathrm{P}$. Total carbon and nitrogen were determined with duplicate samples using an elemental analyzer (Fisons Instruments NA1500NCS). Total phosphorous was measured on duplicate samples using the dry-oxidation, acid hydrolysis method (Solorzano and Sharp 1980). Chlorophyll $a$ sub-samples were diluted 100 fold and a $1 \mathrm{ml}$ aliquot was filtered onto a $2.5 \mathrm{~cm}$ glass-fiber filter that was frozen; chlorophyll $a$ was extracted using $90 \%$ acetone and read flurometrically within 24 hours. Periphyton sub-sample dry weight, ash-free dry mass, and chlorophyll $a$ content from experimental bags (but not samples from the marsh) were extrapolated to the whole bag using the volume of periphyton removed at the end of the experiment and the estimated volume at the halfway point. I interpolated periphyton volume in experimental bags at the halfway point. First, I calculated an expected periphyton volume in each bag by summing the amount added to bags on day 0 and 20 and subtracting the amount removed by sub-sampling $(200 \mathrm{ml}+$ $200 \mathrm{ml}-30 \mathrm{ml}$ ). Rate of change was calculated as observed volume minus expected, 
divided by the experiment length (observed - expected/39 days). I then estimated periphyton volume halfway through the experiment by multiplying the rate of change by 20 (no. of days in first half of the experiment) and adding the initial periphyton volume in the bags $(200 \mathrm{ml})$. Periphyton sub-samples from the marsh were expressed on a $\mathrm{mg} / \mathrm{g}$ for dry weight and ash-free dry mass; chlorophyll $a$ was expressed on a ug/g dry weight.

I quantified periphyton taxonomic composition with samples collected on the final day of the experiment to examine algal variation among sites, determine the effects of transplantation on composition, and by comparing composition in bags with and without snails explore the effects of grazing. Compositional differences between bags with and without snails provide insight into the parts of the periphyton mat that snails consumed. Samples were thawed, diluted to a known volume, and homogenized; an aliquot was spread onto a cover-slip allowed to dry and mounted on slides with clear nail polish. At least 500 cells were counted using an Olympus BX 41 compound light microscope with a $100 \times$ oil immersion objective and a total magnification of $1000 \times$. Cells were grouped into coccoid blue green, filamentous blue green, coccoid green, filamentous green, 3 size classes of diatoms, 3 size classes of desmids, and filamentous desmids. Biovolume of each group was estimated by approximating cells to different geometric shapes.

I examined variation in snail and periphyton lipid profiles for insight into the portion of periphyton mat that snails assimilated. The periphyton sub-sample along with the snail samples were freeze-dried, weighed, and sent to Microbial Insights (Rockford, TN; www.microbe.com/) for phospholipid fatty acid analysis. Phospholipids were extracted with methanol:chloroform:0.05 M potassium phosphate buffer (2:1:0.8) with agitation 
(Bligh and Dyer 1959). Phospholipids were identified on a gas chromatograph with flame ionization detection (GC-FID).

\section{Data Analysis}

I tested for differences in snail predator density among sites with repeated measures analysis of variance (RANOVA); snail predator density was square-root transformed and block was treated as a random effect. I used backward stepping logistic regression (Trexler and Travis 1993, Juliano 2001) to test for differences in snail predation with site, event (before or after experiment), shell length, water depth, and block as predictor variables.

The general form of the model used for the remaining analyses tested for effects of site, snail presence, periphyton origin, their interactions, and block as a random effect. Because I measured individual snail growth (biomass), periphyton dry weight, ash-free dry mass, chlorophyll $a$, and C:P ratio multiple times from experimental bags and from the surrounding marsh, RANOVA was used to test for differences. Periphyton dry weight, ash-free dry mass, and chlorophyll $a$ were square root transformed.

Egg production, periphyton taxonomic composition, and lipid composition of periphyton and snails were all measured on the last day of the experiment. Small nonexperimental snails were added to experimental bags with periphyton despite pre-sorting the periphyton. Experimental snails were marked and could be distinguished from nonexperimental snails, but eggs were indistinguishable. Therefore, I took the difference between the number of egg masses in bags with experimental snails and those without experimental snails to account for eggs laid by non-experimental snails. I calculated the 
per-capita reproductive rate by dividing this difference by the number of snails in each bag at the start of the experiment (15). Per-capita reproductive rate was $\log +1$ transformed and served as the dependent variable in an ANOVA testing for effects of site and periphyton origin.

I tested for compositional differences in periphyton with a multivariate analysis of variance (MANOVA) where the square-root relative abundance of each group served as the dependent variables. Canonical axes from significant effects were plotted to examine differences in composition, and I used standardized canonical loadings to determine which periphyton groups contributed to differences along each canonical axis.

To quantify variation in lipid profiles for snails and periphyton, I reduced the number of dependent variables with a principal components analysis on the covariance structure of the relative abundance (\% of total) of each lipid and saved the first two components, which explained $99 \%$ of the variation for periphyton and $92 \%$ for snails. These two principal components served as dependent variables in a MANOVA testing for effects of site, snail, periphyton origin, and their interaction for periphyton samples and site, periphyton origin, and their interaction for snail samples. There was no block term because only one site pair (near and far) was analyzed for lipids.

Three bags at three different sites were excluded from analyses because halfway through the experiment they were found with gaping holes. The replicates that were destroyed included two bags in block two, one near with near periphyton and one far with near periphyton; neither contained snails. The third bag was in the first block, near the canal with near periphyton and did not have snails. All statistical procedures were conducted with JMP 4.04 and SAS 9.2. 


\section{RESULTS}

Over the course of the experiment, the marsh environment changed with the progression of the wet season. Generally, the marsh filled, periphyton mats expanded, stem density increased, and there were more small fish and invertebrates at the end of the experiment than at the start (Table 1). Despite seasonal variation at sites, snail predators were more numerous at the two sites near the canal in three of four instances (Fig 1A). Snail predation was greater at sites near the canal $\left(\mathrm{DF}=3\right.$, Wald $\chi^{2}=10.04, \mathrm{P}=0.02$, Fig 1B). No control snails were found dead or detached from their tethers. Periphyton had higher chlorophyll $a$ values $\left(\mathrm{F}_{3,18.2}=8.0 ; \mathrm{P}<0.01\right)$ and lower $\mathrm{C}: \mathrm{P}$ ratios $\left(\mathrm{F}_{3,13}=26.1 ; \mathrm{P}\right.$ $<0.01)$ near the canal. I found no evidence for periphyton compositional differences or lipid profile differences among sites for samples collected from the surrounding marsh.

Periphyton ash-free dry mass was higher at the end of the experiment than at earlier points in the experiment $\left(\mathrm{F}_{1,29.6}=243.43, \mathrm{P}<0.01\right.$, Fig 2$)$. Snails reduced periphyton in experimental bags $27 \%$ as measured by ash-free dry mass $\left(\mathrm{F}_{1,30.1}=21.8, \mathrm{P}<0.01\right)$. Similarly, during the first half of the experiment snails reduced periphyton chlorophyll $a$ by $55 \%$; however, by the conclusion, chlorophyll $a$ concentrations were $20 \%$ higher in bags with snails compared to no snail controls (snail-by-day: $\mathrm{F}_{1,29.3}=42.8 ; \mathrm{P}<0.01$ ). Snail grazing had no effect on periphyton C:P ratios.

I found little evidence that snails discriminated among available periphyton resources; snail addition did not alter periphyton taxonomic composition as revealed by MANOVA $\left(\mathrm{F}_{6,24}=1.36 ; \mathrm{P}=0.27\right)$. However, periphyton taxonomic composition in the experimental bags varied among sites despite little variation in the marsh samples $\left(\mathrm{F}_{18,68.4}\right.$ $=2.32 ; \mathrm{P}<0.01)$. Transplanted periphyton resembled the site of origin more than the site 
where it was placed, which led to the significant site-by-transplant interaction $\left(\mathrm{F}_{18,68.4}=\right.$ 5.37; $\mathrm{P}<0.01)$. The first canonical axis $(\mathrm{CA})$ from the MANOVA separated sites near the canal from far sites (Fig 3). Three taxonomic groups were strongly associated with CA 1: filamentous greens were more numerous at sites far from the canal and had the highest loadings (1.17), followed by desmids (0.65), which were also more common far from the canal, and diatoms (- 0.55) which were more abundant near the canal (Fig 4). The relative abundance of filamentous blue greens, coccoid blue-greens, and coccoid greens did not vary among sites.

I quantified phospholipid fatty acids in periphyton and snails from one experimental block (block 2) to examine the variation in lipid profiles among sites near and far from the canal in addition to measuring the portion of the periphyton mat snails assimilated. Periphyton and snail lipid profiles between near and far sites were similar and snails appeared to assimilate periphyton associated with 18:109 (Fig 5). The MANOVA using the first two principal components of phospholipids revealed differences between sites and site-by-periphyton origin; adding snails to bags did not affect lipid profiles $\left(\mathrm{F}_{2,13}=\right.$ 3.3; $\mathrm{P}=0.07)$. Profiles were different among sites $\left(\mathrm{F}_{2,13}=5.4 ; \mathrm{P}=0.02\right)$, and the effect of sites depended on whether the periphyton was transplanted (site-by-transplant: $F_{2,13}=$ 20.4; $\mathrm{P}<0.01$ ). Visualization of the first and second principal components indicated that PC 2 separated periphyton from different sites and that transplanted periphyton resembled the site of origin (Fig 6). Similar to periphyton counts, I found little evidence that snail additions affected periphyton lipid profiles. Lipid profiles of snail tissue were marginally different between near and far sites $\left(\mathrm{F}_{2,7}=4.7 ; \mathrm{P}=0.05\right)$; there was evidence that snails feeding on transplanted periphyton had different profiles $\left(\mathrm{F}_{2,7}=9.1 ; \mathrm{P}=0.01\right)$. 
Snail survivorship averaged $0.68 \pm 0.04$ (mean $\pm \mathrm{SE}$ ) experiment-wide; there was no difference in survivorship among sites $\left(\mathrm{F}_{3,16}=0.59 ; \mathrm{P}=0.63\right)$, transplanting periphyton $\left(F_{1,16}=0.10 ; \mathrm{P}=0.75\right)$, or their interaction $\left(\mathrm{F}_{3,16}=0.23 ; \mathrm{P}=0.87\right)$. Snails grew $3.36 \pm$ $0.12 \mathrm{mg} /$ day (mean $\pm 1 \mathrm{SE}$ ) during the experiment; when growth was considered on locally derived periphyton at a site, they grew $3 \%$ faster at sites near the canal (Table 2). However, when transplanted periphyton was included, growth at a site depended on where the periphyton originated. Snails grew $10 \%$ faster when they were placed far from the canal and fed periphyton that originated near the canal (Fig 7). They had similar growth at sites near the canal regardless of periphyton origin and they grew slowest on periphyton that originated far from the canal, at sites far from the canal.

I found snails laid $80 \%$ more egg masses at sites far compared to near the canal $\left(\mathrm{F}_{3,13}\right.$ $=4.2 ; \mathrm{P}=0.03 ;$ Fig 8$)$.

\section{DISCUSSION}

Reciprocally transplanting periphyton between sites near and far from a canal revealed that canals can have counteracting effects of predator cues and resource quality on growth rates and reproductive rates of snails. Near canals, phosphorous enrichment slightly outweighed non-consumptive predator effects (chemical cues) for snail growth; they grew faster and they were slightly more numerous as sites near the canal. However, predator cues depressed snail growth at sites near the canal because snails grew fastest at sites far from canals on periphyton that originated near canals. Conversely, egg production was highest at sites far from the canal suggesting predator cues delayed egg production in favor of growth. Snails reduced periphyton mats through grazing but did 
not alter the composition compared to controls. Although snails indiscriminately grazed periphyton, they differentially assimilated oleic acid (18:1 $\omega 9)$, a fatty acid identified as a biomarker for green algae, signifying they likely assimilate green algae over other algal groups.

Differences among sites resulted from their proximity to the canal; seasonal variation in the marsh environment had similar effects at the four experimental sites. Periphyton volume decreases with increasing phosphorous enrichment in the Everglades (Browder et al. 1994, McCormick et al. 2001, Gaiser et al. 2006). Despite lower periphyton volume in enriched marshes, phosphorous enriched periphyton often contains more chlorophyll $a$ in addition to lower C:P ratios (Gaiser et al. 2006). Low levels of enrichment do not alter periphyton taxonomic composition, but chronic exposure or high loads of phosphorous can cause dramatic changes in composition (McCormick et al. 2001). I found sites far from the canal to be like un-enriched marshes; periphyton volume was higher (thicker floating mats), higher C:P ratios, and lower chlorophyll $a$ concentrations compared to sites near the canal that resembled marshes receiving low to intermediate phosphorous enrichment. Periphyton samples from the marsh surrounding the experiment indicated composition was similar among sites providing further evidence that marshes near the canal were not highly enriched.

Snails are important primary consumers that often maintain periphyton standing crop at low levels (Brönmark 1989, Hill 1992, Rosemond 1994, Feminella and Hawkins 1995). Research on planorbid and many other snails find they are opportunistic grazers that consume periphyton indiscriminately owing partially to their large size compared to their resources (Calow 1970, Calow and Calow 1975, Brown 1982, Morales and Ward 
2000, Hillebrand et al. 2002). Regardless of diet selectivity, snail grazing can have positive effects on resources through nutrient regeneration (McCormick and Stevenson 1991, Hillebrand et al. 2002). For example, grazing clears dead and decaying periphyton, which frees space in the periphyton mat and releases nutrients for uptake by growing periphyton mats. At the mid-point of our experiment, periphyton mass and chlorophyll $a$ levels were lower in experimental bags with snails; at the conclusion, periphyton chlorophyll $a$ was higher in bags with snails, while periphyton mass remained much lower. Geddes et al. (2003) found similar results with other grazers in the Everglades and concluded that nutrient regeneration led to the positive effects of grazers on periphyton. These results, combined with those from a mesocosm experiment that also found evidence for nutrient regeneration (CBR unpublished data) indicate that it appears to be a common positive feedback loop in the Everglades. There was no evidence that snails altered periphyton C:P ratios, which would suggest that snails make phosphorous more available than in their absence. Instead, snails are likely removing dead and decaying cells clearing space for new periphyton growth. Studies are needed to examine the proximate causes of positive feedbacks between grazers and their periphyton resources.

I found that snails haphazardly consumed periphyton, causing a reduction in mass compared to controls, but no compositional change in the mat community. Although snails did not seem to select components of the periphyton mat to consume, they may have differentially assimilated mat components. I quantified phospholipid fatty acids in both periphyton mat and snail tissue to determine if snails incorporated only certain portions of the periphyton mat into their tissue. Few studies have used phospholipid fatty acids to infer diet. In the most relevant study, Taipale et al. (2009) found that 
phospholipids in Daphnia turnover every week and are a better source of long term diet than fat stores in short-lived and fast growing species. Analysis of total lipids is an emerging tool for inferring diet by using essential fatty acids as biomarkers for resources (Arts and Wainman 1999, Iverson et al. 2004, Ruess et al. 2005, Lau et al. 2008b). Essential fatty acids are a group of lipids produced by autotrophs and are required by consumers to meet dietary requirements (Arts et al. 2009). Different autotrophs produce a variety of fatty acids, but a few or only one essential fatty acid. These fatty acids act as tracers because they are assimilated into the somatic tissue of the consumer without alteration. Several studies have identified fatty acid biomarkers for diatoms (Dunstan et al. 1994), green algae (Napolitano et al. 1994), and blue green algae (Fredrickson et al. 1986). Napolitano (1999) summarizes the efforts to identify fatty acid biomarkers and concludes that $20: 5 \omega 3$ is a marker for diatoms, $18: 1 \omega 9$ is a marker for green algae, and

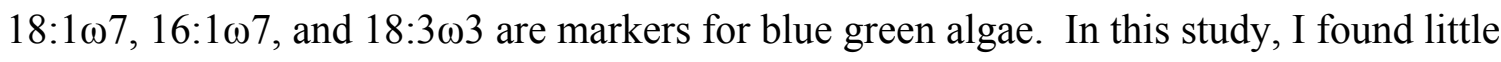
variability in phospholipid fatty acid profiles among sites for periphyton or snails. Grazing reduced phospholipid fatty acid concentrations reflecting their consumption of periphyton. Comparison of snail-tissue fatty acid profiles and the profiles of the periphyton they consumed revealed that oleic acid $(18: 1 \omega 9)$ occurred in much greater quantities in snail tissue than in periphyton. This fatty acid is a biomarker for green algae indicating that snails may assimilate more green algae than other components of the periphyton mat. This is especially apparent when compared to $18: 1 \omega 7$, a biomarker for blue green algae that was prominent in periphyton, but occurred at low levels in snails. Alternatively, snails may be synthesizing oleic acid. Controlled feeding experiments are necessary to determine their potential to produce this fatty acid. However, these results 
suggest that although snails consume the periphyton mat opportunistically (probably because they are large compared to the mat's constituents), they only assimilate a portion of the periphyton mat that includes substantial amounts of green algae.

Ecological stoichiometry is an approach for understanding the complexity of nature through the concept of mass balance among chemical elements (Sterner and Elser 2002). The stoichiometric hypothesis suggests that elemental imbalances between resources (e.g., food quality) and consumers (grazers) limit the growth and production of consumers. Elser et al. (2005) found that moderate phosphorous enrichment of stromatolite microbial mats lowered mat C:P ratios $(\sim 550)$ and led to increased growth rates (higher RNA:DNA ratios) of hydrobiid snails; longer enrichment resulted in much lower C:P ratios $(\sim 100)$, less growth, and higher mortality. These results suggest there are lower and upper stoichiometric constraints for these snails (Elser et al. 2005). The phosphorous enrichment gradient common along canals in the Everglades provides an opportunity to test this theory. Our experimental results support ecological stoichiometry theory in many regards. I did not measure the phosphorous content of snails but, snails fed periphyton with lower C:P ratios (originated near canal) grew faster than those fed periphyton with higher C:P ratios (originated far from canal). Stoichiometric constraint did not explain all of the variation in snail growth rate because a site-by-periphyton origin interaction indicated that snail growth also depended on the proximity of the site to the canal; I believe that this can be explained by higher predator density, snail mortality, and water-born predator cues near the canal.

Many studies have examined the interactions between predators, prey, and prey resources in shaping community structure (Hairston et al. 1960, Power 1984, Power et al. 
1989, Shurin et al. 2002, Nystrom et al. 2003, Schmitz 2003, Gruner et al. 2008).

Historically, consumptive effects were thought to be the primary way predators affected prey populations (Murdoch et al. 2003); however, recent research has revealed the importance of non-consumptive effects (e.g., activity, growth, morphology) on prey and subsequently their resources (Schmitz and Suttle 2001, Brown and Kotler 2004, Preisser et al. 2005, Werner and Peacor 2006, Peckarsky et al. 2008a). Research in the Everglades suggest that small fish abundance increases in phosphorous enriched areas but that most invertebrates show a mixed response, some increase while others decline in density (Rader and Richardson 1994, Turner et al. 1999, McCormick et al. 2004, Rehage and Trexler 2006). Relatively few studies have considered the importance of predators on community structure in wetlands (Batzer 1998, Batzer et al. 2000, Dorn et al. 2006, Chick et al. 2008). Size based exclusion of predators in the Everglades indicates that several invertebrate taxa respond by moving into predator free cages (Dorn et al. 2006, Chick et al. 2008). A mesocosm experiment using a food-web fragment of periphyton, snails, and crayfish from the Everglades revealed that decreasing periphyton C:P ratios enhanced snail growth and reproduction, while predator cues (non-consumptive effects) decreased snail growth and reproduction by decreasing their activity; consumptive effects on growth and reproduction were minimal (CBR unpublished data).

I used a gradient of phosphorous enrichment and threats of predation created by a canal to examine their interactive effects on snail mortality, growth, and reproduction in nature. Predator density was variable, but three out of the four times I compared near and far sites, predators were more numerous near canals. Direct estimates of predation from tethering experiments that allowed snails to at least partially escape predators 
revealed that mortality was higher near $(0.19 \pm 0.03 \% /$ day, mean $\pm \mathrm{SE})$ compared to far $(0.13 \pm 0.01 \% /$ day, mean $\pm \mathrm{SE})$ from canals; given these relative estimates of consumption, predators may strongly depress snail populations throughout the Everglades. However, this direct mortality may not be the most important impact of predators on snail population dynamics. Non-consumptive effects on snail growth emerged after considering transplanted periphyton. Snails grew fastest on periphyton that originated near canals, but was placed far from canals, indicating that phosphorous enriched periphyton led to higher growth rates that in turn were dampened by predator cues near the canal. Without transplanting periphyton, I might have concluded that the canal had a small or no net effect on snail growth rate, but instead, it appears that along with increased nutrients come increased predator threats that result in a much smaller difference in growth rate than expected based on resource quality alone. Predator cues also appeared to alter the allocation of resources toward reproduction. Contrary to expectation, snails laid more egg masses at sites far from canals where there were fewer predator cues regardless of periphyton origin. I expected to find a result similar to snail growth - higher egg production far from the canal on enriched periphyton that originated near the canal. Theory on life history evolution with size-based predators predicts that organisms will delay reproduction until they reach a size refuge from predation (Stearns and Koella 1986, Abrams and Rowe 1996, Chase 1999). Size-based predators could explain the dearth of egg production near the canal if they were an important component of the food web because snails would delay reproduction in areas where size-based predators were more numerous (i.e., near canals). Crayfish and belostomatids are both entry-based predators that are also constrained to consuming smaller snails. These two 
were the most numerous invertebrate snail predators in our samples and entry-based predation accounted for $70 \%$ of the mortality from tethering, suggesting that size-based predation is important to predator-snail interactions in the Everglades. Alternatively, trematode infections, which slow or eliminate snail reproductive rates (Sousa 1983, Brown et al. 1988, Bernot 2003), may explain the difference in the number of egg masses between sites near and far from the canal because snail infection rate often increases with increasing nutrient enrichment (Johnson and Chase 2004).

Canals are dredged to mitigate flooding and irrigate agriculture; they are ubiquitous in human-dominated wetland ecosystems. In addition to altering the natural hydrology, canals alter aquatic communities surrounding canals. In the Everglades, canals facilitate spread of phosphorous-rich water into adjacent marshes with numerous effects including phosphorus-enriched periphyton and increased densities of some consumers but not others at intermediate levels. At high levels marshes experience diurnal anoxia, altered periphyton composition, and shifts in aquatic community structure (Browder et al. 1994, Turner et al. 1999, McCormick et al. 2001, Gaiser et al. 2004, Gaiser et al. 2005, King and Richardson 2007). I observed that snail predators were generally more numerous and that the relative rates of predation were higher near compared to far from canals. I found that the stimulatory effects of low to intermediate levels of phosphorous enrichment on snail growth were simultaneously dampened by the more numerous predator cues associated with higher predator abundance near canals that resulted in only small increases in growth and population density at sites near canals. Additionally, egg production was lower near compared to far from canals. My results suggest that population dynamics of snails near canals are different from those far from canals, but 
these effects are essentially masked because the bottom-up and top-down effects largely cancel. I propose that other consumers encounter similar trade-offs near canals, which could explain why the abundance of some taxa are similar near canals while others increase.

\section{Acknowledgments}

I would like to thank the Aaron Parker, Lisa Jiang, Adam Obaza, Liz Harrison, Amy Williams, Justin Dummit, Ryan Lomax, for assistance in the field. I am grateful to Franco Tobias for assistance in periphyton counts. Financial support for this work was provided by a research fellowship to CBR from the Everglades Foundation, and field data were provided by ENP-FIU Cooperative Agreement H5000060104, Task numbers J5284060023 and J5297070024 to Joel Trexler. 


\section{LITERATURE CITED}

Abrams, P. A. 2008. Measuring the population-level consequences of predator-induced prey movement. Evolutionary Ecology Research 10:333-350.

Abrams, P. A., B. A. Menge, G. C. Mittelbach, D. A. Spiller, and P. Yodzis. 1996. The role of indirect effects in food webs. in G. A. Polis and K. O. Winemiller, editors. Food webs: Integration of patterns and dynamics. Chapman Hall, New York.

Abrams, P. A., and L. Rowe. 1996. The effects of predation on the age and size of maturity of prey. Evolution 50:1052-1061.

Alfaro, A. C. 2008. Diet of Littoraria scabra, while vertically migrating on mangrove trees: Gut content, fatty acid, and stable isotope analyses. Estuarine Coastal and Shelf Science 79:718-726.

Aronson, R. B., and K. L. Heck. 1995. Tethering experiments and hypothesis testing in ecology. Marine Ecology Progress Series 121:307-309.

Aronson, R. B., K. L. Heck, and J. F. Valentine. 2001. Measuring predation with tethering experiments. Marine Ecology-Progress Series 214:311-312.

Arts, M. T., M. T. Brett, and M. J. Kainz, editors. 2009. Lipids in aquatic ecosystems. Springer, New York.

Arts, M. T., and B. C. Wainman, editors. 1999. Lipids in freshwater ecosystems. Springer-Verlag, New York.

Batzer, D. P. 1998. Trophic interactions among detritus, benthic midges, and predatory fish in a freshwater marsh. Ecology 79:1688-1698.

Batzer, D. P., C. R. Pusateri, and R. Vetter. 2000. Impacts of predation on marsh invertebrates: Direct and indirect effects. Wetlands 20:307-312.

Bernot, R. J. 2003. Trematode infection alters the antipredator behavior of a pulmonate snail. Journal of the North American Benthological Society 22:241-248.

Bligh, E. G., and W. J. Dyer. 1959. A rapid method of total lipid extraction and purification. Canadian Journal of Biochemistry and Physiology 37:911-917.

Brönmark, C. 1989. Interactions between epiphytes, macrophytes and freshwater snails: A review. Journal of Molluscan Studies 55:299-311. 
Browder, J. A., P. J. Gleason, and D. R. Swift. 1994. Periphyton in the Everglades: Spatial variation, environmental correlates, and ecological implications. Pages 379-418 in S. M. Davis and J. C. Ogden, editors. Everglades: The ecosystem and its restoration. St. Lucie Press, Del Ray Beach, Florida.

Brown, J. S., and B. P. Kotler. 2004. Hazardous duty pay and the foraging cost of predation. Ecology Letters 7:999-1014.

Brown, K. M. 1982. Resource overlap and competition in pond snails: An experimental analysis. Ecology 63:412-422.

Brown, K. M., B. K. Leathers, and D. J. Minchella. 1988. Trematode prevalance and the population dynamics of freshwater pond snails. American Midland Naturalist 120:289-301.

Calow, P. 1970. Studies on the natural diet of Lymnaea pereger obtusa (Kobelt) and its possible ecological implications. Proceedings of the Malacological Society of London 39:203-215.

Calow, P., and L. J. Calow. 1975. Cellulase activity and niche separation in freshwater gastropods. Nature 255:478-480.

Carpenter, S. R., J. J. Cole, J. R. Hodgson, J. F. Kitchell, M. L. Pace, D. Bade, K. L. Cottingham, T. E. Essington, J. N. Houser, and D. E. Schindler. 2001. Trophic cascades, nutrients, and lake productivity: Whole-lake experiments. Ecological Monographs 71:163-186.

Chase, J. M. 1999. To grow or to reproduce? The role of life-history plasticity in food web dynamics. American Naturalist 154:571-586.

Chick, J. H., P. Geddes, and J. C. Trexler. 2008. Periphyton mat structure mediates trophic interactions in a subtropical marsh. Wetlands 28:378-389.

Clampitt, P. T. 1970. Comparative ecology of the snails Physa gyrina and Physa integra. Malacologia 10:113-151.

Corr, M., A. P. Covich, and T. P. Yoshino. 1984. Vertical movement and time allocation of a freshwater pulmonate snail. Hydrobiologia 112:69-72.

Crowl, T. A., and A. P. Covich. 1990. Predator-induced life-history shifts in a freshwater snail. Science 247:949-951.

Davis, S. M. 1994. Phosphorus inputs and vegetation sensitivity in the Everglades. Pages 357-378 in S. M. Davis and J. C. Ogden, editors. Everglades: The ecosystem and its restoration. St. Lucie Press, Del Ray Beach, Florida. 
DeWitt, T. J., A. Sih, and J. A. Hucko. 1999. Trait compensation and cospecialization in a freshwater snail: Size, shape and antipredator behaviour. Animal Behaviour 58:397-407.

Dorn, N. J., J. C. Trexler, and E. E. Gaiser. 2006. Exploring the role of large predators in marsh food webs: Evidence for a behaviorally-mediated trophic cascade. Hydrobiologia 569:375-386.

Dunstan, G. A., J. K. Volkman, S. M. Barrett, J. M. Leroi, and S. W. Jeffrey. 1994. Essential polyunsaturated fatty-acids from fourteen species of diatom (Bacillariophyceae). Phytochemistry 35:155-161.

Elser, J. J., J. H. Schampel, M. Kyle, J. Watts, E. W. Carson, T. E. Dowling, C. Tang, and P. D. Roopnarine. 2005. Response of grazing snails to phosphorus enrichment of modern stromatolitic microbial communities. Freshwater Biology 50:1826-1835.

Elser, J. J., R. W. Sterner, A. E. Galford, T. H. Chrzanowski, D. L. Findlay, K. H. Mills, M. J. Paterson, M. P. Stainton, and D. W. Schindler. 2000. Pelagic C:N:P stoichiometry in a eutrophied lake: Responses to a whole-lake food-web manipulation. Ecosystems 3:293-307.

Feminella, J. W., and C. P. Hawkins. 1995. Interactions between stream herbivores and periphyton: A quantitative analysis of past experiments. Journal of the North American Benthological Society 14:465-509.

Fredrickson, H. L., T. E. Cappenberg, and J. W. Deleeuw. 1986. Polar lipid ester-linked fatty-acid composition of Lake Vechten seston - An ecological application of lipid analysis. Fems Microbiology Ecology 38:381-396.

Frost, P. C., H. Hillebrand, and M. Kahlert. 2005. Low algal carbon content and its effect on the C:P stoichiometry of periphyton. Freshwater Biology 50:1800-1807.

Frost, P. C., R. S. Stelzer, G. A. Lamberti, and J. J. Elser. 2002. Ecological stoichiometry of trophic interactions in the benthos: Understanding the role of C:N:P ratios in lentic and lotic habitats. Journal of the North American Benthological Society 21:515-528.

Gaiser, E. E., J. H. Richards, J. C. Trexler, R. D. Jones, and D. L. Childers. 2006. Periphyton responses to eutrophication in the Florida Everglades: Cross-system patterns of structural and compositional change. Limnology and Oceanography 51:617-630.

Gaiser, E. E., L. J. Scinto, J. H. Richards, K. Jayachandran, D. L. Childers, J. C. Trexler, and R. D. Jones. 2004. Phosphorus in periphyton mats provides the best metric for 
detecting low-level P enrichment in an oligotrophic wetland. Water Research 38:507-516.

Gaiser, E. E., J. C. Trexler, J. H. Richards, D. L. Childers, D. Lee, A. L. Edwards, L. J. Scinto, K. Jayachandran, G. B. Noe, and R. D. Jones. 2005. Cascading ecological effects of low-level phosphorus enrichment in the Florida Everglades. Journal of Environmental Quality 34:717-723.

Gruner, D. S., J. E. Smith, E. W. Seabloom, S. A. Sandin, J. T. Ngai, H. Hillebrand, W. S. Harpole, J. J. Elser, E. E. Cleland, M. E. S. Bracken, E. T. Borer, and B. M. Bolker. 2008. A cross-system synthesis of consumer and nutrient resource control on producer biomass. Ecology Letters 11:740-755.

Hairston, N. G., F. E. Smith, and L. B. Slobodkin. 1960. Community structure, population control, and competition. American Naturalist 94:421-425.

Hill, W. R. 1992. Food limitation and interspecific competition in snail-dominated streams. Canadian Journal of Fisheries and Aquatic Sciences 49:1257-1267.

Hillebrand, H., and M. Kahlert. 2001. Effect of grazing and nutrient supply on periphyton biomass and nutrient stoichiometry in habitats of different productivity. Limnology and Oceanography 46:1881-1898.

Hillebrand, H., M. Kahlert, A. L. Haglund, U. G. Berninger, S. Nagel, and S. Wickham. 2002. Control of microbenthic communities by grazing and nutrient supply. Ecology 83:2205-2219.

Hoverman, J. T., J. R. Auld, and R. A. Relyea. 2005. Putting prey back together again, integrating predator-induced behavior, morphology, and life history. Oecologia 144:481-491.

Iverson, S. J., C. Field, W. D. Bowen, and W. Blanchard. 2004. Quantitative fatty acid signature analysis: A new method of estimating predator diets. Ecological Monographs 74:211-235.

Johnson, P. T. J., and J. M. Chase. 2004. Parasites in the food web: Linking amphibian malformations and aquatic eutrophication. Ecology Letters 7:521-526.

Jordan, F., S. Coyne, and J. C. Trexler. 1997. Sampling fishes in vegetated habitats: Effects of habitat structure on sampling characteristics of the $1-\mathrm{m}^{2}$ throw trap. Transactions of the American Fisheries Society 126:1012-1020.

Juliano, S. A. 2001. Nonlinear curve fitting. Pages 178-196 in S. M. Scheiner and J. Gurevitch, editors. Design and analysis of ecological experiments. Oxford, New York. 
King, R. S., and C. J. Richardson. 2007. Subsidy-stress response of macroinvertebrate community biomass to a phosphorus gradient in an oligotrophic wetland ecosystem. Journal of the North American Benthological Society 26:491-508.

Lau, D. C. P., K. M. Y. Leung, and D. Dudgeon. 2008a. Experimental dietary manipulations and concurrent use of assimilation-based analyses for elucidation of consumer-resource relationships in tropical streams. Marine and Freshwater Research 59:963-970.

Lau, D. C. P., K. M. Y. Leung, and D. Dudgeon. 2008b. Experimental dietary manipulations for determining the relative importance of allochthonous and autochthonous food resources in tropical streams. Freshwater Biology 53:139147.

Lima, S. L. 1998. Nonlethal effects in the ecology of predator-prey interactions - What are the ecological effects of anti-predator decision-making? Bioscience 48:25-34.

McCormick, P. V., S. Newman, S. Miao, D. E. Gawlik, and D. Marley. 2002. Effects of anthropogenic phosphorus inputs on the Everglades. Pages 83-126 in J. W. Porter and K. G. Porter, editors. The Everglades, Florida Bay, and coral reefs of the Florida Keys: An ecosystem sourcebook. CRC Press, Boca Raton.

McCormick, P. V., M. B. O'Dell, R. B. E. Shuford, J. G. Backus, and W. C. Kennedy. 2001. Periphyton responses to experimental phosphorus enrichment in a subtropical wetland. Aquatic Botany 71:119-139.

McCormick, P. V., R. B. E. Shuford, and P. S. Rawlik. 2004. Changes in macroinvertebrate community structure and function along a phosphorus gradient in the Florida Everglades. Hydrobiologia 529:113-132.

McCormick, P. V., and R. J. Stevenson. 1991. Grazer control of nutrient availability in the periphyton. Oecologia 86:287-291.

Michel, E., P. B. McIntyre, and J. Chan. 2007. A snail's space sets a snail's pace: Movement rates of Lavigeria gastropods in Lake Tanganyika, East Africa. Journal of Molluscan Studies 73:195-198.

Morales, J. B. T., and A. K. Ward. 2000. Differential incorporation of algae and bacteria by Elimia clara (Prosobranchia : Pleuroceridae) - A study using dual-labeled epilithon. Journal of the North American Benthological Society 19:289-297.

Murdoch, W. C., C. Briggs, and R. Nisbet. 2003. Consumer-resource dynamics. Princeton University Press, Princeton NJ. 
Napolitano, G. E. 1999. Fatty acids as trophic and chemical markers in freshwater ecosystems. in M. T. Arts and B. C. Wainman, editors. Lipids in freshwater ecosystems. Springer-Verlag, New York, NY.

Napolitano, G. E., W. R. Hill, J. B. Guckert, A. J. Stewart, S. C. Nold, and D. C. White. 1994. Changes in periphyton fatty-acid composition in chlorine-polluted streams. Journal of the North American Benthological Society 13:237-249.

Noe, G. B., D. L. Childers, and R. D. Jones. 2001. Phosphorus biogeochemistry and the impact of phosphorus enrichment: Why is the Everglades so unique? Ecosystems 4:603-624.

Nystrom, P., A. R. McIntosh, and M. J. Winterbourn. 2003. Top-down and bottom-up processes in grassland and forested streams. Oecologia 136:596-608.

Osenberg, C. W., and G. C. Mittelbach. 1996. The relative importance of resource limitation and predator limitation in food chains. Pages 134-148 in G. A. Polis and K. O. Winemiller, editors. Food Webs: Integration of patterns and dynamics. Chapman Hall, New York.

Peckarsky, B. L., P. A. Abrams, D. I. Bolnick, L. M. Dill, J. H. Grabowski, B. Luttbeg, J. L. Orrock, S. D. Peacor, E. L. Preisser, O. J. Schmitz, and G. C. Trussell. 2008a. Revisiting the classics: Considering nonconsumptive effects in textbook examples of predator-prey interactions. Ecology 89:2416-2425.

Peckarsky, B. L., B. L. Kerans, B. W. Taylor, and A. R. McIntosh. 2008b. Predator effects on prey population dynamics in open systems. Oecologia 156:431-440.

Peckarsky, B. L., A. R. McIntosh, B. W. Taylor, and J. Dahl. 2002. Predator chemicals induce changes in mayfly life history traits: A whole-stream manipulation. Ecology 83:612-618.

Pimentel, D., and P. C. White Jr. 1959. Biological environment and habits of Australorbis glabratus. Ecology 40:541 - 550.

Power, M. E. 1984. Depth distributions of armored catfish: Predator-induced resource avoidance. Ecology 65:523-528.

Power, M. E. 1992. Top-down and bottom-up forces in food webs: Do plants have primacy. Ecology 73:733-746.

Power, M. E., T. L. Dudley, and S. C. Cooper. 1989. Grazing catfish, fishing birds, and attached algae in a Panamanian stream. Environmental Biology of Fishes 26:285294. 
Preisser, E. L., D. I. Bolnick, and M. F. Benard. 2005. Scared to death? The effects of intimidation and consumption in predator-prey interactions. Ecology 86:501-509.

Pringle, C. M. 1990. Nutrient spatial heterogeneity - Effects on community structure, physiognomy, and diversity of stream algae. Ecology 71:905-920.

Rader, R. B., and C. J. Richardson. 1994. Response of macroinvertebrates and small fish to nutrient enrichment in the northern Everglades. Wetlands 14:134-146.

Rehage, J. S., and J. C. Trexler. 2006. Assessing the net effect of anthropogenic disturbance on aquatic communities in wetlands: Community structure relative to distance from canals. Hydrobiologia 569:359-373.

Rosemond, A. D. 1994. Multiple factors limit seasonal variation in periphyton in a forest stream. Journal of the North American Benthological Society 13:333-344.

Rosemond, A. D., P. J. Mulholland, and J. W. Elwood. 1993. Top-down and bottom-up control of stream periphyton - Effects of nutrients and herbivores. Ecology 74:1264-1280.

Ruess, L., K. Schutz, D. Haubert, M. M. Haggblom, E. Kandeler, and S. Scheu. 2005. Application of lipid analysis to understand trophic interactions in soil. Ecology 86:2075-2082.

Schmitz, O. J. 2003. Linking individual-scale trait plasticity to community dynamics. Ecology 84:1081-1082.

Schmitz, O. J., and K. B. Suttle. 2001. Effects of top predator species on direct and indirect interactions in a food web. Ecology 82:2072-2081.

Shurin, J. B., E. T. Borer, E. W. Seabloom, K. Anderson, C. A. Blanchette, B. Broitman, S. D. Cooper, and B. S. Halpern. 2002. A cross-ecosystem comparison of the strength of trophic cascades. Ecology Letters 5:785-791.

Silliman, B. R., and M. D. Bertness. 2002. A trophic cascade regulates salt marsh primary production. Proceedings of the National Academy of Sciences of the United States of America 99:10500-10505.

Silliman, B. R., and J. C. Zieman. 2001. Top-down control of Spartina alterniflora production by periwinkle grazing in a Virginia salt marsh. Ecology 82:2830-2845.

Solorzano, L., and J. H. Sharp. 1980. Determination of total dissolved phosphorus and particulate phosphorus in natural-waters. Limnology and Oceanography 25:754757. 
Sousa, W. P. 1983. Host life history and the effect of parasitic castration on growth: A field study of Cerithidea californica Haldeman (Gastropoda: Prosobranchia) and its trematode parasites. Journal of Experimental Marine Biology and Ecology 73:273-296.

Stearns, S. C., and J. C. Koella. 1986. The evolution of phenotypic plasticity in lifehistory traits - Predictions of reaction norms for age and size at maturity. Evolution 40:893-913.

Steinman, A. D., C. D. McIntire, and R. R. Lowry. 1987. Effects of herbivore type and density on chemical composition of algal assemblages in laboratory streams. Journal of the North American Benthological Society 6:189-197.

Sterner, R. W., and J. J. Elser. 2002. Ecological stoichiometry: The biology of elements from molecules to the biosphere. Princeton University Press, Princeton, New Jersey.

Taipale, S., P. Kankaala, H. Hamalainen, and R. I. Jones. 2009. Seasonal shifts in the diet of lake zooplankton revealed by phospholipid fatty acid analysis. Freshwater Biology 54:90-104.

Tilman, D. 1988. Plant strategies and the dynamics and structure of plant communities. Princeton University Press, Princeton, NJ.

Trexler, J. C., and J. Travis. 1993. Nontraditional regression analyses. Ecology 74:16291637.

Turner, A. M. 2004. Non-lethal effects of predators on prey growth rates depend on prey density and nutrient additions. Oikos 104:561-569.

Turner, A. M., R. J. Bernot, and C. M. Boes. 2000. Chemical cues modify species interactions: The ecological consequences of predator avoidance by freshwater snails. Oikos 88:148-158.

Turner, A. M., J. C. Trexler, C. F. Jordan, S. J. Slack, P. Geddes, J. H. Chick, and W. F. Loftus. 1999. Targeting ecosystem features for conservation: Standing crops in the Florida Everglades. Conservation Biology 13:898-911.

Vermeij, G. J., and J. D. Currey. 1980. Geographical variation in the strength of thaidid snail shells. Biological Bulletin 158:383-389.

Werner, E. E., and S. D. Peacor. 2003. A review of trait-mediated indirect interactions in ecological communities. Ecology 84:1083-1100. 
Werner, E. E., and S. D. Peacor. 2006. Lethal and nonlethal predator effects on an herbivore guild mediated by system productivity. Ecology 87:347-361. 
Table 4.1. Abiotic and biotic measurements (mean $\pm \mathrm{SE}$ ) for the two sites near and the two sites far from the canal taken in late June, before the experiment, and mid August, after the experiment. The marsh filled, periphyton grew, and the number of fish and invertebrates generally increased during the experiment as the wet season progressed. Snail predator density is the sum of Mayan cichlids, peninsula newts, belostomatids, leeches, crayfish, Anisoptera, and creeping water bugs. Snail mortality was assessed with tethered snails. All other parameters were quantified with $1-\mathrm{m}^{2}$ throw traps.

\begin{tabular}{lllll}
\hline & \multicolumn{2}{c}{ Near canal } & \multicolumn{2}{c}{ Far from canal } \\
Block and Parameter & \multicolumn{1}{c}{ Before } & \multicolumn{1}{c}{ After } & \multicolumn{1}{c}{ Before } & After \\
\hline Block 1 & & & & \\
Water depth $(\mathrm{cm})$ & $24.7(1.6)$ & $70.6(1.6)$ & $47(2)$ & $96.4(0.6)$ \\
Periphyton biovolume $\left(\mathrm{ml} / \mathrm{m}^{2}\right)$ & $2200(434)$ & $3171(509)$ & $4000(384)$ & $4271(611)$ \\
Stem density $\left(\right.$ no. $\left./ \mathrm{m}^{2}\right)$ & $28(3.3)$ & $23.7(2.9)$ & $29.9(4.8)$ & $37.4(7.8)$ \\
Small ${ }^{\mathrm{a}}$ fish density $\left(\mathrm{no} . / \mathrm{m}^{2}\right)$ & $8(3)$ & $15.6(2.1)$ & $13(1.3)$ & $15.3(2.5)$ \\
Invertebrate density $\left(\mathrm{no} . / \mathrm{m}^{2}\right)$ & $16.3(2.7)$ & $35.6(5.3)$ & $43.1(4.3)$ & $20.0(4.9)$ \\
$\quad$ Snail density $\left(\right.$ no. $\left./ \mathrm{m}^{2}\right)$ & $1.1(0.5)$ & $1.6(0.6)$ & 0 & $0.1(0.1)$ \\
Snail predator density $\left(\mathrm{no} . / \mathrm{m}^{2}\right)$ & $7.9(1.8)$ & $8.7(1.4)$ & $11(1.0)$ & $3.9(1.2)$ \\
Snail predation $(\%)$ & $0.15(0.03)$ & $0.28(0.03)$ & $0.09(0.04)$ & $0.2(0.05)$ \\
Block 2 & & & & \\
Water depth $(\mathrm{cm})$ & $36.1(1.6)$ & $75.9(1.6)$ & $54.9(1.2)$ & $92.3(1.8)$ \\
Periphyton biovolume $\left(\mathrm{ml}^{2} / \mathrm{m}^{2}\right)$ & $2271(435)$ & $3957(589)$ & $2914(325)$ & $5600(254)$ \\
Stem density $\left(\right.$ no. $\left./ \mathrm{m}^{2}\right)$ & $21.9(3.3)$ & $25(2.2)$ & $11.7(1.7)$ & $9.9(2.1)$ \\
Small ${ }^{a}$ fish density $\left(\mathrm{no} . / \mathrm{m}^{2}\right)$ & $16.6(2.4)$ & $31.1(5.1)$ & $12.4(3)$ & $43(4.8)$ \\
Invertebrate density $\left(\mathrm{no} . / \mathrm{m}^{2}\right)$ & $53.1(6.7)$ & $37.6(6.2)$ & $32.4(7.4)$ & $29.0(5.1)$ \\
$\quad$ Snail density $\left(\right.$ no. $\left./ \mathrm{m}^{2}\right)$ & $7.7(2.4)$ & $0.4(0.3)$ & $0.3(0.2)$ & $2.4(0.5)$ \\
Snail predator density $\left(\mathrm{no} . / \mathrm{m}^{2}\right)$ & $8.7(1.7)$ & $6.3(1.4)$ & $5.6(1.3)$ & $4.4(1.1)$ \\
Snail predation $(\%)$ & $0.20(0.03)$ & $0.12(0.08)$ & $0.13(0)$ & $0.13(0.03)$ \\
\hline
\end{tabular}

${ }^{\mathrm{a}}<8 \mathrm{~cm}$ std. length 
Table 4.2. Repeated measures analysis of variance of snail growth on local periphyton alone and with local and transplanted periphyton.

\begin{tabular}{llrrr}
\hline Variable & Effect & df & \multicolumn{1}{c}{ F } & \multicolumn{1}{c}{ P } \\
\hline Local periphyton & Day & $2,21.7$ & 114.2 & $<0.001$ \\
& Day $\times$ site & $6,7.74$ & 0.9 & 0.533 \\
& Site & $3,7.74$ & 6.5 & 0.016 \\
\hline Local and transplanted & Day & $2,41.2$ & 154.7 & $<0.001$ \\
periphyton & Day $\times$ site & $6,23.8$ & 0.4 & 0.898 \\
& Day $\times$ transplant & $2,41.2$ & 1.2 & 0.327 \\
& Day $\times$ site $\times$ transplant & $6,23.8$ & 0.8 & 0.618 \\
& Site & $3,23.8$ & 1.1 & 0.367 \\
& Transplant & $1,41.2$ & 1.0 & 0.330 \\
& Site $\times$ transplant & $3,23.8$ & 3.5 & 0.031 \\
\hline
\end{tabular}




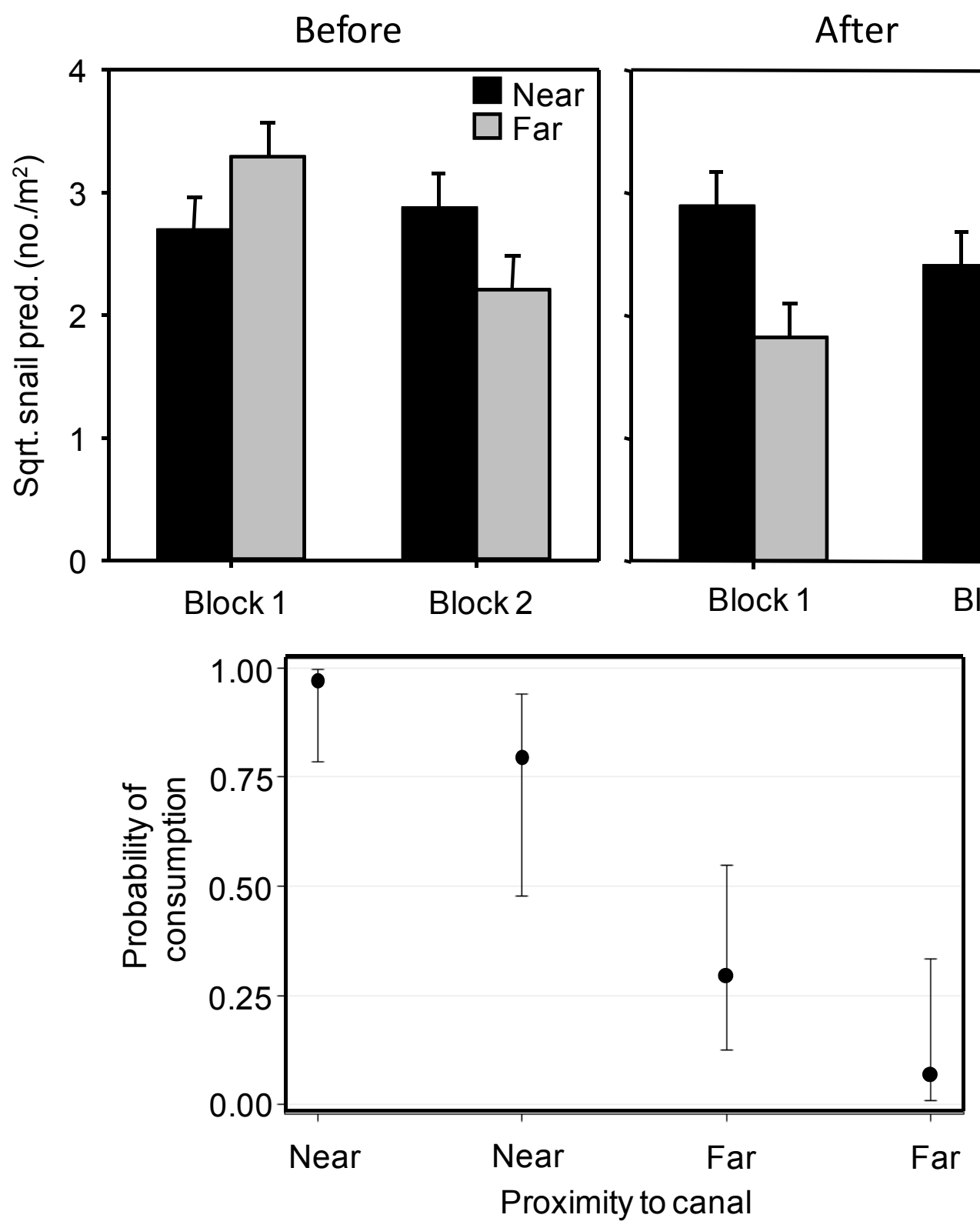

Fig 4.1. Snail predator density (least square mean \pm SE) at sites near (black) and far (grey) from the canal, top. The probability that tethered snails would be consumed by a predator, bottom. 

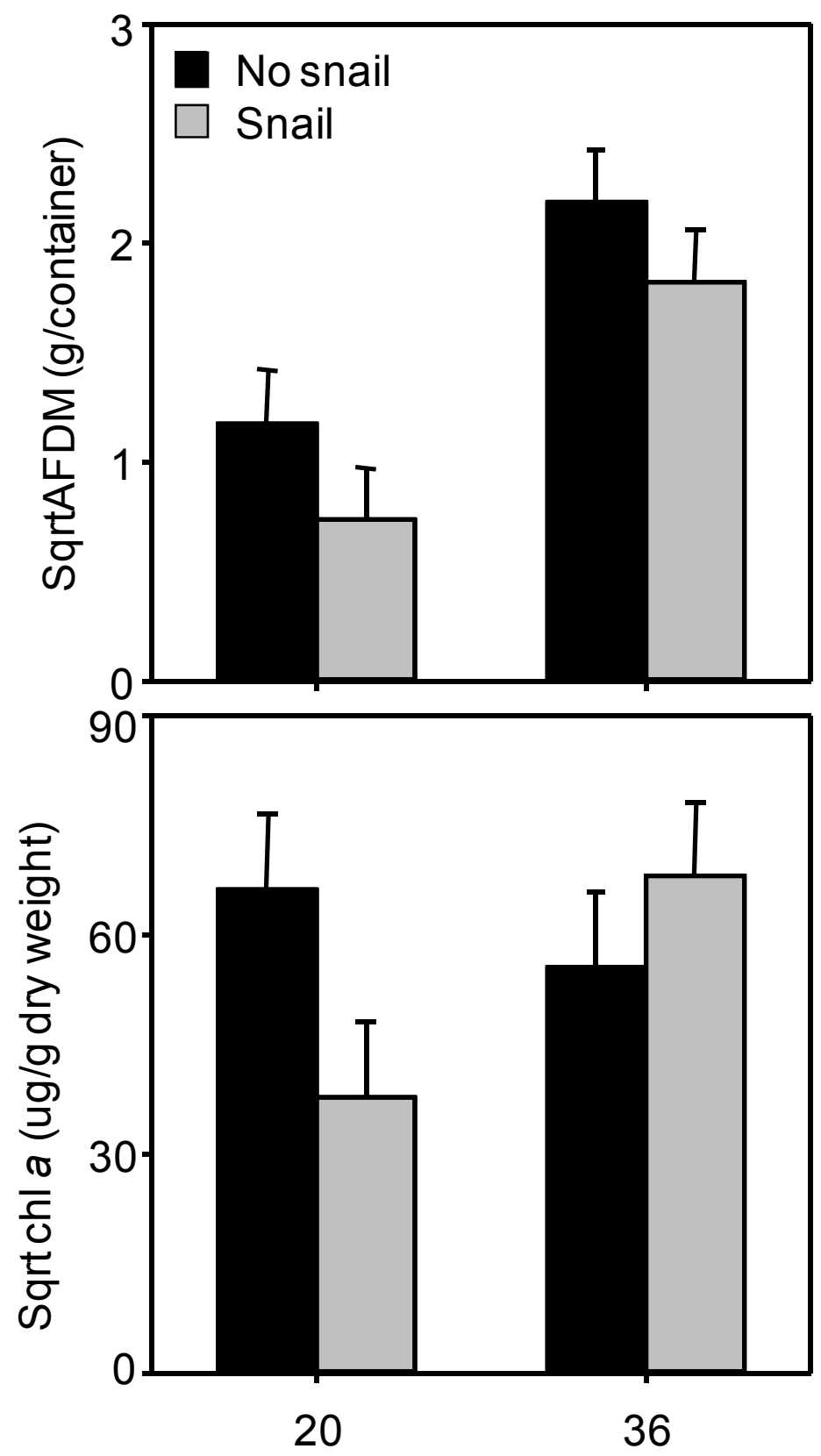

Fig 4.2. Periphyton characteristics from containers with (gray) and without (black) snails added. Periphyton ash-free dry mass, and chlorophyll $a$ values used in analysis were scaled up from sub-samples. The least-square means with standard errors are plotted. 


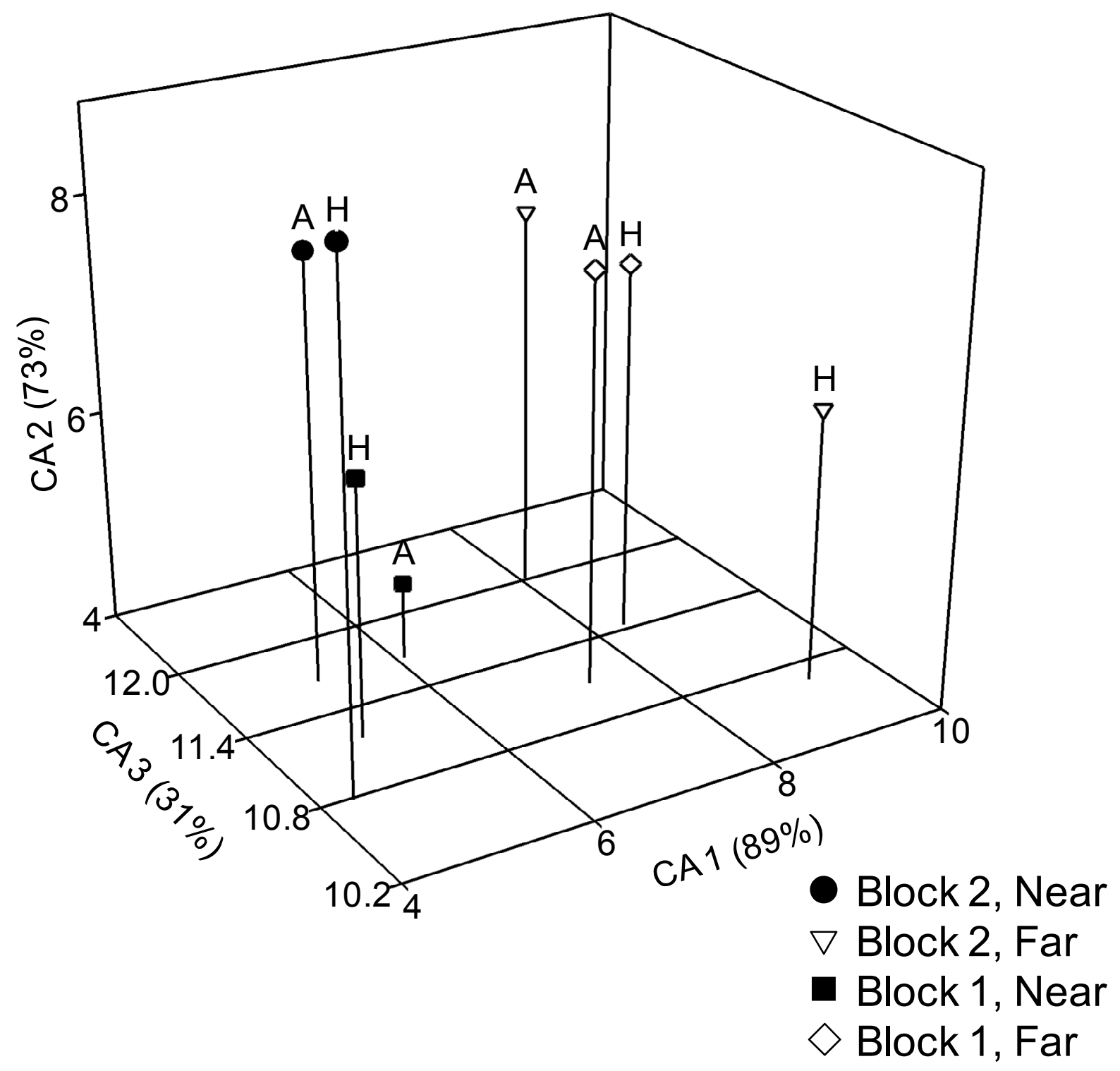

Fig 4.3. Canonical axes from the MANOVA of soft algae counts for the site-bytransplant interaction. The first axis separates sites located near (filled) compared to far (open) from the canal. Axis two largely separates blocks. Grazing did not affect algal composition. Pins are labeled to indicate periphyton held at the home site where it was collected $(\mathrm{H})$ or away site $(\mathrm{A})$ distant from where it was collected. 


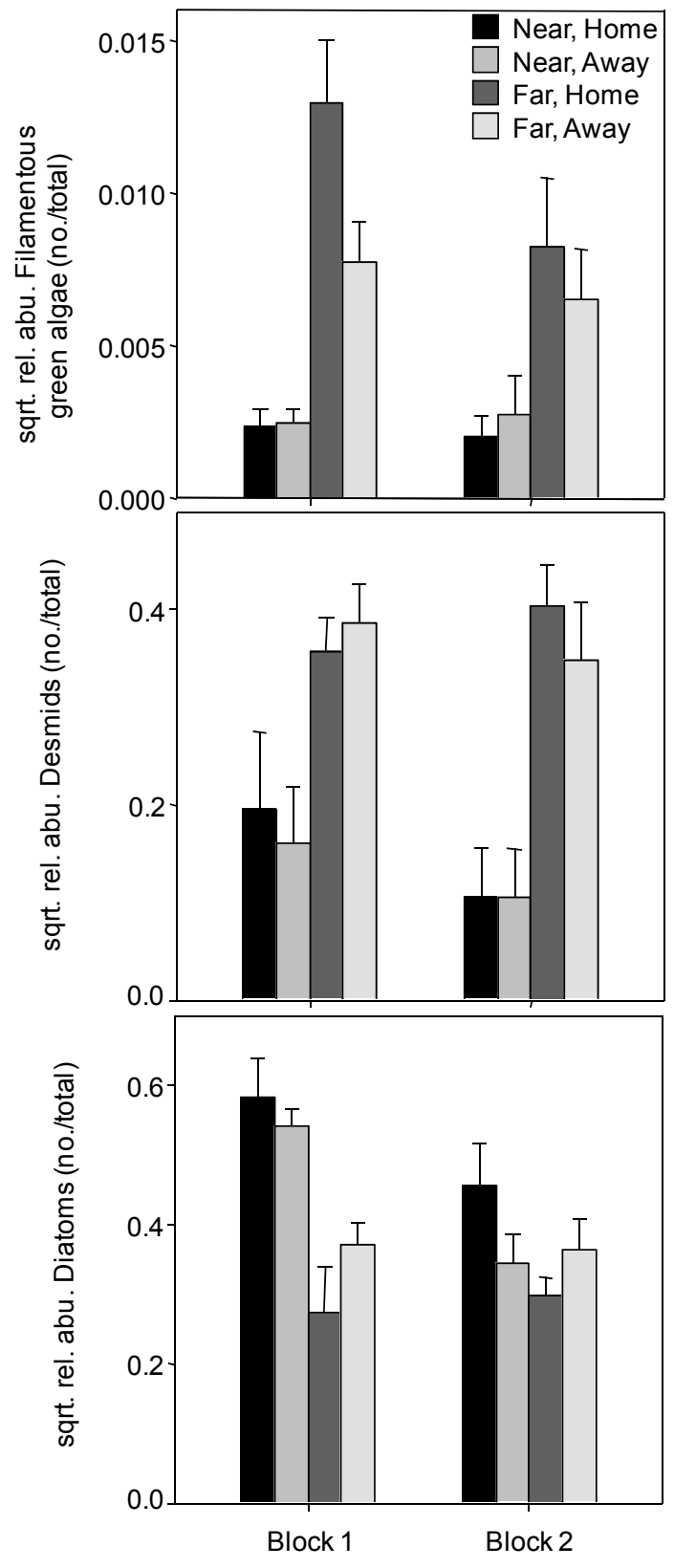

Fig 4.4. Relative abundance (mean $\pm \mathrm{SE}$ ) of soft algae groups identified by MANOVA to be different between near and far sites from a canal. 


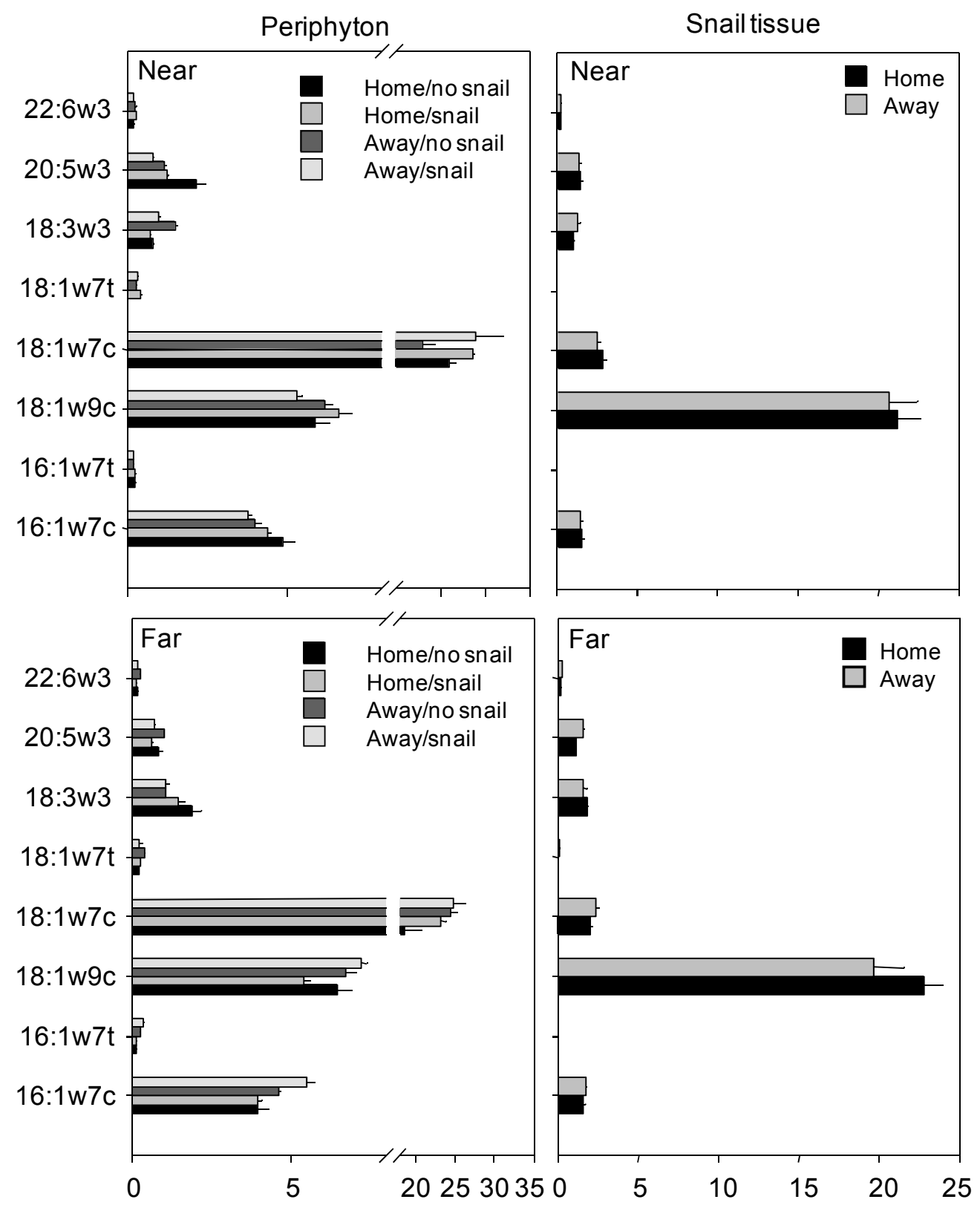

Fig 4.5. Relative abundance of periphyton and snail lipids identified as biomarkers from the second block (one near and one far site from the canal). Local periphyton (home) was placed into bags at the site; transplanted (away) was placed in bags at the opposite site. Half of the bags had snails. Note the accumulation of 18:109 in snail tissue. It has been identified as a green algae biomarker and suggests snails assimilate green algae compared to other types. 


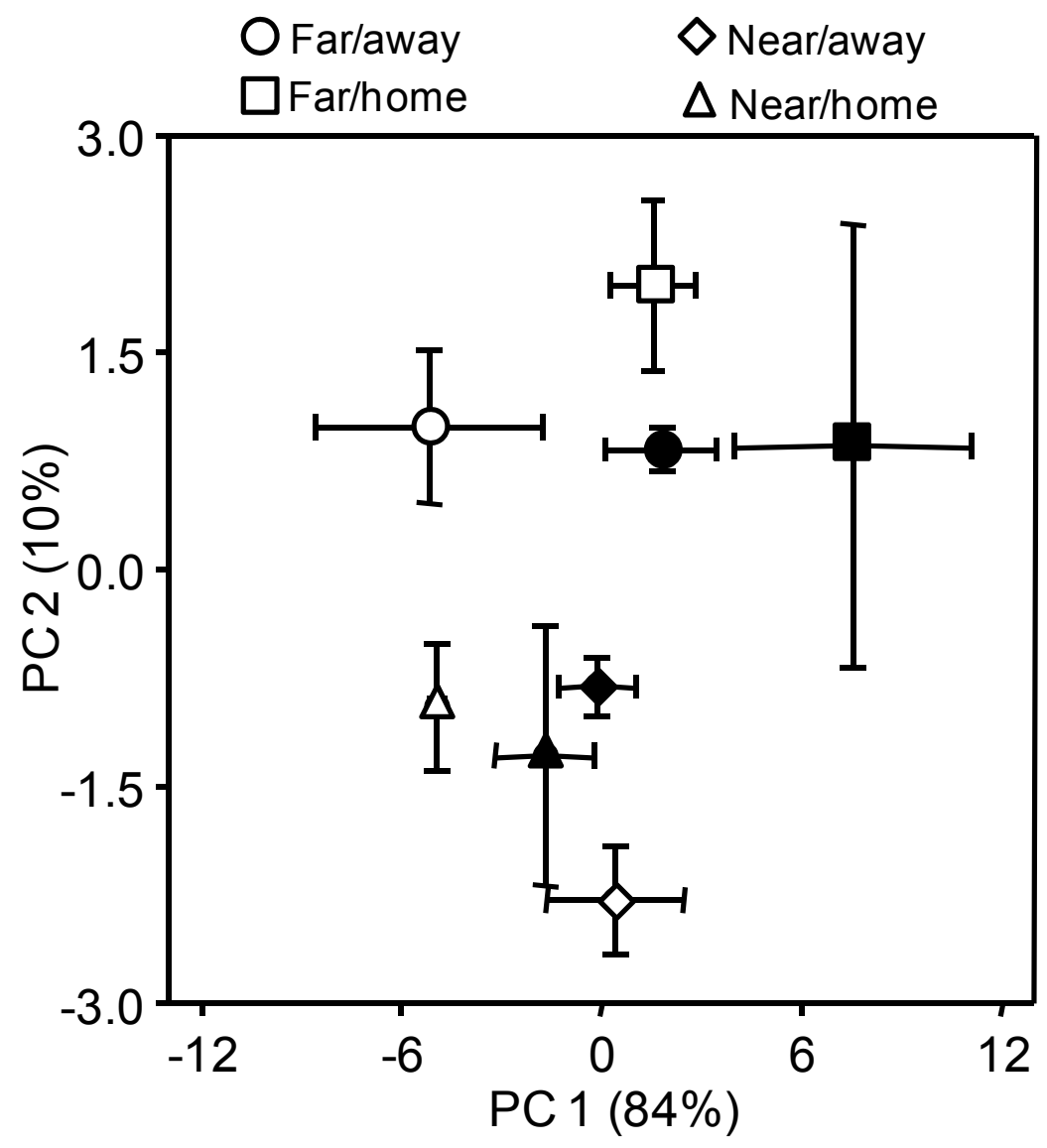

Fig 4.6. The first two principal components (mean $\pm \mathrm{SE}$ ) from an analysis on the relative abundance of lipids in periphyton that was reciprocally transplanted in experimental bags between a site near and a site far from a canal. Half of the bags received snails (open), while no snails were added to the others (filled). 


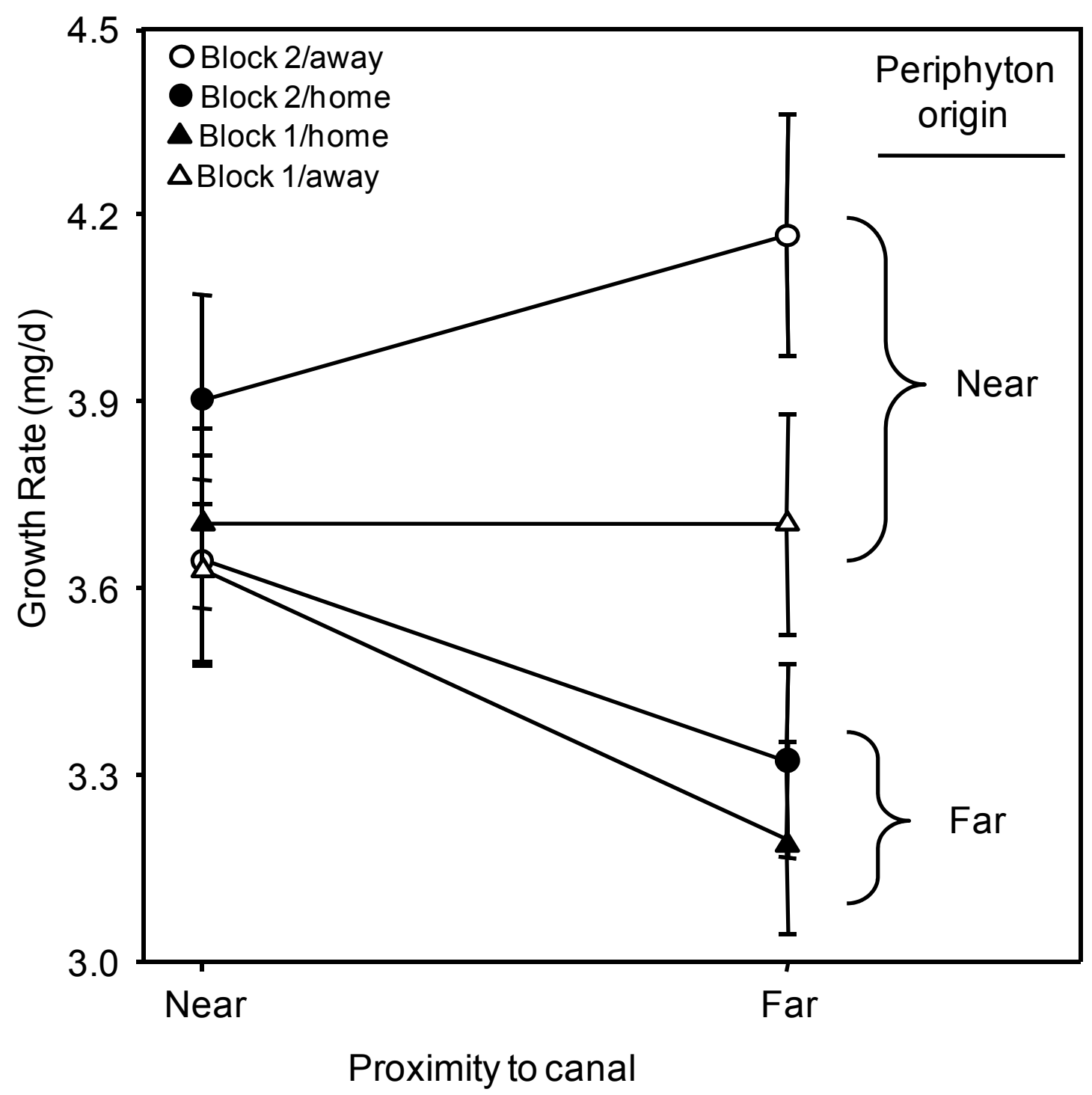

Fig 4.7. Snail growth rate (mean $\pm \mathrm{SE}$ ) near and far from a canal fed periphtyon that originated near or far from the canal and reciprocally transplanted. Lines connect local periphyton (home, filled) to transplanted periphyton (away, open). 


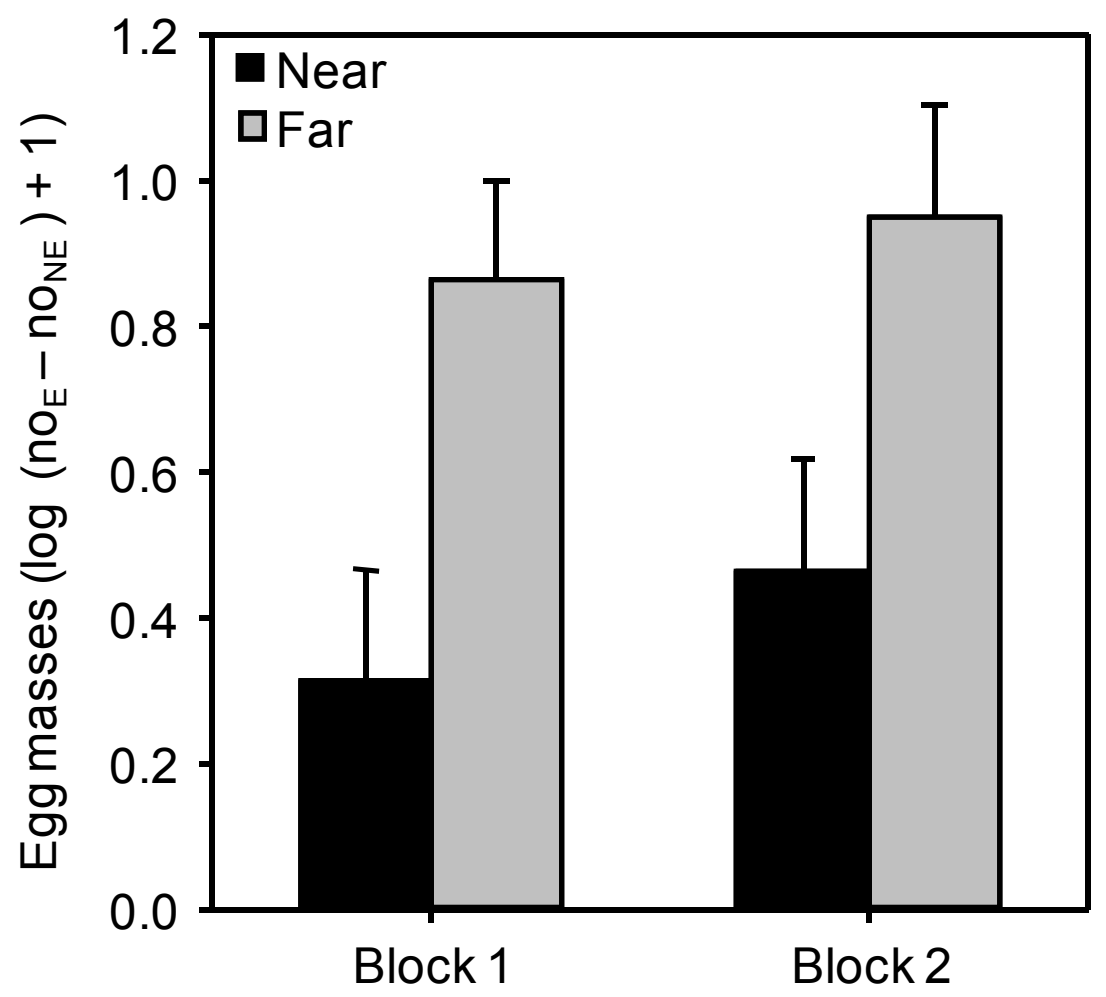

Fig 4.8. Number of egg masses on a standard substrate between sites near and far from a canal. The y-axis is the log difference between egg masses in bags with experimental snails and bags without experimental snails. More egg masses were laid far from the canal. 
CHAPTER V

BIOTIC AND ABIOTIC DRIVERS OF SNAIL POPULATION DYNAMICS IN A SEASONALLY FLOODED WETLAND 


\section{INTRODUCTION}

The predator-permanence hypothesis proposed by Wellborn et al. (1996) states that aquatic communities change along a spatial gradient of water permanence from temporary ponds and wetlands to permanent ponds and lakes because of trade-offs associated with the ability of different species to cope with abiotic and biotic factors along the gradient. Fish cannot occur in temporary ponds because they dry completely and many quickly developing invertebrates are excluded from permanent ponds because they are susceptible to piscine predators. This framework of community structure across space can be adapted to changing community structure through time at a single location when immigration of community members is considered (Tonn et al. 2004, Werner et al. 2007). Aquatic communities of seasonally flooded wetlands that are connected to permanent water bodies (e.g., flood-plain rivers, ridge and slough wetlands) may resemble ephemeral ponds immediately upon re-flooding following the dry season and permanent water bodies during the wet season because of the immigration of some taxa and the emigration of others. The return time between drying events may determine the relative similarity to permanent water bodies that these wetlands attain in the wet season (Trexler et al. 2005). The taxa that are able to persist in the midst of this variation, encounter a range of abiotic and biotic conditions seasonally. Therefore, the relative importance of exogenous and endogenous factors acting on resident populations change seasonally and must be accounted for to fully understand the controls of population fluctuations over muti-year scales.

Disturbance and the susceptibility to predation are the central abiotic and biotic drivers of community structure along the predator-permanence gradient. Predation 
replaces disturbance as the important mechanism structuring aquatic communities as pond permanence increases. Typically, traits associated with coping in temporary ponds are not the same as those enabling persistence in permanent ponds with fish predators. Species composition along the gradient is determined by trade-offs between traits that enable them to persist with each of these factors. Disturbance frequency affects population size, stability, and growth by removing biomass (Grime 1977, Sousa 1984, Grimm and Fisher 1989). Predation is an important biotic factor regulating population growth by removing organisms and altering their traits (Sih et al. 1985, Sih et al. 1998, Lima 2002, Schmitz et al. 2008). Species in aquatic ecosystems with frequent disturbances possess traits that enable them to cope with drought conditions by rapid growth and reproduction, aestivation, production of desiccation-resistant egg cases, or dispersal to other suitable habitats. Species coexisting with fish predators often possess a set of traits that enable them to complete their life cycle with predators that may include slower growth, maturing at a smaller size, and alteration of habitat use by responding to chemical cues. However, some species occur in both temporary and permanent ecosystems that require them to simultaneously cope with both situations. Persistence is accomplished by altering habitat use, developmental rates, and morphologies through phenotypic plasticity (Pigliucci 2001, DeWitt and Langerhans 2004). Disturbance and predation operate in different ways to affect population dynamics.

Freshwater snails are important components of pond, lake, stream, and many wetland ecosystems because they are primary consumers and are prey to a variety of predators (Dillon 2000). Numerous studies have examined the abiotic and biotic factors affecting their distributions in streams (Newbold et al. 1983, Hawkins and Furnish 1987, 
Rosemond et al. 1993, Hill et al. 1995, Munoz et al. 2000). Research in permanent ponds also reveal the importance of these factors on snail populations (Brown 1982, Brönmark 1985, Brown and Devries 1985, Lodge et al. 1994, Osenberg and Mittelbach 1996), but relatively few studies have considered their importance in temporary ponds and wetlands (but see Turner and Chislock 2007). The Florida Everglades is an expansive sub-tropical oligotrophic wetland with distinct wet and dry seasons (Davis and Ogden 1994). Topography varies little across the Everglades landscape, but the hydroperiod of marshes varies predictably from annual drying near the ecosystem margins to multi-year inundation in central sloughs (Davis and Ogden 1994). Throughout the Everglades, large fishes find refuge in sloughs and canals during the dry season; they disperse from these deep-water refugia with the onset of the wet season and can travel up to $20 \mathrm{~km}$ to repopulate previously dried marshes (unpublished radio-tracking data). Therefore, this ecosystem is an ideal place to test the application of the predator permanence hypothesis that is typically applied across space to a seasonal or temporal gradient of water permanence. Numerous snail species occur in the Everglades, but most are rare. Pomacea paludosa (Florida apple snail), Haitia cubensis (Carib physa), and Planorbella $s p$. are the three most abundant snails (Thompson 2004). Planorbella form a species complex in the Everglades, but Planorbella duryi (Seminole Ramshorn) is the most common species in the system. Because the Seminole Ramshorn is widely distributed in the Everglades, I use this species to examine evidence for the effects of disturbance, habitat complexity, and predation on regulating populations in the Everglades.

In this study, I use a twelve-year time series of snail density (modeled as the percapita rate of population change $r_{t}$ (Turchin 2003) and size, crayfish density, 
molluscivorous fish catch-per-unit-effort (CPUE), field mortality rate, and habitat complexity to examine the abiotic and biotic factors affecting snail populations at four sites. I further examined the potential impact of predators using laboratory foraging trials with two key predator types. Drawing from the predator permanence hypothesis, I predict that snail populations will be regulated by water depth during the dry season, and primarily by fish predators in the wet season. Crayfish, which are not as susceptible to drought as molluscivorous fish but are also omnivorous, should exhibit a negative relationship with changes in snail density and represent a chronic but small source of snail mortality throughout the year (Fig 1).

\section{METHODS}

Time series

Data Collection-Snail standing crop was collected as part of a long-term monitoring project to assess the effects of water-management changes on aquatic communities in the Everglades (Trexler et al. 2003). I chose four sites to examine snail population dynamics; sites 03 and 11 are in Water Conservation Area 3A (WCA) and sites CP and TS are in Taylor Slough (TSL) (for map see: Ruetz et al. 2005). Marshes in WCA, a management unit in the central part of the ecosystem, include areas with the longest hydroperiods of the ecosystem and relatively high phosphorous availability (Gaiser et al. 2006). In contrast, marshes in TSL, an area in southern part of the ecosystem, experience relatively shorter hydroperiods and low levels of phosphorous availability (Gaiser et al. 2006). All sites were spikerush-dominated sloughs. The four sites have similar hydroperiods despite the differences between the two regions because sites 03 and 11 occur on the western 
edge of WCA, while CP and TS are near the center of the relatively short-hydroperiod TSL. Aquatic communities at each of these sites were sampled five times a year beginning in July 1996 and ending in December 2007, representing roughly 12 water years (June - May). The five sampling events each year capture seasonal variation; July and October represent the wet season, December is a transitional period, and February and April capture the dry season. Each site was home to three plots $\left(100 \mathrm{~m}^{2}\right)$ where either 5 samples in WCA or 7 in TSL were taken during each event. Samples were taken with $1-\mathrm{m}^{2}$ throw traps (1.6 mm mesh) following standard procedures (Jordan et al. 1997). Briefly, after the trap was thrown, all emergent plants were identified and counted; periphyton bio-volume was quantified with a 2-1 graduated cylinder with drain holes; fish and invertebrates, including snails, were removed with a bar seine (1.6 $\mathrm{mm}$ mesh) until 3 consecutive passes were empty; a D-ring net $(1.2 \mathrm{~mm}$ mesh) was swept through the water column and a second net ( $4.8 \mathrm{~mm}$ mesh) was scraped across the benthos until 5 passes of each net were empty. Organisms were anesthetized with MS-222, preserved in 10\% formalin and stored in $70 \%$ ethanol. Snail standing crop was estimated by measuring the shell length of each snail collected at each site during the twelve years and converting that to wet tissue mass with locally derived length to mass relationships (Obaza and Ruehl unpublished data). The average snail standing crop among traps at each plot served as the unit of observation.

Data Analysis-As may be expected in a 12-year study, some missing data were encountered at each site. For example, sampling was discontinued at site 11 in 2007 because vegetation became too dense to sample, so I used previous trends at the site to interpret events occurring in 2007. All sites dried multiple times during the twelve-year 
period. Sites were not sampled in periods when water depths were less than 5 -cm and represent missing values in the dataset. Sampling gaps during the dry season primarily occurred in April and July at all sites.

To determine the effects of water permanence, habitat complexity, and crayfish predators on snail density, I asked three questions: how does snail density respond to hydrologic variation; does habitat complexity contribute to explaining variation in snail density, and what is the relationship between snail density and the density of a known molluscivore, the crayfish? In all time-series models, I used the per capita realized population change $\left(\mathrm{r}_{\mathrm{t}}\right)$ as the response variable, which was calculated as $\log \left(\mathrm{N}_{\mathrm{t}} / \mathrm{N}_{\mathrm{t}-1}\right)$, where $\mathrm{N}_{\mathrm{t}}$ is the population density in the current time step and $\mathrm{N}_{\mathrm{t}-1}$ is the population density in the previous time step. Using $r_{t}$ as the dependent variable simplifies model complexity because it accounts for autocorrelation in the time-series (Turchin 2003). I modeled the data in three hierarchical steps to evaluate information from the time series relevant to these questions. Because hydrologic variation is the most important abiotic driver in the Everglades, I considered it in the first step with eight models that contained different combinations of water depth, change in water depth $\left(\mathrm{WD}_{t} / \mathrm{WD}_{\mathrm{t}-1}\right)$, lag water depth $\left(\mathrm{WD}_{\mathrm{t}-1}\right)$, days since a site was last dry (DSD), and $\mathrm{DSD}^{2}$. The second step involved taking the best model from the first step and adding different variables that described habitat complexity with three additional models that included stem density, periphyton volume, and the two combined. In the third step I took the best model from step two and added various combinations of lag snail density $(\mathrm{t}-1)$, and lag snail size $(\mathrm{t}$ $-1)$, and lag crayfish density $(\mathrm{t}-1)$. 
I used a model selection approach that compared Akaike's Information Criterion (AIC) to choose the best model in each step; models with the lowest AIC are considered preferred because they capture greater amounts of information in the data than those with large AIC values (Anderson 2008). Models differing in AIC values by $\leq 2$ were considered to capture similar amounts of information, while models with AIC $>2$ or larger than the best model were considered to capture less information.

I used the change in water depth between time steps to model recession or flooding of the marsh; lag water depth modeled the effect of the prior water depth on the change in snail density between time steps. The DSD modeled complete drying of the site and I included a quadratic term for DSD because it spans years and likely exhibits nonlinear dynamics with the dependent variable. Aquatic vegetation and periphyton provide refuge and resources for snails. Periphyton in the Everglades often forms thick floating mats in association with bladderworts (Utricularia spp.) as well as forming around stems of emergent aquatic vegetation. They each represent complex structure that I quantify as habitat complexity. Both of these variables were log transformed for normality. Lag snail density tested for negative density dependence, while lag snail size modeled the effect of body size on the change in snail density. There are two species of crayfish in the Everglades. The Everglades crayfish (Procambarus alleni) is more common in frequently drying marshes and Slough Crayfish (Procambarus fallax) is more common in deeper marshes and sloughs (Dorn and Trexler 2007, Dorn and Volin 2009). I combined both species into a single variable because performance trials indicated they had similar effects on snails and I was interested in the net effect of crayfish on snails. I modeled the effects of crayfish predation with lag crayfish density, which examines the relationship 
between crayfish density in the prior time step and the change in snail density. Crayfish density was log transformed to correct for over-dispersion.

I reported the parameter estimates and standard errors $(\beta \pm$ S.E. $)$, the standardized $\beta$ weights, the squared semi-partial correlation, and the adjusted $\mathrm{R}^{2}$ for the final model at each site. The standardized $\beta$ weights are parameter estimates that are adjusted by their standard deviation and provide a weighted effect size for each parameter (Tabachnick and Fidell 2007). The squared semi-partial correlation relates the amount of variation explained by the whole model to each parameter. The adjusted $\mathrm{R}^{2}$ reports the amount of variation in the dependent variable that is explained by the total model and adjusted for model complexity.

\section{Large molluscivorous fish}

Data Collection—Redear sunfish and Mayan cichlids are the primary molluscivorous fishes in the Everglades. Large fish (>8-cm standard length) are present at low density in the Everglades (Chick et al. 2004), but could influence snail population dynamics if they can consume large numbers of snails in short periods of time (Lodge et al. 1987, Huckins 1997). I addressed the potential for large redear sunfish and Mayan cichlids $(>8-\mathrm{cm}$ standard length) to affect snail density with time-series data from airboat-mounted electrofishing (Chick et al. 1999). Catch per unit effort (CPUE) of large fishes was collected from 1997 - 2007 at three of the four sites with three, 5-min (pedal time) transects near the three throw-trap plots roughly around the same time as throw-trap samples were collected (for detailed methods see Chick et al. 1999, Chick et al. 2004). 
Data Analysis - Because large fish are rare in the Everglades, I created a presenceabsence variable and used logistic regression to model the probability of large fish occurrence within each region (i.e., TSL, WCA). I tested for effects of year, season,

year-by-season, water depth, DSD, $\mathrm{DSD}^{2}$ and used model selection to determine the best model from the set for each region.

\section{Tethering experiment}

Data Collection- I conducted snail tethering experiments at TS, CP, 03, and 11 for each sampling event during 2007 to estimate the relative rate of predation across space and seasons. At each site during each event, twenty adult snails (9-14 $\mathrm{mm}$, shell length) were tethered to individual PVC stakes spaced 3 meters apart. Tethers were arranged in two blocks with a 1-m length of 6-1b monofilament; snails were attached to the end of the monofilament with cyanoacrylic adhesive that was applied to their shell. Tethers allowed snails to move freely, feed on periphyton, and gave them the opportunity to hide. I controlled for the negative effects of handling, abiotic factors (e.g., low DO) at each site, and the possibility of escape by tethering 4 snails in a $1-\mathrm{m}^{2}$ cage in each block. There was no mortality for snails tethered inside cages, although a strong wind storm flipped one cage during one event, all but one snail was still attached to their tether in the flipped cage. Experiments were scored after 4 days and the mode of predation was determined by examining shell remains at the end of tethers. Shell fragments indicated a crushing predator like a fish consumed the snail, while an empty shell revealed that an entry based predator like a crayfish or a belostomatid consumed the snail (Fig 2). If the snail was 
gone from the tether it was removed from all analyses because I was specifically interested in estimating predation rate by mode of predation.

Data Analysis-Site 11 and site 03 were too shallow to sample in April and site 11 remained too dry in July to sample. Since this analysis was for only one year, idiosyncrasies among sites could more easily be interpreted than in the time series study; therefore, spatial and seasonal variation were included in a single statistical model. I used logistic regression to separately model the probability that snails were consumed in each region, sites nested within regions, seasons (i.e., sampling events), water depth, tethered-snail size, and the associated interactions. Similar to the time series, model selection was used to find the best model out of the set.

\section{Consumption rate trials}

Data collection-To determine the potential effect of entry (crayfish) versus crushing (fish) predators on snail densities, I quantified the maximum amount of snail biomass different individuals of a single fish species and two crayfish species could consume in twenty four hours. I chose to use Mayan cichlids because they are introduced, they are more numerous than redear sunfish, and relatively little is known about their feeding ecology. With hook and line, I collected ten Mayan cichlids from the Everglades that ranged in size from 10 to $20 \mathrm{~cm}$ standard length. These fish were transported and held until trials began at the Daniel Beard Research Center in Everglades National Park in 2.2 $\times 1 \times 1 \mathrm{~m}(\mathrm{~L} \times \mathrm{W} \times \mathrm{H})$ concrete mesocosms that were filled to a depth of $30 \mathrm{~cm}(660 \mathrm{l})$ with well water and covered with $50 \%$ shade cloth. Fish were starved for 24-hours before each trial to provide consistent responses and similar motivation to feed. For fish 
smaller than $15-\mathrm{cm}$ standard length $(\mathrm{n}=5), 30$ snails of a known size $(6-13 \mathrm{~mm}$ shell length) were stocked into each mesocosm and given a day to acclimate after which fish were added and allowed to eat snails for 24 hours. Sixty snails (6-13 mm shell length) were stocked into tanks with fish that were larger than $15 \mathrm{~cm}(\mathrm{n}=5)$. The next day, fish were removed and the snails that remained alive were measured; snail biomass consumed was calculated as the difference.

Crayfish consumption rates were estimated for both species in outdoor mesocosm trays $(88 \times 42 \times 15 \mathrm{~cm}, \mathrm{~L} \times \mathrm{W} \times \mathrm{H})$ that were filled to a depth of $10 \mathrm{~cm}$ with $\mathrm{RO}$ water and covered with fiberglass window screen. I collected seventeen Slough $(17-31 \mathrm{~mm}$ carapace length) and twenty-eight Everglades Crayfish (14 - $38 \mathrm{~mm}$ carapace length) for these trials. After experimental trays were filled with water, ten snails ranging in size from $4-9 \mathrm{~mm}$ were added and allowed to acclimate for three hours, after which crayfish were added and allowed to feed for twenty-four hours. Similar to fish trials, the surviving snails were measured and the amount of snail biomass consumed was calculated as the difference between initial biomass and final biomass.

Data Analysis-I examined crayfish consumption rates using regression with the expectation that larger individuals would consume more snail biomass than smaller individuals. The amount of snail biomass consumed for each trial was calculated as the difference between the initial tank biomass and the live snail biomass remaining after twenty four hours. Snail biomass consumed and fish or crayfish size were log transformed to normalize data. 


\section{Handling time trials}

Data Collection-I examined the potential for a snail size refuge from entry-based and crushing predators by measuring the time-to-consumption of snails ranging from 2 to 22-mm shell length for fish and 4 to 14-mm shell length for crayfish by different sized

fish and crayfish. I used seven of the ten Mayan cichlids from the consumption rate trials that ranged in size from $10-20 \mathrm{~cm}$ standard length and ran from 23 to 61 trials per fish. Fish trials were conducted by presenting a snail of known size to a fish, noting the time the fish ingested the snail, and noting the amount of time that passed until the fish swallowed the snail tissue. Typically, fish would crush the snail, swallow the tissue and expel shell fragments from the mouth. With relatively large snails, fish would gradually crack the shell and expel fragments piece-meal until the integrity of the shell was compromised. Occasionally, and especially with large snails, fish would repeatedly reject the snail; if the fish rejected the snail and did not return to it after 3 minutes the trial was stopped and the snail was removed.

Crayfish handling time trials were conducted with a video camera (Sony DCR-SR 100) because preliminary trials indicated they altered their behavior in the presence of an observer. I used 24 Everglades Crayfish and 11 Slough Crayfish; between 5 and 13 trials were run per crayfish. More crayfish were used with fewer trials because preliminary trials revealed substantial variation among individuals in their propensity to consume snails. For each trial, a single snail of known size was placed into an 18-1 aquarium without substrate and filled to a depth of $8-\mathrm{cm}$ with RO water. The aquarium was placed on a stand above the video camera. After the snail acclimated ( $1-5$ minutes), a crayfish was introduced to the tank and the camera was set to record. Crayfish trials lasted for 
two hours. The position of the camera below the aquarium allowed me to consistently observe snail consumption. I scored these trials by noting the time on the video recorder when the crayfish attacked the snail and again when the empty shell was discarded. Often, crayfish would discard the live snail multiple times before eventually consuming or rejecting it. They spent considerable time handling the live snails while moving around the aquarium. I scored these events as part of handling time because they had possession of the snail.

Data Analysis_-Fish handling time was quantified with exponential models where shell length was used to predict handling time for each fish. The inflection of the exponential curve indicated the snail size refuge. Crayfish handling times were modeled with logistic regression to determine the snail size refuge because the relationship between snail size and handling time was not continuous; snails were either consumed or not regardless of crayfish size. I tested for effects of log shell length and crayfish identity. Shell length was transformed to meet assumptions of normality.

\section{RESULTS}

\section{Population dynamics}

There was substantial spatial and temporal variation in snail density, crayfish density, and water depth during the twelve-year study at all four sites. Snail density and crayfish density tended to be higher at sites in WCA than sites in TSL (Fig 3). Peaks in snail and crayfish density were much higher at site 03 and site 11 than site TSL and site CP. Both snails and crayfish recovered quickly after sites dried completely. Seasonal trends in crayfish density, snail density, and body size emerge after averaging across years (Fig. 4 
A -C). During the early wet season (July), snail densities were low and consisted primarily of large individuals; these were replaced by more numerous small individuals by December, and populations consisted of many large individuals by April.

Comparatively, there was much less seasonal variation in periphyton volume and stem density, but there was distinct spatial variation; stem density was much higher at site 11 and periphyton volume was greater in TSL (Fig $5 \mathrm{~A}-\mathrm{C}$ ). There was consistent variation in water depth among sites and years. Water depth was much greater in the wet season (July - December) and gradually declined during the dry season (February - April).

Change in water depth was retained in the most parsimonious models for predicting the change in snail density at the four sites; the final model for site 03 also contained lag water depth. Model fit with these variables was considerably better with this variable compared to DSD for sites in WCA (Table 1) and TSL (Table 2). When habitat complexity was added to the final depth model, periphyton volume emerged as the best predictor at site 03 and TS, while stem density predicted the change in snail density better than periphyton volume at site 11 and $\mathrm{CP}$. Adding biotic variables to the best abiotic models improved fit considerably. Snail density in the previous time step was the best predictor of snail density change between time steps for all sites. Among the biotic variables considered, snail density in the previous time step (lag snail density) and body size in the previous time step (lag size) was included in the final model for every site. Lag crayfish density was included in the final model at site 03 .

Parameter estimates from the final models for each site revealed the magnitude and direction of relationships between the independent variables and the dependent variable. Change in water depth was inversely correlated with the change in snail density at all 
sites; the rate of snail-density change increased with decreasing changes in water depth (Table 3, Fig 6). Stem density was negatively correlated with the change in snail density at 11 and CP. Periphyton volume was negatively associated with snail density change at TS; the relationship was positive at site 03 . However, none of the correlations between snail density change and habitat complexity were very strong (Table 3 ). Per capita change in snail density was negatively correlated with snail density at the previous time at all sites, indicating negative density dependence. Crayfish density in the prior step was also negatively correlated with the change in snail density at site 03 , but not at the other three sites (Fig 6).

Large molluscivorous fish were sparsely distributed in the marshes of the Everglades. A total of 41 such fish were caught at CP and TS in TSL over the 11 year period, while 16 were caught at site 03 in WCA during that time. Water depth was the single best indicator of large fish presence in the marshes surrounding 03 in WCA (Table 4). Similarly, water depth and year were the best predictors of encountering a molluscivore in TSL out of the plausible models I examined. In both regions, the probability of encountering large molluscivores increased with increasing water depth (Fig 7). Although sampling period was not included in the final models for either region, marshes are deepest during the wet season suggesting that molluscivorous fishes are more numerous in the marshes in the wet season.

\section{Field Mortality Rates}

A total of 115 out of 389 tethered snails were consumed during the year and mortality ranged from 1 to $20 \%$ per day among the four sites across the five sampling periods. The 
most parsimonious logistic regression model contained sampling period as the best predictor of snail mortality (Table 5). Snails had a higher probability of being consumed during the wet season in July and October than in dry season sampling periods (Fig 8A). Among the 115 snails that were eaten, 75 were consumed by entry based predators and 40 were consumed by crushing predators. Water depth was the only independent variable in the final model from the set used to predict the mode of predation. The probability of being consumed by a crushing predator increased with increasing water depth (Fig 8B).

\section{Snail Consumption Rates}

Both fish and crayfish consumed snails. I found that smaller Mayan cichlids (10 - 14 cm standard length) consumed between 1 and 7 snails $(0.1-0.6 \mathrm{~g}$ wet tissue) in a twentyfour hour period, while larger fish (16 - $21 \mathrm{~cm}$ standard length) consumed substantially more. They ate between 15 and 59 snails $(1.8-6.8 \mathrm{~g}$ wet tissue) over the same period. There was a strong positive log-linear relationship between fish length and snail biomass consumed (Fig 9A). Among the 45 crayfish I surveyed, both species displayed similar propensities to consume snails ( $\mathrm{DF}=1, \chi^{2}=0.3, \mathrm{P}=0.61$ ). However, only $40 \%$ of the Everglades and $47 \%$ of the Slough Crayfish consumed snails. For the crayfish that did eat snails, they consumed much smaller numbers of snails than Mayan cichlids, between 0 and 2 snails $(0-0.2 \mathrm{~g}$ wet tissue) during a twenty four period. Further, there was no relationship with the amount of snail tissue consumed and crayfish carapace length (Fig 9B). 


\section{Predator Handling Time}

Large Mayan cichlids (19-21 cm standard length) consumed the largest snails we could find to offer them, although it sometimes took them considerably longer to crush the shell and consume the tissue of these large snails compared to relatively smaller ones (Fig 10). Smaller fish (14 and $17 \mathrm{~cm}$ standard length) could not consume snails larger than 16 or $17 \mathrm{~mm}$, while the smallest fish we tested $(10$ and $12 \mathrm{~cm})$ could not consume snails larger than $10 \mathrm{~mm}$. Interestingly, individual fish varied in their giving-up time. For example, the $14-\mathrm{cm}$ fish I tested took nearly 30 minutes to consume a $16 \mathrm{~mm}$ snail, while most other fish gave up after several attempts at crushing a large snail for their size. Crayfish did not exhibit much variation in handling time despite testing a range of sizes for both species (Everglades: 15 - $34 \mathrm{~mm}$, Slough $19-31 \mathrm{~mm}$ carapace width). Time to consumption for Everglades crayfish varied from 350 to 9,800 seconds (mean =2,290.6 \pm 346.9 mean \pm SE); Slough Crayfish varied between 171 and 10,742 seconds (mean $=$ $2,556.5 \pm 504.7)$. Although there was no relationship between crayfish size and handling time, I took another approach for determining a snail size refuge from crayfish. I created a binary variable for whether a snail was consumed. The results of this logistic regression revealed that the probability of consumption was greater for smaller snails (DF $=1$, Wald $\left.\chi^{2}=4.2, \mathrm{P}=0.04\right)$. Individuals of both species consumed relatively large snails $($ Everglades $=12.5$, Slough $=12.2 \mathrm{~mm})$, but the mean size consumed was considerably smaller $($ Everglades $=7.3 \pm 0.2$, Slough $=7.7 \pm 0.3)$. Therefore, snails larger than $10 \mathrm{~mm}$ were too large for crayfish to consume, and many snails larger than 8 $\mathrm{mm}$ were not consumable by most crayfish. 


\section{DISCUSSION}

Snail populations at the four sites exhibited substantial evidence of regulation during the 12-year period. Consideration of a variety of abiotic and biotic factors revealed that no single factor explained population regulation, although prior snail density was the strongest predictor of the rate of population change, followed by changes in water depth. Most interestingly, at one of the four study sites I found a negative correlation between prior crayfish density and the per-capita rate of snail density change indicating that crayfish negatively affect snail density at site 03 . Although large molluscivorous fishes were too sparse to include as an independent variable and formally test for their relationship with snail density change, feeding studies demonstrated their potential to consume numerous snails when they frequent shallow marshes during the wet season.

Disturbance, defined here as the removal of biomass (Grime 1977), has profound effects on the size, growth, and stability of populations (Sousa 1984, Grimm and Fisher 1989). Time since disturbance is a widely used variable for quantifying population or community response to a disturbance event (Noble and Slatyer 1980, Grimm and Fisher 1989). Drying events are common disturbances in wetlands that reset populations of aquatic organisms to varying degrees, depending on the length of the disturbance. Recently flooded marshes are quickly colonized by individuals that emerge from aestivation, hatch from desiccation resistant egg cases, or migrate from surrounding marshes that remained flooded. Days-since-dry, a measure that describes fluctuations in small fish populations in the Everglades (Ruetz et al. 2005, Trexler et al. 2005) did not account for changing snail densities suggesting that drying events did not severely limit snail populations. However, evidence from seasonal variation in snail densities and body 
size indicated that the dry season did affect snail populations; they emerged from the driest months (May and June) at much lower densities, but with a similar size structure. Many species of snails, including species in the Planorbidae, survive drying events by aestivating (Pimentel and White Jr. 1959, Boss 1974, Heeg 1977, Fretter and Peake 1979). This life history trait could explain the observed pattern. The relatively few large individuals present after the dry season were likely those that were successful at aestivation although there is no formal link between aestivation success and body size. The change in water depth was a better indicator of snail density change than time since re-flooding. Water depth was negatively correlated with snail per capita population growth; increasing water depths resulted in decreasing snail densities. Such a pattern could emerge from populations that are alternately diluted and concentrated as the spatial extent of the marsh changes with water depth. This explanation would require that sampling plots were located in locally deep areas where snails concentrated or that trap sampling efficiency changes non-linearly with water depth changes. Sampling plots within a site are randomly arranged with respect to local topography and sampling bias does not appear likely because methodological studies with this sampling protocol indicate it is robust to sampling bias associated with water depth in the spike-rush dominated marshes where samples were collected (Jordan et al. 1997, Turner and Trexler 1997, Dorn et al. 2005). One alternative explanation is that decreasing water depths positively affect snail population growth by decreasing the effects of biotic interactions present during the wet season.

The strongest predictor of snail density change at all sites was prior snail density, suggesting that self-limiting processes for resources account for much of the observed 
regulation. Competition for resources is one mechanism that might explain this phenomenon. Snail species often compete in small headwater streams where grazer biomass is high and periphyton production is low from a combination of grazing, light limitation, and resource limitation (Hawkins and Furnish 1987, Hill 1992). Nutrient additions in small streams often have strong effects on snail growth, periphyton composition, and competitive interactions (Hill 1992, Rosemond et al. 1993). The Everglades has the opposite situation in regards to trophic structure; it supports high levels of periphyton production but low grazer densities (Browder et al. 1994, Turner et al. 1999, Gaiser et al. 2005, Liston and Trexler 2005). The two ecosystems share a response to nutrient additions; phosphorous enrichment in the Everglades increases resource quality that leads to increases in consumer density and biomass of many taxa (Turner et al. 1999). Experiments with snails and periphyton in the Everglades reveal interplay between periphyton quality and threats of predation on snail growth and reproduction, but these traits were unaffected by density manipulations (CBR unpublished data). These experimental results suggest snail populations are limited by resource quality and predator effects (consumptive and non-consumptive). The longterm sampling protocol reported in this study does not include direct measurements of resource quality at each site. However, other research demonstrates a north-to-south gradient of phosphorous enrichment in the Everglades that alters the composition and chlorophyll $a$ content of periphyton (Gaiser et al. 2006). Site 03 and 11 in WCA, the more phosphorous enriched region in the middle of the ecosystem, had higher peak densities and consistently higher densities than sites in the relatively phosphorous poor TSL region to the south, suggesting that many parts of the system cannot support large 
populations of grazers because resources are of poor quality. Within WCA, site 03 supported a larger population than site 11, which may result from disturbance events negatively affecting snail survival because drying events are more frequent and longer lasting at 11 than they are at site 03 . Therefore, at the landscape scale, phosphorous enrichment appears to have positive effects on snail population growth for at least one site. Interestingly, this was also the site where changes in snail density were negatively correlated with crayfish density in the prior time step suggesting that crayfish have the potential to regulate snail population dynamics at site 03 .

Predation is an important biotic factor regulating populations in many ecosystems (Brown and Devries 1985, Sih et al. 1985, Sih et al. 1998, Lima 2002, Turner and Chislock 2007, Schmitz et al. 2008, Wirsing et al. 2008). The importance of predation in shaping wetland aquatic communities and affecting prey populations in wetlands has received attention recently (Batzer and Resh 1991, Batzer 1998, Batzer et al. 2000, Dorn et al. 2006, Chick et al. 2008). However, few studies have considered the importance of molluscivores limiting snail populations in wetlands. Insight on their potential role can be gained by drawing upon prior accounts of snail predators that occur in wetlands and recent research in temporary ponds.

Snails are consumed by a variety of vertebrate and invertebrate predators including sciomyzid flies, leeches, dytiscid beetles, belostomatid bugs, odonates, crayfish, and fish (Eisenberg 1966, Eckbald 1976, Rowe 1987, Weber and Lodge 1990, Brönmark 1992, Mittelbach et al. 1992, Huckins 1997). Among these, fish and crayfish are capable of consuming a large number of snails ( $>100)$ daily (Lodge et al. 1987). However, crayfish in the Everglades consume between 1 and 2 juvenile snails $(<10 \mathrm{~mm})$ daily; the disparity 
is likely because the crayfish species in the Everglades are comparatively small. Redear sunfish specialize on snails and fish collected from Midwestern ponds contained between 0 and $20 \mathrm{mg}$ of snail tissue in their stomachs (Huckins et al. 2000). In a survey, an adult redear $(15.5 \mathrm{~cm}$ standard length) from the Everglades consumed many juvenile and adult snails up to $18 \mathrm{~mm}$ (CBR unpublished data). I conducted extensive performance trials with Mayan cichlids because little is known about their potential to alter community and population structure in the Everglades where they are introduced. They are omnivorous throughout their native (Mexico and Central America) and introduced range (South Florida); populations in South Florida include a considerable number of snails in their diet (Bergmann and Motta 2005). Mayan cichlids consumed increasingly larger numbers and sizes of snails with larger individual fish. Small Mayans $(<15 \mathrm{~cm})$ consumed much less snail biomass, between 100 and $300 \mathrm{mg}$, than large Mayans $(>15 \mathrm{~cm})$ that consumed 3000 to $7000 \mathrm{mg}$ of snail tissue in a day. These trials were done in experimental mesocosms and represent what Mayans in these size classes can consume, not necessarily what they consume in nature. However, these trials indicate they have potential to substantially affect snail populations.

The performance trials suggest that crayfish and fish could contribute to limiting snails in the Everglades. I found evidence supporting this hypothesis at site 03, where snail populations were relatively large. The other sites may not have exhibited this relationship because they are more severely limited by drying (site 11), resource quality (sites CP and TS), or predation rates are relatively constant across the observed range of snail densities (density independent mortality). Although redear and Mayan cichlids could not be included in the time-series analysis that tested for the effects of snail-density 
change because they were too sparse, long-term electrofishing data provided an estimate of their presence or absence in the marsh; they were most likely to be found in the marsh whenever the water was deep in both WCA and TSL. Deep water occurs most often during the wet season when observed snail densities are relatively low and body size changes from large individuals to smaller individuals. These results suggest fish and crayfish predation may contribute to the low observed snail densities during the wet season when large fish capable of consuming numerous snails frequent the marsh. Predation may decrease during the dry season because large fish move to deep water refugia.

Estimates of snail mortality from the field support the notion that mortality from molluscivorous fish is an important source of mortality for planorbid snails. Tethering experiments conducted in 2007 revealed that snail mortality was highest in the wet season, lowest in the dry season and averaged $10 \%$ per day at most sites across seasons. Although these estimates are relative because snails were constrained, it does suggest that snails were often encountered and consumed by predators. Mode of predation provides insight into the seasonal variation in the types of predators consuming snails. Remains at the ends of tethers revealed that crushing predators were responsible for $35 \%$ of consumption events and the probability that a snail was consumed by a crushing predator increased with water depth. This is important because fish are the only crushing predators in the Everglades and they are rare compared to entry-based predators like crayfish, signifying that fish contributed disproportionately to snail mortality compared to their occurrence in the marsh. Therefore, small entry-based snail predators such as crayfish consume relatively little snail biomass per individual, but because they are 
comparatively numerous, represent chronic source of snail mortality most of the year. Adult molluscivorous fishes probably consume substantial numbers of snails when they frequent the marsh during the wet season.

The predator permanence hypothesis proposes that aquatic community structure changes as water permanence increases because of trade-offs associated with demands from the abiotic and biotic conditions inherent to ecosystems along the water permanence gradient (Wellborn et al. 1996). In temporary ponds or wetlands, aquatic communities are composed of organisms that are highly active and have fast generation times, but are poor competitors or have few defenses from predators. Relatively permanent ponds contain numerous invertebrate predators and the associated prey assemblages are less active, have more developed predator defenses, or are better competitors than temporary ponds. Permanent ponds that rarely or never dry contain fish predators with small relatively inactive prey that have well developed predator defenses. The predator permanence model was primarily developed for spatial gradients in pond permanence, but I have applied it to temporal variation. I propose that a single location in a wetland that is associated with permanent water bodies (e.g., drowned river mouths, ridge and slough wetlands) corresponds to an ephemeral pond, a fishless pond, and a pond with fish predators all in the same year depending on the season because fish generally disperse well and move from marshes to refuge sites and back to marshes as the seasons change. Thus, spatial variation in pond permanence is traded for seasonal variation in water depth because of their association with canals, sloughs, and rivers that act as sources of predators. 
I found evidence supporting this hypothesis for one site in the current study. During the 12 year time series site 03 exhibited characteristics of a temporary pond with few crayfish toward the end of the dry season in April; resembled a fish-less permanent pond during the middle of the dry season when crayfish reached their peak densities, and had characteristics of a permanent pond in the wet season when there were relatively few crayfish but more numerous molluscivores because of the increased water depth. During 2007, a typical year for all sites, snails suffered high mortality in the wet season from crushing predators like fish and similarly high mortality in the dry season from entrybased predators like crayfish and dragonfly naiads at site 03 . The other three sites resembled fishless ponds and temporary ponds (11 and TS) or only temporary ponds (CP) throughout the time series. These other sites may not have exhibited the full range of habitats proposed by Wellborn et al.(1996) because they dry more frequently, a likely explanation for site 11, or have fewer resources to support higher densities of predators and prey, which could be the case at CP and TS. Future studies in ecosystems that vary temporally in abiotic factors that also vary across space should consider the similarities in spatial and temporal variation in community and population structure.

Disturbance, predation by fish and crayfish, and resource quality combined to affect population dynamics of the Seminole Ramshorn in the Everglades (Fig 1). Variation in habitat complexity did not explain changes in snail density. Curiously, prior snail density was the best predictor of per-capita population change suggesting they are self-limiting. I argued against competition as a likely explanation for this phenomenon because densities rarely reach over $10 / \mathrm{m}^{2}$ and there is copious periphyton available for consumption (Turner et al. 1999). I argued that despite the quantity, resource quality may place an 
upper limit on population size because phosphorous enriched sites had larger populations than those with much less phosphorous. Alternatively, trematode parasites may represent an unmeasured but important process regulating snail population dynamics that would manifest as a self-limiting feedback. Trematode infection rates increase with increasing size and they slow or eliminate snail reproductive rates (Sousa 1983, Brown et al. 1988, Bernot 2003). Therefore, trematode infection rates should be included with predation and competition as a potentially important biotic driver of snail population dynamics in freshwater ecosystems and their inclusion is a next step for understanding the myriad biotic and abiotic factors limiting population dynamics of freshwater snails.

\section{Acknowledgments}

I thank the many technicians, graduate students, and post-docs that collected data for the time series. I am grateful to Elizabeth Huselid for assistance with performance trials and Casey Smith and Lisa Jiang for measuring many, many snails. Financial support for this work was provided by a research fellowship to CBR from the Everglades Foundation, and field data were provided by ENP-FIU Cooperative Agreement H5000060104, Task numbers J5284060023 and J5297070024 to Joel Trexler. This material is also based upon work supported by the National Science Foundation through the Florida Coastal Everglades Long-Term Ecological Research program under Grant No. DBI-0620409. 


\section{LITERATURE CITED}

Anderson, D. R. 2008. Model based inference in the life sciences: A primer on evidence. Springer.

Batzer, D. P. 1998. Trophic interactions among detritus, benthic midges, and predatory fish in a freshwater marsh. Ecology 79:1688-1698.

Batzer, D. P., C. R. Pusateri, and R. Vetter. 2000. Impacts of predation on marsh invertebrates: Direct and indirect effects. Wetlands 20:307-312.

Batzer, D. P., and V. H. Resh. 1991. Trophic interactions among a beetle predator, a chironomid grazer, and periphyton in a seasonal wetland. Oikos 60:251-257.

Bergmann, G. T., and P. J. Motta. 2005. Diet and morphology through ontogeny of the nonindigenous Mayan cichlid Cichlasoma (Nandopsis) urophthalmus (Gunther 1862) in southern Florida. Environmental Biology of Fishes 72:205-211.

Bernot, R. J. 2003. Trematode infection alters the antipredator behavior of a pulmonate snail. Journal of the North American Benthological Society 22:241-248.

Boss, K. J. 1974. Oblomovism in the Mollusca. Transactions of the American Microscopical Society 93:460 - 481.

Brönmark, C. 1985. Freshwater snail diversity - Effects of pond area, habitat heterogeneity and isolation. Oecologia 67:127-131.

Brönmark, C. 1992. Leech predation on juvenile freshwater snails: Effects of size, species, and substrate. Oecologia 91:526-529.

Browder, J. A., P. J. Gleason, and D. R. Swift. 1994. Periphyton in the Everglades: Spatial variation, environmental correlates, and ecological implications. Pages 379-418 in S. M. Davis and J. C. Ogden, editors. Everglades: The ecosystem and its restoration. St. Lucie Press, Del Ray Beach, Florida.

Brown, K. M. 1982. Resource overlap and competition in pond snails: An experimental analysis. Ecology 63:412-422.

Brown, K. M., and D. R. Devries. 1985. Predation and the distribution and abundance of a pulmonate pond snail. Oecologia 66:93-99.

Brown, K. M., B. K. Leathers, and D. J. Minchella. 1988. Trematode prevalance and the population dynamics of freshwater pond snails. American Midland Naturalist 120:289-301. 
Chick, J. H., S. Coyne, and J. C. Trexler. 1999. Effectiveness of airboat electrofishing for sampling fishes in shallow vegetated habitats. North American Journal of Fisheries Management 19:957-967.

Chick, J. H., P. Geddes, and J. C. Trexler. 2008. Periphyton mat structure mediates trophic interactions in a subtropical marsh. Wetlands 28:378-389.

Chick, J. H., C. R. Ruetz, and J. C. Trexler. 2004. Spatial scale and abundance patterns of large fish communities in freshwater marshes of the Florida Everglades. Wetlands 24:652-664.

Davis, S. M., and J. C. Ogden, editors. 1994. Everglades: The ecosystem and its restoration. St. Lucie Press, Delray Beach, FL.

DeWitt, T. J., and R. B. Langerhans. 2004. Integrated solutions to environmental heterogeneity: Theory of multimoment reaction norms. Pages 98-111 in T. J. DeWitt and S. M. Scheiner, editors. Phenotypic plasticity functional and conceptual approaches. Oxford University Press, New York.

Dillon, R. T. 2000. The ecology of freshwater molluscs. Cambridge University Press, Cambridge.

Dorn, N. J., and J. C. Trexler. 2007. Crayfish assemblage shifts in a large drought-prone wetland: The roles of hydrology and competition. Freshwater Biology 52:23992411 .

Dorn, N. J., J. C. Trexler, and E. E. Gaiser. 2006. Exploring the role of large predators in marsh food webs: Evidence for a behaviorally-mediated trophic cascade. Hydrobiologia 569:375-386.

Dorn, N. J., R. Urgelles, and J. C. Trexler. 2005. Evaluating active and passive sampling methods to quantify crayfish density in a freshwater wetland. Journal of the North American Benthological Society 24:346-356.

Dorn, N. J., and J. C. Volin. 2009. Resistance of crayfish (Procambarus spp.) populations to wetland drying depends on species and substrate. Journal of the North American Benthological Society 28:766-777.

Eckbald, J. 1976. Biomass and energy transfer by a specialized predator of aquatic snails. Freshwater Biology 6:19 - 21.

Eisenberg, R. M. 1966. The regulation of density in a natural population of the pond snail, Lymnaea elodes. Ecology 47:889 - 906.

Fretter, V., and J. Peake. 1979. Pulmonates. Academic Pres, New York. 
Gaiser, E. E., J. H. Richards, J. C. Trexler, R. D. Jones, and D. L. Childers. 2006.

Periphyton responses to eutrophication in the Florida Everglades: Cross-system patterns of structural and compositional change. Limnology and Oceanography 51:617-630.

Gaiser, E. E., J. C. Trexler, J. H. Richards, D. L. Childers, D. Lee, A. L. Edwards, L. J. Scinto, K. Jayachandran, G. B. Noe, and R. D. Jones. 2005. Cascading ecological effects of low-level phosphorus enrichment in the Florida Everglades. Journal of Environmental Quality 34:717-723.

Grime, J. P. 1977. Evidence for the existence of three primary strategies in plants and its relevance to ecological and evolutionary theory. American Naturalist 111:11691194.

Grimm, N. B., and S. G. Fisher. 1989. Stability of periphyton and macroinvertebrates to disturbance by flash floods in a desert stream. Journal of the North American Benthological Society 8:293-307.

Hawkins, C. P., and J. K. Furnish. 1987. Are snails important competitors in stream ecosystems. Oikos 49:209-220.

Heeg, J. 1977. Oxygen consumption and the use of metabolic reserves during starvation and aestivation in Bulinus (Physopisis) africanus (Pulmonata: Planorbidae). Malacologia 16:549 - 560.

Hill, W. R. 1992. Food limitation and interspecific competition in snail-dominated streams. Canadian Journal of Fisheries and Aquatic Sciences 49:1257-1267.

Hill, W. R., M. G. Ryon, and E. M. Schilling. 1995. Light limitation in a stream ecosystem: Responses by primary producers and consumers. Ecology 76:12971309.

Huckins, C. J. F. 1997. Functional linkages among morphology, feeding performance, diet, and competitive ability in molluscivorous sunfish. Ecology 78:2401-2414.

Huckins, C. J. F., C. W. Osenberg, and G. C. Mittelbach. 2000. Species introductions and their ecological consequences: An example with congeneric sunfish. Ecological Applications 10:612-625.

Jordan, F., S. Coyne, and J. C. Trexler. 1997. Sampling fishes in vegetated habitats: Effects of habitat structure on sampling characteristics of the $1-\mathrm{m}^{2}$ throw trap. Transactions of the American Fisheries Society 126:1012-1020. 
Lima, S. L. 2002. Putting predators back into behavioral predator-prey interactions. Trends in Ecology \& Evolution 17:70-75.

Liston, S. E., and J. C. Trexler. 2005. Spatiotemporal patterns in community structure of macroinvertebrates inhabiting calcareous periphyton mats. Journal of the North American Benthological Society 24:832-844.

Lodge, D. M., K. M. Brown, S. P. Klosiewski, R. A. Stein, A. P. Covich, B. K. Leathers, and C. Brönmark. 1987. Distribution of freshwater snails: Spatial scale and the relative importance of physicochemical and biotic factors. American Malacological Bulletin 5:73-84.

Lodge, D. M., M. W. Kershner, J. E. Aloi, and A. P. Covich. 1994. Effects of an omnivorous crayfish (Orconectes rusticus) on a freshwater littoral food web. Ecology 75:1265-1281.

Mittelbach, G. G., C. W. Osenberg, and P. C. Wainwright. 1992. Variation in resource abundance affects diet and feeding morphology in the pumpkinseed sunfish (Lepomis gibbosus). Oecologia 90:8-13.

Munoz, I., M. Real, H. Guasch, E. Navarro, and S. Sabater. 2000. Resource limitation by freshwater snail (Stagnicola vulnerata) grazing pressure: An experimental study. Archiv Fur Hydrobiologie 148:517-532.

Newbold, J. D., J. W. Elwood, R. V. O'Neill, and A. L. Sheldon. 1983. Phosphorus dynamics in a woodland stream ecosystem: A study of nutrient spiraling. Ecology 64:1249-1265.

Noble, I. R., and R. O. Slatyer. 1980. The use of vital attributes to predict successional changes in plant-communities subject to recurrent disturbances. Vegetatio 43:521.

Osenberg, C. W., and G. C. Mittelbach. 1996. The relative importance of resource limitation and predator limitation in food chains. Pages 134-148 in G. A. Polis and K. O. Winemiller, editors. Food Webs: Integration of patterns and dynamics. Chapman Hall, New York.

Pigliucci, M. 2001. Phenotypic plasticity: Beyond nature and nuture. Johns Hopkins University Press, Baltimore, MD.

Pimentel, D., and P. C. White Jr. 1959. Biological environment and habits of Australorbis glabratus. Ecology 40:541 - 550. 
Rosemond, A. D., P. J. Mulholland, and J. W. Elwood. 1993. Top-down and bottom-up control of stream periphyton - Effects of nutrients and herbivores. Ecology 74:1264-1280.

Rowe, R. J. 1987. Predatory versatility in a larval dragonfly, Hemianax papuensis (Odonata: Aeshnidae). Journal of Zoology 211:193-207.

Ruetz, C. R., III, J. C. Trexler, F. Jordan, W. F. Loftus, and S. A. Perry. 2005. Population dynamics of wetland fishes: Spatiotemporal patterns shaped by hydrological disturbance? Journal of Animal Ecology 74:322-332.

Schmitz, O. J., J. H. Grabowski, B. L. Peckarsky, E. L. Preisser, G. C. Trussell, and J. R. Vonesh. 2008. From individuals to ecosystem function: Toward an integration of evolutionary and ecosystem ecology. Ecology 89:2436-2445.

Sih, A., P. Crowley, M. Mcpeek, J. W. Petranka, and K. Strohmeier. 1985. Predation, competition, and prey communities - A review of field experiments. Annual Review of Ecology and Systematics 16:269-311.

Sih, A., G. Englund, and D. Wooster. 1998. Emergent impacts of multiple predators on prey. Trends in Ecology \& Evolution 13:350-355.

Sousa, W. P. 1983. Host life history and the effect of parasitic castration on growth: A field study of Cerithidea californica Haldeman (Gastropoda: Prosobranchia) and its trematode parasites. Journal of Experimental Marine Biology and Ecology 73:273-296.

Sousa, W. P. 1984. The role of disturbance in natural communities. Annual Review of Ecology and Systematics 15:353-391.

Tabachnick, B. G., and L. S. Fidell. 2007. Using multivariate statistics, 5th edition. Pearson Education, Boston, MA, USA.

Thompson, F. G. 2004. An identification manual for the freshwater snails of Florida. http://www.flmnh.ufl.edu/malacology/fl-snail/snails1.htm

Tonn, W. M., P. W. Langlois, E. E. Prepas, A. J. Danylchuk, and S. M. Boss. 2004. Winterkill cascade: Indirect effects of a natural disturbance on littoral macroinvertebrates in boreal lakes. Journal of the North American Benthological Society 23:237-250.

Trexler, J. C., W. F. Loftus, and J. H. Chick. 2003. Setting and monitoring restoration goals in the absence of historical data: The case of fishes in the Florida Everglades. Pages 351-376 in D. E. Busch and J. C. Trexler, editors. Monitoring 
ecoregional initiatives: Interdisciplinary approaches for determining status and trends of ecosystems. Island Press, Washington, D. C.

Trexler, J. C., W. F. Loftus, and S. A. Perry. 2005. Disturbance frequency and community structure in a twenty-five year intervention study. Oecologia 145:140152.

Turchin, P. 2003. Complex population dynamics: A theoretical/empirical synthesis. Princeton University Press, Princeton, NJ.

Turner, A. M., and M. F. Chislock. 2007. Dragonfly predators influence biomass and density of pond snails. Oecologia 153:407-415.

Turner, A. M., and J. C. Trexler. 1997. Sampling aquatic invertebrates from marshes: Evaluating the options. Journal of the North American Benthological Society 16:694-709.

Turner, A. M., J. C. Trexler, C. F. Jordan, S. J. Slack, P. Geddes, J. H. Chick, and W. F. Loftus. 1999. Targeting ecosystem features for conservation: Standing crops in the Florida Everglades. Conservation Biology 13:898-911.

Weber, L. M., and D. M. Lodge. 1990. Periphytic food and predatory crayfish: Relative roles in determining snail distribution. Oecologia 82:33-39.

Wellborn, G. A., D. K. Skelly, and E. E. Werner. 1996. Mechanisms creating community structure across a freshwater habitat gradient. Annual Review of Ecology and Systematics 27:337-363.

Werner, E. E., D. K. Skelly, R. A. Relyea, and K. L. Yurewicz. 2007. Amphibian species richness across environmental gradients. Oikos 116:1697-1712.

Wirsing, A. J., M. R. Heithaus, A. Frid, and L. M. Dill. 2008. Seascapes of fear: Evaluating sublethal predator effects experienced and generated by marine mammals. Marine Mammal Science 24:1-15. 
Table 5.1. Model selection results from different competing models that predicted the change in snail density at site 03 in WCA with exogenous and endogenous independent variables. Akaike Information Criterion (AIC) values are the $-2 \log$ likelihood for ecah model, $\triangle \mathrm{AIC}$ is the difference from the base model, and $\omega \mathrm{i}$ is the Akaike weight for each model that gives the relative likelihood. Lower AIC values indicate a better model and the best model in each set is in bold.

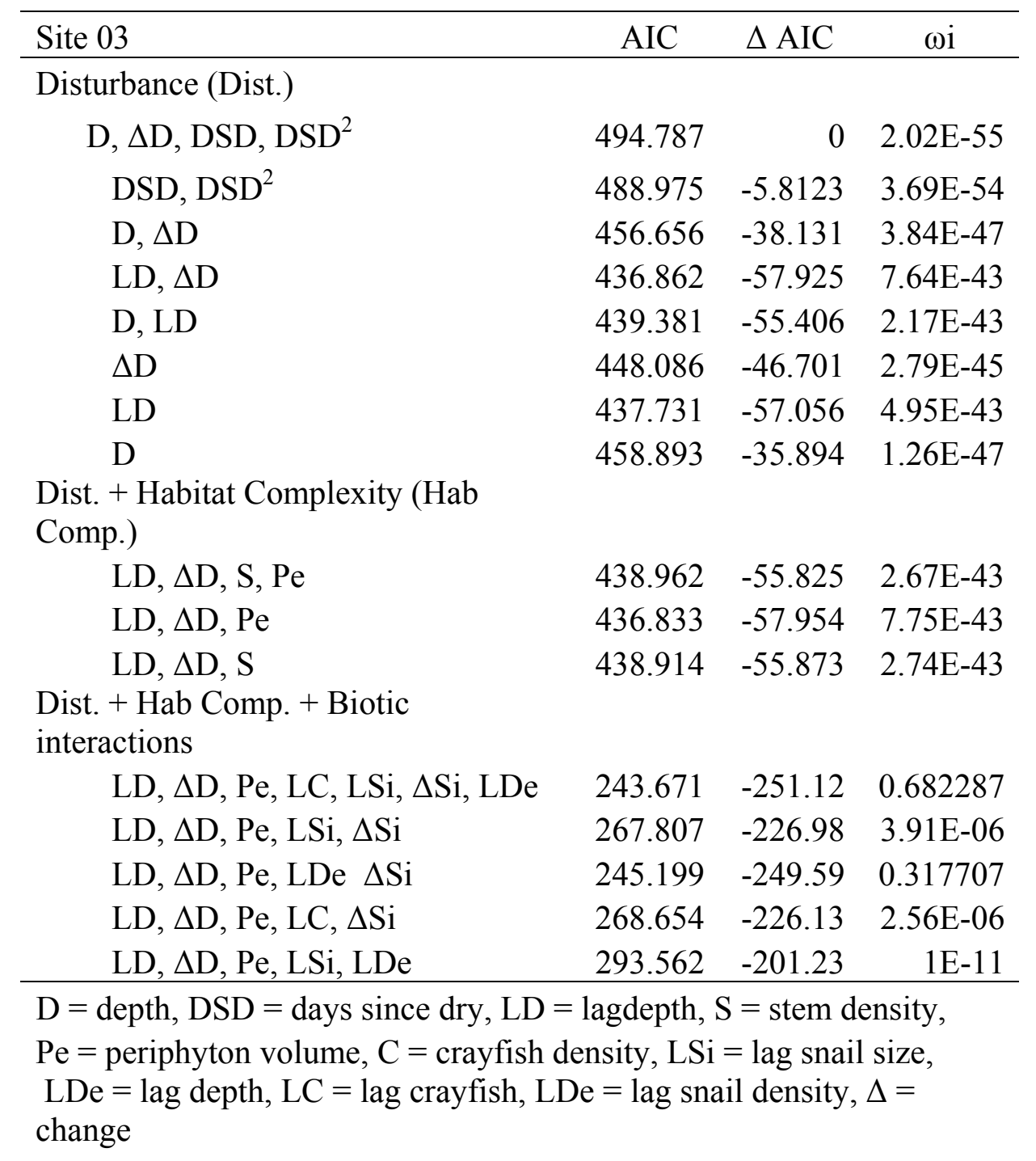


Table 5.2. Model selection results from different competing models that predicted the change in snail density at two 11 in WCA with exogenous and endogenous independent variables. Akaike Information Criterion (AIC) values are the -2 log likelihood for ecah model, $\triangle \mathrm{AIC}$ is the difference from the base model, and $\omega \mathrm{i}$ is the Akaike weight for each model that gives the relative likelihood. Lower AIC values indicate a better model and the best model in each set is in bold.

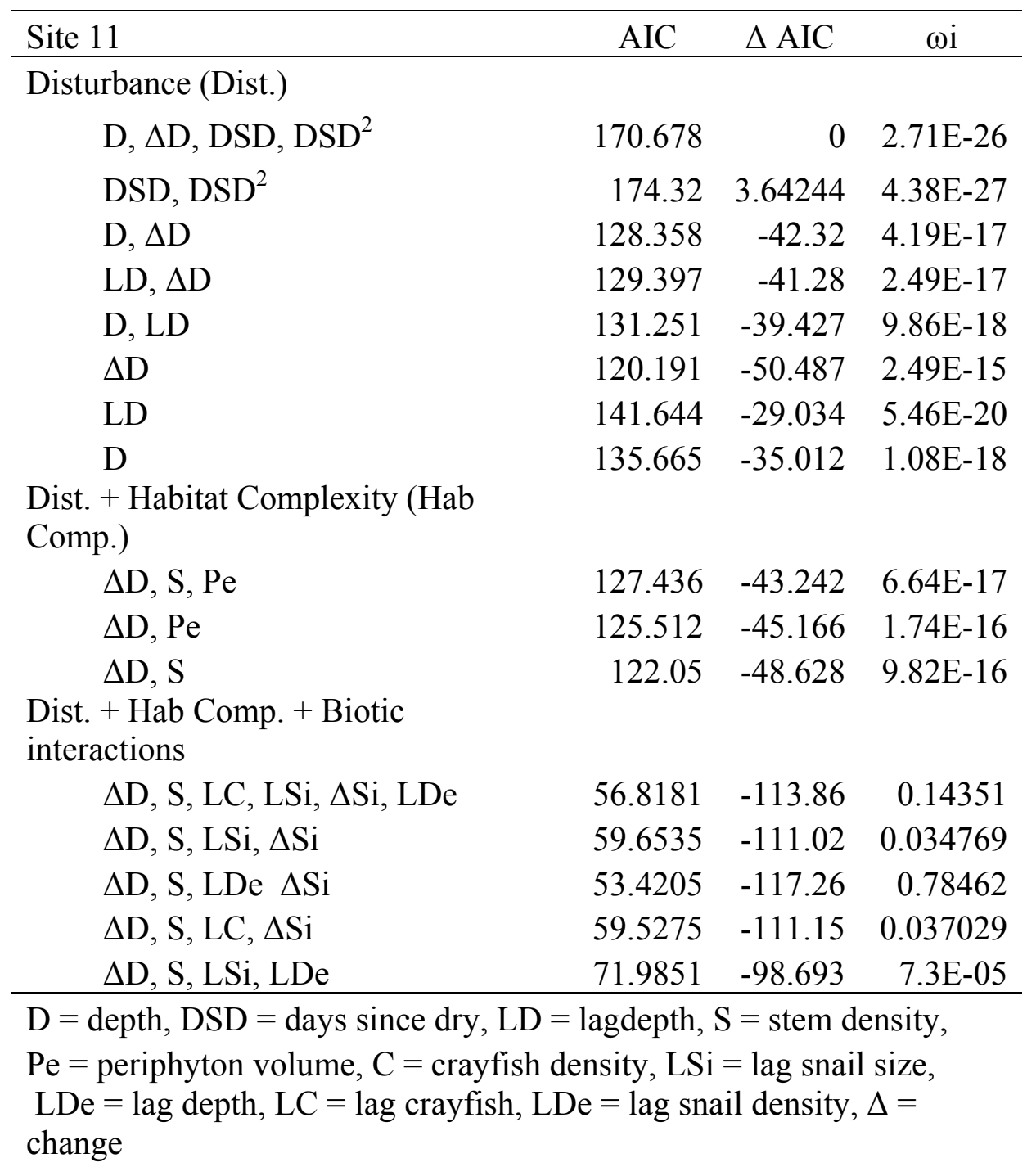


Table 5.3. Model selection results from different competing models that predicted the change in snail density at site CP in TSL with exogenous and endogenous independent variables Akaike Information Criterion (AIC) values are the $-2 \log$ likelihood for ecah model, $\triangle \mathrm{AIC}$ is the difference from the base model, and $\omega \mathrm{i}$ is the Akaike weight for each model that gives the relative likelihood. Lower AIC values indicate a better model and the best model in each set is in bold.

\begin{tabular}{|c|c|c|c|}
\hline Site CP & AIC & $\Delta \mathrm{AIC}$ & $\omega \mathrm{i}$ \\
\hline \multicolumn{4}{|l|}{ Disturbance (Dist.) } \\
\hline $\mathrm{D}, \Delta \mathrm{D}, \mathrm{DSD}, \mathrm{DSD}^{2}$ & 224.07 & 0 & $1.83 \mathrm{E}-30$ \\
\hline $\mathrm{DSD} \mathrm{DSD}^{2}$ & 238.33 & 14.26 & $1.46 \mathrm{E}-33$ \\
\hline $\mathrm{D}, \Delta \mathrm{D}$ & 176.995 & -47.076 & $3.05 \mathrm{E}-20$ \\
\hline $\mathrm{LD}, \Delta \mathrm{D}$ & 181.72 & -42.351 & $2.87 \mathrm{E}-21$ \\
\hline $\mathrm{D}, \mathrm{LD}$ & 175.787 & -48.283 & $5.58 \mathrm{E}-20$ \\
\hline$\Delta \mathrm{D}$ & 171.887 & -52.183 & $3.92 \mathrm{E}-19$ \\
\hline LD & 193.343 & -30.727 & $8.59 \mathrm{E}-24$ \\
\hline $\mathrm{D}$ & 184.499 & -39.571 & $7.16 \mathrm{E}-22$ \\
\hline \multicolumn{4}{|l|}{ Dist. + Habitat Complexity (Hab } \\
\hline$\Delta \mathrm{D}, \mathrm{S}, \mathrm{Pe}$ & 178.981 & -45.09 & $1.13 \mathrm{E}-20$ \\
\hline$\Delta \mathrm{D}, \mathrm{Pe}$ & 176.798 & -47.273 & $3.36 \mathrm{E}-20$ \\
\hline$\Delta \mathrm{D}, \mathrm{S}$ & 174.896 & -49.174 & $8.71 \mathrm{E}-20$ \\
\hline \multicolumn{4}{|l|}{$\begin{array}{l}\text { Dist. + Hab Comp. + Biotic } \\
\text { interactions }\end{array}$} \\
\hline$\Delta \mathrm{D}, \mathrm{S}, \mathrm{LC}, \mathrm{LSi}, \Delta \mathrm{Si}, \mathrm{LDe}$ & 90.7471 & -133.32 & 0.163166 \\
\hline$\Delta \mathrm{D}, \mathrm{S}, \mathrm{LSi}, \Delta \mathrm{Si}$ & 101.778 & -122.29 & 0.000657 \\
\hline$\Delta \mathrm{D}, \mathrm{S}, \mathrm{LDe} \Delta \mathrm{Si}$ & 87.4836 & -136.59 & 0.834248 \\
\hline$\Delta \mathrm{D}, \mathrm{S}, \mathrm{LC}, \Delta \mathrm{Si}$ & 99.6237 & -124.45 & 0.001928 \\
\hline$\Delta \mathrm{D}, \mathrm{S}, \mathrm{LSi}, \mathrm{LDe}$ & 114.092 & -109.98 & $1.39 \mathrm{E}-06$ \\
\hline $\begin{array}{l}\mathrm{D}=\text { depth, } \mathrm{DSD}=\text { days since dry } \\
\mathrm{Pe}=\text { periphyton volume }, \mathrm{C}=\text { cra } \\
\mathrm{LDe}=\text { lag depth }, \mathrm{LC}=\text { lag cray } \\
\text { change }\end{array}$ & $\begin{array}{l}\text { lagdepth, } \\
\text { nsity, LSi } \\
\text { e lag sna }\end{array}$ & $\begin{array}{l}=\text { stem d } \\
=\text { lag snai }\end{array}$ & $\begin{array}{l}\text { nsity, } \\
\text { size, } \\
\Delta=\end{array}$ \\
\hline
\end{tabular}


Table 5.4. Model selection results from different competing models that predicted the change in snail density at site TS in TSL with exogenous and endogenous independent variables Akaike Information Criterion (AIC) values are the $-2 \log$ likelihood for ecah model, $\triangle$ AIC is the difference from the base model, and wi is the Akaike weight for each model that gives the relative likelihood. Lower AIC values indicate a better model and the best model in each set is in bold.

\begin{tabular}{|c|c|c|c|}
\hline Site TS & AIC & $\Delta \mathrm{AIC}$ & $\omega \mathrm{i}$ \\
\hline \multicolumn{4}{|l|}{ Disturbance (Dist.) } \\
\hline $\mathrm{D}, \Delta \mathrm{D}, \mathrm{DSD}, \mathrm{DSD}^{2}$ & 233.281 & 0 & $5.94 \mathrm{E}-36$ \\
\hline $\mathrm{DSD}, \mathrm{DSD}^{2}$ & 237.37 & 4.08968 & $7.69 \mathrm{E}-37$ \\
\hline $\mathrm{D}, \Delta \mathrm{D}$ & 185.777 & -47.504 & $1.23 \mathrm{E}-25$ \\
\hline $\mathrm{LD}, \Delta \mathrm{D}$ & 187.572 & -45.708 & $5 \mathrm{E}-26$ \\
\hline $\mathrm{D}, \mathrm{LD}$ & 191.822 & -41.458 & 5.97E-27 \\
\hline$\Delta \mathrm{D}$ & 178.647 & -54.633 & 4.34E-24 \\
\hline LD & 209.638 & -23.642 & $8.08 \mathrm{E}-31$ \\
\hline $\mathrm{D}$ & 193.363 & -39.918 & $2.77 \mathrm{E}-27$ \\
\hline \multicolumn{4}{|l|}{ Dist. + Habitat Complexity (Hab } \\
\hline \multicolumn{4}{|l|}{ Comp.) } \\
\hline$\Delta \mathrm{D}, \mathrm{S}, \mathrm{Pe}$ & 185.412 & -47.869 & $1.47 \mathrm{E}-25$ \\
\hline$\Delta \mathrm{D}, \mathrm{Pe}$ & 181.369 & -51.911 & $1.11 \mathrm{E}-24$ \\
\hline$\Delta \mathrm{D}, \mathrm{S}$ & 182.383 & -50.897 & $6.7 \mathrm{E}-25$ \\
\hline \multicolumn{4}{|l|}{$\begin{array}{l}\text { Dist. + Hab Comp. + Biotic } \\
\text { interactions }\end{array}$} \\
\hline$\Delta \mathrm{D}, \mathrm{Pe}, \mathrm{LC}, \mathrm{LSi}, \Delta \mathrm{Si}, \mathrm{LDe}$ & 76.7601 & -156.52 & 0.057769 \\
\hline$\Delta \mathrm{D}, \mathrm{Pe}, \mathrm{LSi}, \Delta \mathrm{Si}$ & 100.218 & -133.06 & 4.65E-07 \\
\hline$\Delta \mathrm{D}, \mathrm{Pe}, \mathrm{LDe} \Delta \mathrm{Si}$ & 71.1766 & -162.1 & 0.942205 \\
\hline$\Delta \mathrm{D}, \mathrm{Pe}, \mathrm{LC}, \Delta \mathrm{Si}$ & 100.385 & -132.9 & $4.28 \mathrm{E}-07$ \\
\hline$\Delta \mathrm{D}, \mathrm{Pe}, \mathrm{LSi}, \mathrm{LDe}$ & 92.2719 & -141.01 & $2.47 \mathrm{E}-05$ \\
\hline \multicolumn{4}{|c|}{$\begin{array}{l}\mathrm{D}=\text { depth, } \mathrm{DSD}=\text { days since dry, } \mathrm{LD}=\text { lagdepth, } \mathrm{S}=\text { stem density, } \\
\mathrm{Pe}=\text { periphyton volume, } \mathrm{C}=\text { crayfish density, } \mathrm{LSi}=\text { lag snail size, } \\
\mathrm{LDe}=\text { lag depth, } \mathrm{LC}=\text { lag crayfish, } \mathrm{LDe}=\text { lag snail density, } \Delta= \\
\text { change }\end{array}$} \\
\hline
\end{tabular}


Table 5.5. Summary statistics for the final models from the selection procedure for each site. The per-capita rate of change in snail density served as the dependent variable in each model.

\begin{tabular}{|c|c|c|c|c|c|}
\hline Independent variables & $\beta \pm \mathrm{SE}$ & $\begin{array}{c}\beta \\
\text { weights }\end{array}$ & $\begin{array}{c}\text { Sq. } \\
\text { semi- } \\
\text { partial } \\
\text { corr. }\end{array}$ & $\begin{array}{l}\text { Adj. } \\
\mathrm{R}^{2}\end{array}$ & Rank \\
\hline \multicolumn{6}{|l|}{ WCA, $03(n=87)$} \\
\hline Lag water depth $(\mathrm{cm})$ & $-0.004 \pm 0.008$ & -0.082 & 0.002 & 0.397 & 7 \\
\hline$\Delta$ Water depth $(\mathrm{cm})$ & $-0.193 \pm 0.093$ & -0.231 & 0.033 & & 3 \\
\hline Log periphyton volume (ml) & $0.089 \pm 0.066$ & 0.132 & 0.014 & & 5 \\
\hline Log lag crayfish density (no. $/ \mathrm{m}^{2}$ ) & $-0.341 \pm 0.162$ & -0.216 & 0.034 & & 2 \\
\hline Log lag snail size $(\mathrm{mm})$ & $-0.134 \pm 0.190$ & -0.126 & 0.004 & & 4 \\
\hline $\log \Delta$ snail size $(\mathrm{mm})$ & $-0.005 \pm 0.129$ & -0.006 & 0.000 & & 6 \\
\hline Log lag snail density (no./m²) & $-0.617 \pm 0.109$ & -0.551 & 0.251 & & 1 \\
\hline \multicolumn{6}{|l|}{ WCA, $11(n=35)$} \\
\hline$\Delta$ Water depth $(\mathrm{cm})$ & $-0.177 \pm 0.010$ & -0.297 & 0.074 & 0.352 & 2 \\
\hline Log stem density (no./m²) & $-0.032 \pm 0.160$ & -0.036 & 0.001 & & 4 \\
\hline Log lag snail density (no./m²) & $-0.461 \pm 0.191$ & -0.391 & 0.126 & & 1 \\
\hline $\log \Delta$ snail size $(\mathrm{mm})$ & $0.064 \pm 0.069$ & 0.151 & 0.018 & & 3 \\
\hline \multicolumn{6}{|l|}{ TSL, CP $(n=66)$} \\
\hline$\Delta$ Water depth $(\mathrm{cm})$ & $-0.167 \pm 0.063$ & -0.286 & 0.073 & 0.358 & 2 \\
\hline Log stem density (no./m²) & $-0.123 \pm 0.070$ & -0.191 & 0.033 & & 3 \\
\hline Log lag snail density (no./m²) & $-0.468 \pm 0.119$ & -0.447 & 0.163 & & 1 \\
\hline $\log \Delta$ snail size $(\mathrm{mm})$ & $0.058 \pm 0.048$ & 0.125 & 0.016 & & 4 \\
\hline \multicolumn{6}{|l|}{ TSL, TS $(\mathrm{n}=55)$} \\
\hline$\Delta$ Water depth $(\mathrm{cm})$ & $-0.071 \pm 0.067$ & -0.116 & 0.012 & 0.463 & 3 \\
\hline Log periphyton volume (ml) & $-0.109 \pm 0.040$ & -0.289 & 0.081 & & 2 \\
\hline Log lag snail density (no./m²) & $-0.784 \pm 0.125$ & -0.656 & 0.419 & & 1 \\
\hline $\log \Delta$ snail size $(\mathrm{mm})$ & $0.003 \pm 0.046$ & 0.006 & 0.000 & & 4 \\
\hline
\end{tabular}


Table 5.6. Logistic model selection results from long-term data on large fish occurrence in two regions (TSL and WCA). Seasonality was modeled as period and was treated as a continuous variable, while year was modeled as a fixed effect. Akaike Information Criterion (AIC) values are the $-2 \log$ likelihood for ecah model, $\triangle \mathrm{AIC}$ is the difference from the base model, and $\omega \mathrm{i}$ is the Akaike weight for each model that gives the relative likelihood. Lower AIC values indicate a better model and the best model in each set is in bold.

\begin{tabular}{|c|c|c|c|c|c|c|}
\hline \multirow[b]{2}{*}{ Variable } & \multicolumn{3}{|c|}{ WCA $(n=93)$} & \multicolumn{3}{|c|}{$\operatorname{TSL}(\mathrm{n}=221)$} \\
\hline & $\mathrm{K}$ & AIC & $\Delta \mathrm{AIC}$ & $\mathrm{K}$ & AIC & $\Delta \mathrm{AIC}$ \\
\hline $\mathrm{P}$ & 1 & 86.23 & 0.00 & 1 & 216.01 & 0.00 \\
\hline Y & 9 & 88.26 & 2.03 & 10 & 214.46 & -1.55 \\
\hline D & 1 & 80.36 & -5.87 & 1 & 207.37 & -8.64 \\
\hline $\mathrm{P}, \mathrm{Y}$ & 9 & 85.52 & -0.71 & 10 & 215.58 & -0.43 \\
\hline $\mathbf{D}, \mathbf{Y}$ & 9 & 75.01 & -11.21 & 10 & 210.03 & -5.97 \\
\hline $\mathrm{D}, \mathrm{P}$ & 1 & 86.49 & 0.26 & 1 & 209.33 & -6.68 \\
\hline $\mathrm{P}, \mathrm{Y}, \mathrm{D}$ & 9 & 79.51 & -6.72 & 10 & 211.34 & -4.66 \\
\hline $\mathrm{P}, \mathrm{Y}, \mathrm{P} \times \mathrm{Y}, \mathrm{D}$ & 9 & 80.75 & -5.48 & 10 & 214.26 & -1.74 \\
\hline $\mathrm{P}, \mathrm{Y}, \mathrm{P} \times \mathrm{Y}, \mathrm{D}, \mathrm{D} \times \mathrm{Y}$ & 9 & 93.70 & 7.47 & 10 & 216.36 & 0.35 \\
\hline $\mathrm{P}, \mathrm{Y}, \mathrm{P} \times \mathrm{Y}, \mathrm{D}, \mathrm{D} \times \mathrm{Y}, \mathrm{D} \times \mathrm{P}$ & 9 & 95.70 & 9.47 & 10 & 218.35 & 2.34 \\
\hline $\begin{array}{l}\mathrm{P}, \mathrm{Y}, \mathrm{P} \times \mathrm{Y}, \mathrm{D}, \mathrm{D} \times \mathrm{Y}, \mathrm{D} \times \mathrm{P}, \\
\mathrm{DSD}, \mathrm{DSD}^{2}\end{array}$ & 9 & 94.96 & 8.73 & 10 & 220.41 & 4.40 \\
\hline
\end{tabular}

$\mathrm{P}=$ period, $\mathrm{Y}=$ year, $\mathrm{D}=$ water depth, $\mathrm{DSD}=$ days since

site dried 
Table 5.7. Logistic regression model-selection results from tethering experiments conducted in 2007 at four sites in two regions testing for effects that predict mortality and mode of predation (entry, 0 vs. crushing, 1). Sites were modeled as fixed effects and nested within regions. Periods represented seasonal variation and was modeled as a continuous variable. Akaike Information Criterion (AIC) values are the $-2 \log$ likelihood for ecah model, $\Delta$ AIC is the difference from the base model, and $\omega$ i is the Akaike weight for each model that gives the relative likelihood. Lower AIC values indicate a better model and the best model in each set is in bold.

\begin{tabular}{|c|c|c|c|c|c|}
\hline \multirow[b]{2}{*}{ Variables } & \multirow[b]{2}{*}{$\mathrm{K}$} & \multicolumn{2}{|c|}{ Mortality $(\mathrm{n}=389)$} & \multicolumn{2}{|c|}{ Mode $(n=115)$} \\
\hline & & AIC & $\triangle \mathrm{AIC}$ & AIC & $\Delta \mathrm{AIC}$ \\
\hline $\mathbf{P}$ & 1 & 462.82 & 0.00 & 152.04 & 0.00 \\
\hline $\mathrm{R}$ & 1 & 475.19 & 12.36 & 151.88 & -0.17 \\
\hline$S(R)$ & 2 & 476.41 & 13.59 & 155.33 & 3.28 \\
\hline D & 1 & 476.77 & 13.95 & 143.92 & -8.12 \\
\hline $\mathrm{Sn}$ & 1 & 475.87 & 13.04 & 152.42 & 0.38 \\
\hline $\mathrm{P}, \mathrm{R}$ & 1 & 464.12 & 1.29 & 153.32 & 1.28 \\
\hline $\mathrm{P}, \mathrm{S}(\mathrm{R})$ & 2 & 464.13 & 1.30 & 156.90 & 4.85 \\
\hline $\mathrm{P}, \mathrm{D}$ & 1 & 462.46 & -0.36 & 145.62 & -6.42 \\
\hline $\mathrm{R}, \mathrm{D}$ & 1 & 475.89 & 13.07 & 145.30 & -6.74 \\
\hline$P, R, S(R), S n$ & 2 & 464.46 & 1.64 & 146.75 & -5.29 \\
\hline $\mathrm{P}, \mathrm{R}, \mathrm{S}(\mathrm{R}), \mathrm{Sn}$ & 2 & 465.31 & 2.49 & 158.86 & 6.82 \\
\hline$P, R, S(R), D$ & 2 & 465.74 & 2.92 & 150.27 & -1.77 \\
\hline $\mathrm{P}, \mathrm{R}, \mathrm{S}(\mathrm{R}), \mathrm{Sn}, \mathrm{D}$ & 2 & 466.69 & 3.86 & 152.01 & -0.04 \\
\hline $\mathrm{P}, \mathrm{R}, \mathrm{S}(\mathrm{R}), \mathrm{Sn}, \mathrm{D}, \mathrm{D} \times \mathrm{P}$ & 2 & 468.66 & 5.84 & 153.96 & 1.91 \\
\hline $\mathrm{P}, \mathrm{R}, \mathrm{S}(\mathrm{R}), \mathrm{Sn}, \mathrm{D}, \mathrm{D} \times \mathrm{P}, \mathrm{D} \times \mathrm{R}$ & 2 & 468.16 & 5.34 & 155.32 & 3.28 \\
\hline $\begin{array}{l}\mathrm{P}, \mathrm{R}, \mathrm{S}(\mathrm{R}), \mathrm{Sn}, \mathrm{D}, \mathrm{D} \times \mathrm{P}, \mathrm{D} \times \mathrm{R}, \\
\mathrm{D} \times \mathrm{S}(\mathrm{R})\end{array}$ & 2 & 470.96 & 8.14 & 156.75 & 4.71 \\
\hline
\end{tabular}




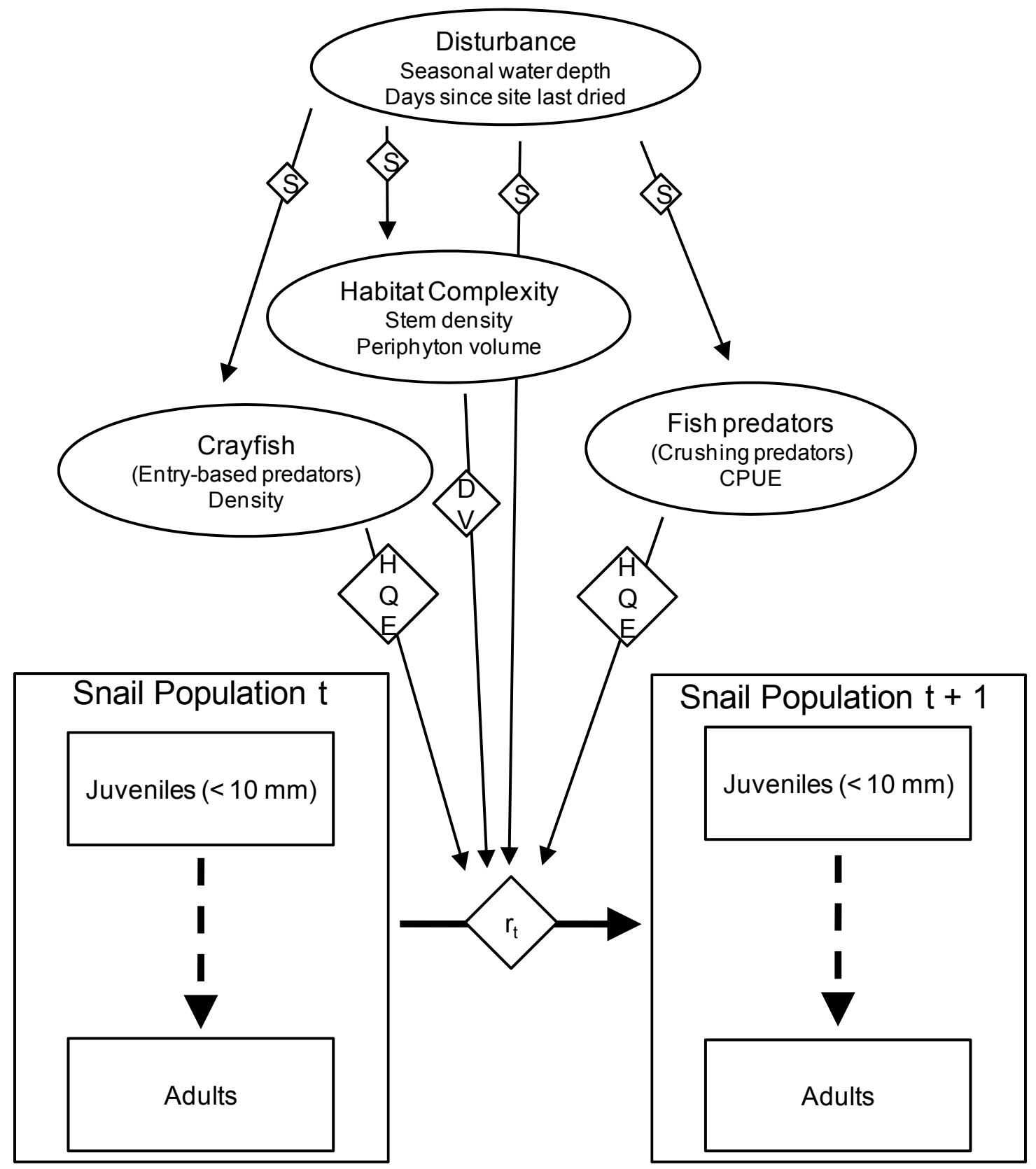

Fig 5.1. Conceptual diagram of abiotic and biotic drivers affecting snail populations in the Everglades that were measured in this study. Snail populations at time $t$ and $t+1$ are shown with juveniles and adults to represent the continuous variation in size used in the model. Disturbance affects the survival (S) of emergent stems, periphyton, snails, crayfish and fish; it also affects the presence $(\mathrm{P})$ of fish in the marsh. Habitat complexity affects the change in juvenile and adult snail density by variation in the density of stems (D) and the volume (V) of periphyton. Fish and crayfish affect the change in snail density. Predator effects on the change in snail density were measured by quantifying handling time $(\mathrm{H})$, consumption rate $(\mathrm{Q})$, and encounter rate $(\mathrm{E})$. Encounter rate was measured with tethering studies in the field. 


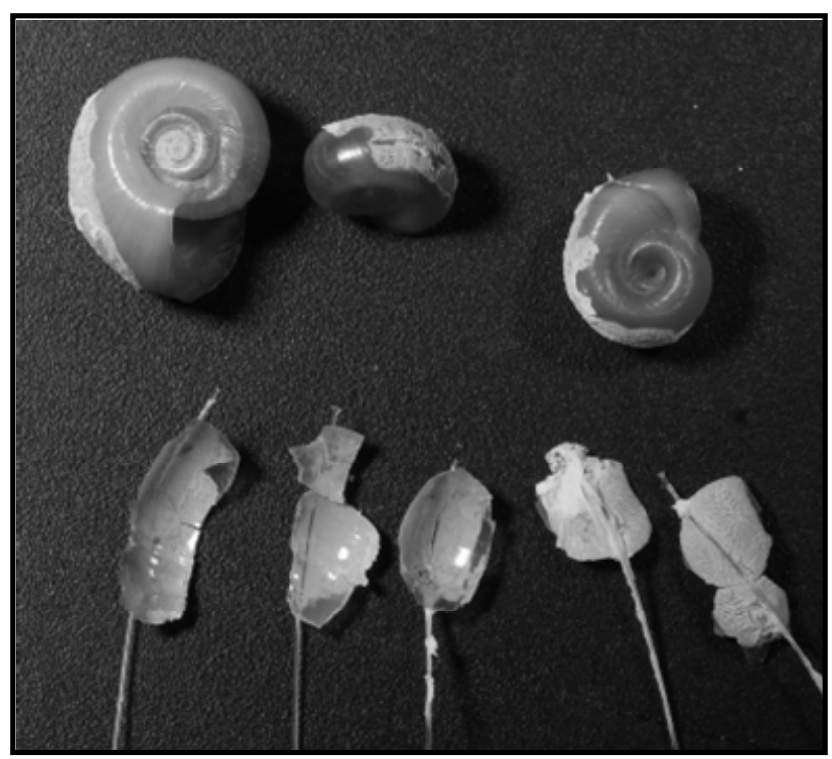

Fig 5.2. Snail shell remains found at the end of tethers. Intact empty shells were left by entry based predators like a crayfish (top), while a crushing predator, like a fish, left shell fragments (bottom). 


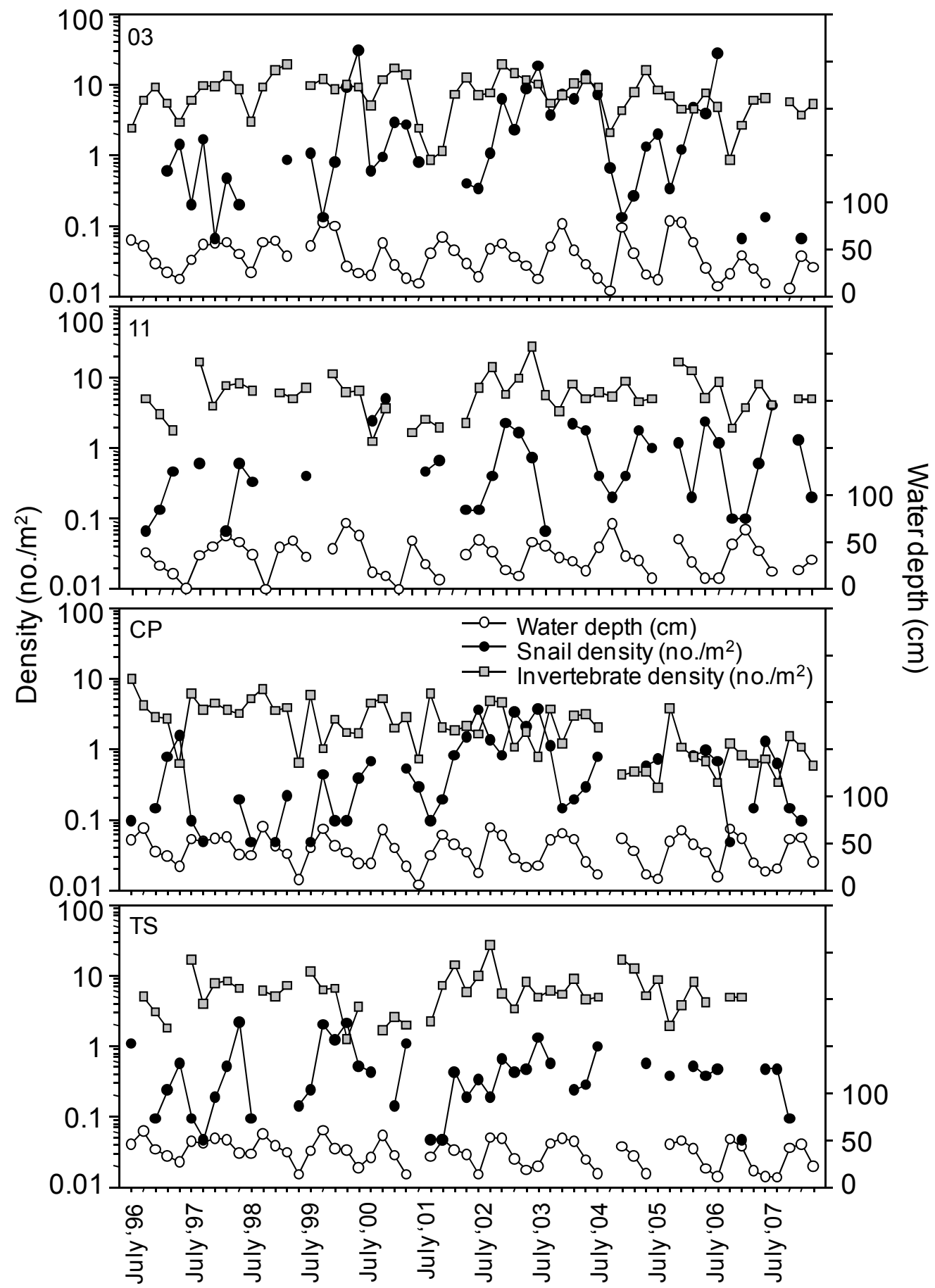

Fig 5.3. Snail density, closed circle and invertebrate density, square, compared to water depth, open circle, for a twelve year period at four sites in the Everglades. Site 03 and 11 are in WCA, while CP and TS are in TSL. Site 3 was deeper and did not dry as often as site 11, while the two sites in TSL had very similar hydrology. Note the log scale on the left $y$-axis for density and the right y-axis for water depth is a linear scale. 

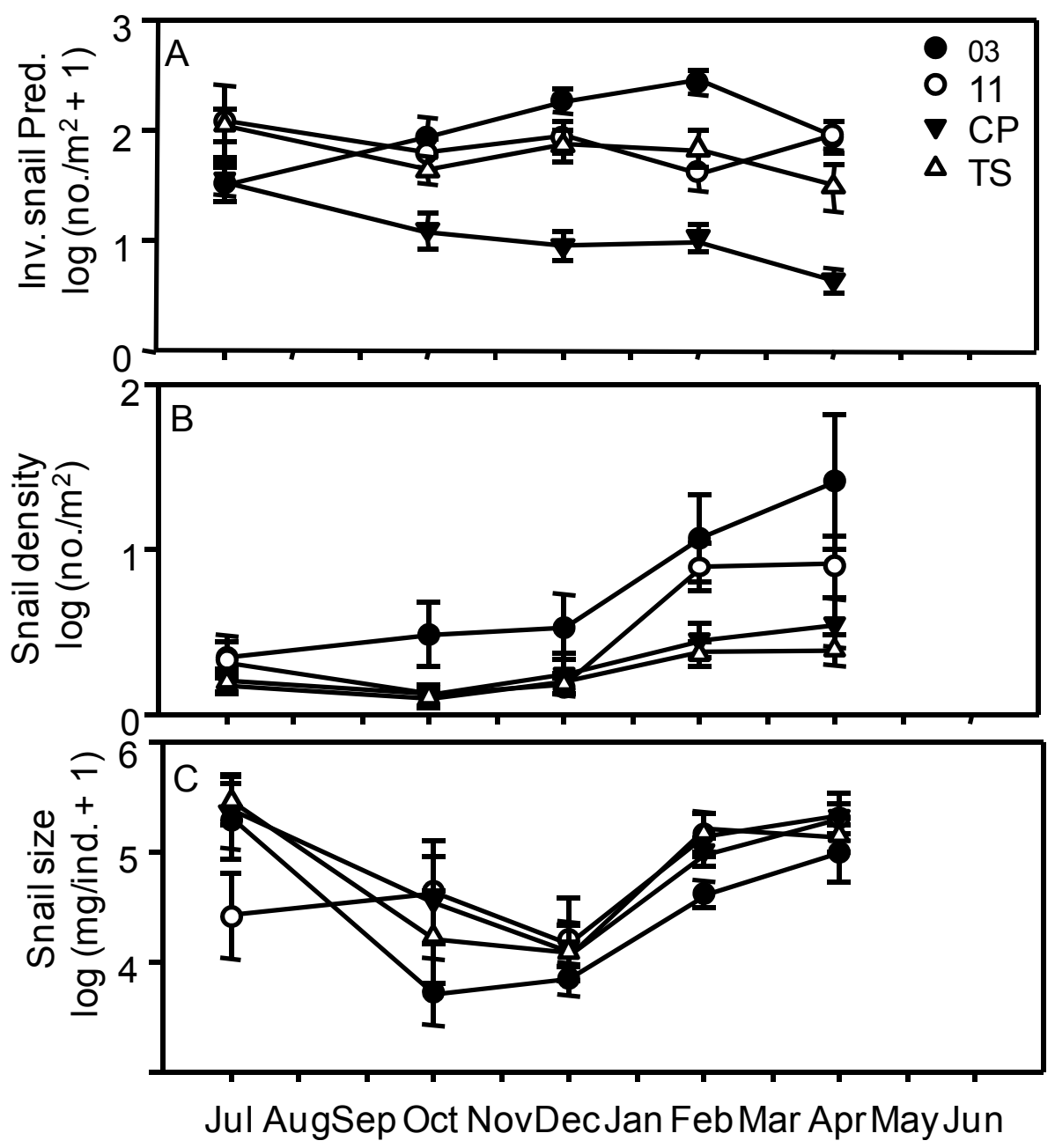

Fig. 5.4. Seasonal variation (mean $\pm \mathrm{SE}, 12 \mathrm{y}$ ) in a variety of biotic variables. Plots show crayfish density, A, snail density, $\mathrm{B}$, and individual snail size, $\mathrm{C}$ at two sites in WCA $(03,11)$ and TSL (CP, TS). 

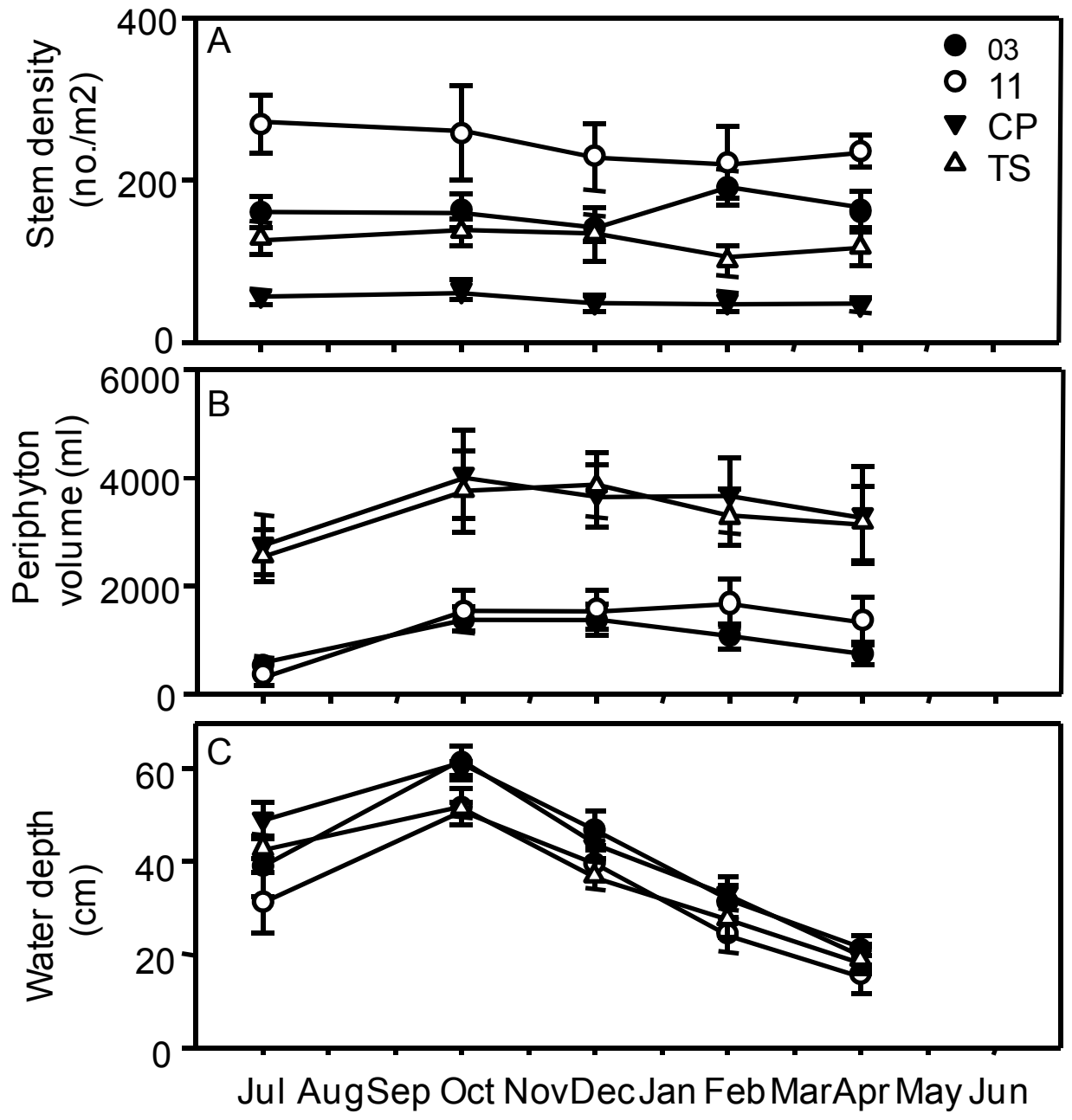

Fig. 5.5. Seasonal variation (mean $\pm \mathrm{SE}, 12 \mathrm{y}$ ) in abiotic variables. Plots show stem density, A, periphyton volume, B, and water depth, $\mathrm{C}$ at two sites in $\mathrm{WCA}(03,11)$ and TSL (CP, TS). 


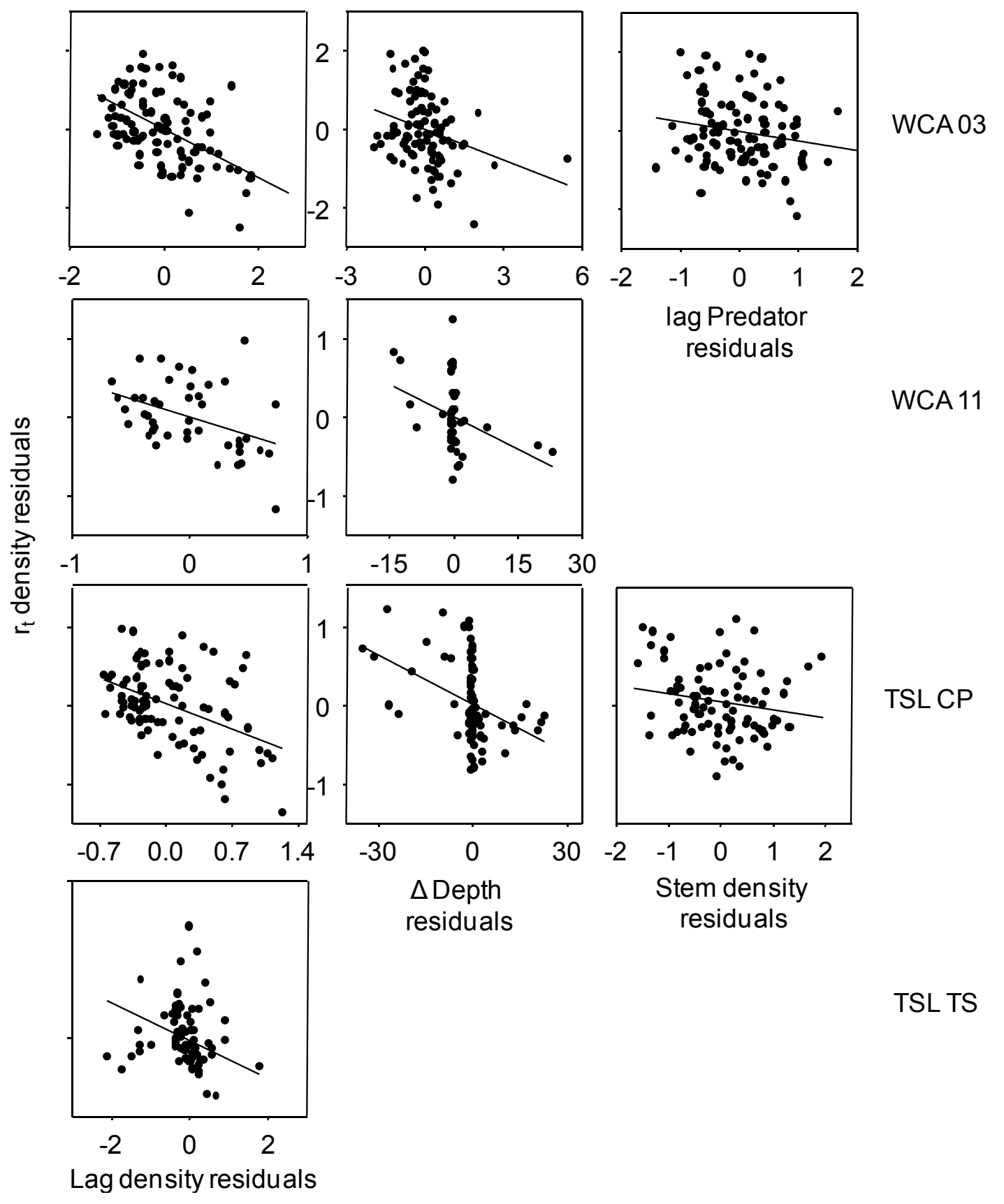

Fig 5.6. Partial regression plots for the log change in snail density $\left(\mathrm{no} / \mathrm{m}^{2}\right)$ and depth $(\mathrm{cm}), \operatorname{lag} \log$-snail density $\left(\mathrm{no} / \mathrm{m}^{2}\right), \log$ stem density $\left(\mathrm{no} / \mathrm{m}^{2}\right)$, or lag log-crayfish density $\left(\mathrm{no} / \mathrm{m}^{2}\right)$ at two sites in WCA and two sites in TSL. Not all independent variables retained in the final model exhibited strong correlations $(>|0.2|)$ with the change in snail density and are not shown. Site and region labels are on right. Plots show residuals for the dependent and independent variables after each was regressed separately on the other independent variables. Note that the $\mathrm{x}$ - and $\mathrm{y}$-axis scales change. 


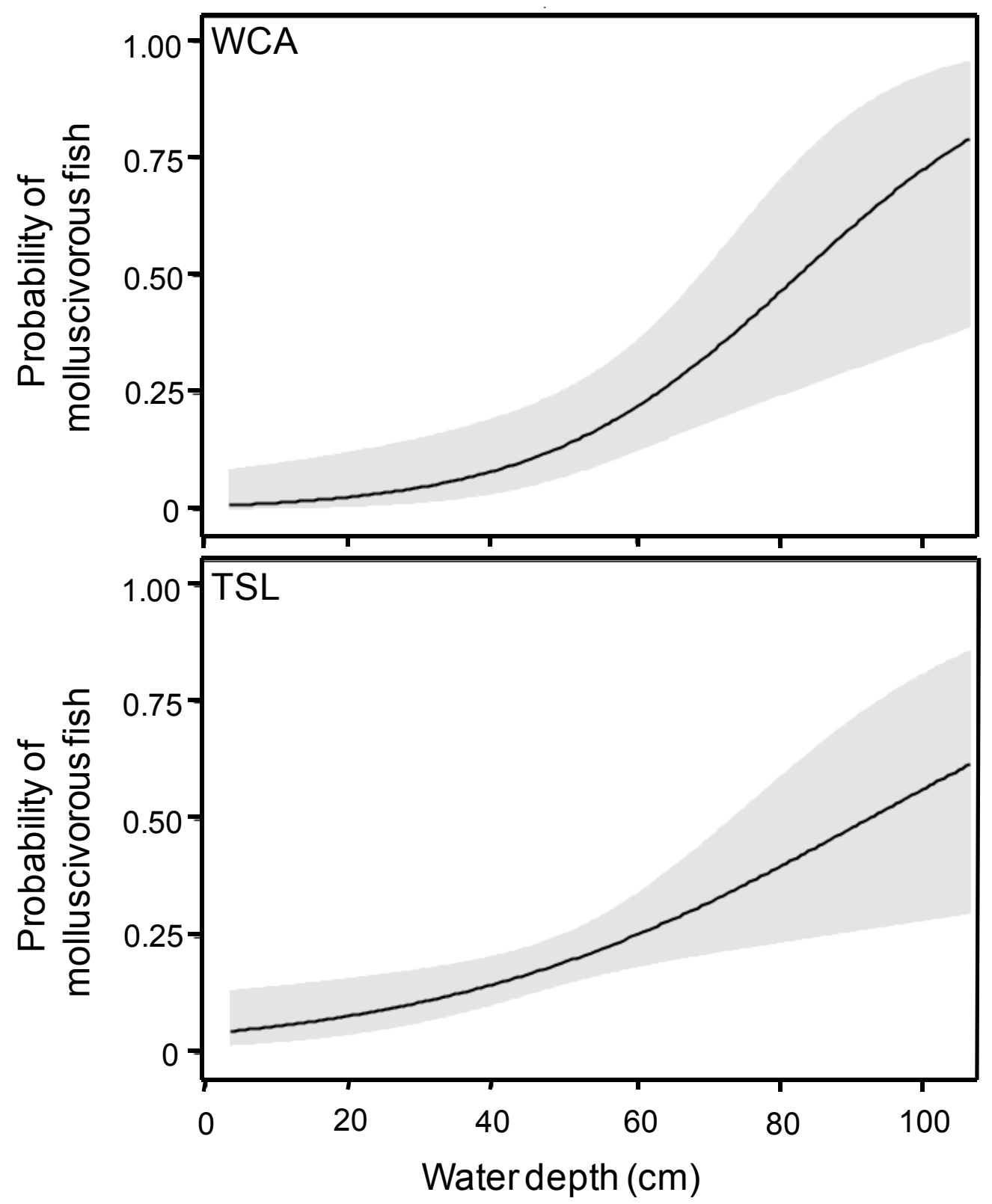

Fig 5.7. Probability and $95 \%$ confidence bands of catching a molluscivorous fish with increasing depth in WCA and TSL between 1996 and 2007. Results are from a model selection procedure where water depth was the best model in WCA and water depth and year was the most parsimonious model in TSL. 

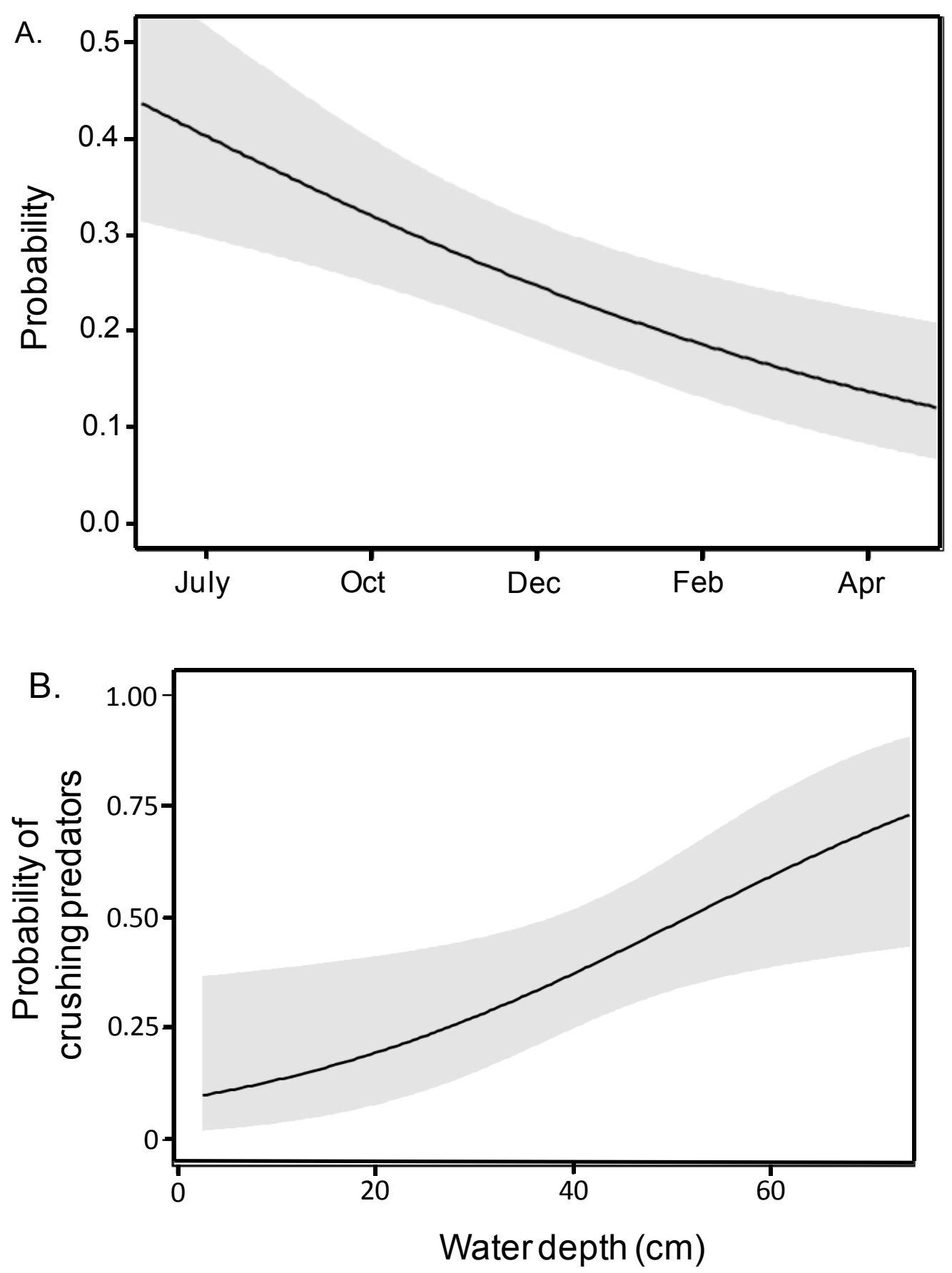

Fig 5.8. Variation in the probability of snail mortality estimated from tethering, A, and the probability that a mortality resulted from a crushing predator, B. Each plot displays the predicted relationship and $95 \%$ confidence band with the independent variable that was the best predictor chosen from a set of models using AIC. The probability of mortality was greatest in July and October during the wet season and the probability that the consumed snails were eaten by a crushing predator increased with water depth. 

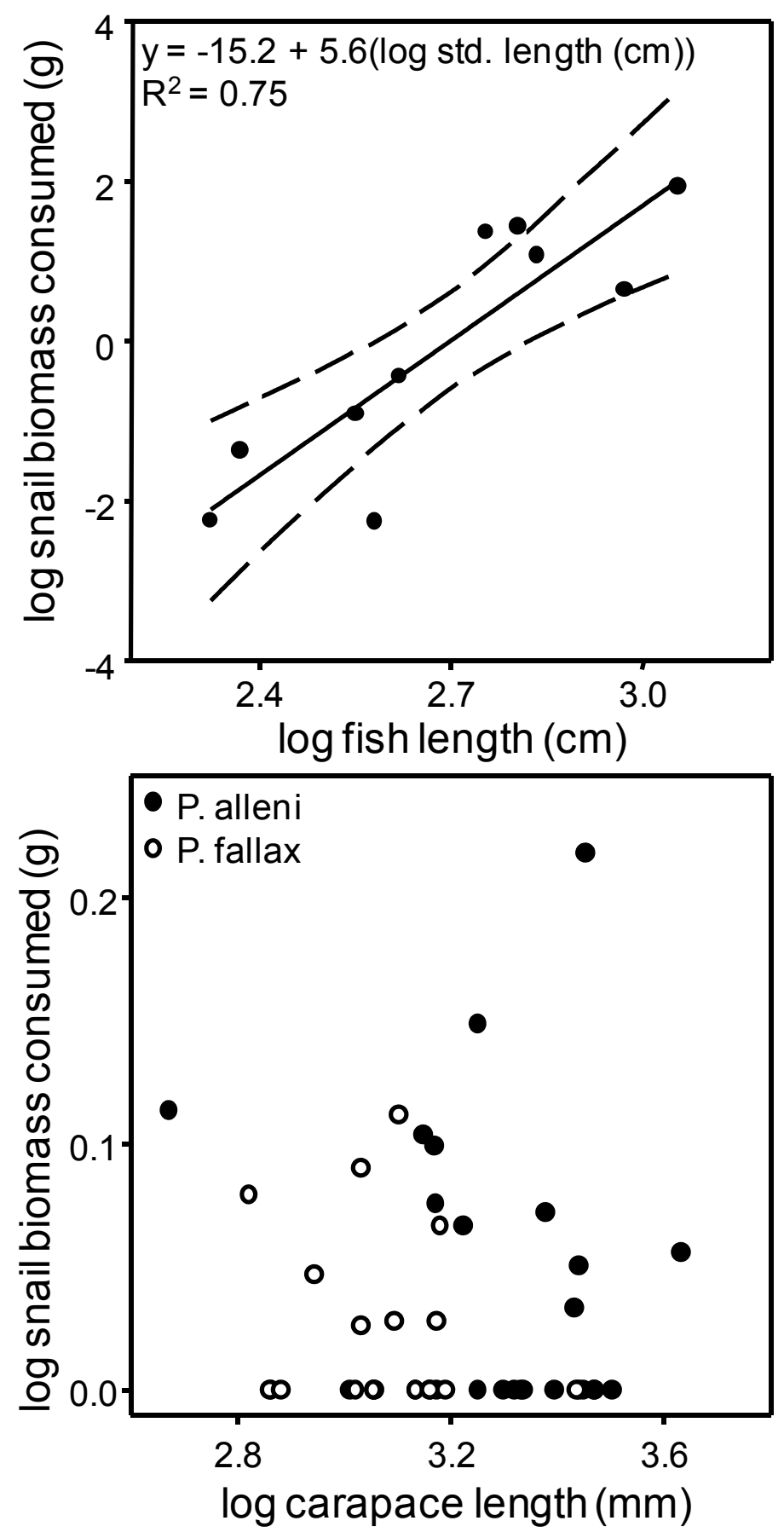

Fig 5.9. Snail biomass (g) consumed in 24-hours by different sized Mayan cichlids, top, and two species of crayfish, bottom. Note the positive relationship between fish and consumption of snail biomass as indicated by the regression line (solid) and 95\% CI lines (dashed); there was no size relationship with crayfish consumption. 


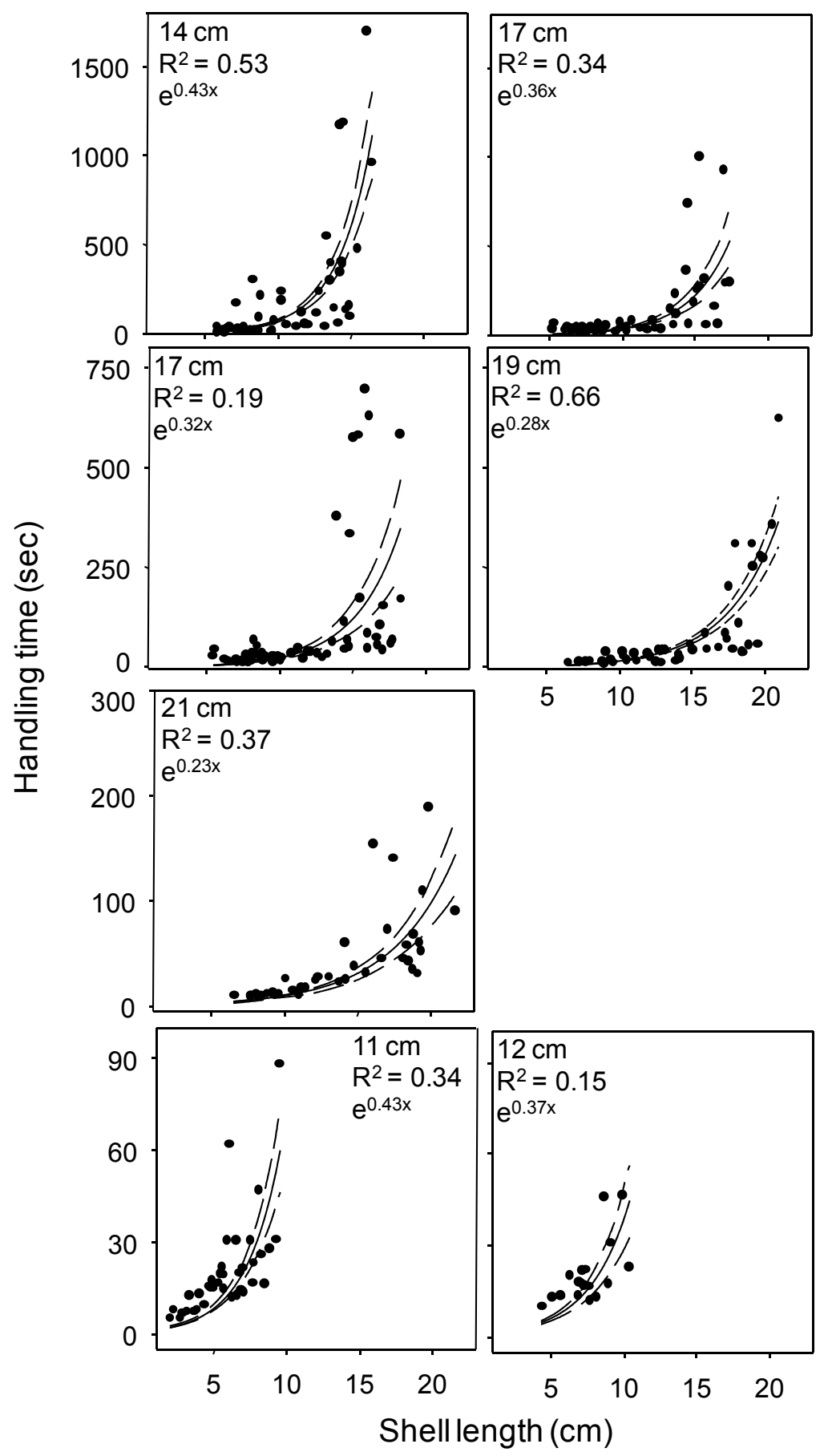

Fig 5.10. Time to consumption of different sized snails by different sized Mayan cichlids. Exponential curves and 95\% confidence intervals demonstrate snail size refugia. Standard length, model fit, and the equation for each line is in the upper left, or right of each panel. Note the y-axis is different for each row. Long handling times are not necessarily associated with larger fish. 
CHAPTER VI

SUMMARY 
Many populations vary spatially and temporally within well defined bounds; understanding why they are bounded has been the subject of considerable ecological research for nearly eight decades. Abiotic factors generally filter the regional species pool to include those capable of maintaining populations within an ecosystem. Many of those same abiotic factors operate locally to affect population dynamics of resident species. Disturbance affects a population by removing individuals, while other factors like nutrient availability stimulate individual growth and reproduction that can have positive effects on population growth. Predation is an important biotic factor affecting population dynamics that removes individuals through consumption and depresses population growth through non-consumptive effects by altering the behavior, physiology, morphology, growth, and reproduction of individuals. A complete picture of the relative impact that disturbance, resource quality and predation have on population dynamics emerges when they are considered together. I took an integrative approach to examining the relative importance of these factors by combining field experiments, mesocosm experiments, time-series analysis, and performance trials to understand the population dynamics of the Seminole Ramshorn snail in the Florida Everglades. The Everglades is a large sub-tropical karstic wetland characterized by high standing stocks of periphyton but relatively few consumers. It was once an extremely oligotrophic wetland from Lake Okeechobee in the north to Florida Bay in the south, but agricultural activities and the construction of an extensive canal system has established a gradient of phosphorous enrichment that stretches from north to south.

My first study distinguished the Everglades and other karstic wetlands from lakes, streams, ponds, rivers, and other types of wetlands by revealing that these ecosystems 
support extremely low snail abundance and standing crop in comparison to other ecosystems. I used the results of this review as the basis for my subsequent experimental studies to understand why snails are relatively rare in the Everglades. A mesocosm experiment separated the consumptive and non-consumptive effects of crayfish predators at different levels of phosphorous enrichment on snail behavior, growth, morphology, and reproduction. Path analysis revealed that the net-effect of each was similar in magnitude, but nutrients slightly outweighed the non-consumptive predator effects. Snail growth and reproduction were limited by resources at ambient nutrient levels found in the Everglades and non-consumptive predator effects reduced growth and reproduction. Interestingly, mimicking direct consumption had negligible effects on growth but appeared to improve survival for remaining individuals. Improved resource quality through phosphorous enrichment, non-consumptive predator effects, and their interactions are likely to have profound consequences on population dynamics of aquatic snails in the Everglades. However, quantifying the relative importance of each on population dynamics in natural systems is problematic because the stimulatory effects of improved resources can largely be canceled by non-consumptive effects of predators since the magnitude of their net effects were similar.

A naturally occurring gradient of phosphorous enrichment and predators along a canal served as the basis to separate their effects in the field. I designed a reciprocal transplant experiment to isolate the effects of predator cues from nutrients on snail growth and reproduction. I found that during the experiment, predation rate and predator densities were generally greater near canals. Snail growth rates on local periphyton were faster near canals; however, when transplanted periphyton that was higher quality was 
considered, snail growth was fastest at sites far from canals on periphyton that originated near canals. Egg production was highest far from canals. This study of the phosphorous gradient builds on prior work demonstrating that canals alter aquatic community structure. I extend this work by providing evidence that population dynamics of snails are different near compared to far from canals and suggest that the interplay between predators and nutrients could explain why other organisms show only minor or no response to human-impacted ecosystems.

The mesocosm and field study considered trade-offs between resources and threats of predation on the growth and reproduction of snails among other traits. The final study, did not address nutrients directly, but considered a twelve-year time series of snail density and body size at four sites that varied in the degree of phosphorous enrichment. The time-series directly addressed the relative importance of crayfish, molluscivorous fishes, habitat complexity, and disturbance (seasonal water permanence) on snail population dynamics. Field estimates of mortality (encounter rate) were quantified with tethering experiments. Water permanence and resource quality affected snail density the most; invertebrate predators were a small but chronic source of mortality. Molluscivorous fishes represented a substantial source of mortality but only during the wet season. Therefore, aquatic communities in seasonally flooded marshes that connect to permanent water bodies appear to go through an annual succession; in the dry season populations are most affected by abiotic factors, like water permanence, while biotic factors, like fish and crayfish predation, become increasingly important to populations during the wet season. Phosphorous enrichment appears to alter the magnitude and the nature of interactions. The site experiencing the most phosphorous enrichment supported 
the largest snail populations and also exhibited evidence of negative density dependence with crayfish suggesting that predators become increasingly important with increasing nutrient enrichment.

Combined, these studies reveal interplay between the positive effects of nutrients, and the negative effects of seasonal drying, predators, and their cues that limit snail populations in the Everglades. Nutrients emerge as the most important factor because the Everglades, and similar ecosystems, have extraordinarily low phosphorous levels and although periphyton production is high, it is of low nutritional quality. Phosphorous additions lead to increased growth and reproductive rates that ultimately have positive effects on population growth rates. Seasonal drying removes a portion of the snail population annually but they appear to recover quickly due to life history traits enabling them to resist desiccation. Predator effects become important at certain times and places in the Everglades, but do not amount to the chronic effects of low resource quality for snail populations. These findings offer experimental results that bolster data collected through monitoring efforts designed to assess the Comprehensive Everglades Restoration Plan (CERP) and provide insight into the general understanding of the interactive effects of nutrients, seasonality, and predators in structuring populations. 
APPENDIX 
Appendix. Database of studies used in the review (Chapter II). An asterisk next to standing crop values indicates I estimated biomass from shell length with length-to-width regressions and multiplied by density to calculate standing crop. Standing crop values are the estimated wet mass when data were reported in other units. We assumed an $85 \%$ loss for dried, and a $90 \%$ loss for ashed samples. Loss estimates were determined from pulmonate and caenogastropod snails found in the Everglades (unpublished data).

Taxonomic groups were based on names reported in the study except where names occur in parentheses, which are the most recent classifications. Studies in the review are listed in the literature cited section that follows. 


\begin{tabular}{|c|c|c|c|c|c|}
\hline Ecosystem & $\begin{array}{l}\text { Density } \\
\left(\text { No. } / \mathrm{m}^{2}\right)\end{array}$ & $\begin{array}{l}\text { Standing } \\
\text { Crop } \\
\left(\mathrm{g} / \mathrm{m}^{2}\right)\end{array}$ & Location & Taxonomic group & Study \\
\hline 1 st order & - & 0 & Oregon & Oxytrema silicula (Juga silicula) & Anderson et al. 1978 \\
\hline 3rd order & - & 0.0047 & Oregon & Oxytrema silicula (Juga silicula) & Anderson et al. 1978 \\
\hline 5 th order & - & 1.25 & Oregon & Oxytrema silicula (Juga silicula) & Anderson et al. 1978 \\
\hline 7th order & - & 1.87 & Oregon & Oxytrema silicula (Juga silicula) & Anderson et al. 1978 \\
\hline 6th order & - & 3.75 & Oregon & Oxytrema silicula (Juga silicula) & Anderson et al. 1978 \\
\hline 3rd order & - & 4.71 & Oregon & Oxytrema silicula (Juga silicula) & Anderson et al. 1978 \\
\hline 2 nd order & - & 36.58 & Oregon & Oxytrema silicula (Juga silicula) & Anderson et al. 1978 \\
\hline spring & 185.2 & - & $\begin{array}{l}\text { Northern } \\
\text { Spain }\end{array}$ & Bythinella, Theodoxus fluviatilis & $\begin{array}{l}\text { Barquin and Death } \\
2004\end{array}$ \\
\hline stream & 3.5 & - & $\begin{array}{l}\text { Northern } \\
\text { Spain }\end{array}$ & Bythinella Theodoxus fluviatilis & $\begin{array}{l}\text { Barquin and Death } \\
2004\end{array}$ \\
\hline pond & 16500 & - & Wisconsin & Amnicola limosa, Gyraulus parvus & Beckett et al. 1992 \\
\hline karstic wetland & 0.9 & - & $\begin{array}{l}\text { Everglades, } \\
\text { Florida }\end{array}$ & Pomacea paludosa & Bennetts et al.. 2006 \\
\hline river & 367 & - & $\begin{array}{l}\text { United } \\
\text { Kingdom }\end{array}$ & $\begin{array}{l}\text { Bithynia tentaculata, Lymnaea } \\
\text { auricularia, Planorbis albus, } \\
\text { Potamopyrgus jenkinsi, Valvata } \\
\text { piscinalis, Viviparus viviparus }\end{array}$ & $\begin{array}{l}\text { Bishop and DeGaris } \\
1974\end{array}$ \\
\hline 2 nd order & 47.95 & - & Michigan & Elimia & Breen 2008 \\
\hline
\end{tabular}




\begin{tabular}{|c|c|c|c|c|c|}
\hline Ecosystem & $\begin{array}{c}\text { Density } \\
\left(\text { No. } / \mathrm{m}^{2}\right)\end{array}$ & $\begin{array}{l}\text { Standing } \\
\text { Crop } \\
\left(\mathrm{g} / \mathrm{m}^{2}\right)\end{array}$ & Location & Taxonomic group & Study \\
\hline pond & 628.5 & & Sweden & $\begin{array}{l}\text { Acroloxus lacustris, Anisus vortex, } \\
\text { Bathyomphalus contortus, } \\
\text { Gyraulus albus, Gyraulus crista, } \\
\text { Hippeutis complanatus, Lymnaea } \\
\text { auricularia, Lymnaea peregra, } \\
\text { Lymnaea stagnalis, Physa } \\
\text { fontinalis, Planorbarius corneus }\end{array}$ & Bronmark 1988 \\
\hline pond & 435 & - & Indiana & $\begin{array}{l}\text { Aplexa hypnorum, Gyraulus parva, } \\
\text { Helisoma trivolvis, Lymnaea elodes } \\
\text { (palustris), Lymnaea humilis, } \\
\text { Physa gyrina }\end{array}$ & Brown 1982 \\
\hline pond & 510 & - & Indiana & $\begin{array}{l}\text { Aplexa hypnorum, Gyraulus parva, } \\
\text { Helisoma trivolvis, Lymnaea elodes } \\
\text { (palustris), Lymnaea humilis, } \\
\text { Physa gyrina }\end{array}$ & Brown 1982 \\
\hline pond & 880 & - & Indiana & $\begin{array}{l}\text { Aplexa hypnorum, Gyraulus parva, } \\
\text { Helisoma trivolvis, Lymnaea elodes } \\
\text { (palustris), Lymnaea humilis, } \\
\text { Physa gyrina }\end{array}$ & Brown 1982 \\
\hline
\end{tabular}




\begin{tabular}{|c|c|c|c|c|c|}
\hline Ecosystem & $\begin{array}{l}\text { Density } \\
\left(\mathrm{No} . / \mathrm{m}^{2}\right)\end{array}$ & $\begin{array}{l}\text { Crop } \\
\left(\mathrm{g} / \mathrm{m}^{2}\right)\end{array}$ & Location & Taxonomic group & Study \\
\hline pond & 510 & - & Indiana & $\begin{array}{l}\text { Aplexa hypnorum, Gyraulus parva, } \\
\text { Helisoma trivolvis, Lymnaea elodes } \\
\text { (palustris), Lymnaea humilis, } \\
\text { Physa gyrina }\end{array}$ & Brown 1982 \\
\hline pond & 20.9 & - & Indiana & Lymnaea elodes & $\begin{array}{l}\text { Brown and DeVries } \\
1985\end{array}$ \\
\hline pond & 1.8 & - & Indiana & Lymnaea elodes & $\begin{array}{l}\text { Brown and DeVries } \\
1985\end{array}$ \\
\hline lake & 2667.94 & - & Wisconsin & $\begin{array}{l}\text { Amnicola limosa, Amnicola } \\
\text { lustrica, Campeloma decisum, } \\
\text { Gyraulus hirsutus, Gyraulus parva, } \\
\text { Helisoma anceps, Helisoma } \\
\text { campanulatum, Lymnaea } \\
\text { emarginata, Lymnaea stagnalis, } \\
\text { Physella spp., Promonetus } \\
\text { exacuous, Valvata tricarinata }\end{array}$ & Brown and Lodge 1993 \\
\hline lake & 1290.23 & - & Michigan & Amnicola, Gyraulus, Physa & Brown et al. 1988 \\
\hline river & 869.5 & - & Louisiana & $\begin{array}{l}\text { Campeloma decisum, Vivparus } \\
\text { subpurpureus }\end{array}$ & Brown et al. 1989 \\
\hline lake & 89 & - & New York & Viviparus georgianus & Browne 1978 \\
\hline lake & 67 & - & New York & Viviparus georgianus & Browne 1978 \\
\hline lake & 47 & - & New York & Viviparus georgianus & Browne 1978 \\
\hline reservoir & 106 & - & New York & Viviparus georgianus & Browne 1978 \\
\hline 1st order & 3125 & - & Tennessee & Elimia clavaeformis & Burris et al. 1990 \\
\hline
\end{tabular}




\begin{tabular}{|c|c|c|c|c|c|}
\hline Ecosystem & $\begin{array}{l}\text { Density } \\
\left(\mathrm{No} . / \mathrm{m}^{2}\right)\end{array}$ & $\begin{array}{c}\text { Standing } \\
\text { Crop } \\
\left(\mathrm{g} / \mathrm{m}^{2}\right) \\
\end{array}$ & Location & Taxonomic group & Study \\
\hline ditch & 291.18 & 251.79 & France & $\begin{array}{l}\text { Anisus rotundatus, Lymnaea } \\
\text { palustris, Physa fontinalis }\end{array}$ & Caquet 1993 \\
\hline $\begin{array}{l}\text { snail invaded } \\
\text { wetland }\end{array}$ & 9.9 & - & $\begin{array}{l}\text { Vieneiane, } \\
\text { Lao PDR }\end{array}$ & Pomacea canaliculata & Carlsson 2004 \\
\hline $\begin{array}{l}\text { snail invaded } \\
\text { wetland }\end{array}$ & 11.9 & - & $\begin{array}{l}\text { Vieneiane, } \\
\text { Lao PDR }\end{array}$ & Pomacea canaliculata & Carlsson 2004 \\
\hline $\begin{array}{l}\text { snail invaded } \\
\text { wetland }\end{array}$ & 6.5 & - & $\begin{array}{l}\text { Vieneiane, } \\
\text { Lao PDR }\end{array}$ & Pomacea canaliculata & Carlsson 2004 \\
\hline lake & 520 & - & Iowa & Physa gyrina, Physa integra & Clampitt 1970 \\
\hline lake & 1455 & - & Iowa & Physa integra & Clampitt 1970 \\
\hline lake & 9.32 & - & Michigan & Heilsoma, Physa, Stagnicola & Clampitt 1973 \\
\hline stream & 450 & - & New Zealand & Potamopyrgus antipodarum & Collier et al. 1998 \\
\hline stream & 1450 & - & New Zealand & Potamopyrgus antipodarum & Collier et al. 1998 \\
\hline stream & 1000 & - & New Zealand & Potamopyrgus antipodarum & Collier et al. 1998 \\
\hline stream & 100 & - & New Zealand & Potamopyrgus antipodarum & Collier et al. 1998 \\
\hline stream & 4150 & - & New Zealand & Potamopyrgus antipodarum & Collier et al. 1998 \\
\hline stream & 50 & - & New Zealand & Potamopyrgus antipodarum & Collier et al. 1998 \\
\hline stream & 800 & - & New Zealand & Potamopyrgus antipodarum & Collier et al. 1998 \\
\hline stream & 2025 & - & New Zealand & Potamopyrgus antipodarum & Collier et al. 1998 \\
\hline stream & 2250 & - & New Zealand & Potamopyrgus antipodarum & Collier et al. 1998 \\
\hline stream & 1250 & - & New Zealand & Potamopyrgus antipodarum & Collier et al. 1998 \\
\hline stream & 250 & - & New Zealand & Potamopyrgus antipodarum & Collier et al. 1998 \\
\hline stream & 30 & - & New Zealand & Potamopyrgus antipodarum & Collier et al. 1998 \\
\hline
\end{tabular}




\begin{tabular}{|c|c|c|c|c|c|}
\hline Ecosystem & $\begin{array}{l}\text { Density } \\
\left(\text { No. } / \mathrm{m}^{2}\right)\end{array}$ & $\begin{array}{c}\text { Standing } \\
\text { Crop } \\
\left(\mathrm{g} / \mathrm{m}^{2}\right) \\
\end{array}$ & Location & Taxonomic group & Study \\
\hline stream & 30 & - & New Zealand & Potamopyrgus antipodarum & Collier et al. 1998 \\
\hline stream & 275 & - & New Zealand & Potamopyrgus antipodarum & Collier et al. 1998 \\
\hline stream & 1500 & - & New Zealand & Potamopyrgus antipodarum & Collier et al. 1998 \\
\hline stream & 250 & - & New Zealand & Potamopyrgus antipodarum & Collier et al. 1998 \\
\hline stream & 150 & - & New Zealand & Potamopyrgus antipodarum & Collier et al. 1998 \\
\hline pond & 32.69 & 1.23 & $\begin{array}{l}\text { Rennes, } \\
\text { France }\end{array}$ & Planorbarius planorbis & $\begin{array}{l}\text { Costil and Daguzan } \\
1995^{*}\end{array}$ \\
\hline pond & 11.94 & 1.5 & $\begin{array}{l}\text { Brittany, } \\
\text { France }\end{array}$ & Planorbarius corneus & $\begin{array}{l}\text { Costil and Daguzan } \\
1995^{*}\end{array}$ \\
\hline karstic wetland & 0.24 & - & $\begin{array}{l}\text { Everglades, } \\
\text { Florida }\end{array}$ & Pomacea paludosa & Darby et al. 1999 \\
\hline lake & 0.64 & - & Florida & Pomacea paludosa & Darby et al. 2004 \\
\hline 2 nd order & 220 & - & Virginia & Pleuroceridae & Dazo 1965 \\
\hline lake & 35 & - & Michigan & Pleuroceridae & Dazo 1965 \\
\hline lake & 140 & - & Michigan & Pleuroceridae & Dazo 1965 \\
\hline lake & 18 & - & Michigan & Pleuroceridae & Dazo 1965 \\
\hline river & 20 & - & Tennessee & Pleuroceridae & Dazo 1965 \\
\hline river & 151.5 & - & Michigan & Goniobasis livescens & Dazo 1965 \\
\hline stream & 150 & - & Tennessee & Pleuroceridae & Dazo 1965 \\
\hline stream & 220 & - & Tennessee & Pleuroceridae & Dazo 1965 \\
\hline stream & 80 & - & Tennessee & Pleuroceridae & Dazo 1965 \\
\hline stream & 250 & - & Tennessee & Pleuroceridae & Dazo 1965 \\
\hline stream & 50 & - & Tennessee & Pleuroceridae & Dazo 1965 \\
\hline
\end{tabular}




\begin{tabular}{|c|c|c|c|c|c|}
\hline Ecosystem & $\begin{array}{l}\text { Density } \\
\left(\text { No. } / \mathrm{m}^{2}\right) \\
\end{array}$ & $\begin{array}{l}\text { Standing } \\
\text { Crop } \\
\left(\mathrm{g} / \mathrm{m}^{2}\right) \\
\end{array}$ & Location & Taxonomic group & Study \\
\hline stream & 100 & - & Tennessee & Pleuroceridae & Dazo 1965 \\
\hline stream & 187.36 & - & Michigan & Goniobasis livescens & Dazo 1965 \\
\hline stream & 120 & - & Tennessee & Pleuroceridae & Dazo 1965 \\
\hline stream & 200 & - & Tennessee & Pleuroceridae & Dazo 1965 \\
\hline stream & 35 & - & Tennessee & Pleuroceridae & Dazo 1965 \\
\hline stream & 557.23 & - & Michigan & Goniobasis livescens & Dazo 1965 \\
\hline stream & 64.38 & - & Michigan & $\begin{array}{l}\text { Goniobasis livescens, , Pleurocera } \\
\text { acuta }\end{array}$ & Dazo 1965 \\
\hline 1st order & 0.1 & - & Michigan & Gastropoda & De Mol 2007 \\
\hline 2nd order & 9.75 & - & Michigan & Gastropoda & De Mol 2007 \\
\hline 3rd order & 1.2 & - & Michigan & Gastropoda & De Mol 2007 \\
\hline swamp & 6.49 & - & $\begin{array}{l}\text { Ghent } \\
\text { England }\end{array}$ & Lymnaeidae, Planorbidae & $\begin{array}{l}\text { DeCoster and Persoone } \\
1970\end{array}$ \\
\hline 1st order & 1262.5 & 15.25 & Oregon & Juga plicifera (Juga silicula) & Diamond, J. M. 1976 \\
\hline 3rd order & 1075 & 22.3 & Oregon & Juga plicifera (Juga silicula) & Diamond, J. M. 1976 \\
\hline 4 th order & 425 & 22.88 & Oregon & Juga plicifera (Juga silicula) & Diamond, J. M. 1976 \\
\hline 6 th order & 366.67 & 39.67 & Oregon & Juga plicifera (Juga silicula) & Diamond, J. M. 1976 \\
\hline rice field & 0.16 & - & $\begin{array}{l}\text { Venezuelan } \\
\text { llanos }\end{array}$ & Pomacea doliodes & $\begin{array}{l}\text { Donnay and Bessinger } \\
1993\end{array}$ \\
\hline wetland & 0.041 & - & $\begin{array}{l}\text { Venezuelan } \\
\text { llanos }\end{array}$ & Pomacea doliodes & $\begin{array}{l}\text { Donnay and Bessinger } \\
1993\end{array}$ \\
\hline ditch & 435 & 20.63 & Hong Kong & Melanoides tuberculata & Dudgeon 1986 \\
\hline
\end{tabular}




\begin{tabular}{|c|c|c|c|c|c|}
\hline Ecosystem & $\begin{array}{l}\text { Density } \\
\left(\text { No. } / \mathrm{m}^{2}\right)\end{array}$ & $\begin{array}{l}\text { Standing } \\
\text { Crop } \\
\left(\mathrm{g} / \mathrm{m}^{2}\right)\end{array}$ & Location & Taxonomic group & Study \\
\hline $\begin{array}{l}\text { temperate } \\
\text { wetland }\end{array}$ & 8.4 & - & Mississippi & Micromenetus & Duffy and LaBar 1994 \\
\hline canal & 562.72 & - & $\begin{array}{l}\text { Northwest } \\
\text { England }\end{array}$ & $\begin{array}{l}\text { Bithynia tentaculata, Gyraulus } \\
\text { albus, Lymnaea pergra, Planorbis } \\
\text { planorbis }\end{array}$ & Dussart 1979 \\
\hline canal & 824.12 & - & $\begin{array}{l}\text { Northwest } \\
\text { England }\end{array}$ & $\begin{array}{l}\text { Bithynia tentaculata, Gyraulus } \\
\text { albus, Lymnaea pergra, Planorbis } \\
\text { planorbis }\end{array}$ & Dussart 1979 \\
\hline canal & 323.41 & - & $\begin{array}{l}\text { Northwest } \\
\text { England }\end{array}$ & $\begin{array}{l}\text { Bithynia tentaculata, Gyraulus } \\
\text { albus, Lymnaea pergra, Planorbis } \\
\text { planorbis }\end{array}$ & Dussart 1979 \\
\hline canal & 674.19 & - & $\begin{array}{l}\text { Northwest } \\
\text { England }\end{array}$ & $\begin{array}{l}\text { Bithynia tentaculata, Gyraulus } \\
\text { albus, Lymnaea pergra, Planorbis } \\
\text { planorbis }\end{array}$ & Dussart 1979 \\
\hline lake & 141.55 & - & $\begin{array}{l}\text { Northwest } \\
\text { England }\end{array}$ & $\begin{array}{l}\text { Bithynia tentaculata, Gyraulus } \\
\text { albus, Lymnaea pergra, Planorbis } \\
\text { planorbis }\end{array}$ & Dussart 1979 \\
\hline lake & 270.02 & - & $\begin{array}{l}\text { Northwest } \\
\text { England }\end{array}$ & $\begin{array}{l}\text { Bithynia tentaculata, Gyraulus } \\
\text { albus, Lymnaea pergra, Planorbis } \\
\text { planorbis }\end{array}$ & Dussart 1979 \\
\hline lake & 35.78 & - & $\begin{array}{l}\text { Northwest } \\
\text { England }\end{array}$ & $\begin{array}{l}\text { Bithynia tentaculata, Gyraulus } \\
\text { albus, Lymnaea pergra, Planorbis } \\
\text { planorbis }\end{array}$ & Dussart 1979 \\
\hline lake & 55.64 & - & $\begin{array}{l}\text { Northwest } \\
\text { England }\end{array}$ & $\begin{array}{l}\text { Bithynia tentaculata, Gyraulus } \\
\text { albus, Lymnaea pergra, Planorbis } \\
\text { planorbis }\end{array}$ & Dussart 1979 \\
\hline
\end{tabular}




\begin{tabular}{|c|c|c|c|c|c|}
\hline Ecosystem & $\begin{array}{l}\text { Density } \\
\left(\mathrm{No} . / \mathrm{m}^{2}\right)\end{array}$ & $\begin{array}{l}\text { Standing } \\
\text { Crop } \\
\left(\mathrm{g} / \mathrm{m}^{2}\right)\end{array}$ & Location & Taxonomic group & Study \\
\hline pond & 405.3 & - & $\begin{array}{l}\text { Northwest } \\
\text { England }\end{array}$ & $\begin{array}{l}\text { Bithynia tentaculata, Gyraulus } \\
\text { albus, Lymnaea pergra, Planorbis } \\
\text { planorbis }\end{array}$ & Dussart 1979 \\
\hline pond & 269.06 & - & $\begin{array}{l}\text { Northwest } \\
\text { England }\end{array}$ & $\begin{array}{l}\text { Bithynia tentaculata, Gyraulus } \\
\text { albus, Lymnaea pergra, Planorbis } \\
\text { planorbis }\end{array}$ & Dussart 1979 \\
\hline pond & 585.37 & - & $\begin{array}{l}\text { Northwest } \\
\text { England }\end{array}$ & $\begin{array}{l}\text { Bithynia tentaculata, Gyraulus } \\
\text { albus, Lymnaea pergra, Planorbis } \\
\text { planorbis }\end{array}$ & Dussart 1979 \\
\hline pond & 545.22 & 2.86 & New York & $\begin{array}{l}\text { Gyraulus parvus, Lymnaea } \\
\text { palustris, Physa integra }\end{array}$ & Eckblad 1973 \\
\hline pond & 2657.76 & - & Michigan & Lymnaea elodes & Eisenberg 1966 \\
\hline lake & 14975 & - & Greece & Viviparus contectus & $\begin{array}{l}\text { Eleutheriadis and } \\
\text { Lazaridou-Dimitriadou } \\
1995\end{array}$ \\
\hline $\begin{array}{l}\text { temperate } \\
\text { wetland }\end{array}$ & 2.77 & - & Greece & Bithynia graeca & $\begin{array}{l}\text { Eleutheriadis and } \\
\text { Lazaridou-Dimitriadou } \\
1995\end{array}$ \\
\hline 1 st order & 119 & - & Tennessee & Goniobasis clavaeformis & Elwood et al. 1981 \\
\hline stream & 471.21 & 20.22 & New York & Helisoma trivolvis & Eversole 1978 \\
\hline stream & 10 & - & $\begin{array}{l}\text { North } \\
\text { Carolina }\end{array}$ & Oxytrema proxima & Foin and Stiven 1970 \\
\hline stream & 18 & - & $\begin{array}{l}\text { North } \\
\text { Carolina }\end{array}$ & Oxytrema proxima & Foin and Stiven 1970 \\
\hline stream & 50 & - & North & Oxytrema proxima & Foin and Stiven 1970 \\
\hline
\end{tabular}




\begin{tabular}{|c|c|c|c|c|c|}
\hline Ecosystem & $\begin{array}{l}\text { Sta } \\
\text { Density } \\
\left(\mathrm{No} . / \mathrm{m}^{2}\right)\end{array}$ & $\begin{array}{l}\text { tanding } \\
\text { Crop } \\
\left(\mathrm{g} / \mathrm{m}^{2}\right)\end{array}$ & Location & Taxonomic group & Study \\
\hline stream & 85 & - & $\begin{array}{l}\text { Carolina } \\
\text { North } \\
\text { Carolina }\end{array}$ & Oxytrema proxima & Foin and Stiven 1970 \\
\hline stream & 115 & - & $\begin{array}{l}\text { North } \\
\text { Carolina }\end{array}$ & Oxytrema proxima & Foin and Stiven 1970 \\
\hline stream & 130 & - & $\begin{array}{l}\text { North } \\
\text { Carolina }\end{array}$ & Oxytrema proxima & Foin and Stiven 1970 \\
\hline stream & 210 & - & $\begin{array}{l}\text { North } \\
\text { Carolina }\end{array}$ & Oxytrema proxima & Foin and Stiven 1970 \\
\hline pond & 0.013 & - & $\begin{array}{l}\text { Brittany, } \\
\text { France }\end{array}$ & Gastropoda & Gerard et al. 2008 \\
\hline rice field & 465.17 & 2.76 & Spain & $\begin{array}{l}\text { Lymnaea ovata, Physella acuta, } \\
\text { Planorbis planorbis }\end{array}$ & $\begin{array}{l}\text { Gonzalez-Solis and } \\
\text { Ruiz } 1996\end{array}$ \\
\hline river & - & 32.19 & NW Croatia & Gastropoda & Habdija et al. 1995 \\
\hline $\begin{array}{l}\text { snail invaded } \\
\text { stream }\end{array}$ & 57500 & 28.41 & Wyoming & Potamopyrgus antipodarum & Hall et al. 2006 \\
\hline $\begin{array}{l}\text { snail invaded } \\
\text { stream }\end{array}$ & 71875 & 58.63 & Wyoming & Potamopyrgus antipodarum & Hall et al. 2006 \\
\hline $\begin{array}{l}\text { snail invaded } \\
\text { stream }\end{array}$ & 249166.7 & 163.33 & Wyoming & Potamopyrgus antipodarum & Hall et al. 2006 \\
\hline stream & 38.5 & - & Kentucky & Pleurocera acuta & Hanke Houp 1970 \\
\hline brackish pool & 525.34 & - & St. Vincent & $\begin{array}{l}\text { Drepanotrema lucidum, Physa } \\
\text { marmorata, Potamopyrgus } \\
\text { parvulus }\end{array}$ & $\begin{array}{l}\text { Harrison and Rankin } \\
1978\end{array}$ \\
\hline
\end{tabular}




\begin{tabular}{|c|c|c|c|c|c|}
\hline Ecosystem & $\begin{array}{l}\text { Density } \\
\left(\text { No. } / \mathrm{m}^{2}\right) \\
\end{array}$ & $\begin{array}{l}\text { Crop } \\
\text { Crop } \\
\left(\mathrm{g} / \mathrm{m}^{2}\right)\end{array}$ & Location & Taxonomic group & Study \\
\hline ditch & 2208.5 & - & St. Vincent & $\begin{array}{l}\text { Drepanotrema lucidum, Physa } \\
\text { marmorata }\end{array}$ & $\begin{array}{l}\text { Harrison and Rankin } \\
1978\end{array}$ \\
\hline stream & 12925.7 & - & St. Vincent & $\begin{array}{l}\text { Gundlachia radiata, Physa } \\
\text { marmorata }\end{array}$ & $\begin{array}{l}\text { Harrison and Rankin } \\
1978\end{array}$ \\
\hline stream & 817.3 & - & St. Vincent & $\begin{array}{l}\text { Drepanotrema lucidum, Ferrissia } \\
\text { irrorata, Physa marmorata, } \\
\text { Potamopyrgus parvulus }\end{array}$ & $\begin{array}{l}\text { Harrison and Rankin } \\
1978\end{array}$ \\
\hline $\begin{array}{l}\text { trop. cult. } \\
\text { wetland }\end{array}$ & 874.7 & - & St. Vincent & Physa marmorata & $\begin{array}{l}\text { Harrison and Rankin } \\
1978\end{array}$ \\
\hline $\begin{array}{l}\text { tropical } \\
\text { wetland }\end{array}$ & 608.5 & - & St. Vincent & $\begin{array}{l}\text { Ferrissia irrorata Gundlachia } \\
\text { radiata, Physa marmorata }\end{array}$ & $\begin{array}{l}\text { Harrison and Rankin } \\
1978\end{array}$ \\
\hline 2nd order & 4000 & - & Tennessee & Elimia clavaeformis & Harvey and Hill 1991 \\
\hline 2nd order & 105 & - & California & Physa & $\begin{array}{l}\text { Hemphill and Cooper } \\
1984\end{array}$ \\
\hline lake & 57 & 7.05 & Alaska & Lymnaea, Valvata & Hershey 1990 \\
\hline lake & 631.5 & 30.45 & Alaska & Lymnaea, Valvata & Hershey 1990 \\
\hline 2nd order & 1544 & 47.7 & Tennessee & Elimia clavaeformis & Hill 1992* \\
\hline 2 nd order & 970 & 29.94 & Tennessee & Elimia clavaeformis & Hill et al. $1995^{*}$ \\
\hline lake & 125.5 & - & Sweden & Lymnaea, Theodoxus fluviatilis & $\begin{array}{l}\text { Hillebrand and Kahlert } \\
2001\end{array}$ \\
\hline lake & 85.75 & - & Sweden & Lymnaea, Theodoxus fluviatilis & $\begin{array}{l}\text { Hillebrand and Kahlert } \\
2001\end{array}$ \\
\hline
\end{tabular}




\begin{tabular}{|c|c|c|c|c|c|}
\hline Ecosystem & $\begin{array}{l}\text { Density } \\
\left(\text { No. } / \mathrm{m}^{2}\right)\end{array}$ & $\begin{array}{c}\text { Standing } \\
\text { Crop } \\
\left(\mathrm{g} / \mathrm{m}^{2}\right)\end{array}$ & Location & Taxonomic group & Study \\
\hline lake & 218.25 & - & Sweden & $\begin{array}{l}\text { Hydrobia, Lymnaea, Theodoxus } \\
\text { fluviatilis }\end{array}$ & $\begin{array}{l}\text { Hillebrand and Kahlert } \\
2001\end{array}$ \\
\hline lake & 986.11 & - & New York & Amnicola limosa & Horst and Costa 1975 \\
\hline canal & 988 & 7.22 & New York & Lymnaea palustris & Hunter $1975^{*}$ \\
\hline swamp & 1851 & 49.13 & New York & Lymnaea palustris & Hunter $1975^{*}$ \\
\hline 3 rd order & - & 7.82 & Alabama & Elimia fascinans & Huryn et al. 1995 \\
\hline 4 th order & - & 12.03 & Alabama & Elimia fascinans & Huryn et al. 1995 \\
\hline 3 rd order & - & 13.21 & Alabama & Elimia fascinans & Huryn et al. 1995 \\
\hline 3 rd order & - & 16.24 & Alabama & Elimia cahawbensis & Huryn et al. 1995 \\
\hline 2 nd order & - & 28.39 & Alabama & Elimia cahawbensis & Huryn et al. 1995 \\
\hline 3 rd order & - & 45.06 & Alabama & Elimia cahawbensis & Huryn et al. 1995 \\
\hline reservoir & 1883.3 & - & $\begin{array}{l}\text { United Arab } \\
\text { Emirates }\end{array}$ & Melanoides tuberculata & Ismail and Arif 1993 \\
\hline stream & 473.5 & - & Kentucky & Elimia semicarinata & $\begin{array}{l}\text { Johnson and Brown } \\
1997\end{array}$ \\
\hline karstic wetland & 0.075 & - & Florida & Pomacea paludosa & Karunaratne et al. 2006 \\
\hline karstic wetland & 0.08 & - & Florida & Pomacea paludosa & Karunaratne et al. 2006 \\
\hline karstic wetland & - & 0.9 & Florida & $\begin{array}{l}\text { Aphaostracon pachynotus, } \\
\text { Ferrissia, Laevapex peninsulae, } \\
\text { Littoridinops monroensis, Physella } \\
\text { cubensis, Physella sp., Planorbella } \\
\text { duryi, Planorbella spp. Planorbella } \\
\text { trivolvis intertexta, Pseudosuccinea } \\
\text { columella }\end{array}$ & $\begin{array}{l}\text { King and Richardson } \\
2007\end{array}$ \\
\hline
\end{tabular}




\begin{tabular}{|c|c|c|c|c|c|}
\hline Ecosystem & $\begin{array}{l}\text { Density } \\
\left(\text { No. } / \mathrm{m}^{2}\right)\end{array}$ & $\begin{array}{l}\text { Standing } \\
\text { Crop } \\
\left(\mathrm{g} / \mathrm{m}^{2}\right)\end{array}$ & Location & Taxonomic group & Study \\
\hline stream & 746 & - & Georgia & Elimia catenaria postelli & $\begin{array}{l}\text { Krieger and Burbanck } \\
1976\end{array}$ \\
\hline karstic wetland & 0.11 & 0.17 & Florida & Pomacea paludosa & Kuslan 1975 \\
\hline river & 213.25 & - & Britian & Lymnaea peregra & Lam and Calow 1989 \\
\hline river & 118.25 & - & Britian & Lymnaea peregra & Lam and Calow 1989 \\
\hline river & 64.67 & - & Britian & Lymnaea peregra & Lam and Calow 1989 \\
\hline lake & 2.79 & - & Wisconsin & Amnicola limosa & Lewis 2001 \\
\hline pond & 366.13 & - & $\begin{array}{l}\text { Oxford, } \\
\text { England }\end{array}$ & $\begin{array}{l}\text { Acroloxus lacustris, Bithynia } \\
\text { tentaculata, Lymnaea peregra, } \\
\text { Lymnaea palustris, Planorbarius } \\
\text { corneus, Planorbis albus, } \\
\text { Planorbis carinatus, Planorbis } \\
\text { contortus, Planorbis vortex, } \\
\text { Segmentina nitida, Valvata } \\
\text { lacustris }\end{array}$ & Lodge 1985 \\
\hline lake & 8713.67 & - & Wisconsin & $\begin{array}{l}\text { Amnicola limosa, Campeloma } \\
\text { decisa, Ferissia spp., Gyraulus } \\
\text { parvus, Helisoma, Lymanaea } \\
\text { emarginata, Lymnaea stagnalis, } \\
\text { Physa, Promenetus exacuous }\end{array}$ & Lodge et al. 1987 \\
\hline stream & 59.38 & - & Eastern Zaire & Biomphalaria pfeifferi & $\begin{array}{l}\text { Loreau and Baluku } \\
1987\end{array}$ \\
\hline $\begin{array}{l}\text { floodplain } \\
\text { wetland }\end{array}$ & - & 22.7 & Missouri & Physidae, Planorbidae & Magee et al. 1993 \\
\hline
\end{tabular}




\begin{tabular}{|c|c|c|c|c|c|}
\hline Ecosystem & $\begin{array}{l}\text { Density } \\
\left(\mathrm{No} . \mathrm{m}^{2}\right)\end{array}$ & $\begin{array}{c}\text { Standing } \\
\text { Crop } \\
\left(\mathrm{g} / \mathrm{m}^{2}\right) \\
\end{array}$ & Location & Taxonomic group & Study \\
\hline 3rd order & 140 & - & Kentucky & Elimia & $\begin{array}{l}\text { McCormick and } \\
\text { Stevenson } 1989\end{array}$ \\
\hline $\begin{array}{l}\text { karstic wetland } \\
\text { stream }\end{array}$ & $\begin{array}{c}4.93 \\
214.53\end{array}$ & $\begin{array}{l}- \\
-\end{array}$ & $\begin{array}{l}\text { Florida } \\
\text { Manitoba, } \\
\text { Canada }\end{array}$ & $\begin{array}{l}\text { Laevapex peninsulae, Physella } \\
\text { Amnicola limosa, Aplexa } \\
\text { hypnorum, Bulimnea megasoma, } \\
\text { Ferrissia rivularis, Fossaria parva, } \\
\text { Gyraulus parvus, Helisoma anceps, } \\
\text { Helisoma campanulatum, Helisoma } \\
\text { trivolvis, Lymnaea s. jugularis, } \\
\text { Oxyloma retusa, Physa gyrina, } \\
\text { Planorbula armigera, Promenetus } \\
\text { exacuous, Stagnicola elodes, } \\
\text { Valvata sincera, Valvata } \\
\text { tricarinata }\end{array}$ & $\begin{array}{l}\text { McCormick et al. } 2004 \\
\text { McKillop } 1985\end{array}$ \\
\hline
\end{tabular}




\begin{tabular}{|c|c|c|c|c|c|}
\hline Ecosystem & $\begin{array}{l}\text { Density } \\
\left(\mathrm{No} . / \mathrm{m}^{2}\right)\end{array}$ & $\begin{array}{c}\text { Standing } \\
\text { Crop } \\
\left(\mathrm{g} / \mathrm{m}^{2}\right)\end{array}$ & Location & Taxonomic group & Study \\
\hline stream & 86.23 & - & $\begin{array}{l}\text { Manitoba, } \\
\text { Canada }\end{array}$ & $\begin{array}{l}\text { Amnicola limosa, Aplexa } \\
\text { hypnorum, Bulimnea megasoma, } \\
\text { Ferrissia rivularis, Fossaria parva, } \\
\text { Gyraulus parvus, Helisoma anceps, } \\
\text { Helisoma campanulatum, Helisoma } \\
\text { trivolvis, Lymnaea s. jugularis, } \\
\text { Oxyloma retusa, Physa gyrina, } \\
\text { Planorbula armigera, Promenetus } \\
\text { exacuous, Stagnicola elodes, } \\
\text { Valvata sincera, Valvata } \\
\text { tricarinata }\end{array}$ & McKillop 1985 \\
\hline stream & 66.92 & - & $\begin{array}{l}\text { Manitoba, } \\
\text { Canada }\end{array}$ & $\begin{array}{l}\text { Amnicola limosa, Aplexa } \\
\text { hypnorum, Bulimnea megasoma, } \\
\text { Ferrissia rivularis, Fossaria parva, } \\
\text { Gyraulus parvus, Helisoma anceps, } \\
\text { Helisoma campanulatum, Helisoma } \\
\text { trivolvis, Lymnaea s. jugularis, } \\
\text { Oxyloma retusa, Physa gyrina, } \\
\text { Planorbula armigera, Promenetus } \\
\text { exacuous, Stagnicola elodes, } \\
\text { Valvata sincera, Valvata } \\
\text { tricarinata }\end{array}$ & McKillop 1985 \\
\hline
\end{tabular}




\begin{tabular}{lcccc}
\hline \multicolumn{5}{c}{ Standing } \\
Density & $\begin{array}{c}\text { Crop } \\
\left(\mathrm{g} / \mathrm{m}^{2}\right)\end{array}$ & Location & Taxonomic group & Study \\
\hline
\end{tabular}

\begin{tabular}{|c|c|c|c|c|c|}
\hline $\begin{array}{l}\text { trop. cult. } \\
\text { wetland }\end{array}$ & 4921 & - & St. Lucia & $\begin{array}{l}\text { Biomphalaria glabrata, } \\
\text { Drepanotrema lucidum, Physa } \\
\text { marmorata, Pyrophorus parvulus }\end{array}$ & McKillop et al. 1981 \\
\hline $\begin{array}{l}\text { trop. cult. } \\
\text { wetland }\end{array}$ & 11152.5 & - & St. Lucia & $\begin{array}{l}\text { Biomphalaria glabrata, } \\
\text { Drepanotrema lucidum, Physa } \\
\text { marmorata, Pyrophorus parvulus }\end{array}$ & McKillop et al. 1981 \\
\hline $\begin{array}{l}\text { trop. cult. } \\
\text { wetland }\end{array}$ & 8128.5 & - & St. Lucia & $\begin{array}{l}\text { Biomphalaria glabrata, } \\
\text { Drepanotrema lucidum, Physa } \\
\text { marmorata, Pyrophorus parvulus }\end{array}$ & McKillop et al. 1981 \\
\hline $\begin{array}{l}\text { trop. cult. } \\
\text { wetland }\end{array}$ & 9998.3 & - & St. Lucia & $\begin{array}{l}\text { Biomphalaria glabrata, } \\
\text { Drepanotrema lucidum, Physa } \\
\text { marmorata, Pyrophorus parvulus }\end{array}$ & McKillop et al. 1981 \\
\hline $\begin{array}{l}\text { trop. cult. } \\
\text { wetland }\end{array}$ & 9246.6 & - & St. Lucia & $\begin{array}{l}\text { Biomphalaria glabrata, } \\
\text { Drepanotrema lucidum, Physa } \\
\text { marmorata, Pyrophorus parvulus }\end{array}$ & McKillop et al. 1981 \\
\hline $\begin{array}{l}\text { trop. cult. } \\
\text { wetland }\end{array}$ & 16224.5 & - & St. Lucia & $\begin{array}{l}\text { Biomphalaria glabrata, } \\
\text { Drepanotrema lucidum, Physa } \\
\text { marmorata, Pyrophorus parvulus }\end{array}$ & McKillop et al. 1981 \\
\hline $\begin{array}{l}\text { trop. cult. } \\
\text { wetland }\end{array}$ & 11549.1 & - & St. Lucia & $\begin{array}{l}\text { Biomphalaria glabrata, } \\
\text { Drepanotrema lucidum, Physa } \\
\text { marmorata, Pyrophorus parvulus }\end{array}$ & McKillop et al. 1981 \\
\hline 2 nd order & - & 11.82 & Virginia & $\begin{array}{l}\text { Leptoxis carinata, Elimia } \\
\text { carinifera, Pleuroceridae }\end{array}$ & Miller 1985 \\
\hline
\end{tabular}




\begin{tabular}{|c|c|c|c|c|c|}
\hline Ecosystem & $\begin{array}{l}\text { Density } \\
\left(\text { No. } / \mathrm{m}^{2}\right)\end{array}$ & $\begin{array}{c}\text { Standing } \\
\text { Crop } \\
\left(\mathrm{g} / \mathrm{m}^{2}\right)\end{array}$ & Location & Taxonomic group & Study \\
\hline 3 rd order & 300 & 25 & Alabama & $\begin{array}{l}\text { Elimia cahawbensis, Elimia clara, } \\
\text { Elimia variata }\end{array}$ & Morales 1990 \\
\hline 4 th order & 1100 & 30 & Alabama & $\begin{array}{l}\text { Elimia cahawbensis, Elimia } \\
\text { showalteri, Pleuroceridae }\end{array}$ & Morales 1990 \\
\hline 2 nd order & 900 & 45 & Alabama & $\begin{array}{l}\text { Elimia clara, Elimia carinifera, } \\
\text { Elimia carinocostata }\end{array}$ & Morales 1990 \\
\hline 2 nd order & 250 & 70 & Alabama & $\begin{array}{l}\text { Elimia cahawbensis, Elimia clara, } \\
\text { Elimia olivula }\end{array}$ & Morales 1990 \\
\hline 3rd order & 150 & 80 & Alabama & Elimia variata & Morales 1990 \\
\hline 2 nd order & 750 & 110 & Alabama & Elimia cahawbensis, Elimia clara & Morales 1990 \\
\hline 3rd order & 950 & 125 & Alabama & Elimia cahawbensis, Pleuroceridae & Morales 1990 \\
\hline 1st order & 650 & 140 & Alabama & Elimia carinifera & Morales 1990 \\
\hline stream & 79 & 9.18 & NE Spain & Stagnicola vulnerata & Munoz 2000 \\
\hline 1st order & - & 65 & Tennessee & Elimia chavaeformes & Newbold et al. 1983 \\
\hline lake & 1628 & - & Norway & $\begin{array}{l}\text { Acrolozus lacustris, Anisus } \\
\text { contotus, Anisus crista, Lymnaea } \\
\text { auricularia, Lymnaea peregra, } \\
\text { Physa fontinalis, Valvata cristata, } \\
\text { Valvata piscinalis }\end{array}$ & Okland 1964 \\
\hline stream & 571 & - & Michigan & Viviparus georgianus & Pace and Szuch 1985 \\
\hline lake & 69.6 & - & Michigan & $\begin{array}{l}\text { Amnicola lustica, Gyraulus parvus, } \\
\text { Valvata tricarinata }\end{array}$ & Pace et al. 1979 \\
\hline
\end{tabular}




\begin{tabular}{|c|c|c|c|c|c|}
\hline Ecosystem & $\begin{array}{l}\text { St } \\
\text { Density } \\
\left(\mathrm{No} / \mathrm{m}^{2}\right)\end{array}$ & $\begin{array}{l}\text { tanding } \\
\text { Crop } \\
\left(\mathrm{g} / \mathrm{m}^{2}\right)\end{array}$ & Location & Taxonomic group & Study \\
\hline stream & 2.73 & - & Puerto Rico & $\begin{array}{l}\text { Australorbis glabratus } \\
\text { (Biomphararia) }\end{array}$ & $\begin{array}{l}\text { Pimentel and White } \\
\text { 1959a }\end{array}$ \\
\hline stream & 6.91 & - & Puerto Rico & $\begin{array}{l}\text { Australorbis glabratus } \\
\text { (Biomphararia) }\end{array}$ & $\begin{array}{l}\text { Pimentel and White } \\
\text { 1959a }\end{array}$ \\
\hline stream & 1.08 & - & Puerto Rico & $\begin{array}{l}\text { Australorbis glabratus } \\
\text { (Biomphararia) }\end{array}$ & $\begin{array}{l}\text { Pimentel and White } \\
\text { 1959a }\end{array}$ \\
\hline river & 1.39 & - & Puerto Rico & $\begin{array}{l}\text { Australorbis glabratus } \\
\text { (Biomphararia) }\end{array}$ & $\begin{array}{l}\text { Pimentel and White } \\
\text { 1959a }\end{array}$ \\
\hline 1 st order & 0.0025 & - & Puerto Rico & $\begin{array}{l}\text { Ampullaria, Biomphalaria } \\
\text { glabrata, Ferrissia beaui, Physa } \\
\text { cubensis, Potamopyrgus coronatus, } \\
\text { Troicorbis albicans }\end{array}$ & $\begin{array}{l}\text { Pimentel and White } \\
1959 \mathrm{~b}\end{array}$ \\
\hline 1 st order & 5.37 & - & Puerto Rico & $\begin{array}{l}\text { Ampullaria, Biomphalaria } \\
\text { glabrata, Ferrissia beaui, Physa } \\
\text { cubensis, Potamopyrgus coronatus, } \\
\text { Troicorbis albicans }\end{array}$ & $\begin{array}{l}\text { Pimentel and White } \\
1959 \mathrm{~b}\end{array}$ \\
\hline river & 146.73 & - & Puerto Rico & Neritina punctulata & Pyron and Covich 2003 \\
\hline river & 116.7 & - & Puerto Rico & Neritina punctulata & Pyron and Covich 2003 \\
\hline $\begin{array}{l}\text { snail invaded } \\
\text { stream }\end{array}$ & 25169.73 & - & Idaho & $\begin{array}{l}\text { Fluminicola, Potamopyrgus } \\
\text { antipodarum, Taylorconcha } \\
\text { serpenticola }\end{array}$ & Richards et al. 2001 \\
\hline 2nd order & 473 & 77 & Alabama & Elimia cahawbensis, Elimia clara & Richardson et al. 1988 \\
\hline
\end{tabular}




\begin{tabular}{|c|c|c|c|c|c|}
\hline Ecosystem & $\begin{array}{c}\text { Density } \\
\left(\mathrm{No} . \mathrm{m}^{2}\right) \\
\end{array}$ & $\begin{array}{l}\text { Standing } \\
\text { Crop } \\
\left(\mathrm{g} / \mathrm{m}^{2}\right)\end{array}$ & Location & Taxonomic group & Study \\
\hline pond & 20.8 & - & $\begin{array}{l}\text { Ontario, } \\
\text { Canada }\end{array}$ & $\begin{array}{l}\text { Amnicola limosa, Campeloma } \\
\text { decisum, Ferrissia parallela, } \\
\text { Gyraulus parvus, Helisoma anceps }\end{array}$ & $\begin{array}{l}\text { Rooke and Mackie } \\
1984\end{array}$ \\
\hline pond & 18.6 & - & $\begin{array}{l}\text { Ontario, } \\
\text { Canada }\end{array}$ & $\begin{array}{l}\text { Amnicola limosa, Campeloma } \\
\text { decisum, Ferrissia parallela, } \\
\text { Gyraulus parvus, Helisoma anceps }\end{array}$ & $\begin{array}{l}\text { Rooke and Mackie } \\
1984\end{array}$ \\
\hline pond & 27.1 & - & $\begin{array}{l}\text { Ontario, } \\
\text { Canada }\end{array}$ & $\begin{array}{l}\text { Amnicola limosa, Campeloma } \\
\text { decisum, Ferrissia parallela, } \\
\text { Gyraulus parvus, Helisoma anceps }\end{array}$ & $\begin{array}{l}\text { Rooke and Mackie } \\
1984\end{array}$ \\
\hline pond & 23.2 & - & $\begin{array}{l}\text { Ontario, } \\
\text { Canada }\end{array}$ & $\begin{array}{l}\text { Amnicola limosa, Campeloma } \\
\text { decisum, Ferrissia parallela, } \\
\text { Gyraulus parvus, Helisoma anceps }\end{array}$ & $\begin{array}{l}\text { Rooke and Mackie } \\
1984\end{array}$ \\
\hline pond & 11.9 & - & $\begin{array}{l}\text { Ontario, } \\
\text { Canada }\end{array}$ & $\begin{array}{l}\text { Amnicola limosa, Campeloma } \\
\text { decisum, Ferrissia parallela, } \\
\text { Gyraulus parvus, Helisoma anceps }\end{array}$ & $\begin{array}{l}\text { Rooke and Mackie } \\
1984\end{array}$ \\
\hline
\end{tabular}




\begin{tabular}{|c|c|c|c|c|c|}
\hline Ecosystem & $\begin{array}{l}\text { Density } \\
\left(\mathrm{No} . / \mathrm{m}^{2}\right)\end{array}$ & $\begin{array}{l}\text { Crop } \\
\text { Cropding } \\
\left(\mathrm{g} / \mathrm{m}^{2}\right)\end{array}$ & Location & Taxonomic group & Study \\
\hline pond & 2.8 & - & $\begin{array}{l}\text { Ontario, } \\
\text { Canada }\end{array}$ & $\begin{array}{l}\text { Amnicola limosa, Campeloma } \\
\text { decisum, Ferrissia parallela, } \\
\text { Gyraulus parvus, Helisoma anceps }\end{array}$ & $\begin{array}{l}\text { Rooke and Mackie } \\
1984\end{array}$ \\
\hline 1st order & 1310 & 40.48 & Tennessee & Elimia clavaeformis & Rosemond 1994* \\
\hline loch & 407.48 & - & Scotland & $\begin{array}{l}\text { Ancylus fluviatilis, Lymnaea } \\
\text { peregra, Physa fontinalis }\end{array}$ & Russell Hunter 1961 \\
\hline pond & 117.96 & - & $\begin{array}{l}\text { Rhodesia } \\
\text { Africa }\end{array}$ & Bulinus globosus & Shiff 1964 \\
\hline pond & 1422.37 & - & Ohio & Gastropoda & Smith 2003 \\
\hline pond & 356.86 & - & Ohio & Gastropoda & Smith 2003 \\
\hline $\begin{array}{l}\text { floodplain } \\
\text { wetland }\end{array}$ & 255 & - & $\begin{array}{l}\text { North } \\
\text { Carolina }\end{array}$ & Gastropoda & Sniffen 1981 \\
\hline stream & 210.6 & 66.4 & Virginia & Leptoxis carinata & $\begin{array}{l}\text { Stewart and Garcia } \\
2002\end{array}$ \\
\hline karstic wetland & 0.38 & 1.62 & Belize & Pomacea flagellata & This Study (Belize) \\
\hline karstic wetland & 3.4 & 1.01 & Florida & $\begin{array}{l}\text { Haitia cubensis, Planorbella, } \\
\text { Pomacea paludosa }\end{array}$ & This Study (Florida) \\
\hline karstic wetland & 0.78 & 1.15 & Mexico & $\begin{array}{l}\text { Physa, Planorbella, Pomacea } \\
\text { flagellata }\end{array}$ & This Study (Mexico) \\
\hline
\end{tabular}




\begin{tabular}{|c|c|c|c|c|c|}
\hline Ecosystem & $\begin{array}{l}\text { Density } \\
\left(\text { No. } / \mathrm{m}^{2}\right)\end{array}$ & $\begin{array}{l}\text { Standing } \\
\text { Crop } \\
\left(\mathrm{g} / \mathrm{m}^{2}\right)\end{array}$ & Location & Taxonomic group & Study \\
\hline lake & 113.86 & - & $\begin{array}{l}\text { Ibadan, } \\
\text { Nigeria }\end{array}$ & $\begin{array}{l}\text { Afrogyrus coretus, Biomphalaria } \\
\text { pfeifferi, Bulinus forskali, Bulinus } \\
\text { rohlfsi, Lymnaea natalensis, } \\
\text { Melanoides tuberculata }\end{array}$ & Thomas and Tait 1984 \\
\hline reservoir & 128.6 & - & $\begin{array}{l}\text { Ibadan, } \\
\text { Nigeria }\end{array}$ & $\begin{array}{l}\text { Biomphalaria pfeifferi, Bulinus } \\
\text { rohlfsi, Lymnaea natalensis, } \\
\text { Melanoides tuberculata }\end{array}$ & Thomas and Tait 1984 \\
\hline stream & 51 & - & $\begin{array}{l}\text { Ibadan, } \\
\text { Nigeria }\end{array}$ & Biomphalaria pfeifferi & Thomas and Tait 1984 \\
\hline lake & 50.5 & - & Washington & Gyraulus & Thut 1969 \\
\hline pond & 12.5 & 2 & Pennsylvania & Aplexa, Gyraulus, Stagnicola & Turner unpublished \\
\hline swamp & 12.5 & 2.5 & Pennsylvania & $\begin{array}{l}\text { Physa gyrina, Planorbula, } \\
\text { Stagnicola }\end{array}$ & Turner unpublished \\
\hline gravel pit & 20 & 2.5 & Pennsylvania & Physa acuta & Turner unpublished \\
\hline pond & 20 & 3.25 & Pennsylvania & $\begin{array}{l}\text { Helisoma anceps, Helisoma } \\
\text { trivolvis, Physa acuta }\end{array}$ & Turner unpublished \\
\hline pond & 20 & 3.25 & Pennsylvania & $\begin{array}{l}\text { Helisoma anceps, Helisoma } \\
\text { trivolvis, Physa acuta }\end{array}$ & Turner unpublished \\
\hline pond & 25 & 3.28 & Pennsylvania & $\begin{array}{l}\text { Heilsoma trivolvis, Physa gyrina, } \\
\text { Pseudosuccina }\end{array}$ & Turner unpublished \\
\hline pond & 27.5 & 5.25 & Pennsylvania & Physa gyrina, Pseudosuccina & Turner unpublished \\
\hline lake & 10 & 5.5 & Pennsylvania & Helisoma trivolvis, Physa acuta & Turner unpublished \\
\hline
\end{tabular}




\begin{tabular}{|c|c|c|c|c|c|}
\hline Ecosystem & $\begin{array}{l}\text { Density } \\
\left(\text { No. } / \mathrm{m}^{2}\right)\end{array}$ & $\begin{array}{l}\text { Standing } \\
\text { Crop } \\
\left(\mathrm{g} / \mathrm{m}^{2}\right) \\
\end{array}$ & Location & Taxonomic group & Study \\
\hline gravel pit & 65 & 5.75 & Pennsylvania & $\begin{array}{l}\text { Fossaria spp., Physa acuta, } \\
\text { Pseudosuccina }\end{array}$ & Turner unpublished \\
\hline $\begin{array}{l}\text { temperate } \\
\text { wetland }\end{array}$ & 32.5 & 6 & Pennsylvania & $\begin{array}{l}\text { Gyraulus, Physa gyrina, Physa } \\
\text { acuta, Pseudosuccina }\end{array}$ & Turner unpublished \\
\hline gravel pit & 102.5 & 8 & Pennsylvania & Helisoma trivolvis, Physa acuta & Turner unpublished \\
\hline pond & 37.5 & 14.93 & Pennsylvania & $\begin{array}{l}\text { Gyraulus, Helisoma trivolvis, } \\
\text { Physa gyrina, Physa acuta }\end{array}$ & Turner unpublished \\
\hline pond & 32.5 & 17.08 & Pennsylvania & Helisoma trivolvis, Physa acuta & Turner unpublished \\
\hline pond & 105 & 26.13 & Pennsylvania & $\begin{array}{l}\text { Fossaria, Helisoma trivolvis, Physa } \\
\text { acuta }\end{array}$ & Turner unpublished \\
\hline pond & 225 & 30.73 & Pennsylvania & $\begin{array}{l}\text { Fossaria, Helisoma trivolvis, Physa } \\
\text { acuta }\end{array}$ & Turner unpublished \\
\hline pond & 507.5 & 35.25 & Pennsylvania & $\begin{array}{l}\text { Helisoma trivolvis, Physa acuta, } \\
\text { Pseudosuccina }\end{array}$ & Turner unpublished \\
\hline pond & 150 & 63.48 & Pennsylvania & $\begin{array}{l}\text { Helisoma trivolvis, Physa gyrina, } \\
\text { Physa acuta }\end{array}$ & Turner unpublished \\
\hline
\end{tabular}




\begin{tabular}{|c|c|c|c|c|c|}
\hline Ecosystem & $\begin{array}{l}\text { Density } \\
\left(\mathrm{No} . / \mathrm{m}^{2}\right) \\
\end{array}$ & $\begin{array}{l}\text { Standing } \\
\text { Crop } \\
\left(\mathrm{g} / \mathrm{m}^{2}\right)\end{array}$ & Location & Taxonomic group & Study \\
\hline fluvial wetland & 1654.57 & 8.68 & Michigan & $\begin{array}{l}\text { Gastropoda, Amnicola, Aplexa, } \\
\text { Birgella, Cincinnatia, Fossaria, } \\
\text { Gyraulus, Helisoma, Laevapex, } \\
\text { Marstonia, Minetus, Physa, } \\
\text { Physella, Plnorbella, Promenetus, } \\
\text { Pseudosuccinea, Stagnicola, } \\
\text { Valvata }\end{array}$ & Uzarski unpublished \\
\hline stream & 130.71 & - & Costa Rica & Neritina latissima & $\begin{array}{l}\text { Valdez and Villabos } \\
1981\end{array}$ \\
\hline stream & 1040.8 & - & Costa Rica & Neritina latissima & $\begin{array}{l}\text { Valdez and Villabos } \\
1981\end{array}$ \\
\hline borrow pit & 108.19 & - & $\begin{array}{l}\text { Rhodesia } \\
\text { Africa }\end{array}$ & $\begin{array}{l}\text { Biomphalaria pfeifferi, Bulinus } \\
\text { globosus, Bulinus tropicus, } \\
\text { Gyraulus, Lymnaea natalensis }\end{array}$ & Williams 1970 \\
\hline lake & 158.72 & - & $\begin{array}{l}\text { Rhodesia } \\
\text { Africa }\end{array}$ & $\begin{array}{l}\text { Biomphalaria pfeifferi, Bulinus } \\
\text { globosus, Bulinus tropicus, } \\
\text { Gyraulus, Lymnaea natalensis }\end{array}$ & Williams 1970 \\
\hline reservoir & 42.95 & - & $\begin{array}{l}\text { Rhodesia } \\
\text { Africa }\end{array}$ & $\begin{array}{l}\text { Biomphalaria pfeifferi, Bulinus } \\
\text { globosus, Bulinus tropicus, } \\
\text { Gyraulus, Lymnaea natalensis }\end{array}$ & Williams 1970 \\
\hline
\end{tabular}




\begin{tabular}{|c|c|c|c|c|c|}
\hline Ecosystem & $\begin{array}{c}\text { Density } \\
\left(\text { No. } / \mathrm{m}^{2}\right) \\
\end{array}$ & $\begin{array}{l}\text { Standing } \\
\text { Crop } \\
\left(\mathrm{g} / \mathrm{m}^{2}\right)\end{array}$ & Location & Taxonomic group & Study \\
\hline reservoir & 151.56 & - & $\begin{array}{l}\text { Rhodesia } \\
\text { Africa }\end{array}$ & $\begin{array}{l}\text { Biomphalaria pfeifferi, Bulinus } \\
\text { globosus, Bulinus tropicus, } \\
\text { Gyraulus, Lymnaea natalensis }\end{array}$ & Williams 1970 \\
\hline stream & 10.14 & - & $\begin{array}{l}\text { Rhodesia } \\
\text { Africa }\end{array}$ & $\begin{array}{l}\text { Biomphalaria pfeifferi, Bulinus } \\
\text { globosus, Bulinus tropicus, } \\
\text { Gyraulus, Lymnaea natalensis }\end{array}$ & Williams 1970 \\
\hline stream & 47.18 & - & $\begin{array}{l}\text { Rhodesia } \\
\text { Africa }\end{array}$ & $\begin{array}{l}\text { Biomphalaria pfeifferi, Bulinus } \\
\text { globosus, Bulinus tropicus, } \\
\text { Gyraulus, Lymnaea natalensis }\end{array}$ & Williams 1970 \\
\hline stream & 14.72 & - & $\begin{array}{l}\text { Rhodesia } \\
\text { Africa }\end{array}$ & $\begin{array}{l}\text { Biomphalaria pfeifferi, Bulinus } \\
\text { globosus, Bulinus tropicus, } \\
\text { Gyraulus, Lymnaea natalensis }\end{array}$ & Williams 1970 \\
\hline stream & 214.2 & - & $\begin{array}{l}\text { Rhodesia } \\
\text { Africa }\end{array}$ & $\begin{array}{l}\text { Biomphalaria pfeifferi, Bulinus } \\
\text { globosus, Bulinus tropicus, } \\
\text { Gyraulus, Lymnaea natalensis }\end{array}$ & Williams 1970 \\
\hline pond & 797.5 & - & New Zealand & Potamopyrgus antipodarum & Winterbourne 1970 \\
\hline $\begin{array}{l}\text { snail invaded } \\
\text { lake }\end{array}$ & 381.46 & - & New York & Potamopyrgus antipodarum & Zaranko et al. 1997 \\
\hline
\end{tabular}




\section{LITERATURE CITED}

Anderson, N. H., J. R. Sedell, L. M. Roberts, and F. J. Triska. 1978. The role of aquatic invertebrates in processing of wood debris in coniferous forest streams. American Midland Naturalist 100:64 - 82.

Barquin, J., and R. G. Death. 2004. Patterns of invertebrate diversity in streams and freshwater springs in northern Spain. Archiv Fur Hydrobiologie 161:329-349.

Beckett, D. C., T. P. Aartila, and A. C. Miller. 1992. Contrasts in density of benthic invertebrates between macrophyte beds and open littoral patches in Eau-Galle lake, Wisconsin. American Midland Naturalist 127:77-90.

Bennetts, R. E., P. C. Darby, and L. B. Karunaratne. 2006. Foraging patch selection by snail kites in response to vegetation structure and prey abundance and availability. Waterbirds 29:88-94.

Bishop, M. J., and H. DeGaris. 1974. A note on population densities of Mollusca in the river Great at Ely, Cambridgeshire. Hydrobiologia 48:195-197.

Breen, M. J. 2008. Movement, habitat use, and foraging of mottled sculpins in a coldwater stream. Grand Vally State University, Allendale, Michigan.

Brönmark, C. 1988. Effects of vertebrate predation on freshwater gastropods: An exclosure experiment. Hydrobiologia 169:363-370.

Brown, C. L., T. P. Poe, J. R. P. French III, and D. W. Schloesser. 1988. Relationships of phytomacrofauna to surface area in naturally occuring macrophyte stands. Journal of the North American Benthological Society 7:129 - 139.

Brown, K. M. 1982. Resource overlap and competition in pond snails: An experimental analysis. Ecology 63:412 - 422 .

Brown, K. M., and D. R. Devries. 1985. Predation and the distribution and abundance of a pulmonate pond snail. Oecologia 66:93-99.

Brown, K. M., and D. M. Lodge. 1993. Gastropod abundance in vegetated habitats: The importance of specifying null models. Limnology and Oceanography 38:217-225.

Brown, K. M., D. Varza, and T. D. Richardson. 1989. Lift histories and population dynamics of two subtropical snails (Prosobranchia: Viviparidae). Journal of the North American Benthological Society 8:222-228.

Browne, R. A. 1978. Growth, mortality, fecundity, biomass and productivity of four lake populations of the prosobranch snail, Viviparus georgianus. Ecology 59:742-750. 
Burris, J. A., M. S. Bamford, and A. J. Stewart. 1990. Behavioral responses of marked snails as indicators of water quality. Environmental Toxicology and Chemistry 9:69-76.

Caquet, T. 1993. Comparative life cycle, biomass and secondary production of three sympatric freshwater gastropod species. Journal of Molluscan Studies 59:43-50.

Carlsson, N. O. L. 2004. Invading herbivory. Effects of the golden apple snail (Pomacea canaliculata) in Asian wetlands. dissertation. Lund University, Lund, Sweden.

Carlsson, N. O. L., C. Brönmark, and L. A. Hansson. 2004. Invading herbivory: The golden apple snail alters ecosystem functioning in Asian wetlands. Ecology 85:1575-1580.

Clampitt, P. T. 1970. Comparative ecology of the snails Physa gyrina and Physa integra. Malacologia 10:113 - 151.

Clampitt, P. T. 1973. Substratum as a factor in the distribution of pulmonate snails in Douglas Lake, Michigan. Malacologia 12:379 - 399.

Collier, K. J., R. J. Wilcock, and A. S. Meredith. 1998. Influence of substrate type and physico-chemical conditions on macroinvertebrate faunas and biotic indices of some lowland Waikato, New Zealand, streams. New Zealand Journal of Marine and Freshwater Research 32:1-19.

Costil, K., and J. Daguzan. 1995. Comparative life cycle and growth of two freshwater gastropod species, Planorbarius corneus (L.) and Planorbis planorbis (L.). Malacologia 37:53 - 68.

Darby, P. C., R. E. Bennetts, J. D. Croop, P. L. Valentine-Darby, and W. M. Kitchens. 1999. A comparison of sampling techniques for quantifying abundance of the Florida apple snail (Pomacea paludosa Say). Journal of Molluscan Studies 65:195-208.

Darby, P. C., P. L. Valentine-Darby, H. F. Percival, and W. M. Kitchens. 2004. Florida apple snail (Pomacea paludosa Say) responses to lake habitat restoration activity. Archiv Fur Hydrobiologie 161:561 - 575.

Dazo, B. C. 1965. The morphology and natural history of Pleurocera acuta and Goniobasis livescens (Gastropoda; Ceritheacea; Pleuroceridae). Malacologia 3:1 80 .

De Mol, N. Y. 2007. Benthic macroinvertebrate response to road-stream crossing and stream bank improvements and longitudinal patterns in Bear, Pine, and Sickle 
creeks, Manistee county, Michigan. Grand Valley State University, Allendale, Michigan.

DeCoster, W., and G. Persoone. 1970. Ecological study of Gastropoda in a swamp in the neighbourhood of Ghent (Belgium). Hydrobiologia 36:65 - 80.

Diamond, J. M. 1976. The population dynamics and reproductive strategy of the stream snail Oxytrema silicula (Gould) in relation to stream order. Masters of Science. Oregon State University, Corvalis, OR.

Donnay, T. J., and S. R. Beissinger. 1993. Apple snail (Pomacea doliodes) and freshwater crab (Dilocarcinus dentatus) population fluctuations in the llanos of Venezuela. Biotropica 25:206-214.

Dudgeon, D. 1986. The life cycle, population dynamics and productivity of Melanoides tuberculata (Müller, 1774) (Gastropoda: Prosobranchia: Thiaridae) in Hong King. Journal of Zoological Society of London 208:37-53.

Duffy, W. G., and D. J. LaBar. 1994. Aquatic invertebrate production in southeastern USA wetlands during winter and spring. Wetlands 14:88 - 97.

Dussart, G. B. J. 1979. Life cycles and distribution of the aquatic gastropod molluscs Bithynia tentaculata (L.), Gyraulus albus (Muller), Planorbis planorbis (L.) and Lymnaea peregra (Muller) in relation to water chemistry. Hydrobiologia 67:223 239.

Eckblad, J. W. 1973. Population studies of three aquatic gastropods in an intermittent backwater. Hydrobiologia 41:199 - 219.

Eisenberg, R. M. 1966. The regulation of density in a natural population of the pond snail, Lymnaea elodes. Ecology 47:889 - 906.

Eleutheriadis, N., and Lazaridou-Dimitriadou. 1995. Density and growth of freshwater prosobranch snails (Bithynia graeca and Viviparus contectus) in relation to water chemistry in Serres, northern Greece. Journal of Molluscan Studies 61:347-352.

Elwood, J. W., J. D. Newbold, A. F. Trimble, and R. W. Stark. 1981. The limiting role of phosphorus in a woodland stream ecosystem: Effects of P enrichment on leaf decompostition and primary producers. Ecology 62:146 - 158 .

Eversole, A. G. 1978. Life cycles, growth and population bioenergetics in the snail Helisoma trivolvis (Say). Journal of Molluscan Studies 44:209 - 222. 
Foin, T. C., and A. E. Stiven. 1970. The relationship of environment and population parameters Oxytrema proxima (Say) (Gastropoda: Pleuroceridae). Oecologia 5:74 $-84$.

Gerard, C., A. Carpentier, and J. M. Paillisson. 2008. Long-term dynamics and community structure of freshwater gastropods exposed to parasitism and other environmental stressors. Freshwater Biology 53:470-484.

González-Solís, J., and X. Ruiz. 1996. Succession and secondary production of gastropods in the Ebro Delta ricefields. Hydrobiologia 337:85-92.

Habdija, I., J. Lajtner, and I. Belinic. 1995. The contribution of gastropod biomass in macrobenthic communities of a karstic river. Internationale Revue Der Gesamten Hydrobiologie 80:103-110.

Hall, R. O., M. F. Dybdahl, and M. C. VanderLoop. 2006. Extremely high secondary production of introduced snails in rivers. Ecological Applications 16:1121-1131.

Hanke Houp, K. 1970. Population dynamics of Pleurocera acuta in a central Kentucky limestone stream. American Midland Naturalist 83:81 - 88.

Harrison, A. D., and J. J. Rankin. 1978. Hydrobiological studies of eastern Lesser Antillean islands III. St. Vincent: Freshwater Mollusca - their distribution, population dynamics and biology. Archiv Fur Hydrobiologie 2 Suppl. 54:123 188.

Harvey, B. C., and W. R. Hill. 1991. Effects of snails and fish on benthic invertebrate assemblages in a headwater stream. Journal of the North American Benthological Society 10:263-270.

Hemphill, N., and S. D. Cooper. 1984. Differences in the community structure of stream pools containing or lacking trout. Verh. Internat. Verein. Limnol. 22:1858 - 1861.

Hershey, A. E. 1990. Snail populations in arctic lakes: Competition mediated by predation. Oecologia 82:26 - 32 .

Hill, W. R. 1992. Food limitation and interspecific competition in snail-dominated streams. Canadian Journal of Fisheries and Aquatic Sciences 49:1257-1267.

Hill, W. R., M. G. Ryon, and E. M. Schilling. 1995. Light limitation in a stream ecosystem: Responses by primary producers and consumers. Ecology 76:12971309. 
Hillebrand, H., and M. Kahlert. 2001. Effect of grazing and nutrient supply on periphyton biomass and nutrient stoichiometry in habitats of different productivity. Limnology and Oceanography 46:1881-1898.

Horst, T. J., and R. R. Costa. 1975. Seasonal migration and density patterns of the freshwater snail Amnicola limosa. The Nautilus 89:56 - 59.

Hunter, R. D. 1975. Growth, fecundity, and bioenergetics in three populations of Lymnaea palustris in upstate New York. Ecology 56:50 - 63.

Huryn, A. D., A. C. Benke, and G. M. Ward. 1995. Direct and indirect effects of geology on the distribution, biomass, and production of the freshwater snail Elimia. Journal of the North American Benthological Society 14:519-534.

Ismail, N. S., and M. S. Arif. 1993. Population dynamics of Melanoides tuberculata (Thiaridae) snails in a desert spring, United Arab Emirates and infection with larval trematodes. Hydrobiologia 257:57-64.

Johnson, P. D., and K. M. Brown. 1997. The role of current and light in explaining the habitat distribution of the lotic snail Elimia semicarinata (Say). Journal of the North American Benthological Society 16:545-561.

Karunaratne, L. B., P. C. Darby, and R. E. Bennetts. 2006. The effects of wetland habitat structure on Florida apple snail density. Wetlands 26:1143-1150.

King, R. S., and C. J. Richardson. 2007. Subsidy-stress response of macroinvertebrate community biomass to a phosphorus gradient in an oligotrophic wetland ecosystem. Journal of the North American Benthological Society 26:491-508.

Krieger, K. A., and W. D. Burbanck. 1976. Distribution and dispersal mechanisms of Oxytrema (Goniobasis) suturalis Haldeman (Gastropoda: Pleuroceridae) in the Yellow River, Georgia, U.S.A. American Midland Naturalist 95:49 - 63.

Kushlan, J. 1975. Population changes of apple snail, Pomacea paludosa, in the southern Everglades. Nautilus 89:21-23.

Lam, P. K. S., and P. Calow. 1989. Intraspecific life-history variation in Lymnaea peregra (Gastropoda: Pulmonata). I. Field study. Journal of Animal Ecology 58:571-588.

Lewis, D. B. 2001. Trade-offs between growth and survival: Responses of freshwater snails to predacious crayfish. Ecology 82:758-765.

Lodge, D. M. 1985. Macrophyte gastropod associations: Observations and experiments on macrophyte choice by gastropods. Freshwater Biology 15:695 - 708. 
Lodge, D. M., K. M. Brown, S. P. Klosiewski, R. A. Stein, A. P. Covich, B. K. Leathers, and C. Brönmark. 1987. Distribution of freshwater snails: Spatial scale and the relative importance of physicochemical and biotic factors. American Malacological Bulletin 5:73 - 84.

Loreau, M., and B. Baluku. 1987. Population dynamics of the freshwater snail Biomphalaria pfeifferi in eastern Zaire. Journal of Molluscan Studies 53:249-265.

Magee, P. A., L. H. Fredrickson, and D. D. Humburg. 1993. Aquatic macroinvertebrate association with willow wetlands in northeastern Missouri. Wetlands 13:304 310 .

McCormick, P. V., R. B. E. Shuford, and P. S. Rawlik. 2004. Changes in macroinvertebrate community structure and function along a phosphorus gradient in the Florida Everglades. Hydrobiologia 529:113-132.

McCormick, P. V., and R. J. Stevenson. 1989. Effects of snail grazing on benthic algal community structure in different nutrient environments. Journal of the North American Benthological Society 8:162 - 172.

McKillop, W. B. 1985. Distribution of aquatic gastropods across the Ordovician dolomite - Precambrian granite contact in southeastern Manitoba, Canada. Canadian Journal of Zoology 63:278-288.

McKillop, W. B., and A. D. Harrison. 1981. Hydrobiological studies of eastern Lesser Antilles islands VI. St. Lucia: Freshwater molluscs and the marsh environment. Archiv Fur Hydrobiologie 4:357 - 419.

Miller, C. 1985. Correlates of habitat favourability for benthic macroinvertebrates at five stream sites in an Appalachian mountain drainage basin, U.S.A. Freshwater Biology 15:709 - 733 .

Morales, J. B. T. 1990. The distribution of freshwater snails among different ordered streams of the Cahaba river drainage, Alabama. Master of Science. University of Alabama, Tuscaloosa, Alabama.

Munoz, I., M. Real, H. Guasch, E. Navarro, and S. Sabater. 2000. Resource limitation by freshwater snail (Stagnicola vulnerata) grazing pressure: An experimental study. Archiv Fur Hydrobiologie 148:517-532.

Newbold, J. D., J. W. Elwood, R. V. O'Neill, and A. L. Sheldon. 1983. Phosphorus dynamics in a woodland stream ecosystem: A study of nutrient spiraling. Ecology 64:1249 - 1265 . 
Okland, J. 1964. The eutrophic Lake Borrevann (Norway) - An ecological study on shore and bottom fauna with special reference to gastropods, including a hydrographic survey.

Pace, G. L., and E. J. Szuch. 1985. An exceptional stream population of the banded applesnail, Viviparus georgianus. Nautilus 99:48 - 53.

Pace, G. L., E. J. Szuch, and R. W. Dapson. 1979. Depth distribution of three gastropods in New Mission Bay, Lake Michigan. Nautilus 93:31-36.

Pimentel, D., and P. C. White Jr. 1959a. Biological environment and habits of Australorbis glabratus. Ecology 40:541 - 550.

Pimentel, D., and P. C. White Jr. 1959b. Physiochemical environment of Australorbis glabratus, intermediate host of Schistosoma mansoni in Puerto Rico. Ecology 40:533 - 541 .

Pyron, M., and A. P. Covich. 2003. Migration patterns, densities, and growth of Neritina punctulata snails in Rio Espiritu Santo and Rio Mameyes, northeastern Puerto Rico. Caribbean Journal of Science 39:338-347.

Richards, D. C., L. D. Cazier, and G. T. Lester. 2001. Spatial distribution of the three snail species, including the invader Potamopyrgus antipodarum, in a freshwater spring. Western North American Naturalist 61:375-380.

Richardson, T. D., J. F. Scheiring, and K. M. Brown. 1988. Secondary production of two lotic snails (Pleuroceridae: Elimia). Journal of the North American Benthological Society 7:234 - 245 .

Rooke, J. B., and G. L. Mackie. 1984. Mollusca of six low-alkalinity lakes in Ontario. Canadian Journal of Fisheries and Aquatic Sciences 41:777 - 782.

Rosemond, A. D. 1994. Multiple factors limit seasonal variation in periphyton in a forest stream. Journal of the North American Benthological Society 13:333-344.

Russell Hunter, W. 1961. Annual variations in growth and density in natural populations of freshwater snails. Proceedings of the Zoological Society of London 136:219 253.

Shiff, C. J. 1964. Studies on Bulinus (Physopsis) globosus in Rhodesia III. Bionomics of a natural population existing in a temporary habitat. Annals of tropical medicine and parasitology 58:240-255.

Smith, G. R., D. A. Vaala, and H. A. Dingfelder. 2003. Distribution and abundance of macroinvertebrates within two temporary ponds. Hydrobiologia 497:161-167. 
Sniffen, R. P. 1981. Benthic invertebrate production during seasonal inundation of a floodplain swamp. University of North Carolina, Chapel Hill, North Carolina.

Stewart, T. W., and J. E. Garcia. 2002. Environmental factors causing local variation in density and biomass of the snail Leptoxis carinata, in Fishpond Creek, Virginia. American Midland Naturalist 148:172-180.

Thomas, J. D., and A. I. Tait. 1984. Control of the snail hosts of schistosomiasis by environmental manipulation a field and laboratory appraisal in the Ibadan area, Nigeria. Philosophical Transactions of the Royal Society of London. Series B, Biological Sciences 305:201 - 253.

Thut, R. N. 1969. A study of the profundal bottom fauna of lake Washington. Ecological Monographs 39:79-100.

Valdez, M. F., and C. R. Villalobos. 1981. Variations in natural populations of Neritina latissima Broderip in Costa Rica. (Gastropoda: Neritidae). in Anales del Instituto de Ciencias del mar y limnologia.

Williams, N. V. 1970. Studies on aquatic pulmonate snails in Central Africa II. Experimental investigation of field distribution patterns. Malacologia 10:165 180.

Winterbourn, M. J. 1970. Population studies on the New Zealand freshwater gastropod Potamopyrgus antipodarum. Malacological Society of London 39:139-149.

Zaranko, D. T., D. G. Farara, and F. G. Thompson. 1997. Another exotic mollusc in the Laurentian Great Lakes: The New Zealand native Potamopyrgus antipodarum (Gray 1843) (Gastropoda, Hydrobiidae). Canadian Journal of Fisheries and Aquatic Sciences 54:809-814. 
VITA

CLIFTON BENJAMIN RUEHL

February 17, 1977

2000

2000

2004
Born, Albany, Georgia

B. S. Biology

Trinity University, San Antonio, Texas

Student Conservation Association Western Fisheries Research Center, Seattle, Washington

M. S. Wildlife \& Fisheries Sciences

Texas A\&M University, College Station, Texas

\section{PUBLICATIONS AND PRESENTATIONS}

Parker, Aaron D., Uzarski, D. G., Sepulveda-Villet, O. J., Stepien, C. A., Ruehl, C. B., Burton, T. M. (2009) "The interplay of morphology, habitat, resource use, and genetic relationships in young yellow perch" Transactions of the American Fisheries Society 138: 899-914

Ruehl, C. B., DeWitt, T.J. (2007) "Trophic plasticity and foraging performance in red drum Sciaenops ocellatus (Linnaeus)." Journal of Experimental Marine Biology and Ecology. 349: 284-294

Ruehl, C. B., DeWitt, T.J. (2005) "Trophic plasticity and fine-grained resource variation in populations of western mosquitofish, Gambusia affinis." Evolutionary Ecology Research. 7: 801-819

Ruehl, C. B. and DeWitt T.J. (2004) "Trophic plasticity and fine-grained resource variation in the western mosquitofish, Gambusia affinis." Trinity University, San Antonio, TX, USA.

Ruehl, C. B., Trexler, J. C. (2009) "Trade-offs between Nutrient and Predator effects in Human-Modified Habitats” Ecological Society of America. Albuquerque, NM, USA.

Ruehl, C. B. (2008) "Separating consumptive and non-consumptive predator effects in the presence of nutrient enrichment" Ecological Society of America. Milwaukee, WI, USA.

Ruehl, C. B., Dorn, N.J., Gaiser, E.E., Trexler, J.C. (2007) "Seasonality and Cage Design in Food Web Experiments" Ecological Society of America. San Jose, CA, USA. 